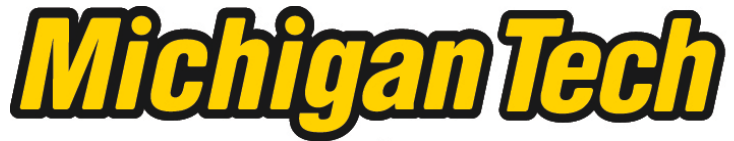 \\ Michigan Technological University Create the Future Digital Commons @ Michigan Tech
}

Dissertations, Master's Theses and Master's Reports - Open

Dissertations, Master's Theses and Master's

Reports

2009

Charge induced enhancement of adsorption for hydrogen storage materials

Xiang Sun

Michigan Technological University

Follow this and additional works at: https://digitalcommons.mtu.edu/etds

Part of the Engineering Science and Materials Commons

Copyright 2009 Xiang Sun

\section{Recommended Citation}

Sun, Xiang, "Charge induced enhancement of adsorption for hydrogen storage materials", Dissertation, Michigan Technological University, 2009.

https://doi.org/10.37099/mtu.dc.etds/15

Follow this and additional works at: https://digitalcommons.mtu.edu/etds

Part of the Engineering Science and Materials Commons 


\title{
CHARGE INDUCED ENHANCEMENT OF ADSORPTION FOR HYDROGEN STORAGE MATERIALS
}

\author{
By
}

XIANG SUN

\author{
A DISSERTATION \\ Submitted in partial fulfillment of the requirements \\ for the degree of \\ DOCTOR OF PHILOSOPHY \\ (Materials Science and Engineering)
}

\section{MICHIGAN TECHNOLOGICAL UNIVERSITY}

2009

Copyright (C) Xiang Sun 2009 
This dissertation, "Charge Induced Enhancement of Adsorption for Hydrogen Storage Materials," is hereby approved in partial fulfillment of the requirements for the degree of DOCTOR OF PHILOSOPHY in the field of Materials Science and Engineering.

\section{DEPARTMENT:}

Materials Science and Engineering

Signatures:

Dissertation Advisor

Typewritten Name:

Department Chair

Typewritten Name:

Date 


\section{Acknowledgements}

I want to thank many people for their help during these past six years time while I was pursuing my $\mathrm{PhD}$. degree in Michigan Tech.

I greatly acknowledge my advisor, Dr. Jiann-Yang Hwang, who has provided financial support, encouragement, and consistent guidance throughout. He taught me how to do research, how to think as a scientist, and how to become a responsible adult. After so many years under his guidance, I am now enthusiastic in my scientific research and hope one day that I can become as successful a professor as he is.

I would like to thank my committee members Dr. Yun Hang Hu, Dr. Jaroslaw W. Drelich, and Dr. Faith A. Morrison for reviewing my dissertation, and giving tremendous and useful advice.

I also want to thank my project group members, Shangzhao Shi and Xuan Li, for their great discussion and teamwork.

Special thanks are given to Stephen F. Forsell, Owen P. Mills, Edward A. Latitila, and Ruth I. Kramer for their technical support in lab operations, materials preparation and characterizations. 
I deeply appreciate the great working and leisure time spent with my coworkers and friends, Xiaodi Huang, Bowen Li, Jian Jia, Madhana Sunder, Rajalakshmi Krishna, Prince, Yayong Liu, Kaikun Yang, Hongwen Zhang, Hanbing Wang, Hao Wang, Rong Lai, Mingsong Bi, Shuhan Ding, Xiaoyue Huang, Ziyou Zhou, Ming Xie, Wei Wang, Ning Cheng, Mimi Yang.

I am indebted to the Department of Materials Science and Engineering at Michigan Technological University for providing an atmosphere and platform conductive to my study, research and life in Houghton. I want to express my appreciation to the professors: Dr. Mark R. Plichta, Dr. Stephen A. Hackney, Dr. Bruce J. Pletka, Dr. Calvin L. White, Dr. Douglas J. Swenson, and Dr. Jong K. Lee in the materials science department for their guidance and encouragement.

I want to express my best thanks to my lovely wife Alice, my father Xiaoming Sun and my mother Hong Cheng, for their support and encouragement.

I sincerely appreciate all the effort I have received from you. Thank you! 


\begin{abstract}
The rising concerns about environmental pollution and global warming have facilitated research interest in hydrogen energy as an alternative energy source. To apply hydrogen for transportations, several issues have to be solved, within which hydrogen storage is the most critical problem. Lots of materials and devices have been developed; however, none is able to meet the DOE storage target.
\end{abstract}

The primary issue for hydrogen physisorption is a weak interaction between hydrogen and the surface of solid materials, resulting negligible adsorption at room temperature. To solve this issue, there is a need to increase the interaction between the hydrogen molecules and adsorbent surface.

In this study, intrinsic electric dipole is investigated to enhance the adsorption energy. The results from the computer simulation of single ionic compounds with hydrogen molecules to form hydrogen clusters showed that electrical charge of substances plays an important role in generation of attractive interaction with hydrogen molecules. In order to further examine the effects of static interaction on hydrogen adsorption, activated carbon with a large surface area was impregnated with various ionic salts including $\mathrm{LiCl}, \mathrm{NaCl}$, $\mathrm{KCl}, \mathrm{KBr}$, and $\mathrm{NiCl}_{2}$ and their performance for hydrogen storage was evaluated by using a volumetric method. Corresponding computer simulations have been carried out by using DFT (Density Functional Theory) method combined with point charge arrays. Both 
experimental and computational results prove that the adsorption capacity of hydrogen and its interaction with the solid materials increased with electrical dipole moment.

Besides the intrinsic dipole, an externally applied electric field could be another means to enhance hydrogen adsorption. Hydrogen adsorption under an applied electric field was examined by using porous nickel foil as electrodes. Electrical signals showed that adsorption capacity increased with the increasing of gas pressure and external electric voltage. Direct measurement of the amount of hydrogen adsorption was also carried out with porous nickel oxides and magnesium oxides using the piezoelectric material PMNPT as the charge supplier due to the pressure. The adsorption enhancement from the PMN-PT generated charges is obvious at hydrogen pressure between 0 and 60 bars, where the hydrogen uptake is increased at about $35 \%$ for nickel oxide and $25 \%$ for magnesium oxide. Computer simulation reveals that under the external electric field, the electron cloud of hydrogen molecules is pulled over to the adsorbent site and can overlap with the adsorbent electrons, which in turn enhances the adsorption energy

Experiments were also carried out to examine the effects of hydrogen spillover with charge induced enhancement. The results show that the overall storage capacity in nickel oxide increased remarkably by a factor of 4 . 


\section{Contents}

Chapter 1 Hydrogen economy ............................................................................................. 1

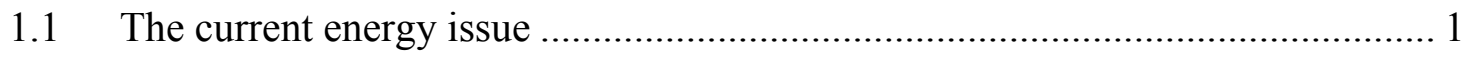

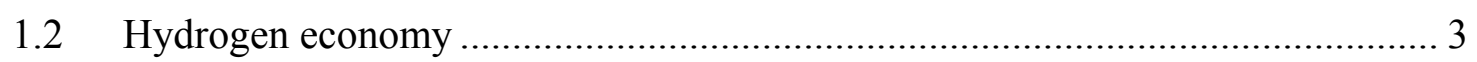

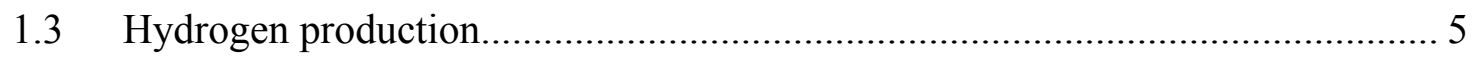

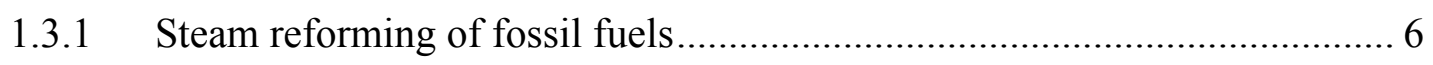

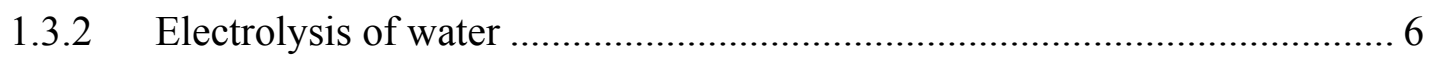

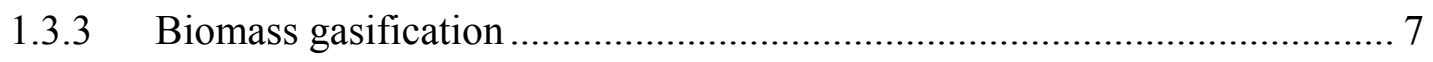

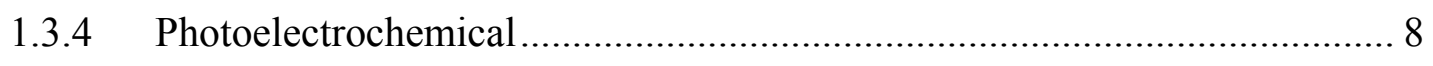

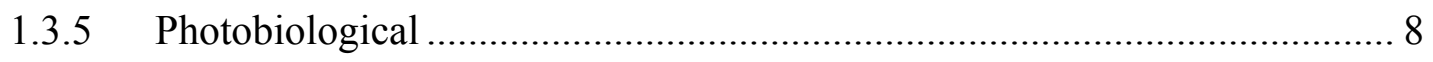

1.3.6 Thermalchemical water splitting........................................................ 9

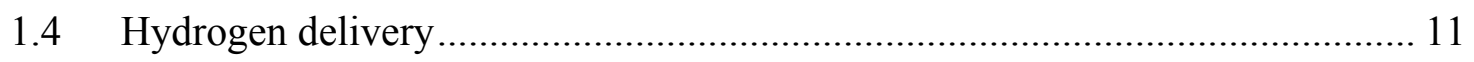

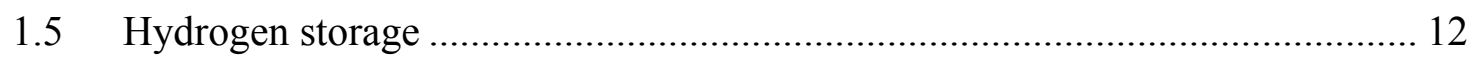

1.6 Hydrogen Fuel Cells............................................................................ 15

Chapter 2 Overview of Hydrogen Storage Technologies .................................................. 20

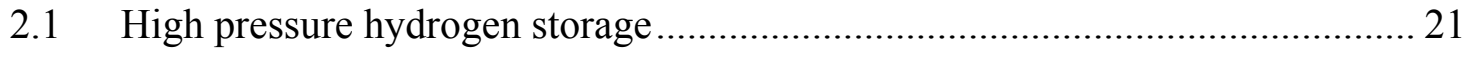

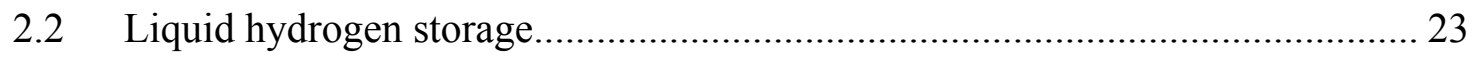

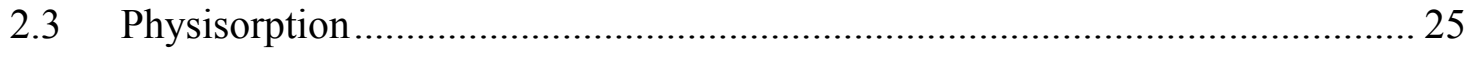

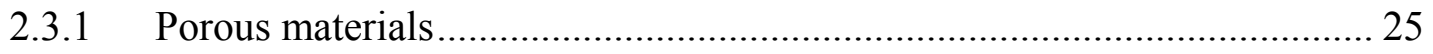

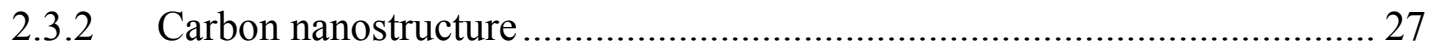

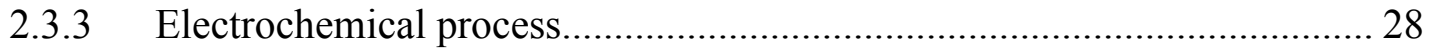

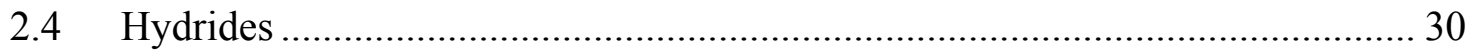

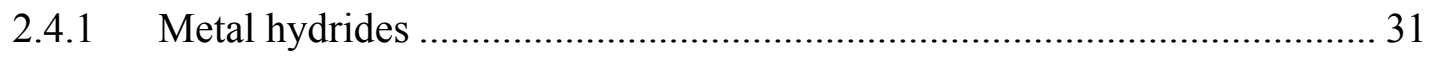

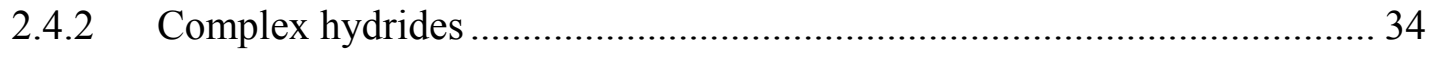

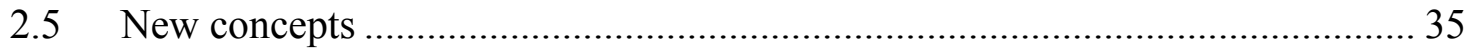

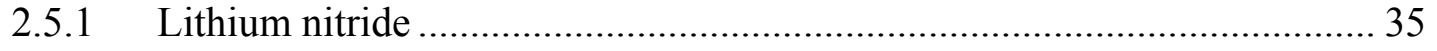

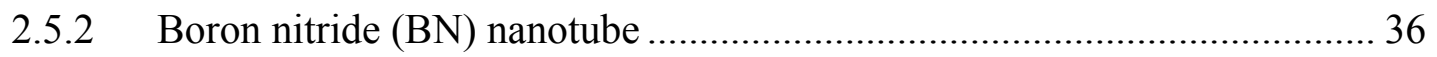

2.5.3 Microporous metal organic frameworks (MOF) ......................................... 37

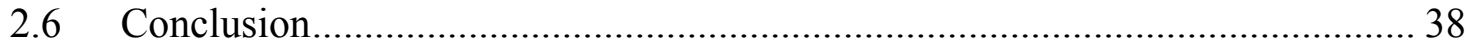

Chapter 3 Project Concept..................................................................................................... 39

Chapter 4 Hydrogen Clusters ................................................................................................ 40

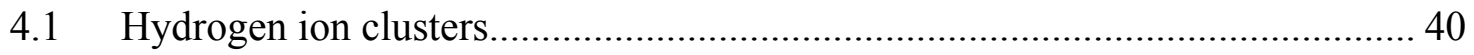




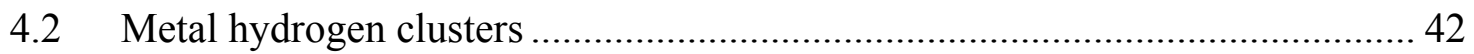

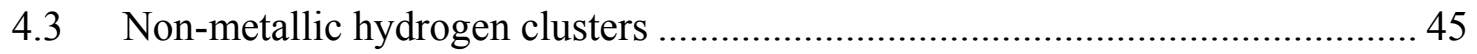

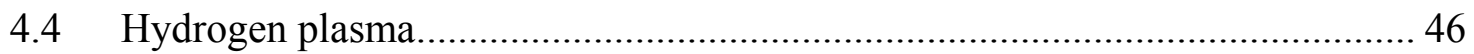

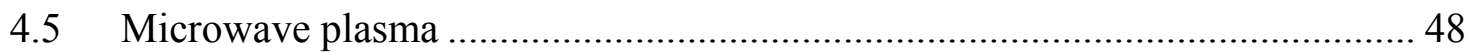

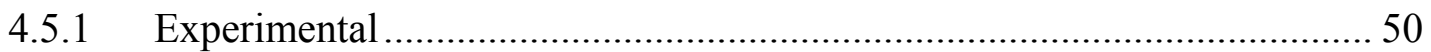

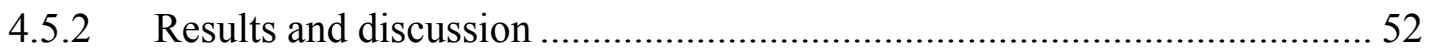

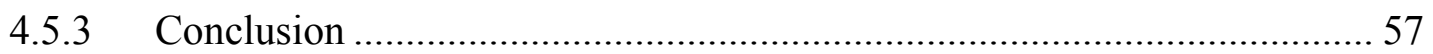

Chapter 5 Density Functional Computation of Hydrogen Clusters............................. 59

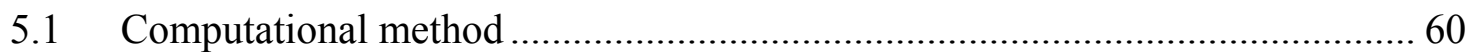

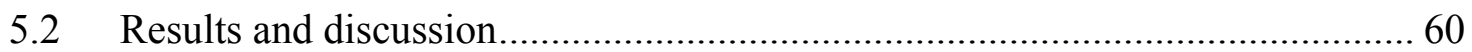

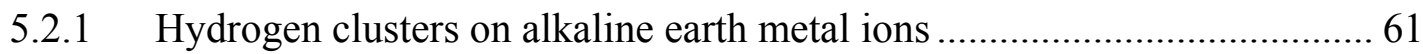

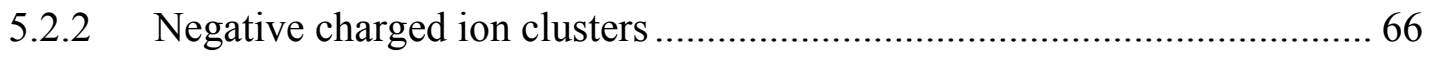

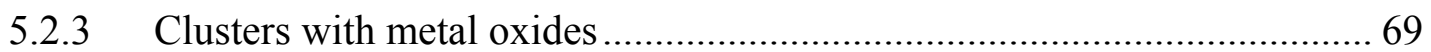

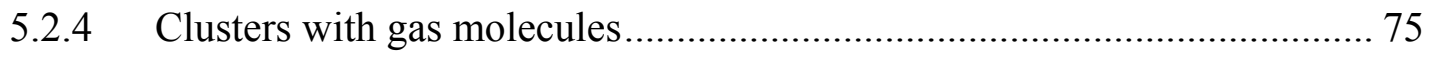

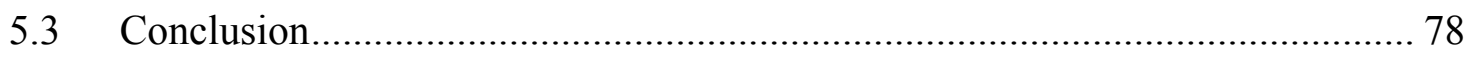

Chapter 6 Salt Impregnated Activated Carbon for Hydrogen Storage....................... 80

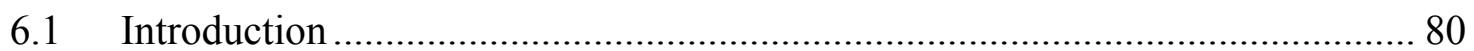

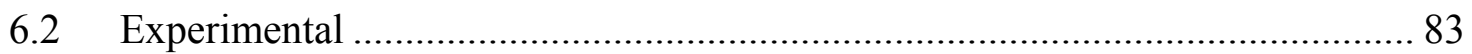

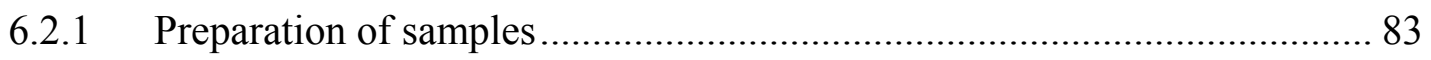

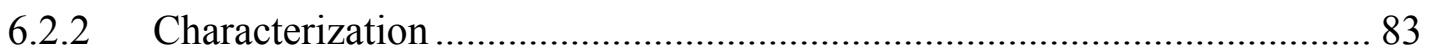

6.2.3 Hydrogen adsorption measurements ....................................................... 84

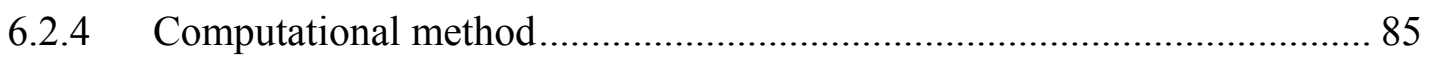

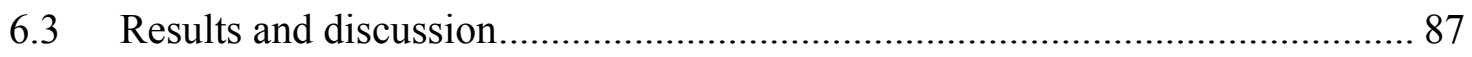

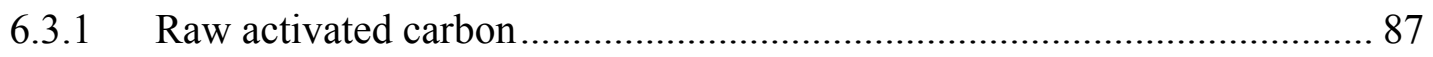

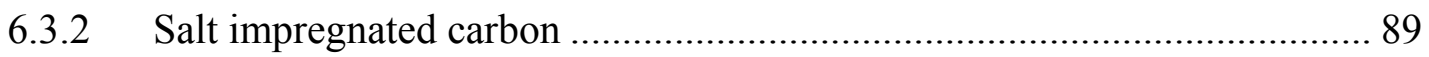

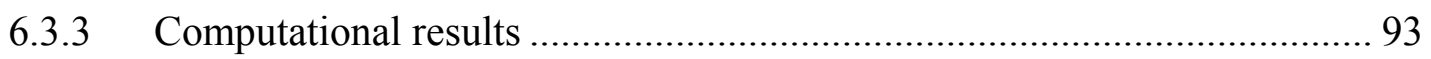

6.3.4 Comparison of experimental and computational results............................. 99

Chapter 7 Qualitative Examination of Electric Field Assisted Hydrogen Adsorption

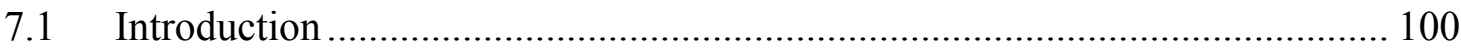

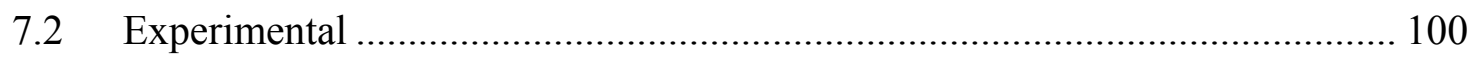

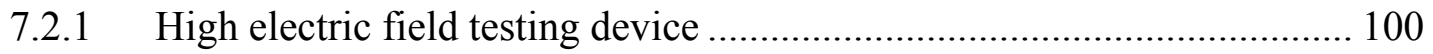

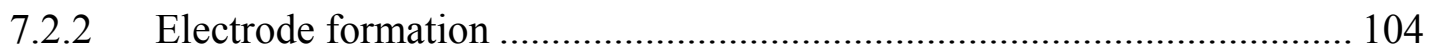




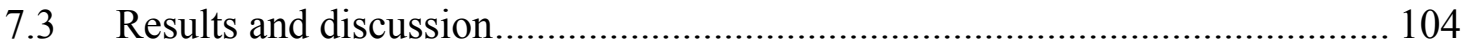

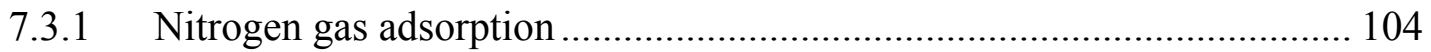

7.3.2 Hydrogen gas adsorption ........................................................................ 110

Chapter 8 Quantitative Examination of Electric Field Assisted Hydrogen Adsorption on Porous Metal Oxides........................................................... 117

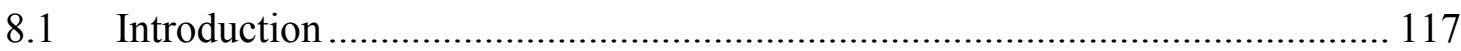

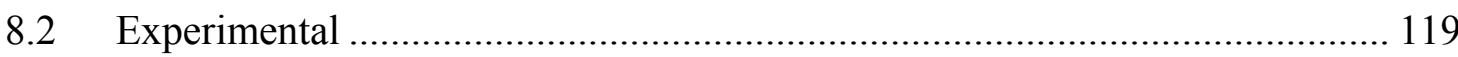

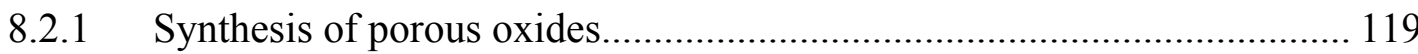

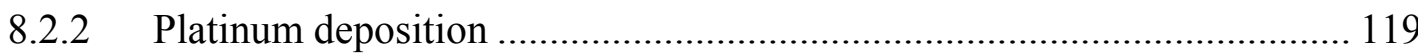

8.2.3 Characterization of the synthesized oxides......................................... 120

8.2.4 Hydrogen storage measurements ..................................................... 120

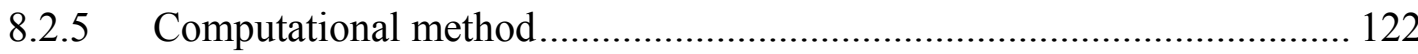

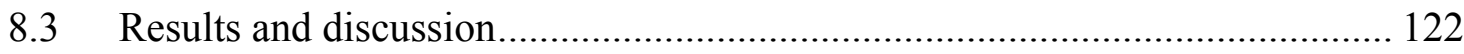

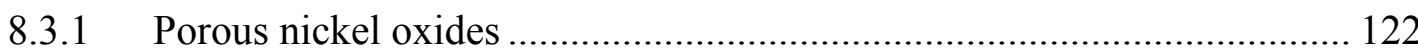

8.3.2 Porous magnesium oxides............................................................. 138

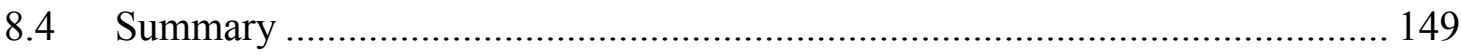

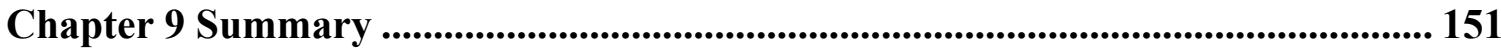

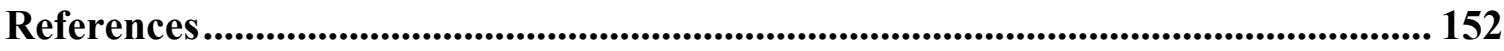

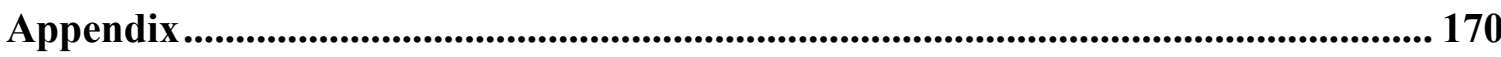




\section{List of Figures}

Figure 1 U.S Transportation Oil Consumption................................................................ 2

Figure 2 Emissions from Fossil Fuel Combustion............................................................ 2

Figure 3 Hydrogen Economy Timeline ................................................................... 4

Figure 4 Elements of the Hydrogen Energy Infrastructure.............................................. 5

Figure 5 Hydrogen production technologies...................................................... 10

Figure 6 National hydrogen storage project............................................................. 15

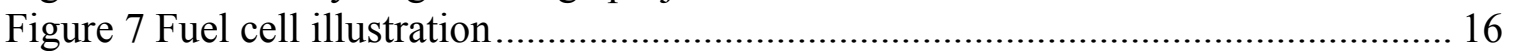

Figure 8 Comparison of today's cost and target for PEM fuel cell ................................. 18

Figure 9 Primitive phase diagram of hydrogen.......................................................... 20

Figure 10 Density change of compressed hydrogen gas as a function of pressure........... 22

Figure 11 A typical high pressure composite cylinder .................................................... 23

Figure 12 Pressure-composition isotherms presenting the hydrogen absorption with the phase transformation from $\alpha$ phase to $\beta$ phase................................................. 33

Figure 13 Schematic picture of experimental system ...................................................... 50

Figure 14 Selected field concentrators, iron pin (left) and copper wires (right)............... 51

Figure 15 Typical plasma images, (a)Concentrator: Fe pin, $4 \mathrm{~kW}, \mathrm{Ar}, 7000 \mathrm{ml} / \mathrm{min}$, (b) Concentrator: Cu powder, $4 \mathrm{~kW}, \mathrm{Ar}_{\mathrm{N}}=1,7000 \mathrm{ml} / \mathrm{min}$, (c) Concentrator: $\mathrm{Cu}$ wire, $4 \mathrm{~kW}$, Ar: $\mathrm{N}_{2}=1: 3,7000 \mathrm{ml} / \mathrm{min}$, (d) Concentrator: Cu powder, $4 \mathrm{~kW}, \mathrm{~N}_{2}$, $7000 \mathrm{ml} / \mathrm{min}$, (e) Concentrator: Fe wire, $4 \mathrm{~kW}, \mathrm{Ar} \mathrm{H}_{2}=1,300 \mathrm{ml} / \mathrm{min}$, (f) Concentrator: Cu wire, $3 \mathrm{~kW}, \mathrm{H} 2,300 \mathrm{ml} / \mathrm{min}$........................................... 53

Figure 16 Gas temperature profiles at $\mathrm{Ar} / \mathrm{N}_{2}=1,3 \mathrm{~kW}$, concentrator: (a) $\mathrm{Cu}$ powder, (b) $\mathrm{Fe}$

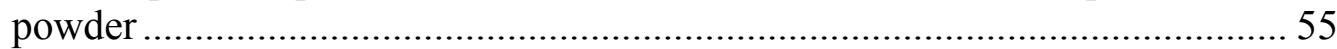

Figure $17 \mathrm{Gas}$ temperature at $2 \mathrm{~kW}, \mathrm{H}_{2} 300 \mathrm{ml} / \mathrm{min}$, concentrator: $\mathrm{Cu}$ powder............... 56

Figure 18 Plasma images and gas temperature at $\mathrm{H} 2300 \mathrm{ml} / \mathrm{min}$, concentrator: $\mathrm{Cu}$ powder, $2 \mathrm{~kW}$ to initiate and $1.5 \mathrm{~kW}$ to maintain ........................................ 56

Figure 19 Failed concentrators, (a) Iron pin after 17 cycles, (b) Cu wire after 6 cycles, (c) $\mathrm{Cu}$ powder after 4 cycles, (d) Iron powder after 10 cycles, (e) Al powder after 7 cycles, (f) Fe wire after 7 cycles ................................................................ 57

Figure 20 Simulated structures of hydrogen-alkaline metal ion clusters $\mathrm{M}^{++}\left(\mathrm{H}_{2}\right)_{\mathrm{n}} \ldots \ldots \ldots . . .62$

Figure 21 Calculated distance between $\mathrm{M}^{++}$and $\mathrm{H}_{2}$ as a function of number of $\mathrm{H}_{2} \ldots \ldots . .63$

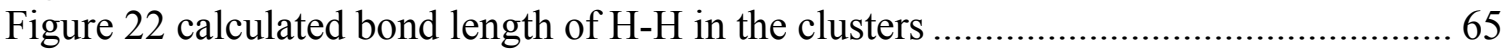

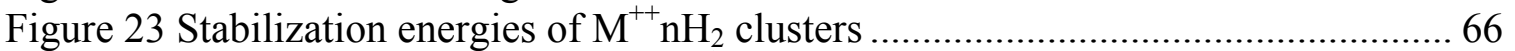

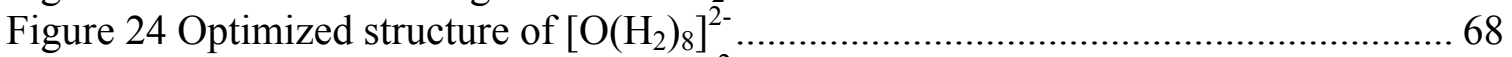

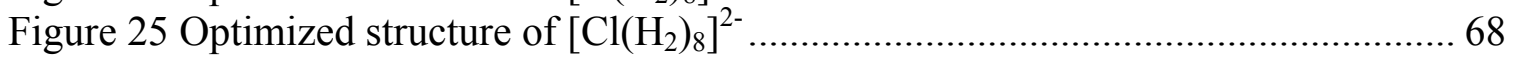

Figure 26 Geometry of $\mathrm{VO}\left(\mathrm{H}_{2}\right)_{8}$ cluster calculated from DFT....................................... 70

Figure 27 Geometry of $\mathrm{CrO}\left(\mathrm{H}_{2}\right)_{8}$ cluster calculated from DFT ……………………..... 71

Figure 28 Geometry of $\mathrm{MnO}\left(\mathrm{H}_{2}\right)_{8}$ cluster calculated from DFT …………………......... 72

Figure 29 Geometry of $\mathrm{FeO}\left(\mathrm{H}_{2}\right)_{8}$ cluster calculated from DFT …................................ 73

Figure 30 Geometry of $\mathrm{CoO}\left(\mathrm{H}_{2}\right)_{8}$ cluster calculated from DFT.................................... 73

Figure 31 Geometry of $\mathrm{NiO}\left(\mathrm{H}_{2}\right)_{8}$ cluster calculated from DFT ..................................... 74

Figure 32 Geometry of $\mathrm{CO}\left(\mathrm{H}_{2}\right)_{8}$ cluster calculated from DFT....................................... 76

Figure 33 Geometry of $\mathrm{CO}_{2}\left(\mathrm{H}_{2}\right)_{8}$ cluster calculated from DFT ................................... 76 
Figure 34 Geometry of $\mathrm{HCl}\left(\mathrm{H}_{2}\right)_{8}$ cluster calculated from DFT .................................... 78

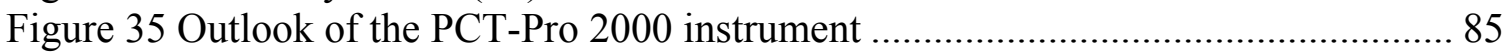

Figure 36 Operating screen of the PCT-Pro 2000 software........................................ 85

Figure 37 Point charge array for cluster simulation................................................. 87

Figure 38 Hydrogen adsorption of activated carbon at $298 \mathrm{~K}$ and $77 \mathrm{~K}$........................ 89

Figure 39 Hydrogen adsorption of salt impregnated carbon at $298 \mathrm{~K}$............................ 92

Figure 40 Hydrogen capacity per surface area of salt impregnated carbon..................... 93

Figure 41 Optimized clusters in point charge ............................................................ 94

Figure 42 optimized geometry of $\mathrm{H} 2$ adsorbed on $\mathrm{LiCl} \mathrm{Li}$ site (a) and $\mathrm{Cl}$ site (b), $\mathrm{NaCl} \mathrm{Na}$ site (c) and $\mathrm{Cl}$ site (d), $\mathrm{KCl} \mathrm{K}$ site(e)andCl (f) site, $\mathrm{KBr} \mathrm{K}$ site(g) and $\mathrm{Br}$ site (h)

Figure 43 High electrical field testing system ...................................................... 101

Figure 44 Electric circuit of the high electric field system ........................................ 102

Figure 45 Adsorption mechanism of the electrodes ................................................. 103

Figure 46 Charging signals at resistor 1 at 50 psi nitrogen pressure, applied voltage $200 \mathrm{~V}$

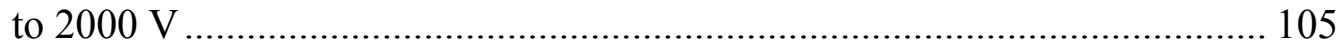

Figure 47 Leakage signals at charging at 50 psi nitrogen pressure, applied voltage $200 \mathrm{~V}$ to $2000 \mathrm{~V}$

Figure 48 Discharge signals at 50 psi nitrogen pressure, applied voltage $200 \mathrm{~V}$ to $2000 \mathrm{~V}$

Figure 49 Charging signals at 150 psi nitrogen pressure, applied voltage $200 \mathrm{~V}$ to $2000 \mathrm{~V}$

Figure 50 Leakage signals at 150 psi nitrogen pressure, applied voltage $200 \mathrm{~V}$ to $2000 \mathrm{~V}$

Figure 51 Discharge signals at 150 psi nitrogen pressure applied voltage $200 \mathrm{~V}$ to $2000 \mathrm{~V}$

Figure 52 Charging signals at 40 psi hydrogen pressure, applied voltage $200 \mathrm{~V}$ to $2000 \mathrm{~V}$

Figure 53 Leakage signals at 40 psi hydrogen pressure applied voltage $200 \mathrm{~V}$ to $2000 \mathrm{~V}$

Figure 54 Discharge signals at 40 psi hydrogen pressure applied voltage $200 \mathrm{~V}$ to $2000 \mathrm{~V}$

Figure 55 Charging signals at hydrogen pressure (a) 200 psi, (b) 400 psi, (c) 600 psi, (d) 1000 psi, applied voltage $200 \mathrm{~V}$ to $2000 \mathrm{~V}$

Figure 56 Discharge signals at hydrogen pressure (a) 200 psi, (b) 400 psi, (c) 600 psi, (d) 1000 psi, applied voltage $200 \mathrm{~V}$ to $2000 \mathrm{~V}$

Figure 57 Discharge signals at applied voltage (a) $200 \mathrm{~V}$, (b) $1000 \mathrm{~V}$, (c) $1500 \mathrm{~V}$, (d) $2000 \mathrm{~V}$, Hydrogen pressure from $200 \mathrm{psi}$ to 1000 psi................................. 116

Figure 58 Schematic of sample holder arrangement................................................ 121

Figure 59 XRD pattern of as-synthesized nickel oxide .......................................... 123

Figure 60 FE-SEM images of as-synthesized nickel oxides.................................... 123

Figure 61 DTA curve of as-synthesized nickel oxides ........................................... 125

Figure 62 Adsorption isotherms of the mesoporous nickel oxides calcined at $300{ }^{\circ} \mathrm{C}$ and $360{ }^{\circ} \mathrm{C}$ for different time 
Figure 63 FE-SEM images of $\mathrm{NiO}$ calcined at $300{ }^{\circ} \mathrm{C}$ for 3 hours.

Figure 64 Hydrogen adsorption isotherms at $298 \mathrm{~K}$ for $\mathrm{NiO}$ samples ......................... 129

Figure 65 Nitrogen adsorption/desorption isotherms of $\mathrm{Pt}$ deposited porous $\mathrm{NiO}$, insert:

$\mathrm{BJH}$ pore size distribution obtained by desorption isotherms .....

Figure 66 FE-SEM images of platinum deposited porous nickel oxide (a)(b), and EDS spectrum (c)

Figure 67 Hydrogen storage of $\mathrm{Pt}$ deposited porous $\mathrm{NiO}$ and enhancement from the PMN-PT

Figure 68 Optimized $\mathrm{Ni}_{5} \mathrm{O}_{5}$ clusters in $13 \times 13 \times 13$ point charges, where a is the lattice parameter, $\mathrm{Q}_{\mathrm{M}}$ is the average Mulliken charge, and $\mathrm{Q}_{\mathrm{p}}$ is the magnitude of the point charge

Figure 69 Optimized geometry of hydrogen adsorbed on nickel site under the influence of electric field

Figure 70 DOSs of orbital of hydrogen molecules which adsorbed on nickel site of the nickel oxide under the applied electric field, insert: higher magnification of the DOSs between -10 to $-2 \mathrm{eV}$.

Figure 71 Optimized geometry of hydrogen adsorbed on oxygen site under the influence of electric field.

Figure 72 DOSs of orbital of hydrogen molecules which adsorbed on oxygen site of the nickel oxide under the applied electric field, insert: higher magnification of the DOSs between -10 to $-2 \mathrm{eV}$

Figure 73 XRD pattern of as-synthesized hydromagnesite ....................................... 138

Figure 74 DTA curve of as-synthesized hydromagnesite........................................... 139

Figure 75 XRD pattern of calcined magnesium oxide................................................ 140

Figure 76 FE-SEM image of the $\mathrm{MgO}$ calcined at $400{ }^{\circ} \mathrm{C}$ for 3 hours......................... 141

Figure 77 Nitrogen adsorption/desorption isotherms of the $\mathrm{MgO}$ product calcined at 400

${ }^{\circ} \mathrm{C}$ for 3 hour, insert: BJH pore size distribution obtained from desorption isotherms

Figure 78 Hydrogen adsorption at $298 \mathrm{~K}$ for the porous $\mathrm{MgO}$ sample and MgO+PMN-PT sample

Figure 79 Optimized Mg5O5 clusters in $13 \times 13 \times 13$ point charges, where a is the lattice parameter, QM is the average Mulliken charge, and Qp is the magnitude of the point charge.

Figure 80 Optimized geometry of hydrogen adsorbed on magnesium site under the influence of electric field....

Figure 81 DOSs of s orbital of hydrogen molecules which adsorbed on magnesium site of the magnesium oxide under the applied electric field, insert: higher magnification of the DOSs between -8 to $-2 \mathrm{eV}$.....

Figure 82 Schematic of the shape of the electron cloud under external electric field .... 147

Figure 83 optimized geometry of hydrogen adsorbed on oxygen site under the influence of electric field....

Figure 84 DOSs of s orbital of hydrogen molecules which adsorbed on oxygen site of the magnesium oxide under the applied electric field, insert: higher magnification of the DOSs between -10 to $-2 \mathrm{eV}$ 


\section{List of Tables}

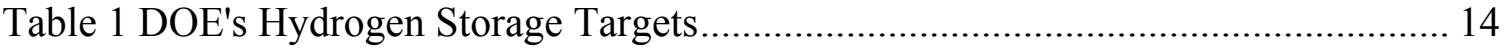

Table 2 Comparison of Current Fuel Cell Technologies .............................................. 17

Table 3 Common material for high pressure hydrogen gas cylinder.............................. 22

Table 4 Observed plasmas of using different concentrators (O-plasma, X-no plasma) ... 53

Table 5 BET analysis of raw carbon and salt impregnated carbon................................. 88

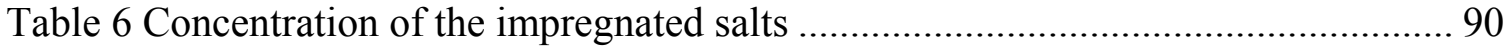

Table 7 Adjusted surface area based on the salt concentration ..................................... 90

Table 8 Optimized cluster parameters, where a is the lattice parameter, $Q_{p}$ is the value of the surrounding point charge and $\mathrm{Q}_{\mathrm{M}}$ is the average Mulliken charges .............. 95

Table 9 The optimized hydrogen bond length $\mathrm{r}_{\mathrm{H}-\mathrm{H}}(\AA)$, Mulliken charge $\mathrm{Q}_{\mathrm{M}}$, adsorption energy Ead ( $\mathrm{kJ} / \mathrm{mole})$, and dipole moment $\mathrm{D}$ (debye) of hydrogen adsorption on

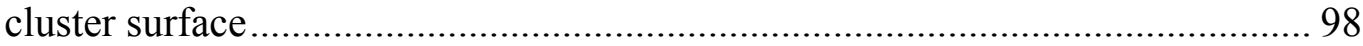

Table 10 Surface properties of calcined nickel oxides .............................................. 127 


\section{CHAPTER 1 HYDROGEN ECONOMY}

\subsection{The current energy issue}

United States transportation currently relies heavily on either gasoline or diesel fuels. Transportation accounts for two thirds of the 20 million barrels of oil this country uses every day [1]. As shown in Figure 1, America imports nearly half of the petroleum consumed for transportation and this is going to continuously rise in the future. By the year 2025, projected oil imports will grow to about 68\% [2]. As more developing countries with high populations expand their economies, the increased demand for oil supplies may cause energy crises. The dependence on foreign energy sources threatens U.S national security. This current situation requires that an alternative energy be developed in order to reduce dependence on foreign energy and insure America's national security.

Air pollution is a major environmental concern for the U.S and even the whole world. As shown in Figure 2, the transportation sector and electric power plants are two major contributors to the nation's air quality problems. The biggest greenhouse gas $\left(\mathrm{CO}_{2}\right)$ emissions are from electric utilities and transportation. It is very clear that a clean form of energy source is needed to improve our air quality and reduce the effects of global warming. 


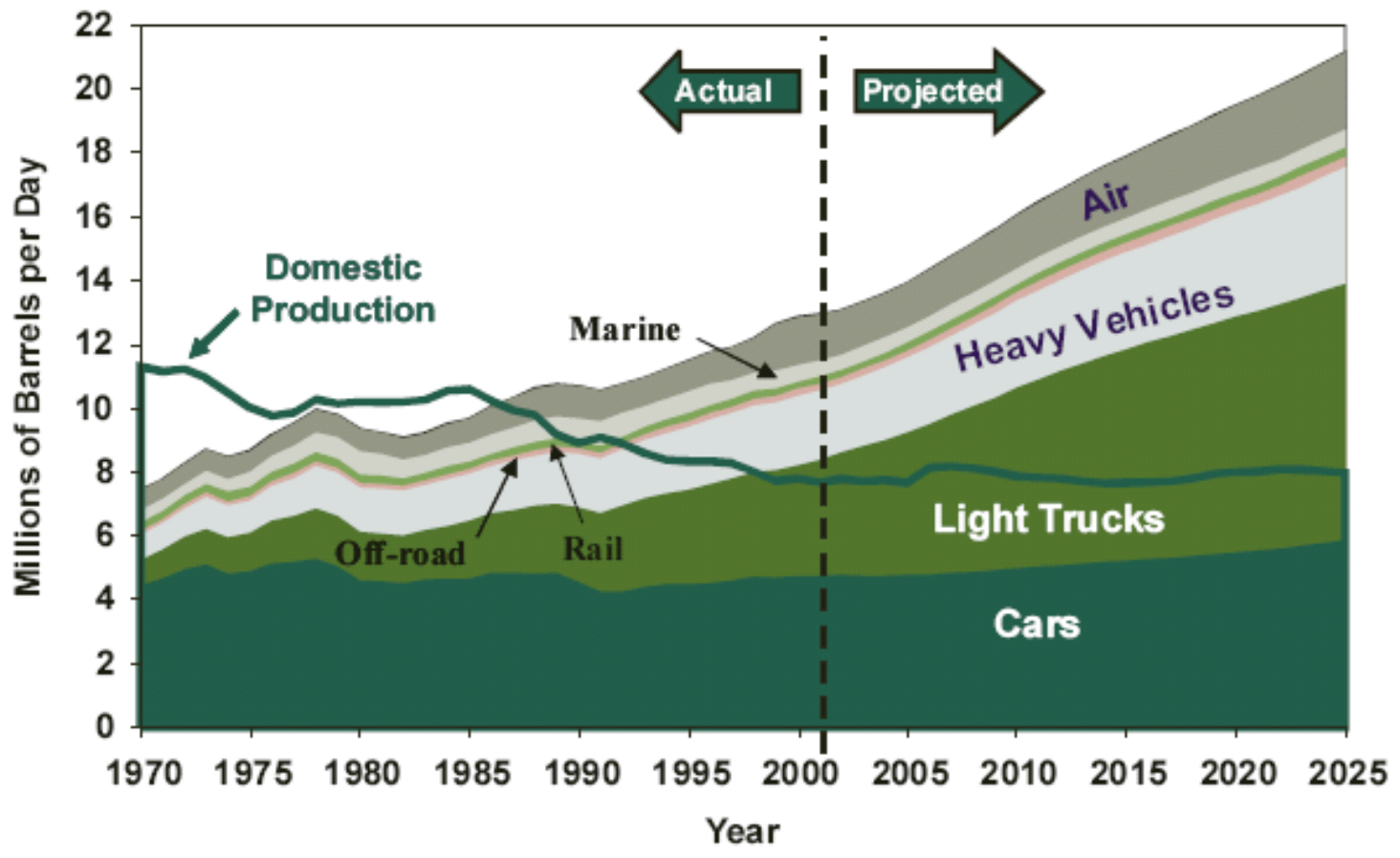

Figure 1 U.S Transportation Oil Consumption [3] (graph courtesy of the DOE, see appendix)

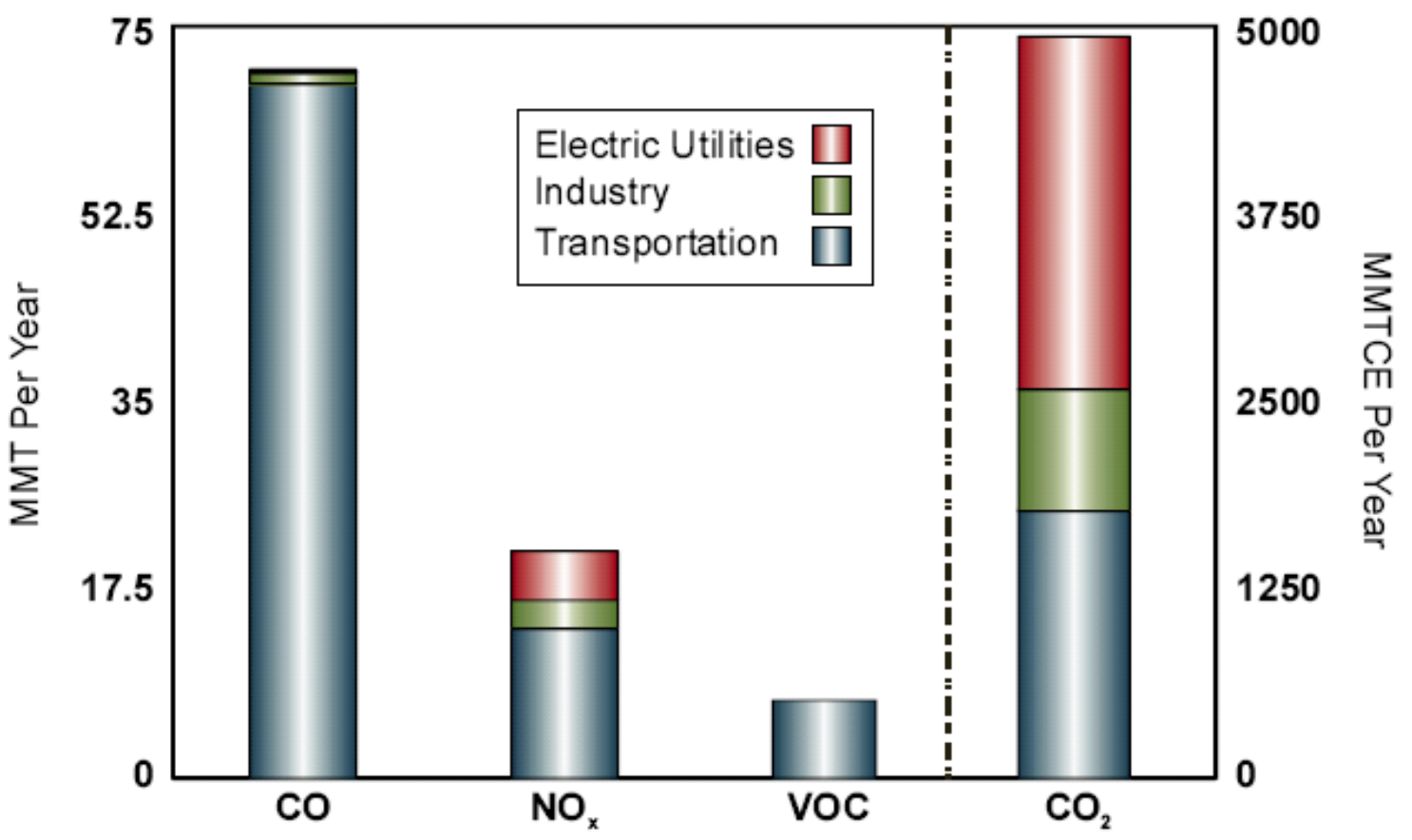

Figure 2 Emissions from Fossil Fuel Combustion [4] (graph courtesy of the DOE, see appendix) 
For both national security and environmental reasons, a nationally produced and clean energy source needs to be developed.

\subsection{Hydrogen economy}

Hydrogen has the greatest potential to be an alternative energy source. It can be produced from various domestic energy sources including natural gas, coal, petroleum or various renewable sources such as wind, solar, and nuclear energy. Hydrogen has the highest energy content per unit of weight of any known fuel, nearly three times the energy content of gasoline (120 MJ/kg for hydrogen and $44 \mathrm{MJ} / \mathrm{kg}$ for gasoline) [2]. Hydrogen can be employed in internal combustion engines with zero emissions or in fuel cells that emit only water emission. The internal combustion engine is said to be $20-30 \%$ efficient, however, the efficiency of fuel cells can reach to $75-80 \%$ [5]. In combination with other technologies such as carbon sequestration and renewable energy sources, hydrogen could make an emission free energy future.

Due to the great benefits of hydrogen energy, President Bush launched the Hydrogen Fuel Initiative which commits $\$ 1.2$ billion over five years for research, development, and demonstration of hydrogen and fuel cell technologies [6]. On January 28, 2003, President Bush stated in his State of the Union message that "With a new national commitment ... the first car driven by a child born today could be powered by hydrogen, and be pollution-free. Join me in this important innovation to make our air significantly cleaner, and our country much less dependent on foreign sources of energy [6]." This project is carried out under the leadership of Department of Energy (DOE). The goal is to put 
hydrogen fuel cell vehicles in the showroom and hydrogen at fueling stations by 2020 . Figure 3 shows the expected timeline for realizing the hydrogen economy. The transition consists of four major phases. In phase I, which is expected to last until 2030, the main effort is to research, develop, and demonstrate critical technologies prior to their commercialization. In Phase II, beginning in 2010 and continuing until 2025, hydrogen technologies are expected to meet or exceed customer requirements, and the government will work on policies and regulations. In Phase III, extending from 2015 to 2035, hydrogen power will begin commercialization and infrastructure business cases will be realized. In the final Phase, from 2030 to 2040, the hydrogen economy will be fully realized and industry will get returns on investment.

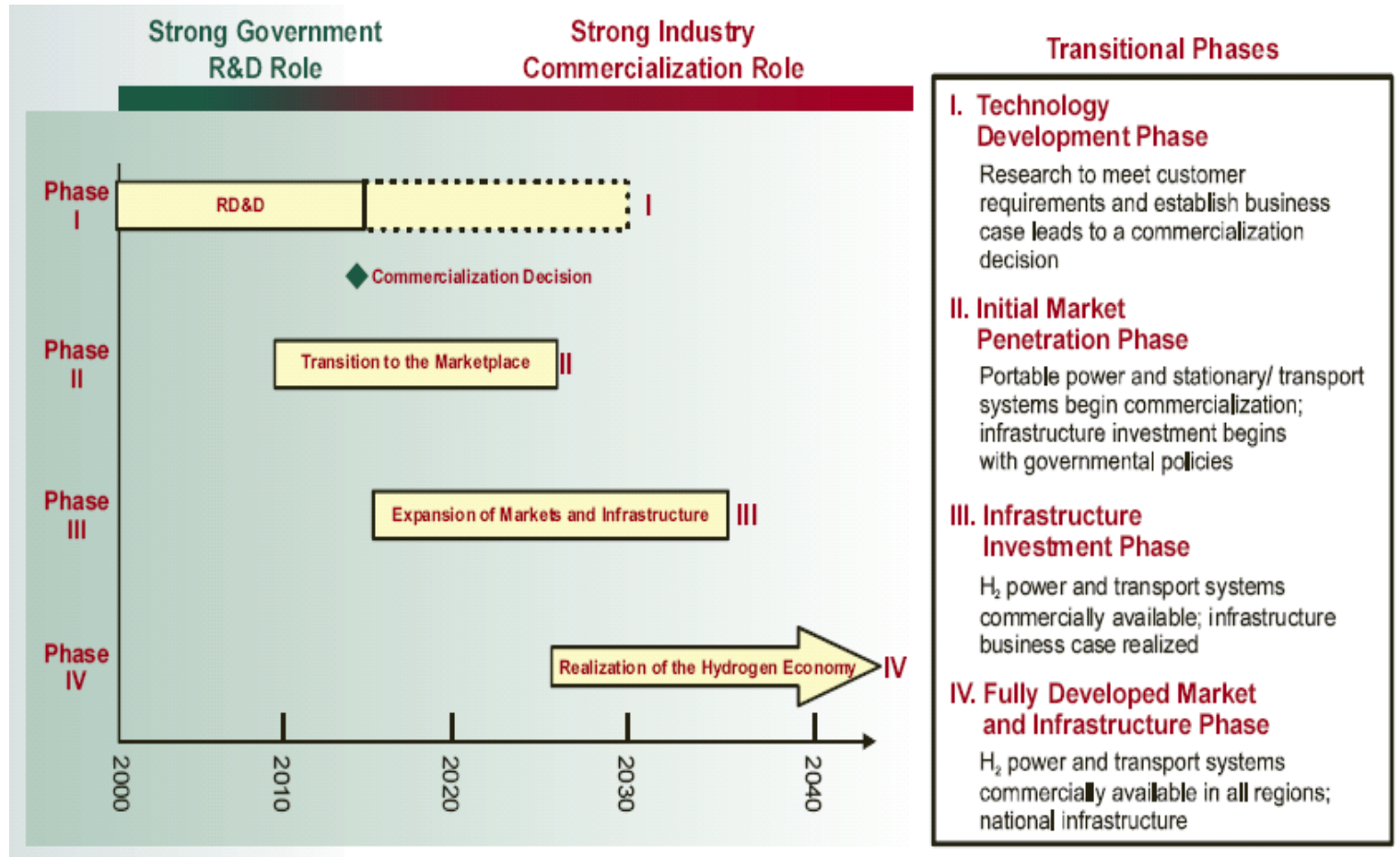

Figure 3 Hydrogen Economy Timeline [1] (graph courtesy of the DOE, see appendix) 
Although hydrogen has attractive advantages for being the next generation of energy, there are still some critical barriers, including, for example, hydrogen storage $(>300$ miles), fuel cell cost (\$30 per $\mathrm{kW})$ and hydrogen cost $(\$ 2.00-3.00$ per gge $)$. In order to make a hydrogen economy successful, the Department of Energy has concentrated its effort on key areas, including the production and delivery of hydrogen, hydrogen storage, the conversion of hydrogen to useful energy by fuel cells or other equipment, and education or demonstrations of its applications as well as the development of codes and standards, as shown in Figure 4.

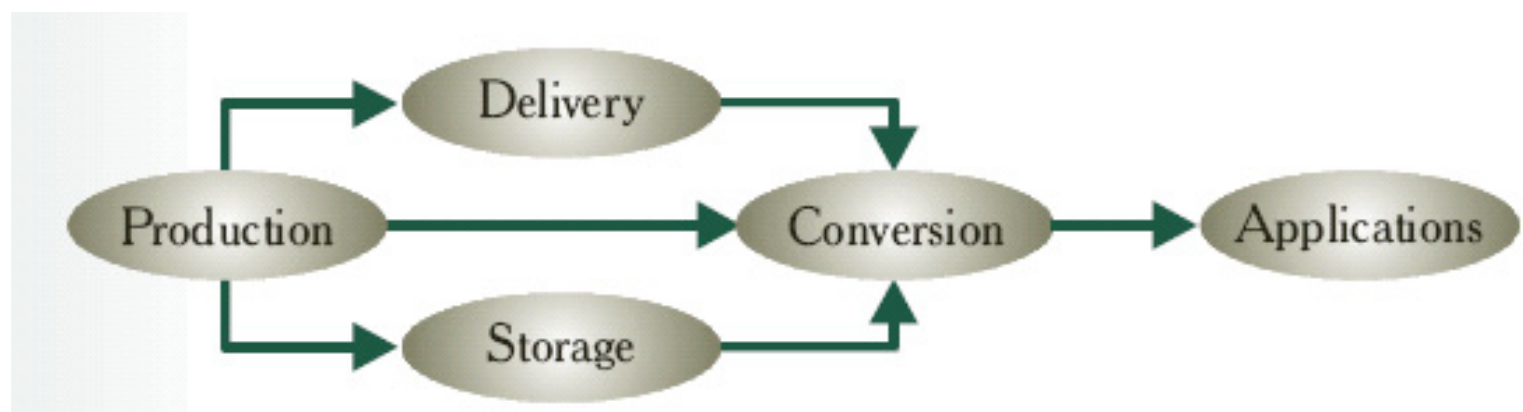

Figure 4 Elements of the Hydrogen Energy Infrastructure [1] (graph courtesy of the DOE, see appendix)

\subsection{Hydrogen production}

Only trace amounts of molecules hydrogen are available in nature, although chemically bound hydrogen is abundant. In order to use hydrogen as a future energy carrier, it is necessary to produce hydrogen in unbound forms. An input energy is always associated with such chemical reaction. Ideally, the energy input should be equal to the energy released by the same hydrogen when burned as a fuel. However, because no real process can be $100 \%$ efficient, there is always a significant energy loss involved. 
Generally, technologies for producing hydrogen can be categorized into six different areas: (1) steam reforming of fossil fuels, (2) electrolysis of water, (3) biomass gasification, (4) photoelectrochemical, (5) photobiological, (6) thermalchemical water splitting, details of which are discussed below.

\subsubsection{Steam reforming of fossil fuels}

Steam reforming is the most widely used process to extract hydrogen from hydrocarbons such as natural gas, methanol, coal or even gasoline [7]. Currently, about $50 \%$ of the world feedstock of hydrogen production is realized by the steam reforming of natural gas [8]. In the United States, about $95 \%$ of the hydrogen is produced by steam reforming [9]. Most of these processes are large scale, producing about 100 million standard cubic feet of hydrogen per day [10]. The techniques for reforming from natural gas and petroleum fraction are well established commercially. Due to environmental concerns about carbon dioxide emissions, fossil fuels for hydrogen production require carbon capture and a sequestration process. The use of coal as a raw material for hydrogen production has been studied extensively over past years, but it is not widely used in the U.S [11].

However, the natural reserve of fossil fuels in earth is limited. This kind of method is not a long term source for hydrogen and can be considered only as a transition strategy.

\subsubsection{Electrolysis of water}

Another major source of producing hydrogen is through the use of water electrolysis by electricity generated by fossil fuels, nuclear energy, wind or solar energy. As long as 
electricity comes from a clean energy source, electrolysis can be considered a nonemission process. Water electrolysis simply uses the electricity to split water molecules into hydrogen and oxygen. Today, two types of electrolyzers are used for commercial use - alkaline and proton exchange membranes (PEM) [10]. However, electrolysis is one of the most energy-intensive methods because the energy requirements for current electrolysis processes are in the range of $53.4-70.1 \mathrm{kWh} / \mathrm{kg}$ of $\mathrm{H}_{2}$ produced [7]. Although the energy efficiencies for commercial electrolyzers range from $60 \%$ to $70 \%$ [12], the overall efficiencies are in the range of $25 \%$ [7]. In addition, the cost of electrolysis is associated with the price of electricity. As a result, this technology would be competitive only where the price of electricity is low [9]. High-temperature

electrolysis (THE) of water converts more of the energy into hydrogen, doubling the efficiency to about $50 \%$ [5]. But the processes are only considered with a nuclear heat source. And this process has only been demonstrated on a laboratory scale, not a commercial scale.

Future efforts will focus on using alternative renewable energy sources like wind and solar power. Although most of these energy sources are only locally available, distributed production is a suitable choice since it requires less capital cost, and does not need extensive hydrogen transport and delivery infrastructure.

\subsubsection{Biomass gasification}

Biomass is considered a widely available renewable energy source. Hydrogen can be produced from gasification of biomass resources such as agricultural residue, including 
plastics, waste grease, peanut shells or crops [10]. Biomass pyrolysis produces a liquid product which contains several components that can be separated into valuable chemicals including hydrogen. Advanced separation techniques are needed to reduce cost and increase efficiency- gasification is well developed, but has not been employed on a commercial stage.

\subsubsection{Photoelectrochemical}

The photoelectrochemical hydrogen production process consists of a semiconducting material and a water electrolyzer to produce hydrogen by splitting water using the sunlight as the only energy source [13]. However, this process is still in the early phase of development and has a number of materials and process related issues [14]. Current research is focused on developing stable and durable semiconductor materials in an aqueous environment. Low cost materials and systems for commercialization are also under research.

\subsubsection{Photobiological}

Photobiological systems use natural photosynthetic microbes such as green algae and bacteria to produce hydrogen by splitting water [10]. There are several approaches associated with this technology, including direct and indirect biophotolysis, darkfermentation, and photofermentation [15]. The hydrogen production rate is relatively slow. Different rates of hydrogen production have been reported from $0.07 \mathrm{mmol} \mathrm{H}_{2} \mathrm{~L}^{-1} \mathrm{~h}^{-}$

${ }^{1}$ to $96 \mathrm{mmol} \mathrm{H} \mathrm{L}^{-1} \mathrm{~h}^{-1}$ [15]. Also the loss of light energy in the process can be as high as 
$80 \%$ [10]. Moreover, this technology is still in the experimental stage, so research and development is needed to understand and develop such photobiological technique [7].

\subsubsection{Thermalchemical water splitting}

Only two kinds of energy sources, solar and nuclear, are used in the thermalchemical water splitting process, because other heating sources are not consistent enough to bring down the cost [5]. Solar energy can be concentrated to generate temperatures over 2000 ${ }^{\circ} \mathrm{C}$ to produce hydrogen from water splitting [10]. The sulfur-iodine (IS) process can produce hydrogen and oxygen from water by using nuclear energy [16]. The chemical reactions of the process are described below:

$$
\begin{aligned}
& \mathrm{I}_{2}+\mathrm{SO}_{2}+2 \mathrm{H}_{2} \mathrm{O} \rightarrow 2 \mathrm{HI}+\mathrm{H}_{2} \mathrm{SO}_{4} \\
& \mathrm{H}_{2} \mathrm{SO}_{4} \rightarrow \mathrm{H}_{2} \mathrm{O}+\mathrm{SO}_{2}+0.5 \mathrm{O}_{2} \\
& 2 \mathrm{HI} \rightarrow \mathrm{H}_{2}+\mathrm{I}_{2}
\end{aligned}
$$

Because all the energy input in this process is heat, it is more efficient than hightemperature electrolysis. None of the thermochemical hydrogen production methods have been tested at production level.

All the current hydrogen production technologies stated above are summarized in Figure 5. Hydrogen produced from fossil fuels requires additional carbon capture and sequestration technologies to reach zero emission. However, currently the cost of production from fossil fuels is very competitive and the amount of carbon released to the atmosphere is no more than that of the gasoline driven cars. But due to the limited nature 
supply of fossil fuels, this production method is not a long term solution and can only be considered as a transition. Future efforts will be focused on using the renewable energy, although the cost is noncompetitive right now and most processes haven't reached the commercialization stage. Significant additional research and development is needed for all these technologies to produce energy and cost competitive hydrogen. The hydrogen cost goal from DOE is in the range from $\$ 2.00 /$ gge (lower bound) to $\$ 3.00 /$ gge (upper bound).

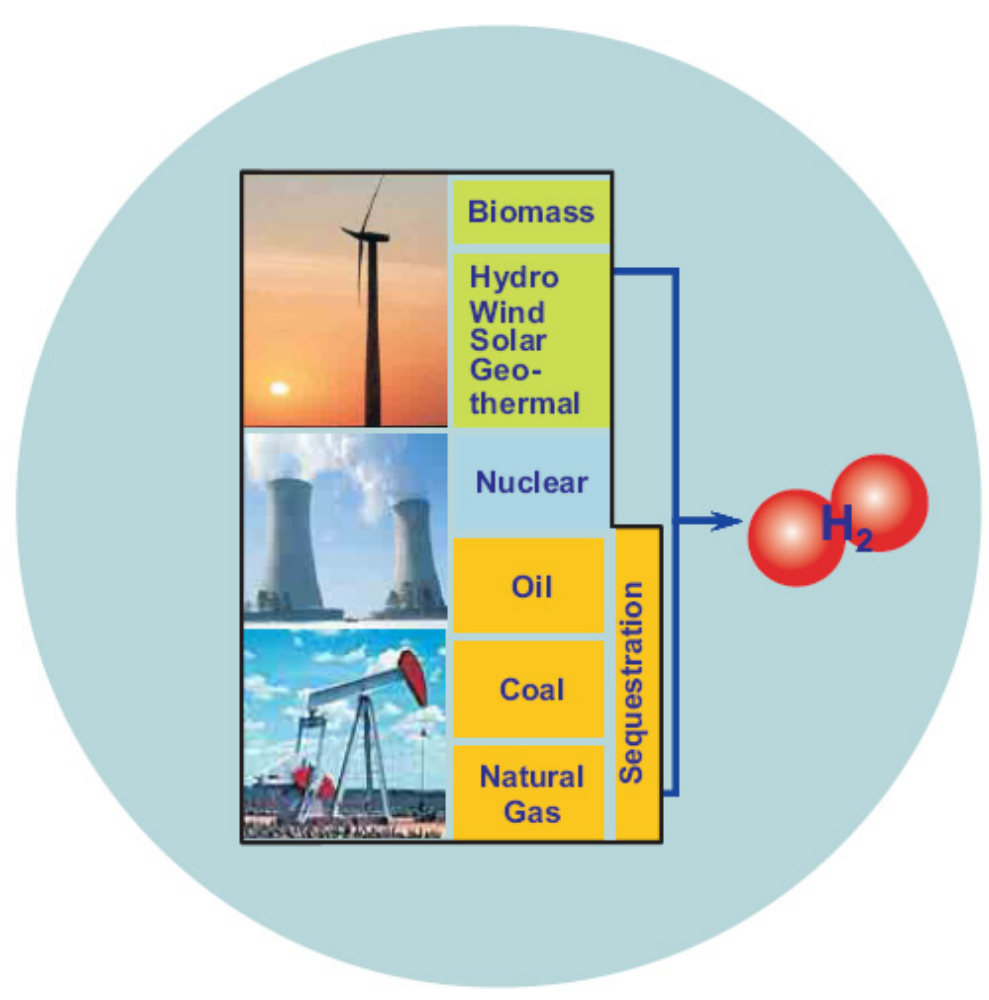

Figure 5 Hydrogen production technologies [1] (graph courtesy of the DOE, see appendix) 


\subsection{Hydrogen delivery}

Currently, hydrogen is delivered through pipelines, or by road using tube trailers and cryogenic tanks, with a small amount transported by barge for special purposes. Hydrogen can also be transported using carriers, such as ethanol or ammonia.

Pipelines are the least expensive way of delivering hydrogen. However, in the United States, the pipeline infrastructure is limited (about 700 miles, compared to more than one million miles for natural gas) to only a few areas where large petroleum refineries and chemical plants are concentrated such as Illinois, California, and the Gulf Coast [17].

For short distances up to 200 miles from the facility, hydrogen is distributed by high pressure tube trailers. Because transporting compressed hydrogen gas is expensive, it is not economical for longer distances.

Liquefied hydrogen $\left(-253{ }^{\circ} \mathrm{C}\right)$ has a higher energy content than hydrogen gases. So for longer distances up to 1000 miles, hydrogen is usually transported as a liquid in superinsulated, cryogenic, over-the-road tankers and then vaporized for use at the customer sites. The major hydrogen producer, Air Products and Chemicals, transports 140 million gallons of liquid hydrogen traveling over 16 million miles every year [10].

If hydrogen is used as the next energy source, a national supply network would have to be established, and this will depend on the development of a cost effective method for hydrogen transportation and delivery. A national wide hydrogen pipeline system would 
require enormous capital costs. Possible solutions would be retro-fitting existing natural gas pipelines for hydrogen or utilizing existing natural gas pipelines for mixed gas service. However, questions regarding the leakage, seals and permeation of hydrogen need to be solved. Researches should also be focused on new materials for constructing lower-cost hydrogen pipelines. Other key challenges are getting lower cost and more energy efficient compression technology and liquefaction technology.

The delivery goal is to have a national supply network that involves pipelines distributing hydrogen to high-demand areas, and trucks or other means distributing gas, liquid and solid hydrogen to rural and other low-demand areas [1]. These delivery technologies should reduce the cost of hydrogen delivery from the point of production to the point of use to less than $\$ 1.30 /$ gge of hydrogen by 2010 and less than $\$ 1.00 /$ gge of hydrogen by 2015.

\subsection{Hydrogen storage}

Hydrogen has the highest gravimetric energy content of any known fuels. However, its low volumetric energy density has only a quarter of the energy of gasoline $(8 \mathrm{MJ} /$ liter for liquid hydrogen versus $32 \mathrm{MJ} /$ liter for gasoline). At atmospheric pressure and ambient temperature, $2 \mathrm{~g}$ of hydrogen gas has a volume of 22.4 liters. Such low volumetric energy density makes hydrogen gas challenging to store, especially for the given requirements to achieve greater than 300-mile driving range compared with today's gasoline driven automobiles. 
The DOE has performed a partnership with major fuel and automotive industries to develop hydrogen storage system targets. The goal of the target is to achieve similar performance and cost levels as the gasoline fuel storage systems. The system includes all components such as tank, valves, piping, etc, not just the storage media. System storage targets for year 2007, 2010, and 2015 are shown in Table 1.

Current research is focused on achieving gravimetric and volumetric capacity targets. There are various hydrogen storage methods for on-board automobiles, the details of which are reviewed in Chapter 2.

The various options include both reversible on-board generation, which means hydrogen refilling can take place on site, and a regenerable off-board method, which requires that the hydrogen refilling cannot be accomplished on-board, and the media must be regenerated off-board. The on-board approaches include high pressure gas, liquid hydrogen, carbon-based materials, high surface area adsorbents, and metal hydrides [19]. Off-board storage includes some of the metal hydrides and chemical hydrides. Currently, only high pressure tanks and liquid hydrogen meet near the target of 2007, however, it is not clear that the 2010 and 2015 targets will be met. The future focus will be transferred to material-based storage systems such as hydrides, and sorbents. 
Table 1 DOE's Hydrogen Storage Targets [18] (table courtesy of the DOE, see appendix)

\begin{tabular}{|c|c|c|c|c|}
\hline Storage Parameter & Units & 2007 & 2010 & 2015 \\
\hline $\begin{array}{l}\text { System Gravimetric Capacity: } \\
\text { Usable, specific-energy from } \mathrm{H}_{2} \\
\text { (net useful energy/max system } \\
\text { mass) }\end{array}$ & $\begin{array}{l}\mathrm{kWh} / \mathrm{kg} \\
\text { ( } \mathrm{kg} \mathrm{H} / 2 / \mathrm{kg} \text { system) }\end{array}$ & $\begin{array}{l}1.5 \\
(0.045)\end{array}$ & $\begin{array}{l}2 \\
(0.06)\end{array}$ & $\begin{array}{l}3 \\
(0.09)\end{array}$ \\
\hline $\begin{array}{l}\text { System Volumetric Capacity: } \\
\text { Usable energy density from } \mathrm{H}_{2} \\
\text { (net useful energy/max system } \\
\text { volume) }\end{array}$ & $\begin{array}{l}\mathrm{kWh} / \mathrm{L} \\
\text { (kg H/2 } / \mathrm{L} \text { system) }\end{array}$ & $\begin{array}{l}1.2 \\
(0.036)\end{array}$ & $\begin{array}{l}1.5 \\
(0.045)\end{array}$ & $\begin{array}{l}2.7 \\
(0.081)\end{array}$ \\
\hline $\begin{array}{l}\text { Storage system cost } \\
\text { (\& fuel cost) }\end{array}$ & $\begin{array}{l}\text { \$/kWh net } \\
(\$ / \mathrm{kg} \mathrm{H}) \\
\$ / g g \text { at pump }\end{array}$ & $\begin{array}{l}6 \\
(200) \\
--\end{array}$ & $\begin{array}{l}4 \\
(133) \\
2-3\end{array}$ & $\begin{array}{l}2 \\
(67) \\
2-3\end{array}$ \\
\hline 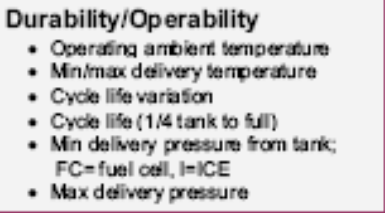 & $\begin{array}{l}{ }^{C} \mathrm{C} \\
{ }^{\circ} \mathrm{C} \\
\% \text { of maan (min) at } \% \text { corfiderice } \\
\text { Cydes } \\
\text { Atm (abs) } \\
\text { Atm (abs) }\end{array}$ & $\begin{array}{l}-20 / 50 \text { (sun) } \\
-30 / 65 \\
\text { N/A } \\
500 \\
8 \text { FC/ } / 10 / C E \\
100\end{array}$ & $\begin{array}{l}-30 / 50 \text { (sun) } \\
-40 / 85 \\
90 / 90 \\
1000 \\
4 \mathrm{FC} / 35 \mathrm{ICE} \\
100\end{array}$ & $\begin{array}{l}-40 / 60 \text { (sun) } \\
-40 / 65 \\
9990 \\
1500 \\
3 F C / 35 \mathrm{ICE} \\
100\end{array}$ \\
\hline $\begin{array}{l}\text { Charging/discharging Rates } \\
\text { - Systam fil tme for } 5 \mathrm{~kg}) \\
\text { - Mnimum full fow rate } \\
\text { : Stat fime to full fow }\left(20^{\circ} \mathrm{C}\right) \\
\text { - Stat fime to full fow }\left(-20^{\circ} \mathrm{C}\right) \\
\text { - Transient response } 10 \%-90 \% \\
\text { and } 90 \%-0 \%\end{array}$ & $\begin{array}{l}\min _{(g / s) / \mathrm{kW}} \\
s \\
s \\
s\end{array}$ & $\begin{array}{l}10 \\
0.02 \\
15 \\
30 \\
1.75\end{array}$ & $\begin{array}{l}3 \\
0.02 \\
5 \\
15 \\
0.75\end{array}$ & $\begin{array}{l}2.5 \\
0.02 \\
5 \\
15 \\
0.75\end{array}$ \\
\hline Fuel Purity ( $\mathrm{H}_{2}$ from storage) & $\% \mathrm{H}_{2}$ & \multicolumn{3}{|c|}{99.99 (dry basis) } \\
\hline \multirow[t]{2}{*}{$\begin{array}{l}\text { Environmental Health \& } \\
\text { Safety } \\
\text { : Pemeation \& leakage } \\
\text { - Tavicily } \\
\text { - Salety } \\
\text { - Loss of useable } \mathrm{H}_{2}\end{array}$} & \multirow{2}{*}{$\begin{array}{l}\text { Soofh } \\
: \\
\text { (ghif) } \mathrm{kg} \mathrm{H}_{2} \text { stored }\end{array}$} & \multicolumn{2}{|l|}{$\begin{array}{l}\text { Meets or } \\
\text { standards }\end{array}$} & applicable \\
\hline & & 1 & 0.1 & 0.05 \\
\hline
\end{tabular}

In July 2003, the DOE issued a "Grand Challenge" to collaborations of multiple universities, industries and federal laboratories to step up their hydrogen storage research. This "Grand Challenge", called the National Hydrogen Storage Project, established Centers of Excellence for research on metal hydrides, chemical hydrogen storage and carbon-based materials as well as independent projects based on new materials and concepts, off-board storage systems and compressed/liquid approaches. Figure 6 shows the organization of this Grand Challenge. All these projects intended to develop a 
selection of relatively lightweight, low cost and high storage density hydrogen storage system.

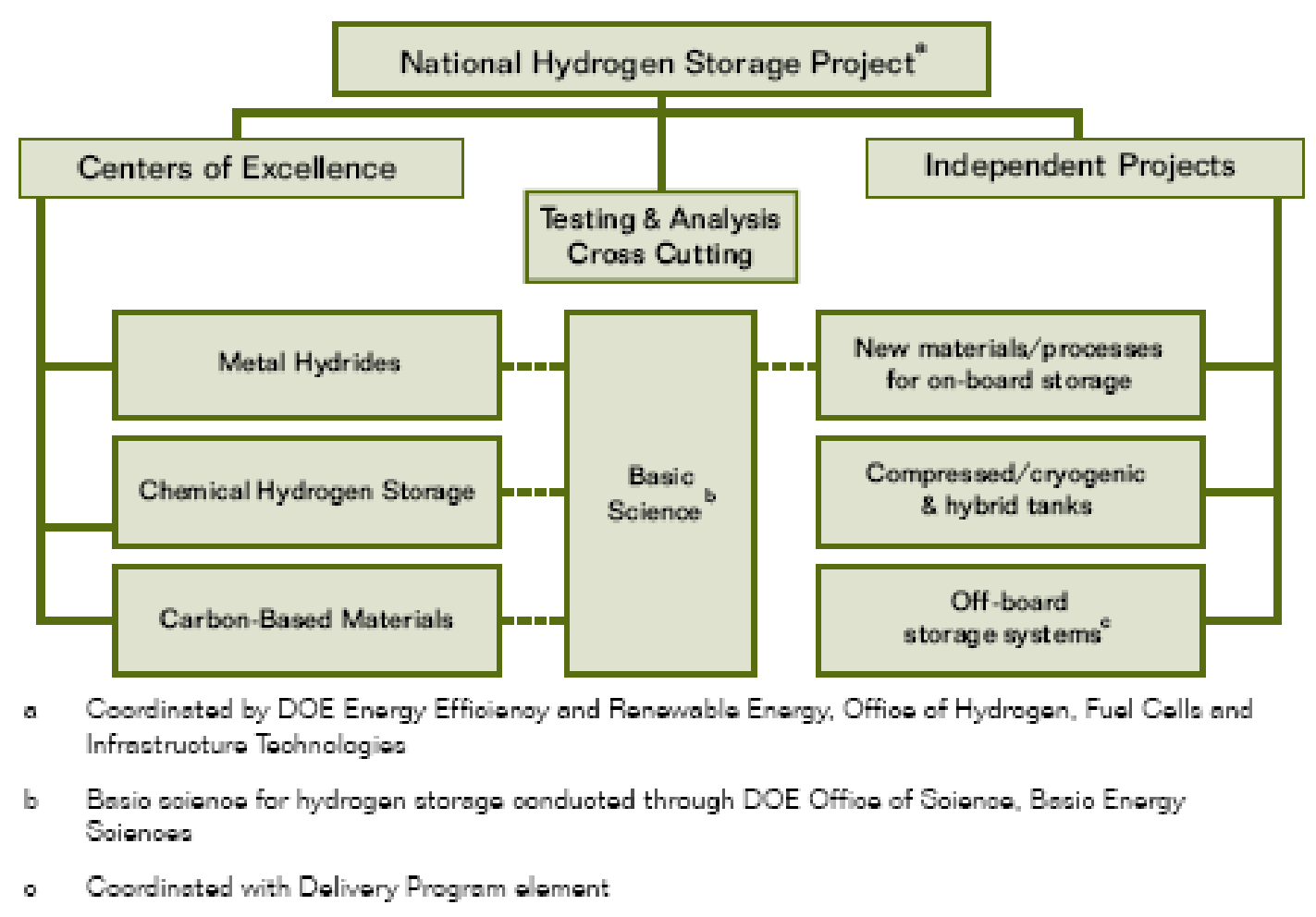

Figure 6 National hydrogen storage project [1] (graph courtesy of the DOE, see appendix)

\subsection{Hydrogen Fuel Cells}

A fuel cell is a device using hydrogen and oxygen to generate electricity by electrochemical process with pure water and useful heat as the byproducts, eliminating air pollution and greenhouse gases. Besides these pollution free advantages, fuel cells are more energy efficient than combustion engines and can have two to three times the energy efficiency as traditional combustion technologies [20]. 
A single fuel cell is composed of an electrolyte sandwiched between two catalyst-coated electrodes, a porous anode and a porous cathode. As shown in Figure 7, in a Polymer Electrolyte Membrane (PEM) fuel cell, which is widely considered the most suitable cell for light duty transportation, hydrogen and oxygen gases are fed through each bipolar plate to anode and cathode, respectively. On the anode, the catalyst causes hydrogen molecules to separate into protons and electrons. Only the protons can pass through the membrane to the other side of the cell while the negatively charged electrons are conducted through an external circuit to the cathode. The flow of electrons can be used as an electricity source to power a motor. On the cathode side, the electrons together with oxygen gases and hydrogen protons form water through an exothermic reaction and the generated heat can be utilized.

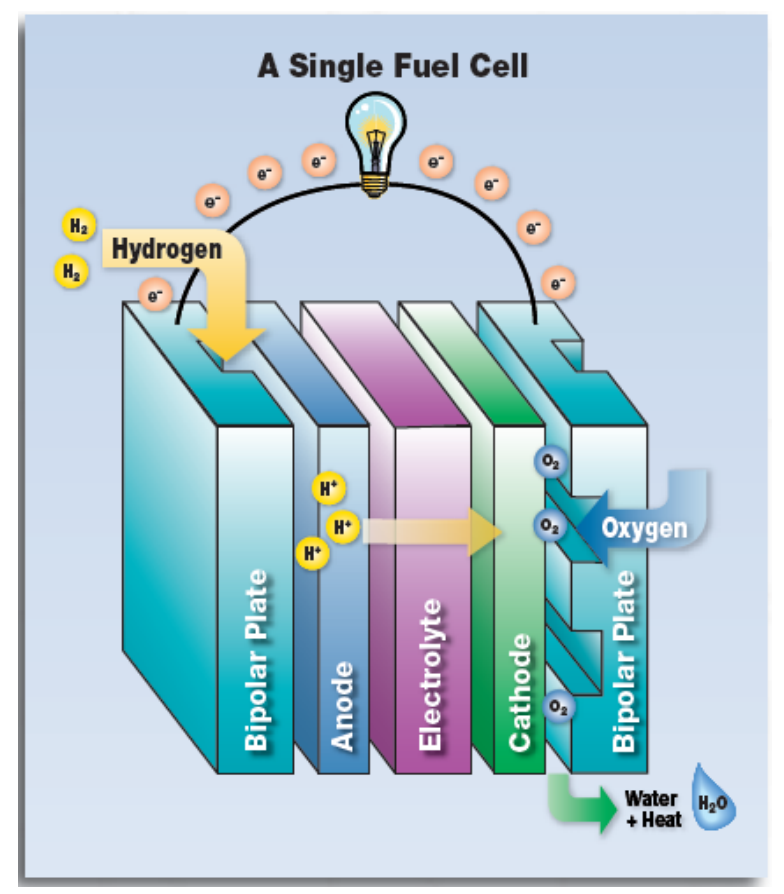

Figure 7 Fuel cell illustration [20] (graph courtesy of the DOE, see appendix) 
There are different types of fuel cells depending on the kind of electrolytes used. Each of these fuel cells has its own advantages, limitations and application areas, as shown in Table 2. For polymer electrolyte membrane and phosphoric acid fuel cells, protons pass through the electrolyte to the cathode to react with oxygen and electrons, producing water and heat. However for alkaline, molten carbonate, and solid oxide fuel cells, negative ions travel through the electrolyte to the anode to combine with hydrogen to generate water and electrons.

Table 2 Comparison of Current Fuel Cell Technologies [21] (table courtesy of the DOE, see appendix)

\begin{tabular}{|l|l|l|l|l|}
\hline Fuel Cell Type & $\begin{array}{l}\text { Operating } \\
\text { Temperature }\end{array}$ & \multicolumn{1}{|c|}{ System Output } & \multicolumn{1}{|c|}{ Efficiency } & \multicolumn{1}{|c|}{ Applications } \\
\hline Alkaline (AFC) & $\begin{array}{l}90-100^{\circ} \mathrm{C} \\
194-212^{\circ} \mathrm{F}\end{array}$ & $10 \mathrm{KW}-100 \mathrm{KW}$ & $60-70 \%$ electric & $\begin{array}{l}\text { - Military } \\
\text { - Space }\end{array}$ \\
\hline $\begin{array}{l}\text { Phosphoric Acid } \\
\text { (PAFC) }\end{array}$ & $\begin{array}{l}150-200^{\circ} \mathrm{C} \\
302-392^{\circ} \mathrm{F}\end{array}$ & $\begin{array}{l}50 \mathrm{KW}-1 \mathrm{MW} \\
(250 \mathrm{KW} \text { module typical) }\end{array}$ & $\begin{array}{l}80-85 \% \text { overall with combined heat } \\
\text { and power (CHP) }\end{array}$ & - Distributed generation \\
\hline $\begin{array}{l}\text { Polymer Electrolyte } \\
\text { Membrane or } \\
\text { Proton Exchange } \\
\text { Membrane (PEM) }\end{array}$ & $\begin{array}{l}50-100^{\circ} \mathrm{C} \\
122-212^{\circ} \mathrm{F}\end{array}$ & $<250 \mathrm{KW}$ & $50-60 \%$ electric & $\begin{array}{l}\text { - Back-up power } \\
\text { - Portable power } \\
\text { - Small distributed generation } \\
\text { - Transportation }\end{array}$ \\
\hline $\begin{array}{l}\text { Molten Cartonate } \\
\text { (MCFC) }\end{array}$ & $\begin{array}{l}600-700^{\circ} \mathrm{C} \\
1112-1292^{\circ} \mathrm{F}\end{array}$ & $\begin{array}{l}<1 \mathrm{MW} \\
(250 \mathrm{KW} \text { module typical) }\end{array}$ & $85 \%$ overall with CHP (60\% electric) & $\begin{array}{l}\text { - Electric utility } \\
\text { - Large distributed generation }\end{array}$ \\
\hline Solid Oxide (SOFC) & $\begin{array}{l}650-1000^{\circ} \mathrm{C} \\
1202-1832^{\circ} \mathrm{F}\end{array}$ & $5 \mathrm{KW}-3 \mathrm{MW}$ & $85 \%$ overall with CHP (60\% electric) & $\begin{array}{l}\text { - Auxiliary power } \\
\text { - Electric utility } \\
\text { - Large distributed generation }\end{array}$ \\
\hline
\end{tabular}

Source: Argome National Laboratory

Dhect Methand Fuel Cells (DMFC) are a subset of PEMFCS typically used for small portable power applications with a stae range of about a subwall to $100 \mathrm{~W}$ and cperating at $60-90^{\circ} \mathrm{C}$.

Cost and durability are the two major challenges for fuel cell commercialization. However, other factors including fuel cell type, size, operating temperature, and gas pressure are also important characteristics affecting performance. The cost of the fuel cell must be reduced to be competitive with the automotive internal combustion engines, which is about $\$ 25-35 / \mathrm{kW}$. So for transportation application, the cost should be reduced 
to $\$ 30 / \mathrm{kW}$ for fuel cell to be competitive. And for durability and reliability, the fuel cell system should have the same level of durability and operating reliability of current combustion engines (5000 hour and 150,000 miles equivalent). Figure 8 shows a comparison between today's high volume cost and target for PEM fuel cells. Current cost is about seven times higher than the DOE's target cost, which indicates that current technologies face cost barriers and need further improvements.

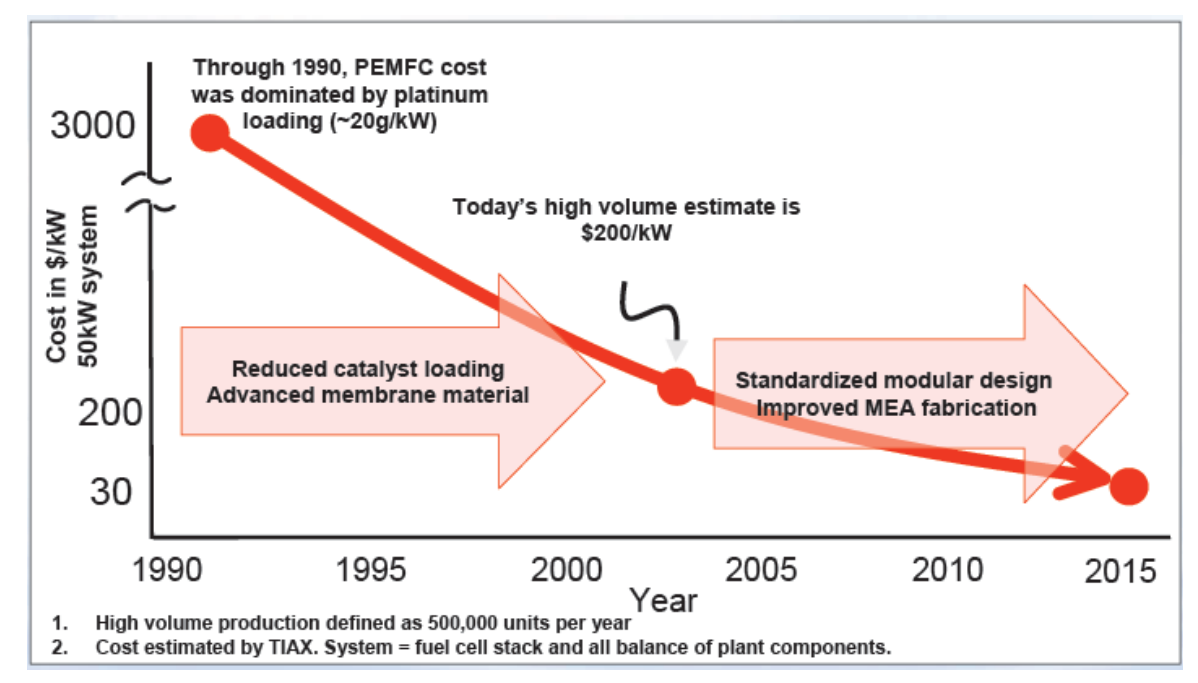

Figure 8 Comparison of today's cost and target for PEM fuel cell [22] (figure courtesy of the DOE, see appendix)

At the present time, there are three primary technology barriers to a hydrogen economy for automobile application: First, hydrogen storage systems have to be developed at vehicle range greater than 300 miles at a reasonable cost and reliable performance; second, low cost and safe hydrogen production and delivery needs to be obtained without causing any environmental effects; finally, fuel cell systems should have competitive operating costs and meet durability requirements. 
Among these barriers to hydrogen storage, no approach right now can meet the requirements without considering the cost. Therefore, research on hydrogen storage is in great demand. 


\section{CHAPTER 2 OVERVIEW OF HYDROGEN STORAGE}

\section{TECHNOLOGIES}

Hydrogen is the most abundant element in the universe. Stars and galaxies are mainly composed of hydrogen in plasma state. Hydrogen is the simplest element, only consisting of a single proton and a single orbiting electron. There are isotopes of hydrogen existing, such as deuterium consisting of a proton and a neutron, tritium composed of one proton and two neutrons. Because the single electron orbiting hydrogen nucleus is very reactive, hydrogen occur as molecules pairs $\left(\mathrm{H}_{2}\right)$ instead of atomic form $(\mathrm{H})$. Hydrogen can form ionic compounds with most elements by taking either a positive charge $\left(\mathrm{H}^{+}\right)$or a negative charge $\left(\mathrm{H}^{-}\right)$. The primitive phase diagram of hydrogen molecule is shown in Figure 9.

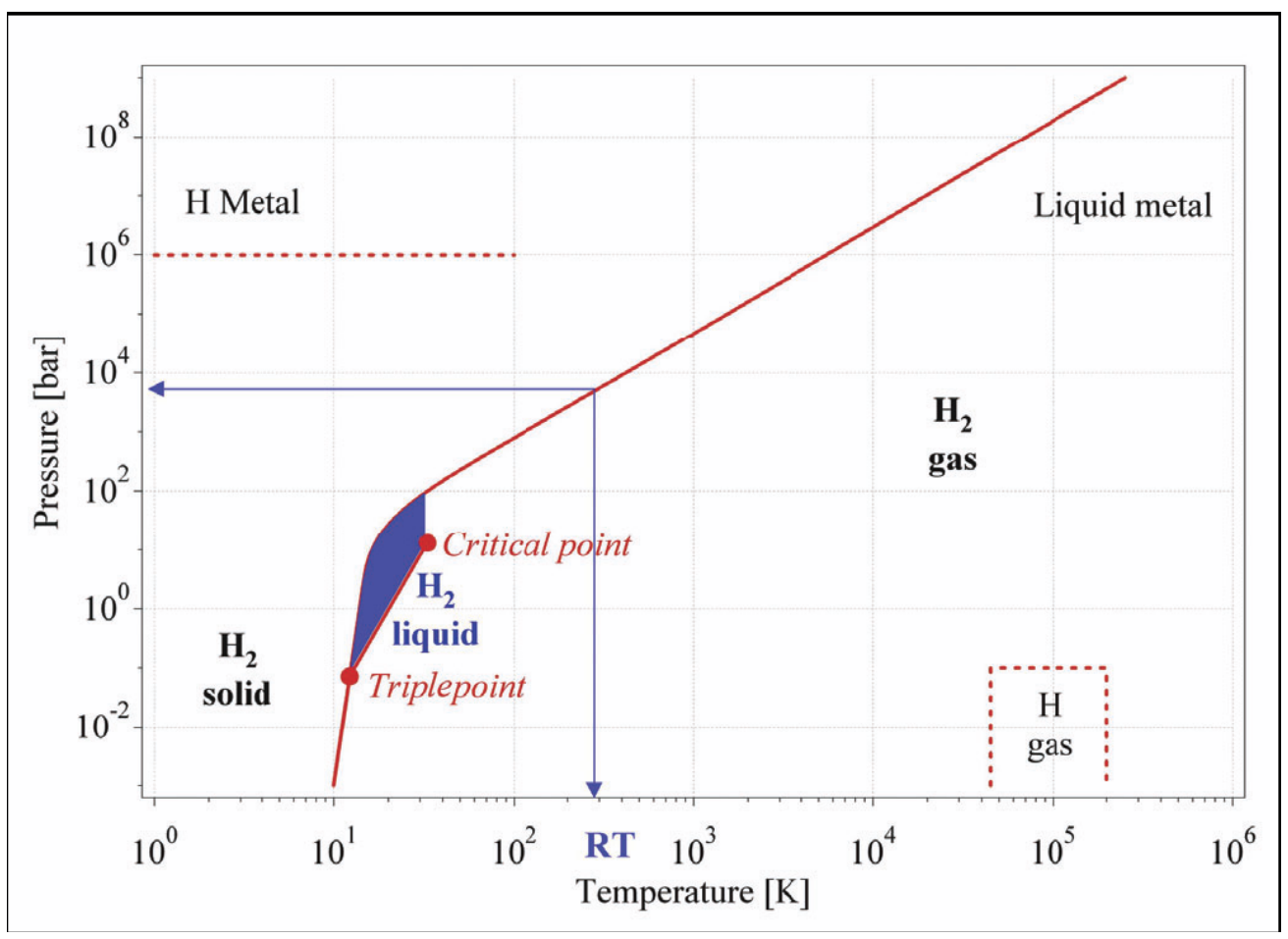

Figure 9 Primitive phase diagram of hydrogen [23] (reprinted with permission from Elsevier, see appendix) 
Hydrogen is a colorless gas at room temperature and atmospheric pressure. It maintains gas form with increasing pressure and temperature, and finally becomes liquid metal at optimum condition. At very low temperature, hydrogen becomes a solid. And hydrogen is a liquid in the small liquid phase region between the triplepoint and critical point. Hydrogen gas at normal temperature should obey the gas law. So by increasing gas pressure, the hydrogen volume density increases. This is the supported fundamental for high pressure hydrogen gas storage. In addition, when the temperature and pressure are lowered and controlled in the hydrogen liquid phase zone, cryogenic hydrogen storage is possible. Hydrogen molecules can also be physically adsorbed onto the surface of a solid due to Van der Waals interactions, which is called physisorption of hydrogen gas. Although hydrogen molecules are not very reactive under normal condition, they do form compounds with elements by representing a negative charge or positive charge, which are called hydrides. Moreover, in recent years researchers around the world are proposing that materials such as nanoporous materials, clathrates, and MOFs can become future potential hydrogen storage materials.

\subsection{High pressure hydrogen storage}

Compression might be the easiest and most common way to store hydrogen in a pressurized cylinder of pressure up to $20 \mathrm{MPa}$ [24]. According to gas law, increasing the gas pressure can reduce the volume, and improve the gas volumetric density [25]. As shown in Figure 10, the volumetric density of compressed hydrogen increases with increasing gas pressure, and reaches maximum at about $40 \mathrm{~kg} / \mathrm{m}^{-3}$. Further increase of pressure has no significant impact on the volumetric density. 


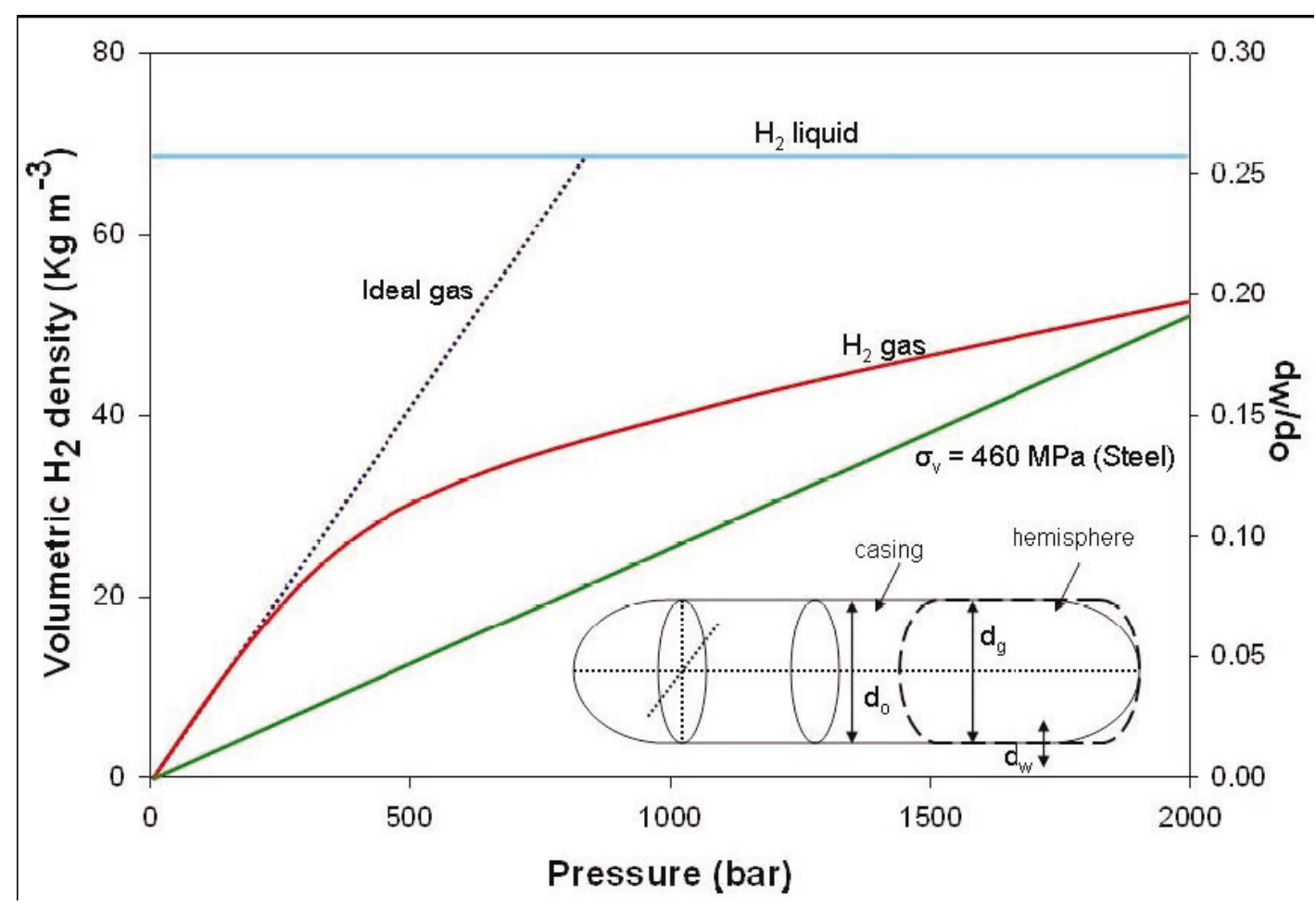

Figure 10 Density change of compressed hydrogen gas as a function of pressure [28] (With kind permission from Springer, see appendix)

The material used for containing high pressure hydrogen gas should have very high tensile strength, low density, little leakage, and no reaction with hydrogen. Most popular materials are stainless steel, $\mathrm{Cu}$ alloy and $\mathrm{Al}$ alloy, as shown in Table 3 .

Table 3 Common material for high pressure hydrogen gas cylinder [26]

\begin{tabular}{llll}
\hline Material & Density $\left[\mathrm{g} / \mathrm{cm}^{3}\right]$ & $\operatorname{Tm}\left[{ }^{\circ} \mathrm{C}\right]$ & $\begin{array}{l}\text { Tensile Strength } \\
{[\mathrm{MPa}]}\end{array}$ \\
\hline $\begin{array}{l}\text { stainless steel AISI } \\
\text { 304 Fe/Cr18/Ni10 }\end{array}$ & 7.93 & $1400-1455$ & $460-1100$ \\
stainless steel AISI & 7.96 & $1370-1400$ & $460-860$ \\
316 & & & \\
$\mathrm{Fe} / \mathrm{Cr} 18 / \mathrm{Ni10} / \mathrm{Mo3}$ & & & \\
$\mathrm{Cu}$ & 8.96 & 1083 & $224-314$ \\
$\mathrm{Al}$ & 2.70 & 660.4 & $50-195$ \\
$\mathrm{~V}$ & 6.1 & 1890 & $260-730$ \\
\hline
\end{tabular}


However, for these materials, the hydrogen embrittlement and permeation are still big concerns. The trend is to move toward lightweight composite cylinders. As shown in Figure 11, this kind of pressure vessel consists of three layers: an outer polymer dome which resists mechanical and corrosion damage, a fiber and resin reinforced shell, and an inner carbon fiber reinforced shell to withstand the mechanical stress. High costs prevent its further applications. But, as the price drops and demand increases, composite cylinders will enjoy widespread use for hydrogen transportation.

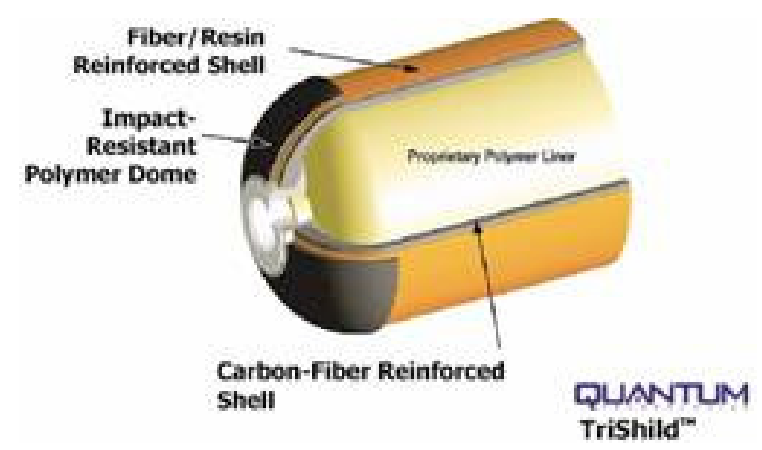

Figure 11 A typical high pressure composite cylinder [27] (With permission from University of Birmingham, see appendix)

The industry goal for high pressure cylinders is that they are capable of withstanding pressure up to $70 \mathrm{MPa}$ at weight of $110 \mathrm{~kg}$ with a gravimetric density of $6 \mathrm{wt} \%$ and a volumetric density of $30 \mathrm{~kg} / \mathrm{m}^{3}$. However, the very high cost associated with hydrogen compression makes it an unlikely storage method. For example, theoretically it takes 2.21 $\mathrm{kWh} / \mathrm{kg}$ energy to compress hydrogen from 0.1 to $80 \mathrm{MPa}$, making the cost of compressed hydrogen much higher than most storage methods.

\subsection{Liquid hydrogen storage}

Hydrogen can be stored in liquid phase at $21.2 \mathrm{~K}$ at atmospheric pressure. As shown in 
Figure 9, the liquid phase region for hydrogen is very narrow and the critical temperature is $33 \mathrm{~K}$, above which no liquid phase exists. Based on total nuclear spins, there are two types of hydrogen molecules: ortho-hydrogen (parallel nuclear spin) and para-hydrogen (antiparallel nuclear spin). Hydrogen at room temperature contains $25 \%$ para- form and $75 \%$ ortho- form. However, when hydrogen is cooled to boiling point $(21.2 \mathrm{~K})$, the orthofrom changes to $0.2 \%$. And the conversion from ortho- form to para- form is an exothermic reaction and very slow. At temperatures lower than $77 \mathrm{~K}$, the enthalpy change of conversion is $523 \mathrm{~kJ} / \mathrm{kg}$, which is higher than the latent heat of vaporization $(451.9$ $\mathrm{kJ} / \mathrm{kg}$ ) [28]. This means that liquid hydrogen should be stored in an open system otherwise the pressure in the closed system can be too high to cause an explosion [24], making the boil-off of liquid hydrogen unpreventable.

The normal liquefaction process of hydrogen is the Joule-Thompson Cycle. It undergoes a compression-cooling-expansion process. However, this process requires large amount of energy. The real work consumes $15.2 \mathrm{kWh} / \mathrm{kg}$ although theoretically only 3.23 $\mathrm{kWh} / \mathrm{kg}$ is needed. This liquefaction is about $30 \%$ of the heating value of hydrogen.

The large amount of energy consumed for liquefaction and the continuous boil-off of hydrogen are two major factors limiting the use of liquid hydrogen as a long term storage method. It may only be suitable for air or space applications where the gas is consumed in a short time and the cost is not an issue. 


\subsection{Physisorption}

Hydrogen molecules can be adsorbed onto the surface of the adsorbent based on the Van der Waals interactions. This interaction has two different terms: an attractive term, which diminishes with the distance from the surface on the order of $10^{-6}$; and a repulsive term, which diminishes with the distance on the order of $10^{-12}$. By considering these two effects, the most stable position which also has the minimum potential energy for an adsorbed molecule is at a distance of about one molecules radius of the adsorbate. According to BET theory of adsorption, the first layer of adsorbates is fixed on the surface of the adsorbent. When the surface is totally covered with adsorbates, other gas molecules would be adsorbed above the first layer forming a second layer of adsorbates, and so on for the subsequent layers [29]. However, the adsorption energy for the first layer is 11-12 $\mathrm{kJ} / \mathrm{mol}$ and it drops to $5.56 \mathrm{~kJ} / \mathrm{mol}$ for the subsequent layers as in nitrogen and carbon black [30]. Therefore, the binding energy for the second layer is similar to the latent heat of vaporization or sublimation of the adsorbate. Obviously, only one single monolayer could exist when the adsorbate is at the temperature equal or above the critical point.

\subsubsection{Porous materials}

Monolayer adsorption mechanism suggests that materials with high surface area could be potential hydrogen storage media. Consequently, porous materials such as activated carbon, zeolite, silicon oxide, aluminum oxide, and porous polymers have been introduced into this area. Jin and coworkers performed analysis of hydrogen adsorption onto activated carbon [31]. Their results showed that the hydrogen adsorption capacity 
increases almost linearly with the specific surface area. This is consistent with the similar observation from Nijkamp and coworkers [32]. They tested the capacity change under lower temperature $77 \mathrm{~K}$ and 1 bar pressure for carbon, silica, alumina and zeolite. Both groups also claimed that micropores are especially important and responsible for hydrogen adsorption. The hydrogen uptake increases linearly with the increasing of the micropore volume. Although Zeolite has low surface area, the hydrogen capacity was significant due to the high micropore volume. On the contrary, mesoporous silica and alumina showed poor storage capacity. One explanation for this is because microporous solids have capillaries at a width not exceeding a few molecules diameters, the attractive force from opposite walls will add up so as a higher adsorption potential can be achieved [33].

Since the Van der Waals interactions are very weak, significant adsorption can only be achieved at low temperature. Zhao et al. studied the temperature dependence of hydrogen storage at various pressures [34]. Their results showed that the adsorption capability decreases exponentially with temperature and increases with pressure. Obviously, temperature dependence is critical because very low amount of storages achieved at room temperature, which also means that extremely high pressure is required to obtain significant storage at ambient temperature. The lowest temperature for hydrogen without liquefaction process is about $77 \mathrm{~K}$ under the cooling effects of liquid nitrogen. Such low temperature is selected for most physisorption system. Recent results indicate that hydrogen adsorption is about $5 \mathrm{wt} \%$ at $77 \mathrm{~K}$ in comparison with the less than $0.5 \mathrm{wt} \%$ at 
room temperature under high pressure for various carbons. For silica, alumina, zeolite, and porous polymers, the maximum capacity is about $3 \mathrm{wt} \%$ at $77 \mathrm{~K}$ [35].

\subsubsection{Carbon nanostructure}

The curvature of the graphite sheets and the cavity inside the nanostructures are the main attractive advantages for hydrogen storage because under such structure, the potential field for adsorption is enhanced, and also the diffusion rate may be influenced [36]. Dillon and coworkers [37] first introduced carbon nanotubes into hydrogen storage, and claimed the storage capacity can be as high as $10 \mathrm{wt} \%$. After that, numerous researchers carried out experiments on carbon nanotube areas for hydrogen storage. However, the results scattered, and various experimentation errors were later discovered. Tibbetts et al. [38] had deeper investigation and claimed in 2001 that any reported capacity higher than $1 \mathrm{wt} \%$ is due to the experimental error. The adsorption mechanism is also based on physisorption as in most porous materials. Several researchers have claimed that capacity increases linearly with micropore volume or specific surface areas and decreases with the increasing of temperature for single wall carbon nanotubes (SWNT), multi wall carbon nanotubes (MWNT), nano fibers and other carbon nanostructures [39-41]. Corresponding theoretical studies have also been performed. Fundamental calculations are based on the physisorption of hydrogen molecules on carbon structure. The adsorption potential was found to be $9 \mathrm{~kJ} / \mathrm{mole}$ for hydrogen inside the nanotubes at $50 \mathrm{~K}$ [42], and it's $25 \%$ higher than the flat graphite, due to the curvature of the carbon nanotube surface. Simulation on temperature dependence was also performed by Williams et al. [43] by grand canonical Monte Carlo study of $\mathrm{H}_{2}$ adsorption in carbon SWNT ropes. They found 
out that the adsorbed hydrogen content increased with the decreasing temperature from $1.4 \mathrm{wt} \%(300 \mathrm{~K}, 10 \mathrm{MPa})$ to $9.6 \mathrm{wt} \%(77 \mathrm{~K}, 10 \mathrm{MPa})$. At lower pressure, the adsorption also decreased from $0.2 \mathrm{wt} \%(300 \mathrm{~K}, 1 \mathrm{MPa})$ to $5.9 \mathrm{wt} \%(77 \mathrm{~K}, 10 \mathrm{MPa})$.

From both experimental and theoretical studies, reversible hydrogen storage in carbon nanostructures is based on physisorption. The amount of hydrogen adsorbed depends on surface area, gas pressure and temperature. No evidence shows that the curvature of carbon nanostructures would have any influence on the adsorption capacity. However, curvature does influence adsorption potential, which means that the same amount of adsorption could be achieved under higher temperature than porous materials. The amount of adsorbed hydrogen in nanostructure at $77 \mathrm{~K}$ is $1.5 \times 10^{-3} \mathrm{wt} \% \cdot \mathrm{m}^{-2} \cdot \mathrm{g}$. By incorporating the maximum specific surface area for SWNT $\left(1315 \mathrm{~m}^{2} / \mathrm{g}\right)$, the highest adsorption capacity of the nanostructures is $2 \mathrm{wt} \%$ [28], which is much lower than the current storage technology.

\subsubsection{Electrochemical process}

The electrochemical process for hydrogen storage on carbon based materials such as activated carbon [44], carbon nanotubes [45], carbon nanofibers [46], carbon black [47] and hydride-carbon composite [48] in alkaline solution is more reasonable and feasible at ambient pressure since no cryogenic and high pressure condition is needed. Usually an alkaline solution is used as electrolyte, since water is then the only proton source. An electrochemical process is performed at a three-electrode cell, where the carbon based electrode is used as the working electrode. The adsorption is shown as below: 


$$
\begin{aligned}
& \mathrm{H}_{2} \mathrm{O}+\mathrm{e}^{-} \rightarrow \mathrm{H}+\mathrm{OH}^{-} \\
& \mathrm{C}+\mathrm{H} \rightarrow \mathrm{CH}_{\mathrm{ad}}
\end{aligned}
$$

In the charging process, when the electrons transfer to the water molecules, the hydrogen atoms are adsorbed onto the carbon surface. In the discharging process, following reactions occur:

$$
\begin{aligned}
& \mathrm{CH}_{\mathrm{ad}}+\mathrm{H}_{2} \mathrm{O}+\mathrm{e}^{-} \rightarrow \mathrm{H}_{2}+\mathrm{OH}^{-}+\mathrm{C} \\
& 2 \mathrm{H} \rightarrow \mathrm{H}_{2} \\
& \mathrm{CH}_{\mathrm{ad}}+\mathrm{CH}_{\mathrm{ad}} \rightarrow \mathrm{H}_{2}+2 \mathrm{C}
\end{aligned}
$$

The recombination of adsorbed hydrogen takes place and molecules hydrogen evolves through an electrochemical method [44].

The electrochemical process for carbon based electrodes is still considered a physisorption process from both experimental and computational studies [48]. In other words, the hydrogen capacity in electrochemical processes is also related to the electrode specific surface area. And the adsorption process is totally reversible. A. Züttel and coworkers [49] summarized that the electrochemistry process capacity at room temperature of carbon based samples has linear relationship with the surface area, and the maximum capacity is $2 \mathrm{wt} \%$. This measured hydrogen uptake is the same for electrochemical process at room temperature and high pressure processes at $77 \mathrm{~K}$. Some researches later found that by decorating metallic alloy particles onto the carbon 
nanostructure surface, the hydrogen capacity could be enhanced due to the synergistic effect between metal and carbon. In details, transition metallic particles can assist the dissociation of hydrogen molecules to form atomic hydrogen, making more hydrogen atoms available for adsorption onto nanostructures [50]. However, the highest achieved capacity was only $2.7 \mathrm{wt} \%$ [51], which is still far below liquid hydrogen storage.

In summary, the reversible hydrogen storage in porous materials and carbon nanostructures is based on the physisorption. The storage capacity is proportional to the specific surface area of the materials, and the adsorption temperature. The electrochemical adsorption capacity at room temperature is the same as high pressure adsorption at $77 \mathrm{~K}$, and the highest capacity is $2 \mathrm{wt} \%$. The experimental results are in good agreement with the theoretical calculations. Although there are reported discoveries that the capacity could be $2.7 \mathrm{wt} \%$, this number is still far below current technology. The advantages of using physisorption include the relative low pressure, the use of cheap materials such as carbon, and uncomplicated storage system. However, the major drawbacks are the low storage temperature, and low amount of hydrogen capacity.

\subsection{Hydrides}

Hydrogen has three common states: $+1,0$, and -1 . Thus the relative changes of chemical properties make hydrogen reactive with metals, intermetallic compounds, and alloys forming hydrides. There are two types of hydrides: metal hydrides, and complex hydrides. Since hydrogen in hydrides has various bonding types: ionic, interstitial, polymeric covalent, volatile covalent, the major difference for metal hydrides and complex hydrides 
is the transition to an ionic or covalent bond for complex hydrides at hydrogen absorption $[28]$.

\subsubsection{Metal hydrides}

Hydrogen can react with many metals and alloys at elevated temperature and form metal hydrides. The binary metallic hydrides usually have high conductivity and metallic appearance. The hydrogen atoms go to the interstitial sites of the metal lattice, and are represented as a negative charge. Many transition metals except for the gap from group 6 (Cr) to group $11(\mathrm{Cu})$, form stable metal hydrides with hydrogen.

Metal hydrides for hydrogen storage application should have high hydrogen content, moderate stability, and fast charge and discharge rate at moderate temperatures. However, all the binary (except Pd) metallic hydrides have high negative enthalpy for the formation of hydrides. It means that binary metal hydrides have high thermal stability and need high decomposition temperatures (above the operating temperature of the fuel cell), which can not be realized in a hydrogen driven vehicle. Therefore, binary metal hydrides are not useful for hydrogen storage. In order to solve the problem, the researchers [52-54] point out the metallic hydrides of intermetallic compounds $\mathrm{AB}_{\mathrm{x}} \mathrm{H}_{\mathrm{n}}$, in which $\mathrm{A}$ is a rare earth or alkaline earth metal tending to form stable hydrides and $\mathrm{B}$ is a transition metal forming only unstable hydrides. The hydride forming capacity could be retained, and the enthalpy could be highly reduced. 
There are four major classes of metal/intermetallic compounds developed for hydrogen storage application [55]: (1) AB type based on Ti as the hydride forming element, (2) $\mathrm{AB}_{5}$ type based on rare earth metals as the forming element, (3) $A_{2} \mathrm{~B}$ type based on magnesium, and (4) $\mathrm{AB}_{2}$ type based on zirconium.

When hydrogen molecules move close to metal surfaces, hydrogen is first attracted by Van der Waals force, which is a physisorption process. At the distance smaller than 0.2 $\mathrm{nm}$ from the metal surface, hydrogen molecules overcome the activation barrier and dissociates into two hydrogen atoms. Hydrogen atoms share electrons with metal atoms at the surface, which is considered a chemisorption process. Then the hydrogen atoms can jump into the interstitial sites of the metal lattice. When the hydrogen to metal ratio is less than 0.1 , the hydride is considered as $\alpha$ phase. As the hydrogen concentration increases, the $\mathrm{H}-\mathrm{H}$ interaction due to the lattice expansion becomes more important and the second phase- $\beta$ phase begins to nucleate. When the hydrogen content increases even higher than 2, the hydrides are ionic or covalent compounds and should belong to complex hydrides.

Figure 12 shows the pressure composition isotherms for hydride transition from $\alpha$ phase to $\beta$ phase. While in the solid solution in the phase transformation, the isotherm shows a flat plateau. The length indicates the amount of hydrogen stored. When it reaches the upper limit of storage in $\beta$ phase, the pressure rises steeply with the hydrogen concentration, which indicates that the hydride is saturated with hydrogen. At higher 
temperature, the transition time from $\alpha$ phase to $\beta$ phase is reduced. When the temperature reaches the critical point $\mathrm{Tc}$, the transition from $\alpha$ phase to $\beta$ phase becomes continuous [56]. The corresponding enthalpy and entropy for formation of metal hydrides could be calculated from the Van't Hoff plot, which is also presented in Figure 12.

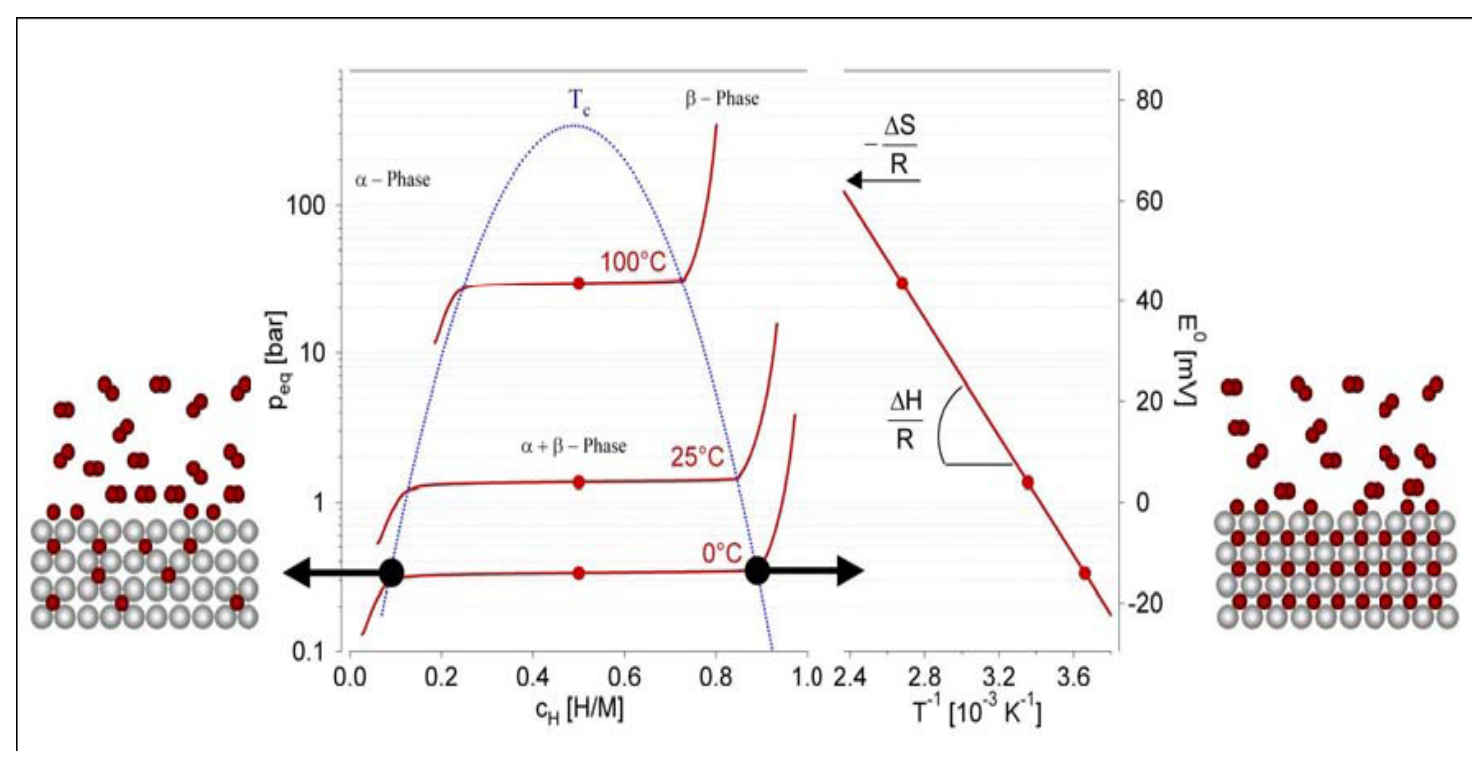

Figure 12 Pressure-composition isotherms presenting the hydrogen absorption with the phase transformation from $\alpha$ phase to $\beta$ phase [28] (With kind permission from Springer, see appendix).

The advantages of using metal hydrides are that some of them can absorb and desorb hydrogen at ambient temperature and atmospheric pressure, which can eliminate the heavy pressure tanks and costly cryogenic tanks. And because most metal hydrides are in solid form, the volumetric density of such materials is very high, such that $115 \mathrm{~kg} / \mathrm{m}^{3}$ in $\mathrm{LaNi}_{5} \mathrm{H}_{6}$. However, metal hydrides usually contain transition metals, so the gravimetric density is limited to less than $3 \mathrm{wt} \%$. As an example, $\mathrm{LaNi}_{5} \mathrm{H}_{6}$ has only $1.4 \mathrm{wt} \%$ storage capacity although it has an extremely high volumetric density. The trend for metal hydrides should move to using light weight metals such as $\mathrm{Al}, \mathrm{Mg}$, Na, etc. However, 
forming such metal hydrides usually involves an exothermic reaction. Significant heat should be applied in order to get hydrogen released. Therefore, challenges still remain before metal hydrides can make suitable hydrogen storage media.

\subsubsection{Complex hydrides}

As the bonding of hydrogen in the hydrides has changed to ionic or covalent, the hydrides are considered as complex hydrides. In complex hydrides, the compounds containing light elements such as $\mathrm{Li}, \mathrm{Mg}, \mathrm{B}$, and $\mathrm{Al}$, have attracted lots of attention. In these materials, hydrogen atoms are located in the corners of a tetrahedron with $\mathrm{B}$, Al, etc at the center. There exist positive ions such as $\mathrm{Na}$ or $\mathrm{Li}$, to compensate the negative charge of $\mathrm{BH}_{4}{ }^{-}$or $\mathrm{AlH}_{4}{ }^{-}$.

Complex hydrides show amazing gravimetric and volumetric capacities. As first presented by Bogdanović and coworkers [57], $\mathrm{NaAlH}_{4}$ has total capacity of $6.7 \mathrm{wt} \%$ after two steps of desorption at pressure of 2 bar and temperature of $60{ }^{\circ} \mathrm{C} . \mathrm{LiBH}_{4}$ and $\mathrm{NaBH}_{4}$ have also received lots of attention [58-59], and these materials could be directly synthesized from the metal, boron and hydrogen [60]. Among all the complex hydrides, $\mathrm{LiBH}_{4}$ has the highest gravimetric hydrogen density known today, $18 \mathrm{wt} \%$ at room temperature. $\mathrm{Al}\left(\mathrm{BH}_{4}\right)_{3}$ has the highest known volumetric density of $150 \mathrm{~kg} / \mathrm{m} 3$ and a very high gravimetric hydrogen density of $17 \mathrm{wt} \%$. However, the absorption and desorption kinetics are unknown and need further research activities. Most of the complex hydrides can meet the DOE target [61]. However, the low dynamics of hydrogen discharge are major problems. Most complex hydrides change their 
morphology and cannot maintain the original structure when the hydrogen is released [62]. Therefore, the reversibility (absorption and desorption cycles) is questionable.

\subsection{New concepts}

Other new and interesting technologies have been investigated in recent years. The examples reviewed below show promising hydrogen storage properties and will receive more research attention.

\subsubsection{Lithium nitride}

Lithium nitride $\left(\mathrm{Li}_{3} \mathrm{~N}\right)$ was first synthesized by Dafert and Miklauz [63] a hundred years ago. It didn't attract significant attention until recently when $\mathrm{Hu}$ and Ruckenstein [64] reported using $\mathrm{Li}_{3} \mathrm{~N}$ as a promising candidate for hydrogen storage. The hydrogen generation of $\mathrm{Li}_{3} \mathrm{~N}$ is composed of two steps, shown as following:

$$
\begin{aligned}
& L i_{3} \mathrm{~N}+\mathrm{H}_{2} \leftrightarrow \mathrm{Li}_{2} \mathrm{NH}+\mathrm{LiH} \\
& L i_{2} \mathrm{NH}+\mathrm{H}_{2} \leftrightarrow 2 \mathrm{LiN}_{2} \mathrm{H}
\end{aligned}
$$

The total absorbed hydrogen capacity is about $11.5 \mathrm{wt} \%$. However, the absorption process only starts at a temperature above $100{ }^{\circ} \mathrm{C}$, and the total desorption of hydrogen can only be realized at temperatures above $320{ }^{\circ} \mathrm{C}$ [65]. It was reported that ammonia formation could be avoided, especially when $\mathrm{TiCl}_{3}$ was added to the system [66]. However, even at trace amounts, ammonia would poison the membrane of the PEM fuel cell [67]. 


\subsubsection{Boron nitride (BN) nanotube}

Like carbon nanotubes, boron nitrides nanotubes also have unique properties which can not be achieved in bulk materials. Ma and coworkers [68] prepared different BN structures and tested their capacities for hydrogen storage at room temperature. Hydrogen capacities up to $1.8 \mathrm{wt} \%$ for multiwall nanotubes and $2.6 \mathrm{wt} \%$ for bamboo nanotubes were achieved. And the capacity consistently increased with the applied pressure. The adsorption mechanism was believed to be major chemical, since about $70 \%$ of the hydrogen was retained after the pressure was released, and the retained hydrogen was released out by heating to $573 \mathrm{~K}$. The computer simulations performed by BarajasBarraza and coworkers [69] also represented that chemisorptions of hydrogen atoms can be found at the external surface of the tube.

The advantages of $\mathrm{BN}$ nanotubes over carbon nanotubes in hydrogen storage are due to the heteropolar bonding of $\mathrm{BN}$, based on which, the binding energy of hydrogen on $\mathrm{BN}$ could be highly increased. As the results from the pseudopotential density functional studies [70] on binding energy, the physisorption binding energy of hydrogen on carbon nanotubes is $40 \%$ smaller than it is on boron nitride nanotubes. This study showed a pathway to a storage medium which could adsorb hydrogen at ambient conditions. Further deformation may have positive effects on hydrogen adsorption [71]. A higher hydrogen storage capacity was achieved by Tang et al [72] in collapsed BN nanotubes. The highest storage capacity was about $4.2 \mathrm{wt} \%$ at $10 \mathrm{MPa}$ pressure. And the collapsed tubes showed much better results than the multiwall tubes. They explained that when the 
tubes collapsed, the specific area increased from 254.2 to $789.1 \mathrm{~m}^{2} / \mathrm{g}$, which caused higher hydrogen adsorption.

However, such chemisorption mechanisms caused the hydrogen to be released at temperatures over $300{ }^{\circ} \mathrm{C}$, which is not applicable in current industry. Moreover, cycling demonstration has not been performed, so the charge/discharge responses are not clear at this moment.

\subsubsection{Microporous metal organic frameworks (MOF)}

The MOFs have similar characteristics as single-walled carbon nanotubes. Both are at nano scale and have open channels. MOFs are crystalline metal-organic frameworks and have cubic cavities. Typical MOFs have inorganic groups $[\mathrm{OZnO} 4]^{6+}$ at the corner of the structure and are connected with carboxylate organic links [73]. The metallic elements can bind hydrogen more strongly than carbon. From the observation and theoretical calculations on hydrogen adsorption sites [74], the metal-oxide cluster is primarily responsible for the adsorption, and the organic linker plays the secondary role. The linkers are isolated from each other and are accessible from all sides, so such materials have extremely high surface areas $\left(2500-3000 \mathrm{~m}^{2} / \mathrm{g}\right)$. From the physisorption view, both the strong bonding effects of metallic elements and the high surface areas make MOFs suitable for hydrogen storage materials. The material MOF-5 showed $4.5 \mathrm{wt} \%$ hydrogen capacity at $78 \mathrm{~K}$ and moderate pressure [75]. However, at room temperature, the capacity decreased to $1 \mathrm{wt} \%$. Other structures such as IRMOF-6 and IRMOF-8 showed doubled 
and quadrupled hydrogen capacities at room temperature and 20 bar pressure. There are still lots of unknown areas with these materials, which need to be further researched.

\subsection{Conclusion}

Hydrogen storage is the major technical barrier for realizing the hydrogen economy for future energy independence. The low gravimetric and volumetric densities along with the safety and cost issues of high pressure tanks have limited its further applications. For the cryogenic methods, the continuous boil off and high energy consumption have also made it unsuitable as long term solution. Porous materials including carbon nanostructures have low gravimetric capacity and the capacity is associated with the total surface area. Also only physisorption exists in porous materials, so cryogenic conditions are required. Metal hydrides show promising gravimetric hydrogen uptake, however, the desorption needs to take place under high temperatures which are not possible in fuel cell driven vehicles. Complex hydrides show amazing gravimetric and volumetric capacities, however, their slow desorption kinetics and reversibility are questionable. Although some new concepts and ideas are being explored in recent years, all of these are under first discovery stages and lots of areas are unknown.

From the discussion above, no current existing technology can meet the DOE's target goals because none have shown satisfactory capacity, cost, durability and efficiency. The target looks difficult to be accomplished with conventional theories. Therefore, other new concepts in hydrogen storage technology have to be investigated. 


\section{CHAPTER 3 PROJECT CONCEPT}

The major problem for physisorption of hydrogen is the weak interaction between hydrogen and solid surface and thus significant storage can only be achieved at liquid nitrogen temperature.

Two strategies are proposed to increase the static interaction between hydrogen and solid materials. The first approach is to increase the ionic charges of solid materials so intrinsic dipole moment would contribute to the overall interaction. The molecules with high ionic charges will be computationally simulated to demonstrate the fundamental concepts. Corresponding experiments with ionic compounds will also be carried out to have comparable data to the computational results.

Introducing an external electric field is another way to further enhance the charge effects. By supplying enough electrical energy, the electron clouds of the hydrogen molecules could be attracted to the adsorbent site, where electron overlapping may occur. This in turn can remarkably enhance the adsorption energy. This approach will be tested both computationally and experimentally.

The overall charge induced effects would be tested both qualitatively and quantitatively. Moreover, computational work will be carried out corresponding to the experiments in order to verify the observations and understand the underlying principles. 


\section{CHAPTER 4 HYDROGEN CLUSTERS}

A cluster is a group of bound atoms at a size between a molecules and a solid. Such substances normally have weak bonding and are stable only at cryogenic conditions or under substantial externally applied fields. Neutral clusters are very weakly bonded by van der Waals force. Whaley [76] observed hydrogen clusters by expanding pure hydrogen gas at cryogenic conditions. More recently, Tejeda and co-workers [77] produced Para- $\mathrm{H}_{2}$ clusters by using the same method for pressures from 1 bar to 0.006 mbar and for temperatures from 24 to $60 \mathrm{~K}$. They observed clusters $\left(\mathrm{pH}_{2}\right)_{\mathrm{N}}$ with $\mathrm{N}$ from 2 to 8 by using Raman Spectroscopy. Later computer simulation work predicted the $\left(\mathrm{pH}_{2}\right)_{\mathrm{N}}$ clusters with $\mathrm{N}$ from 3 to 50 and showed that the clusters exhibit a clear geometrical order [78]. However, hydrogen ion clusters have attracted more attention because ionization makes hydrogen easier to handle. Because of the long range ion-molecules interactions, such clusters grow and exist in a more simple way. Due to the different interaction mechanisms, hydrogen ion clusters may have quite different structures and properties from their neutral species.

\subsection{Hydrogen ion clusters}

Observations of hydrogen ion clusters have been reported by several researchers. Hiraoka and Kebarle [79] studied the stabilities of $\mathrm{H}_{\mathrm{n}}^{+}$for $\mathrm{n}=3,5,7,9$. They produced hydrogen ion clusters by using a short pulse of electrons reacting with pure hydrogen gas at pressures 2-6 torr, and investigated the clusters by using a high ion source pressure mass spectrometer. Their Van't Hoff plots of equilibria $\mathrm{H}_{\mathrm{n}}{ }^{+}+\mathrm{H}_{2}=\mathrm{H}_{\mathrm{n}+2}{ }^{+}$showed that the 
dissociation enthalpies were $9.6,4.1,3.8$, and $2.4 \mathrm{kcal} /$ mole for $\mathrm{n}=3,5,7,9$, respectively. Beuhler et al [80] also studied the $\mathrm{H}_{3}{ }^{+}+\mathrm{H}_{2}=\mathrm{H}_{5}{ }^{+}$and $\mathrm{H}_{5}{ }^{+}+\mathrm{H}_{2}=\mathrm{H}_{7}{ }^{+}$equilibria in a corona discharge ion source at a temperature of $15 \mathrm{~K}$ and pressure of $1 \mathrm{~atm}$, and detected the clusters in a mass spectrometer. Their calculations of dissociation enthalpy for $\mathrm{H}_{5}^{+}$and $\mathrm{H}_{7}^{+}$clusters were 6.6 and $3.1 \mathrm{kcal} /$ mole. Okumura and coworkers [81] produced more hydrogen clusters by using both corona discharge $\left(\sim 200\right.$ Torr, $\left.0^{\circ} \mathrm{C}\right)$ and electron impact ionization $\left(10^{-5}\right.$ torr). They identified hydrogen clusters $\mathrm{H}_{5}{ }^{+}, \mathrm{H}_{7}{ }^{+}, \mathrm{H}_{9}{ }^{+}, \mathrm{H}_{11}{ }^{+}, \mathrm{H}_{13}{ }^{+}$, and $\mathrm{H}_{15}{ }^{+}$by infrared spectroscopy. Negative hydrogen ion clusters $\mathrm{H}_{16}{ }^{-}$have been reported by Mills [82]. He identified the ion clusters by various characterization techniques such as ToF-SIMS (Time of Flight Secondary Ion Mass Spectroscopy), XPS (X-ray photoelectron spectroscopy), etc, in $\mathrm{K}_{2} \mathrm{CO}_{3}$ electrolytes that were concentrated in a rotary evaporator at $50^{\circ} \mathrm{C}$.

Theoretical and modeling works have also been conducted in various levels of calculations. The basic methods belong to either the ab initio models [83-85] or density functional theory (DFT) [86-88]. Both methods concluded that hydrogen clusters consist of $\mathrm{H}_{2}$ units surrounding a $\mathrm{H}_{3}{ }^{+}$core structure. For the hydrogen clusters $\mathrm{H}_{27}{ }^{+}$, the center three hydrogen atoms share one positive electron hole, and other $\mathrm{H}_{2}$ ligands about the $\mathrm{H}_{3}{ }^{+}$ core. In $\mathrm{H}_{9}{ }^{+}$, three $\mathrm{H}_{2}$ molecules are arranged symmetrically around the $\mathrm{H}_{3}{ }^{+}$core with the direction perpendicular to the core triangle. As the clusters get bigger, more and more external hydrogen molecules are lying above and below the $\mathrm{H}_{3}{ }^{+}$plane, and also are making a spherical shell. 
As the cluster size $\mathrm{n}$ increases, the distance between the core triangle and external molecules increases, and the dissociation energies decreases. As the clusters grow, the interaction between the electron-hole delocalization and ion-molecules polarization becomes significantly reduced, resulting in lower bonding energies. Moreover, when the external molecules surround the $\mathrm{H}_{3}{ }^{+}$core symmetrically; the dissociation energies from the calculations differ significantly, for example, $18.0 \mathrm{~kJ} / \mathrm{mole}$ for $\mathrm{H}_{7}^{+}$and $15.8 \mathrm{~kJ} / \mathrm{mole}$ for $\mathrm{H}_{9}{ }^{+}$[89]. This is because the charge migrates smoothly from the internal cluster $\left(\mathrm{H}_{3}{ }^{+}\right.$ core) to the external hydrogen molecules. From the calculations [84], when the cluster size increased from $\mathrm{H}_{13}{ }^{+}$to $\mathrm{H}_{17}{ }^{+}$, the charge localized at the $\mathrm{H}_{3}{ }^{+}$center decreased from $66.4 \%$ to $64.2 \%$.

\subsection{Metal hydrogen clusters}

Hydrogen could form clusters with other substances besides hydrogen ions. A big category includes the metal hydrogen complex. Metal hydrides are of considerable interest as potential hydrogen storage materials. However, metal hydrides maintain their crystal structures so that hydrogen capacity is limited by covalence electrons. When the metals were in their liquid or gases states, more hydrogen could be bonded. Several researchers have reported on hydrogen interaction with metals or metal ions at the molecules level.

Gagliardi and coworkers [90] conducted DFT computation on metal hydrogen complex at molecules level. They claimed that the $\mathrm{MH}_{12}$ such as $\mathrm{WH}_{12}, \mathrm{MoH}_{12}, \mathrm{VH}_{12}{ }^{-}$, and $\mathrm{TiH}_{12}{ }^{2-}$ 
are stable substances. Bauschlicher et al. [91] also reported DFT computational study on $\mathrm{Co}\left(\mathrm{H}_{2}\right)^{\mathrm{nt}}$ clusters from $\mathrm{n}=1$ to 6 . Their calculated bonding energies are consistent with experimental results from Kemper et al [92], who reported that binding energy for six $\mathrm{H} 2$ molecules in $\mathrm{Co}\left(\mathrm{H}_{2}\right)^{\mathrm{n}+}$ were $18.2,17.0,9.6,9.6,4.3$ and $4.0 \mathrm{kcal} / \mathrm{mol}$. A similar experiment was conducted on $\mathrm{Sc}^{+}$and $\mathrm{H}_{2}$ clusters [93]. The $\mathrm{Sc}^{+}$ions were produced via surface ionization of $\mathrm{ScCl}_{3}$ on a hot filament (about $2500 \mathrm{~K}$ ). The ions were injected into a reaction chamber containing $\mathrm{H}_{2}$ at pressure 3 Torr and temperature $300 \mathrm{~K}$. The ion clusters were detected by a quadrupole mass analyzer. The measured dissociation energies of $\mathrm{Sc}\left(\mathrm{H}_{2}\right)^{\mathrm{n}+}$ were $6.4,5.4,5.0$, and $4.5 \mathrm{kcal} / \mathrm{mole}$, for $\mathrm{n}=2$ to 5 . The same experimental system was used to generate and identify $\mathrm{Ti}^{+}\left(\mathrm{H}_{2}\right)_{1-6}$ clusters [94], except the ion source material was $\mathrm{TiCl}_{4}$. The associated binding energies were 7.5, 9.7, 9.3, 8.5, $8.2,8.7 \mathrm{kcal} / \mathrm{mole}$ for $\mathrm{n}=1-6$, respectively. Their corresponding DFT calculation predicted the geometry of the clusters. The $\operatorname{Ti}^{+}\left(\mathrm{H}_{2}\right)_{5}$ has $\mathrm{C}_{2 \mathrm{v}}$ symmetry, and $\mathrm{Ti}^{+}\left(\mathrm{H}_{2}\right)_{6}$ has $\mathrm{D}_{2 \mathrm{~d}}$ symmetry. The $\mathrm{H}_{2}$ molecules arrangement around the $\mathrm{Ti}^{+}$core depends on the calculation of the lowest energy.

The same research group also studied bonding interaction of $\mathrm{Cu}_{2}{ }^{+}$ions with $\mathrm{H}_{2}$ molecules [95]. The $\mathrm{Cu}_{2}{ }^{+}$ions were generated from a copper anode in a glow discharge using an $\mathrm{Ar}$ bath and then mass selected and injected into a chamber with hydrogen gas at 2-4 Torr. The clusters formed and were withdrawn by a small electric field and then detected by a mass analyzer. The bond dissociation energies of $\mathrm{H}_{2}$ ligands are 12.4, 10.1, 4.9, 3.8, 2.1 and $1.7 \mathrm{kcal} / \mathrm{mol}$ for $\mathrm{n}=1-6$, respectively. The same experimental and computational work 
has been done for alkali metal ions. Bushnell and coworkers [96] studied $\mathrm{Na}^{+}\left(\mathrm{H}_{2}\right)_{1,2}$ and $\mathrm{K}^{+}\left(\mathrm{H}_{2}\right)_{1,2}$ clusters by using the same methods as described above. The dissociation enthalpies were found to be 2.45 and $2.25 \mathrm{kcal} / \mathrm{mol}$ for $\mathrm{Na}^{+} \mathrm{H}_{2}$ and $\mathrm{Na}^{+}\left(\mathrm{H}_{2}\right)_{2}$, and 1.45 and $1.26 \mathrm{kcal} / \mathrm{mol}$ for $\mathrm{K}^{+} \mathrm{H}_{2}$ and $\mathrm{K}^{+}\left(\mathrm{H}_{2}\right)_{2}$, respectively. Their ab initio calculations confirmed that the bonding is dominated by electrostatic interaction with very weak covalent interaction. Emmeluth et al [97] reported the observation of $\mathrm{Li}^{+}\left(\mathrm{H}_{2}\right)_{\mathrm{n}}$ with $\mathrm{n}=1-3$ cation clusters and their corresponding infrared spectra. They produced cation clusters by passing supersonic expanded $\mathrm{H}_{2}$ ( 8 bars) gas over a metal rod irradiated by a pulsed laser, where the Li ions were generated. Infrared spectra of the clusters were later detected by a tunable IR source. The spectra of a different stretch band and redshifts predicted the $\mathrm{Li}^{+}\left(\mathrm{H}_{2}\right)_{2}$ clusters have a $\mathrm{H}_{2}-\mathrm{Li}^{+}-\mathrm{H}_{2}$ equilibrium structure with the $\mathrm{H}_{2}$ molecules on opposite sides of the $\mathrm{Li}^{+}$ion and the $\mathrm{Li}^{+}\left(\mathrm{H}_{2}\right)_{3}$ cluster has a trigonal $\mathrm{D}_{3}$ symmetry.

Fundamental theoretical work has been proposed to explain the bonding behavior of interactions between metal ion and hydrogen molecules. Alkali metal ions such as $\mathrm{Na}^{+}$, $\mathrm{K}^{+}$, and $\mathrm{Li}^{+}$, have closed electron shells, so the charge quadrupole and charge induced dipole electrostatic interactions are the major contributors to the bonding with hydrogen. Such interactions have relative low energy in comparison with the covalent bond and result in lower dissociation energies as described above that only $2.45 \mathrm{kcal} / \mathrm{mol}$ for $\mathrm{Na}^{+} \mathrm{H}_{2}$. However, for first row transition metals, e.g. $\mathrm{Sc}^{+}, \mathrm{Ti}^{+}$, and $\mathrm{Co}^{+}$, the bonding is more complex. One example is that if only the ion induced dipole interaction were considered for $\mathrm{Co}^{+}$, the calculated bond energy would be only $4.6 \mathrm{kcal} / \mathrm{mol}$, as the 
experimentally measured bond energy was $18.2 \mathrm{kcal} / \mathrm{mol}$ [94]. There must be other bonding or electron correlations associated with such larger bonding energy. Three electronic interactions have been proposed [93, 95]. First, the electrons from $\mathrm{H}_{2} \sigma$ orbital could be donated to the metal $3 \mathrm{~d}$ orbital or $4 \mathrm{~s}$ orbital. Metal ions with unfilled $3 \mathrm{~d}$ or $4 \mathrm{~s}$ orbital would have this kind of mechanism. Second, for transition metals with filled 3d orbital, back donation from metal $\mathrm{d} \pi$ orbital to hydrogen $\sigma^{*}$ aitibonding orbital can break up the hydrogen molecules to form atomic hydrogen. Third, the metal ions may form $3 \mathrm{~d}-$ 4s hybrid orbital in order to minimize Pauli repulsion. By comparing these three bonding, the charge induced dipole interaction was found to contribute minimally to the overall bonding energy. From the above experimental examples and computational calculations, the bonding energy of $\mathrm{H}_{2}-\mathrm{M}^{+}$varies among all the hydrogen molecules and it depends on the valence configuration of the metal ions. Also for different metals, the bonding energies varied depending on the electrons of $3 \mathrm{~d}$ or $4 \mathrm{~s}$ orbital.

\subsection{Non-metallic hydrogen clusters}

Hydrogen molecules can also interact with water ions. Bae and coworkers [98] first reported the observation of the $\mathrm{H}_{3} \mathrm{O}^{+}\left(\mathrm{H}_{2}\right)_{\mathrm{n}}$ clusters concurrently with the formation of $\mathrm{H}_{3}{ }^{+}\left(\mathrm{H}_{2}\right)_{n}$ by electron impact ionization of hydrogen gas. Several species of $\mathrm{H}_{3} \mathrm{O}^{+}\left(\mathrm{H}_{2}\right)_{\mathrm{n}}$, with $n=1-4$ have been detected. Mills [82] also observed hydrogen ion clusters on water molecules as large as $\mathrm{H}_{3} \mathrm{O}^{+}\left(\mathrm{H}_{2}\right)_{10}$ concurrently with negative cluster $\mathrm{H}_{16}{ }^{-}$.

Besides water, Moroni et al [99] reported both experimental observations and Quantum Monte Carlo simulations on para-hydrogen clusters with carbon monoxide. They 
produced CO- $\left(\text { para } \mathrm{H}_{2}\right)_{\mathrm{N}}$ clusters by passing mixture gas of $0.01 \% \mathrm{CO}, 3 \%$ para $\mathrm{H}_{2}$, and ultrahigh helium through a pulsed supersonic jet. The clusters were recorded using a cooled $\left(-80{ }^{\circ} \mathrm{C}\right)$ pinhole jet nozzle and infrared spectra. They have identified CO-(para $\left.\mathrm{H}_{2}\right)_{\mathrm{N}}$ clusters from $\mathrm{N}=1$ up to 14 . The simulation work showed that the first six $\mathrm{H}_{2}$ molecules were arranged around the oxygen end of the $\mathrm{CO}$ with the buildup of hydrogen toward the carbon end as more hydrogen molecules were attached. The first salvation shell was completed at $\mathrm{N}=12$ and the cluster had nearly spherical structure with $\mathrm{N}$ greater than 12 . Such bonding is mostly due to the polarized dipole electrostatic interaction.

\subsection{Hydrogen plasma}

In order to generate hydrogen clusters, positive or negative hydrogen ions need to be produced first with later hydrogen molecules attaching the ions. Such typical positive ions $\left(\mathrm{H}_{3}{ }^{+}, \mathrm{H}_{2}{ }^{+}\right.$and $\left.\mathrm{H}^{+}\right)$, and one type of negative ion $\left(\mathrm{H}^{-}\right)$, together with electrons and atoms and molecules in a range of excited states are called hydrogen plasma. In other words, generation of hydrogen plasma is the first step to produce hydrogen clusters. As discussed previously, hydrogen ions are generated by pulsed laser, glow discharge, corona discharge, etc. By considering possible large scale processing feasibility, plasma generations with major emphasis on non-thermal and low temperature plasma have been attracted lots of attention. There are several major ways to generate hydrogen plasmas under feasible conditions.

$R F$ discharge 
The electric field generated by the rf driving voltage, excites the electrons to produce plasma. In this kind of discharge, plasma densities are low, $10^{9}-10^{11} \mathrm{~cm}^{-3}[100]$, rf driving voltage $100-1000 \mathrm{~V}$ and typical pressure range of $10-100$ mTorr [101]. The major drawback of this method is that it is impossible to control independently plasma density and energy [101].

\section{Inductive discharge}

Such discharge is produced by applying rf power to a nonresonant inductive coil. The time varying currents circulate in the coil and induce varying magnetic and electric fields, which cause the plasma to be developed. There are no electrodes needed in inductive discharge. Comparing with capacitive discharge, it is a "cleaner" process and the plasma produced would not be contaminated by electrode materials. However, the plasma density is in a medium range $10^{11}-10^{12} \mathrm{~cm}^{-3}[100]$.

\section{Helicon discharge}

Helicon waves belong to the category of whistler waves, which are right-hand circularly polarized electromagnetic waves in free space [102]. Helicon plasma generation was first discovered by Boswell [103]. Because of its ability to produce high-density plasma efficiently, helicon sources have been intensely studied [104]. Helicon sources differ from other inductively coupled radiofrequency (rf) plasmas that a dc magnetic field is required when the gas has been weakly ionized by the electrostatic voltage. Applying a magnetic field can cause a circularly polarized helicon wave in the processing chamber 
and the wave energy is used to raise plasma density [105]. The plasma densities range from $10^{11}-10^{14} \mathrm{~cm}^{-3}$, usually $10^{11}-10^{12} \mathrm{~cm}^{-3}$ for processing [100]. The magnetic fields vary from 20 to $200 \mathrm{G}$.

\section{Discharges}

A high voltage (usually several hundred volts) is applied between anode and cathode [106]. The electrons in the chamber are rapidly accelerated to become "hot". These electrons begin to collide with molecules to produce plasmas. The usual pressure range of this kind of operation is between $0.1-10 \mathrm{~Pa}$ and plasma density is $10^{12} \mathrm{~cm}^{-3}$.

\subsection{Microwave plasma}

Microwave has been applied as an alternative method for plasma generation due to the advantages which may not be realized by other methods. Microwaves are directly introduced into the plasma volume, and the system does not have any vulnerable parts and requires any maintenance [107]. The contamination of plasma by the evaporated materials can be prevented due to the electrodeless arrangement. Plasmas are generally generated under low gas pressure in order to have high plasma density, low gas temperature, and good uniformity. However, atmospheric pressure plasmas have recently attracted a lot of attentions because they eliminate expensive vacuum systems, which make a high processing capacity possible [108].

Atmospheric microwave plasma has been developed in several processing areas especially in surface modification [109] and thermal processing [110]. The unique 
characteristics such as high gas temperature and low plasma density limit its further usages in materials application. In order to generate plasma under such high pressure, huge microwave power has to be supplied which causes very low energy efficiency.

There are some experimental investigations on the effects of field concentrators on the plasma generation. Golubovskii and coworkers [111] have found that by putting $\mathrm{BaTiO}_{3}$ pellets with sharp edges inside the discharge tube, the plasma under atmospheric pressure can be ignited. Another experiment was conducted by Al-Shamma'a et al [112]. They used a copper nozzle with conical tip for feeding nitrogen gas to concentrate the electromagnetic field under an atmospheric pressure. Both experiment and computer simulation results clearly demonstrated that the microwave field around the conical tip was intensively concentrated. Plasmas can be easier ignited at the tip of the concentrator. In order to generate atmospheric plasma at low microwave power and gas temperature, concentrators could be a good approach. The general idea is that by inserting a concentrator which has a sharp edge or thin tip or tiny particles, the gases could be easily broke down around the concentrated sites. However, the concentrated sites usually are at extremely high temperatures, which cause local melting of the material and in turn failure of the concentrator. Materials with high melting temperature or delicate fabrication techniques have to be utilized to generate a better reliable concentrator which has a longer processing lifetime. High cost of such a concentrator would limit its further applications in plasma industry. Replaceable field concentrators could be a better solution. These kinds of concentrators have a relative shorter lifetime but could be 
replaced at a very low cost, which can reduce the operation cost and could be employed in big industry processing. The idea of this part is to test several replaceable concentrators in generation of plasma under microwave radiation, and study their effects.

\subsubsection{Experimental}

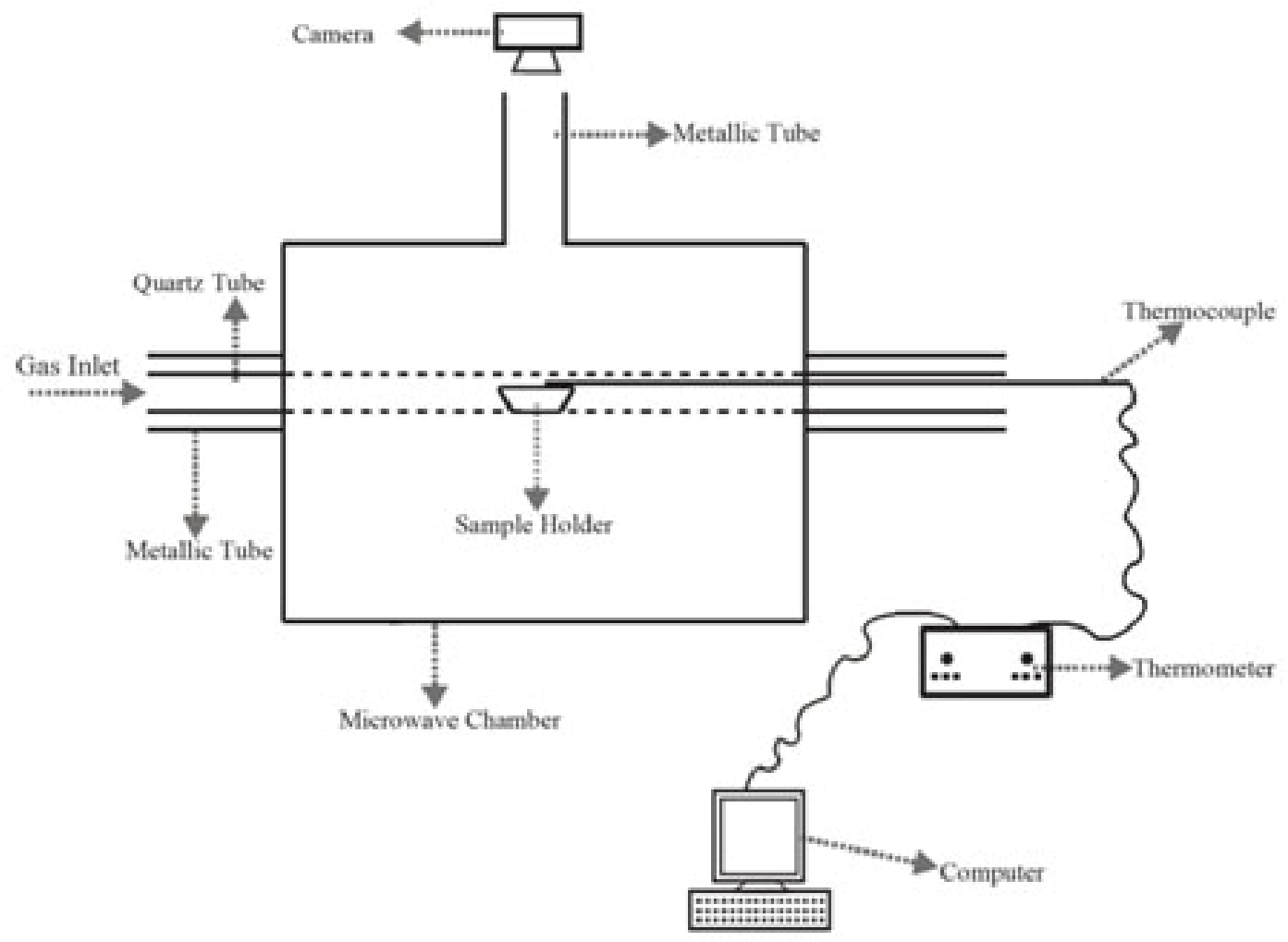

Figure 13 Schematic picture of experimental system

A schematic diagram of the experimental system is shown in Figure 13. The microwave chamber is a multimode resonant oven with up to $4 \mathrm{~kW}$ microwave power. A microwave transparent quartz tube was inserted at the middle of the chamber and extended outward. The out parts were wrapped with metallic tubes with flanges for microwave shielding. Tested gases including argon, nitrogen, hydrogen or the mixture were fed into the tub at 
one atmosphere pressure and different flow rates. Concentrators were put into a clay crucible, at the edge of which a $\mathrm{K}$ type shielded thermocouple was fixed and utilized to record the gas temperature. There is a hole at the top of the furnace, through which plasma images were recorded by the video camera. Each experiment was conducted by starting with the feeding gases for 15 minutes to purge all the air out and the whole tube was filled with testing gases.

Tested field concentrators are summarized below:

Iron pin $\mathrm{D}=0.0645$ inch with tip $\mathrm{D}=0.02$ inch (Figure 14 left)

$\square \mathrm{Cu}$ wire $\mathrm{D}=0.5 \mathrm{~mm}$ (Figure 14 right)

$\square \mathrm{Cu}$ powder $<10$ micron

Fe powder $<10$ micron

$\square$ Al powder $<35$ micron

$\square$ Fe wire $\mathrm{D}=0.5 \mathrm{~mm}$

$\square$ Graphite powder $<35$ micron

All these selected field concentrators are very cheap and could be easily fabricated in commercial scale.

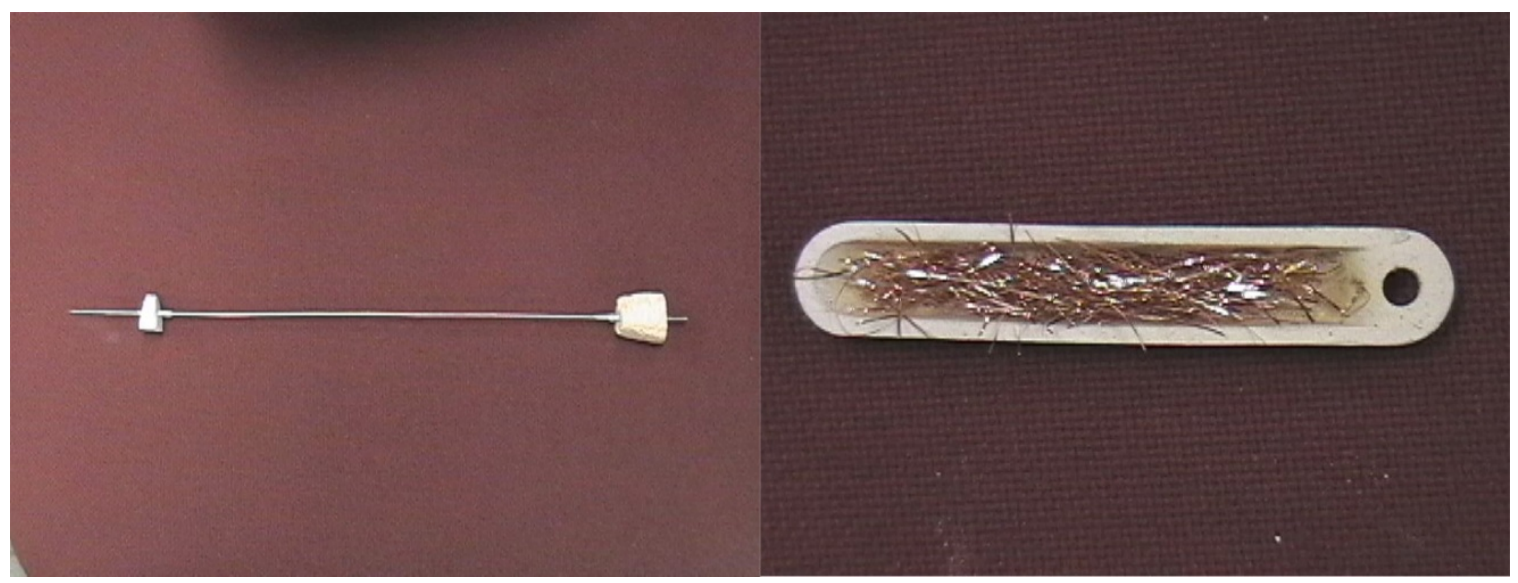

Figure 14 Selected field concentrators, iron pin (left) and copper wires (right) 


\subsubsection{Results and discussion}

Plasma observations were determined by the colorful scenes from the video camera. The results are shown in Table 4 . Under such high flow $7000 \mathrm{ml} / \mathrm{min}$, argon gas is very easy to be ionized, even with or without the concentrators, and the required energy could be as low as $1 \mathrm{~kW}$ power. As nitrogen and argon mixture was fed into the system, no plasma was produced without the presence of concentrators. Several concentrators could assist the plasma generation of $50 \% \mathrm{Ar}$ and $\mathrm{N}_{2}$ mixture. Powders showed better results. When nitrogen was increased into $75 \%$ of the total gases, more microwave power has to be supplied to initialize the plasma. Pure nitrogen gases could also be ionized with the assistance from the concentrators, with which powders worked better and required less energy. Hydrogen gases and mixtures were tested at low flow rate only $300 \mathrm{ml} / \mathrm{min}$ due to the extremely high temperature and exploration considerations. With no concentrators inside, even though there was 50\% argon gas, no plasma was produced. However, with the presence of concentrators, such as graphite powder, plasma could be easily generated at $1 \mathrm{~kW}$ power. Pure hydrogen plasma could also be generated under minimum power when concentrators were used. Some typical plasma images are shown in Figure 15. 
Table 4 Observed plasmas of using different concentrators (O-plasma, X-no plasma)

\begin{tabular}{|c|c|c|c|c|c|c|c|c|c|c|c|c|c|c|c|c|c|c|c|c|c|c|c|c|}
\hline \multirow[b]{2}{*}{ Concentrators } & \multicolumn{4}{|c|}{$\operatorname{Ar}(7000 \mathrm{ml} / \mathrm{min})$} & \multicolumn{4}{|c|}{$\begin{array}{l}\text { Ar:N2=1(total flow } \\
\quad 7000 \mathrm{ml} / \mathrm{min} \text { ) }\end{array}$} & \multicolumn{4}{|c|}{$\begin{array}{c}\text { Ar: } \mathrm{N}_{2}=1: 3 \text { (total flow } \\
7000 \mathrm{ml} / \mathrm{min})\end{array}$} & \multicolumn{4}{|c|}{$\mathrm{N}_{2}(7000 \mathrm{ml} / \mathrm{min})$} & \multicolumn{3}{|c|}{\begin{tabular}{|c|} 
Ar: $\mathrm{H}_{2}=1$ (total \\
flow 300 \\
$\mathrm{ml} / \mathrm{min}$ ) \\
\end{tabular}} & \multicolumn{5}{|c|}{$\mathrm{H}_{2}(300 \mathrm{ml} / \mathrm{min})$} \\
\hline & $1 \mathrm{~kW}$ & $2 \mathrm{~kW}$ & $3 \mathrm{~kW}$ & $4 \mathrm{~kW}$ & $1 \mathrm{~kW}$ & $2 \mathrm{~kW}$ & $3 \mathrm{~kW}$ & $4 \mathrm{~kW}$ & $1 \mathrm{~kW}$ & $2 \mathrm{~kW}$ & $3 \mathrm{~kW}$ & $4 \mathrm{~kW}$ & $1 \mathrm{~kW}$ & $2 \mathrm{~kW}$ & $3 \mathrm{~kW}$ & $4 \mathrm{~kW}$ & $1 \mathrm{~kW}$ & $2 \mathrm{~kW}$ & $3 \mathrm{~kW}$ & $4 \mathrm{~kW}$ & $1 \mathrm{~kW}$ & $2 \mathrm{~kW}$ & $3 \mathrm{~kW}$ & $4 \mathrm{~kW}$ \\
\hline No & $\mathrm{O}$ & $\mathrm{O}$ & $\mathrm{O}$ & $\mathrm{O}$ & $\mathrm{X}$ & $\mathrm{X}$ & $\mathrm{X}$ & $\mathrm{X}$ & & & & & & & & & & & $\mathrm{X}$ & $\mathrm{x}$ & & & & \\
\hline Iron Pin & $\mathrm{O}$ & $\mathrm{O}$ & $\mathrm{O}$ & $\mathrm{O}$ & $\mathrm{X}$ & $\mathrm{X}$ & $\mathrm{O}$ & $\mathrm{O}$ & $\mathrm{X}$ & $\mathrm{X}$ & $\mathrm{X}$ & $\mathrm{O}$ & & & & & & & & & & & & \\
\hline $\mathrm{Cu}$ Wire & & & & & $\mathrm{X}$ & $\mathrm{X}$ & $\mathrm{O}$ & $\mathrm{O}$ & $\mathrm{X}$ & $\mathrm{X}$ & $\mathrm{O}$ & $\mathrm{O}$ & & & $\mathrm{x}$ & $\mathrm{O}$ & $\mathrm{X}$ & $\mathrm{O}$ & $\mathrm{O}$ & $\mathrm{O}$ & $\mathrm{X}$ & $\mathrm{X}$ & $\mathrm{O}$ & $\mathrm{O}$ \\
\hline $\mathrm{Cu}$ Powder & & & & & & $\mathrm{O}$ & $\mathrm{O}$ & $\mathrm{O}$ & & & & & & & & $\mathrm{O}$ & & & $\mathrm{O}$ & $\mathrm{O}$ & & $\mathrm{O}$ & $\mathrm{O}$ & $\mathrm{O}$ \\
\hline Fe Powder & & & & & & $\mathrm{X}$ & $\mathrm{O}$ & $\mathrm{O}$ & & & & & & $\mathrm{X}$ & $\mathrm{O}$ & $\mathrm{O}$ & & & & & & & & \\
\hline Al Powder & & & & & $\mathrm{X}$ & $\mathrm{O}$ & $\mathrm{O}$ & $\mathrm{O}$ & & & & & & & & $\mathrm{O}$ & & & & & & & & \\
\hline Fe Wire & & & & & & & & & & & & & & & & & & $\mathrm{O}$ & $\mathrm{O}$ & $\mathrm{O}$ & & & & \\
\hline $\begin{array}{l}\text { Graphite } \\
\text { Powder }\end{array}$ & & & & & & & & & & & & & & & & & $\mathrm{O}$ & $\mathrm{O}$ & $\mathrm{O}$ & $\mathrm{O}$ & $\mathrm{O}$ & $\mathrm{O}$ & $\mathrm{O}$ & $\mathrm{O}$ \\
\hline
\end{tabular}

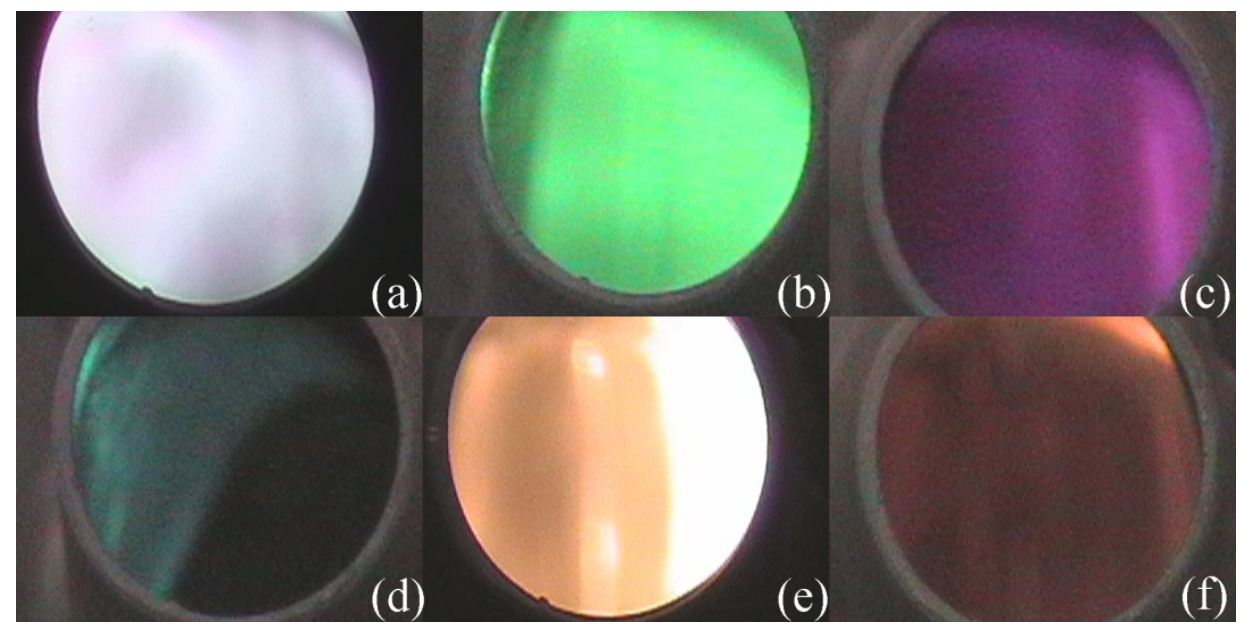

Figure 15 Typical plasma images, (a)Concentrator: Fe pin, 4 kW, Ar, 7000ml/min, (b) Concentrator: Cu powder, $4 \mathrm{~kW}, A r: \mathrm{N}_{2}=1,7000 \mathrm{ml} / \mathrm{min}$, (c) Concentrator: $\mathrm{Cu}$ wire, $4 \mathrm{~kW}, A r: \mathrm{N}_{2}=1: 3,7000 \mathrm{ml} / \mathrm{min}$, (d) Concentrator: $\mathrm{Cu}$ powder, $4 \mathrm{~kW}, \mathrm{~N}_{2}, 7000 \mathrm{ml} / \mathrm{min}$, (e) Concentrator: $\mathrm{Fe}$ wire, $4 \mathrm{~kW}, \mathrm{Ar}: \mathrm{H}_{2}=1,300$ $\mathrm{ml} / \mathrm{min}$, (f) Concentrator: $\mathrm{Cu}$ wire, $3 \mathrm{~kW}, \mathrm{H} 2,300 \mathrm{ml} / \mathrm{min}$

Plasma gas temperature is usually extremely high at atmospheric pressure. The reported gas temperature at a multimode microwave cavity was as high as $4000 \mathrm{~K}$ [113]. However, from our experimental observations, plasma could be initialized at every low gas temperature when concentrators were utilized. As shown in Figure 16, temperature profiles presented that plasma began to occur at only $200{ }^{\circ} \mathrm{C}$ and $100{ }^{\circ} \mathrm{C}$ when copper and iron powders were used as concentrators, respectively. The gas temperature continued to 
rise until it became relatively stable. The final temperature was several folds less than the reported value. It indicates that with the help of concentrators, the gas temperature could be lowered tremendously. The high temperature associated problems such as local melting, and overheating could be prevented.

However in generation of hydrogen plasma, when the plasma was initiated, the gas temperature quickly jumped to the upper detection limit of thermocouple $\left(>1200{ }^{\circ} \mathrm{C}\right)$. As shown in Figure 17, there was a latent period before the plasma began to appear, where the gas temperature rose slowly. As soon as the plasma came out, the temperature soared to $1200{ }^{\circ} \mathrm{C}$ in 6 seconds, and it didn't seem to become stable. No concentrator was found to be able to stabilize the hydrogen plasma. However, we have found out that this can be improved by controlling the microwave power. Sustainable hydrogen plasma could be generated by using higher microwave power to initiate and lower power to maintain. Figure 18 shows an example of sustainable hydrogen plasma generated at changing power. Plasma was initially ignited at higher power level $2 \mathrm{~kW}$, and the gas temperature immediately jumped to nearly $1000{ }^{\circ} \mathrm{C}$. As soon as the power switched to $1.5 \mathrm{~kW}$, the gas temperature was sustained below $1000{ }^{\circ} \mathrm{C}$ for a long period of time. Also from the plasma images, the intensity and shape of the plasma did not change, indicating the sustainable plasmas. 

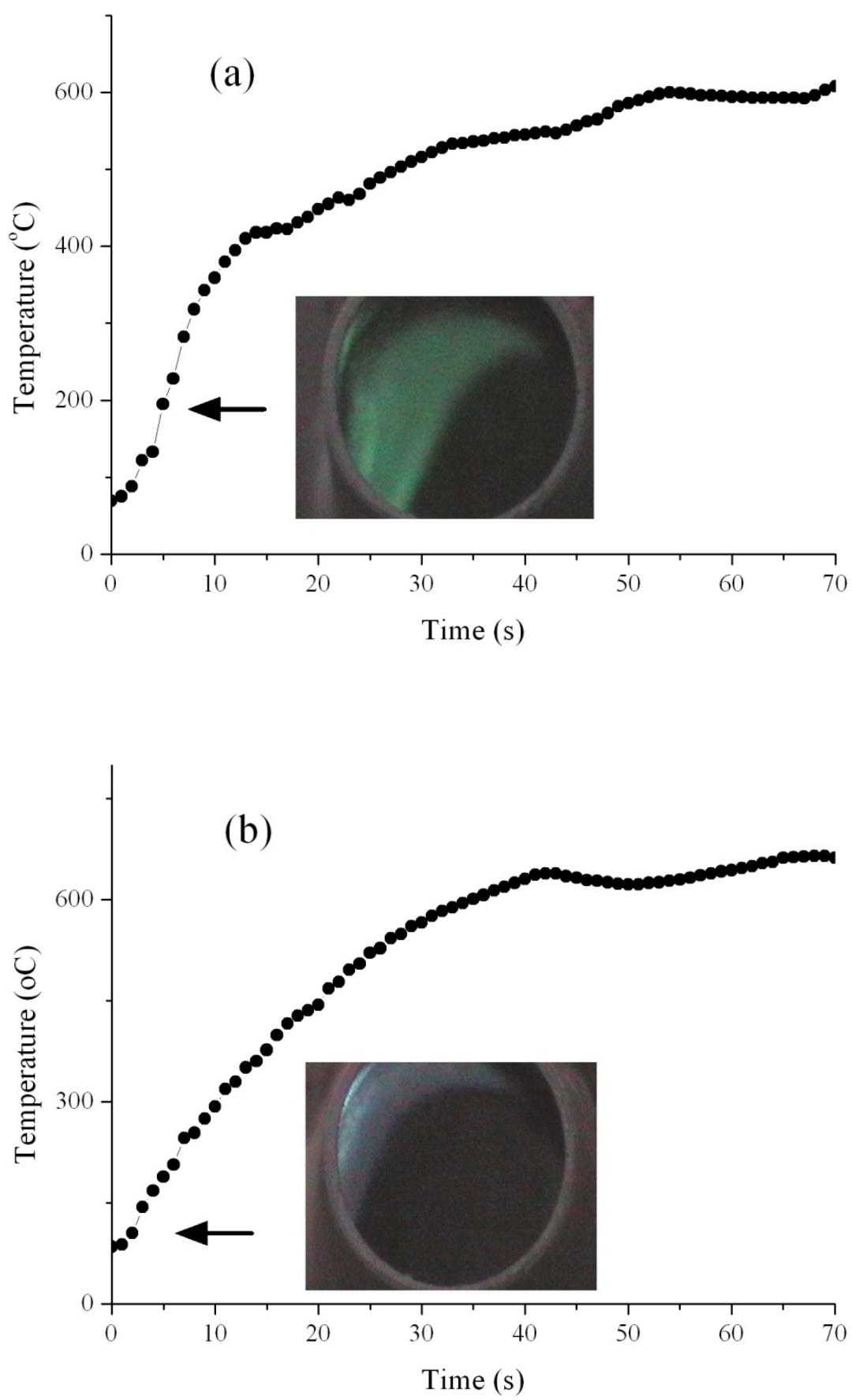

Figure 16 Gas temperature profiles at $A r / N_{2}=1,3 \mathrm{~kW}$, concentrator: (a) $\mathrm{Cu}$ powder, (b) Fe powder 


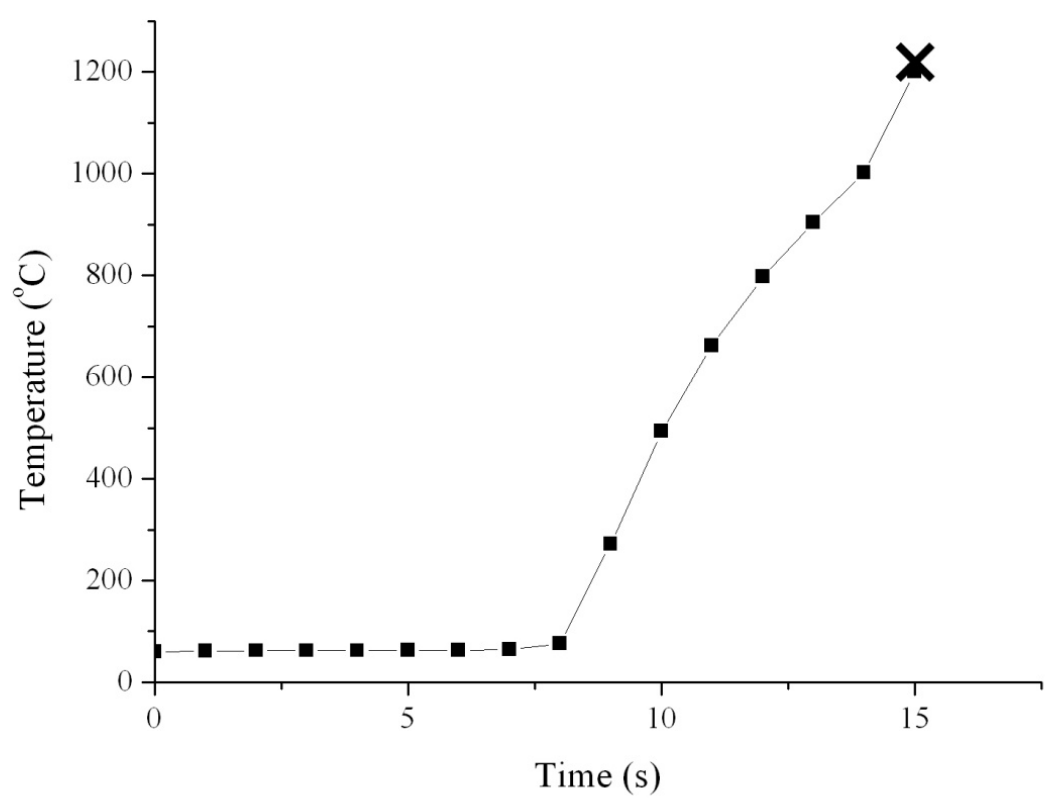

Figure 17 Gas temperature at $2 \mathrm{~kW}, \mathrm{H}_{2} 300 \mathrm{ml} / \mathrm{min}$, concentrator: $\mathrm{Cu}$ powder

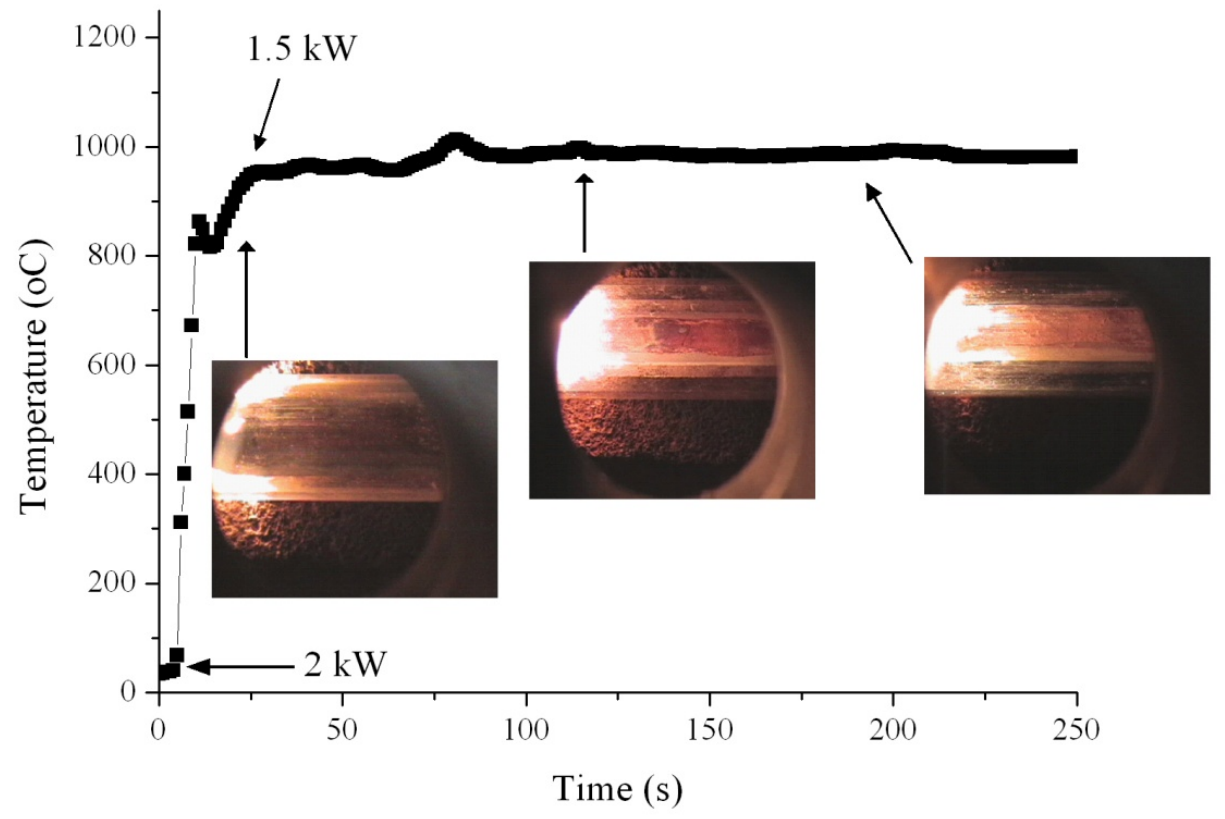

Figure 18 Plasma images and gas temperature at $\mathrm{H} 2300 \mathrm{ml} / \mathrm{min}$, concentrator: $\mathrm{Cu}$ powder, $2 \mathrm{~kW}$ to initiate and $1.5 \mathrm{~kW}$ to maintain 
Although these concentrators showed great capabilities in assisting plasma generation, most concentrators failed after several generation cycles due to melting or sintering. Some failed concentrators after experiments are shown in Figure 19. In order to continue assisting plasma generation, these concentrators should be replaced. However, replacing such concentrators is cheap and feasible. No contamination from the materials of the concentrators was observed since there was no significant weight loss of concentrators before and after experiment. Also no compounds were formed.

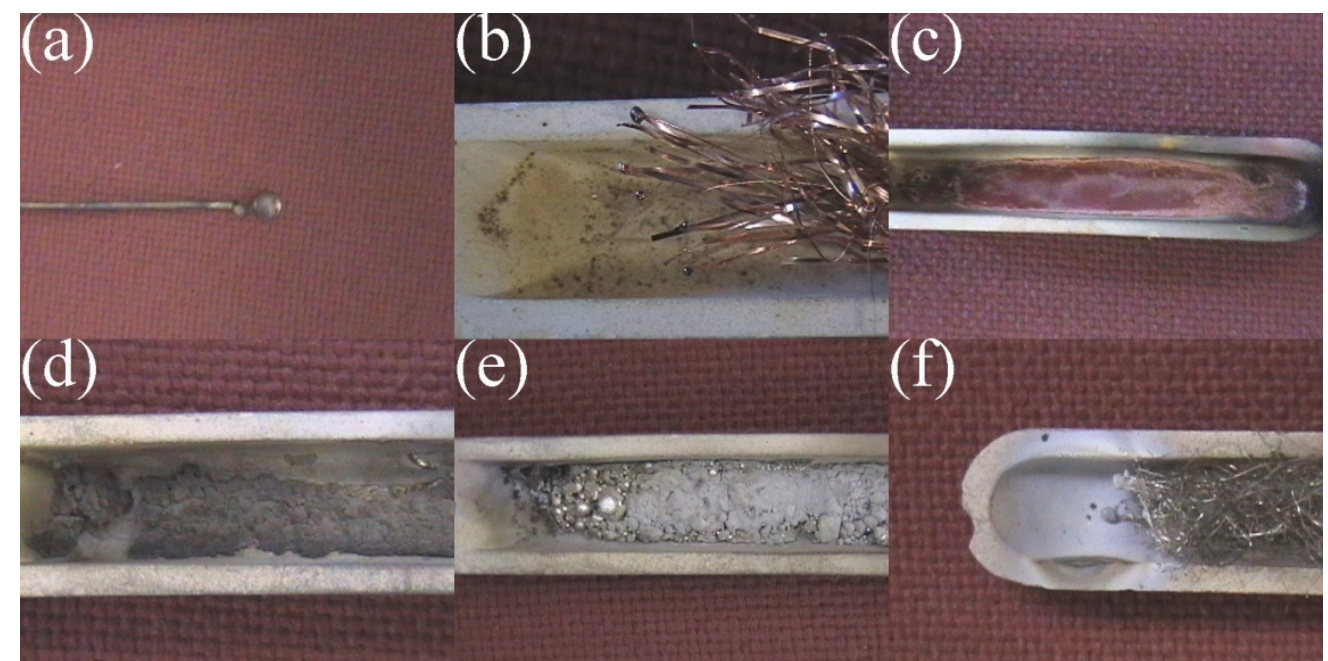

Figure 19 Failed concentrators, (a) Iron pin after 17 cycles, (b) Cu wire after 6 cycles, (c) Cu powder after 4 cycles, (d) Iron powder after 10 cycles, (e) Al powder after 7 cycles, (f) Fe wire after 7 cycles

\subsubsection{Conclusion}

Several field concentrators including pin, wires, and powders have been tested to assist the plasma generation under atmospheric pressure. With the presence of these concentrators, microwave field could be enhanced and gases could be ionized at low power which cannot be realized without field concentrators. Gas mixtures and pure gases all exhibited better ionization ability. Relative low energy was required to generate plasma and the associated gas temperature was much lower. Sustainable plasma was 
observed in both nitrogen gas and gas mixtures. Stable hydrogen plasma could be maintained by microwave power control. Although concentrators have a limited lifetime and need to be replaced after several generation cycles, the cost for such replacement is insignificant. Application of such field concentrators in plasma industries has great feasibility and possible potentials. Hydrogen plasma or hydrogen ions could be easily generated and controlled by using this technology, which made the first step to form hydrogen clusters. 


\section{CHAPTER 5 DENSITY FUNCTIONAL COMPUTATION OF HYDROGEN CLUSTERS}

From previous experimental and theoretical work, hydrogen clusters displayed geometrical arrangements and properties that are quite different from their bulk properties. Also the properties could be changed by combing different ions or atoms with hydrogen. Binding energy, number of hydrogen molecules, geometrical configurations of these clusters all varied depending on the strength and direction of the ligand bond. Such diversity of hydrogen clusters has lead to their possible applications in hydrogen storage materials. In hydrogen clusters, the number of bonded hydrogen molecules is not limited by the covalent electrons. The total weight percentage of hydrogen in clusters could be highly enhanced. In order to reduce the large amount of experimental work on finding suitable substances to form stable hydrogen clusters, computer simulations could be an easy approach. Also computational work could predict the molecules structure, identify correlations between structures and properties, direct and understand experimental data, and explore the bonding mechanism.

There are two major calculation models in computing hydrogen clusters: ab initio and density functional theory (DFT). ab initio calculation is from first principles and that no empirical data is used. It is based on the complicated many-electron wavefunction and can be made to lead to the exact solution, when all approximations are sufficiently small in magnitude. However, extremely large computational time and effort have to be 
applied. In DFT methods, the many-body electronic wavefunction is replaced with the electronic density as the basic quantity. In ab initio calculation, the many-body wavefunction is dependent on $3 \mathrm{~N}$ variables, three spatial variables for each of the $\mathrm{N}$ electrons. In DFT, the density is only a function of three variables and the computational quantity is simpler and practical. So it can be very accurate for little computational cost. The drawback is that it is not possible to estimate the error of the calculations without comparing them to other methods or experiments. DFT has been the major computational method within recent years especially after the development of hybrid functional.

\subsection{Computational method}

Extensive simulation study has been performed to calculate the interaction of hydrogen molecules with different ions, atoms, and compounds in order to lead our late laboratory synthesis. All calculations have been performed based on density functional theory and at $0 \mathrm{~K}$. The basis set used for calculation was $6-311 \mathrm{G}++\mathrm{G}(\mathrm{d}, \mathrm{p})$. B3LYP hybrid functional was proved to be a good approximation for hydrogen complex system [114-117]. In such hybrid functional, the exchange energy from Becke's exchange functional [118] is combined with the exact energy from Hartree-Fock theory to increase the accuracy of the simulation. All computations were conducted by using the GAUSSIAN 03 program [119].

\subsection{Results and discussion}

Here, only lower lying electronic states which yield the most stable structures have been simulated. Other higher energy states and isomers are not presented. 


\subsubsection{Hydrogen clusters on alkaline earth metal ions}

As summarized in the last chapter, both experimental and simulation work of group 1 alkaline metal ions have been done. The results showed that the dipole electrostatic interaction dominate the bonding with $\mathrm{H}_{2}$. Infer to the group 2 alkaline metal ions, they have stronger dipole interactions which may yield better bonding strength and properties. The simulated cluster structures of hydrogen bonded to group 2 alkaline metal ions $\mathrm{Ba}^{++}$, $\mathrm{Sr}^{++}, \mathrm{Ca}^{++}, \mathrm{Mg}^{++}$, and $\mathrm{Be}^{++}$are shown in Figure 20. The geometric configurations of hydrogen attaching to the different alkaline ions are calculated to be identical since all these ions have similar electrons configuration and a closed electron shell. The distances of each hydrogen molecule to the center of the ions are equal. In $\mathrm{M}^{++}-2 \mathrm{H}_{2}$, two hydrogen molecules are placed on the opposite sides of the center ion, and the angle between is $90^{\circ}$. The geometry exhibited $D_{2 d}$ symmetry. Adding one more hydrogen molecule, in $\mathrm{M}^{++}$$3 \mathrm{H}_{2}$, the steric arrangement changed to $C_{3}$ symmetry. The three hydrogen molecules are in the same plane and the metal ion locates at the center. $\mathrm{M}^{++}-4 \mathrm{H}_{2}$ has $T_{d}$ symmetry. The metal ion is at the center of a tetrahedral structure, and the hydrogen molecules locate at the four corners of the tetrahedral. The opposite hydrogen molecules are perpendicular to each other. As one more hydrogen was added on in $\mathrm{M}^{++}-5 \mathrm{H}_{2}$, the cluster changed to high symmetrical $O_{h}$ arrangement. The center of each hydrogen molecule sits at the six corner of an octahedral structure, where the metal ion stands at the center. The hydrogen at each opposite corner is parallel to each other. The $\mathrm{M}^{++}-6 \mathrm{H}_{2}$ exhibits the same highest symmetry $O_{h}$, where hydrogen molecules locate at the eight points of a cubic structure and the metal ion sits at the center. The molecules at the opposite corner in the front are 
parallel to each other and also parallel to the back side of the cube, but perpendicular to the other four molecules.

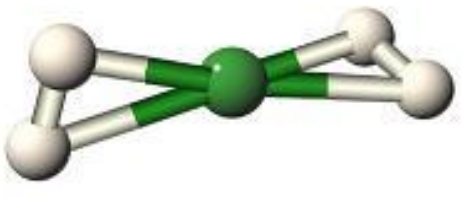

$\mathbf{M}^{++}-\mathbf{2} \mathbf{H}_{2}$

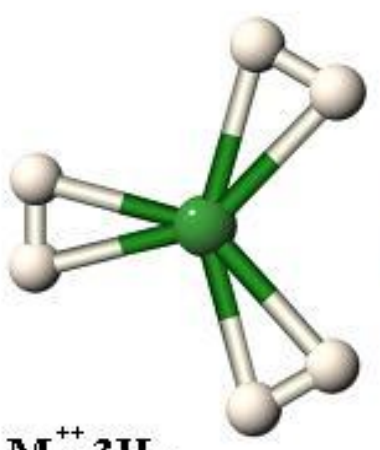

$\mathbf{M}^{++}-\mathbf{3} \mathbf{H}_{2}$
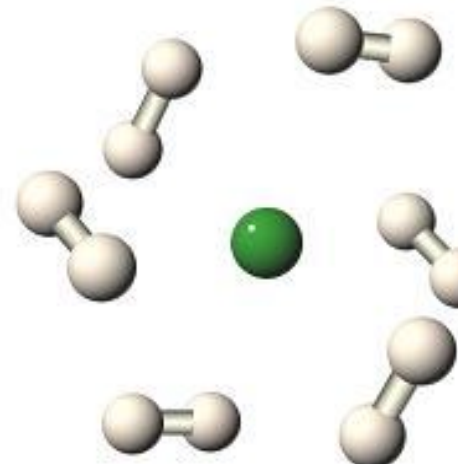

$\mathbf{M}^{++}-6 \mathbf{H}_{2}$

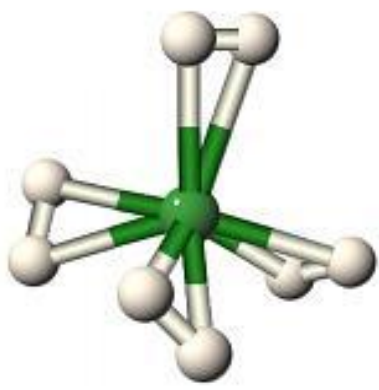

$\mathbf{M}^{++} \cdot \mathbf{4} \mathbf{H}_{2}$
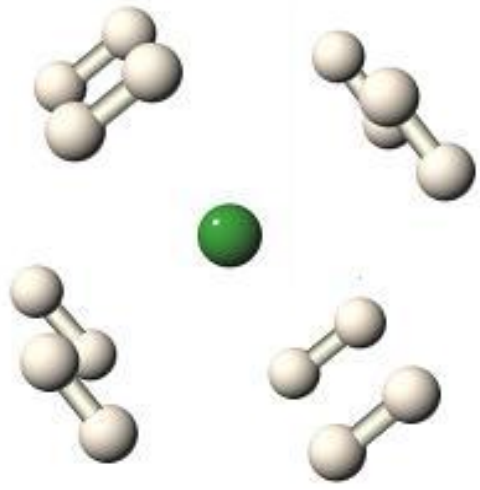

$\mathbf{M}^{++} \cdot \mathbf{8} \mathbf{H}_{2}$

Figure 20 Simulated structures of hydrogen-alkaline metal ion clusters $\mathbf{M}^{++}\left(\mathbf{H}_{2}\right)_{n}$

In order to compare the distance which represents the interaction of the center ion and hydrogen molecules, the distances between the outer $\mathrm{H}_{2}$ subunit and the center of $\mathrm{M}^{++}$are reported in Figure 21. These lengths were calculated as the distance between the center of the hydrogen molecules and the center of metal ions. Comparing the five ion clusters $\mathrm{M}^{++} \mathrm{nH}_{2}, \mathrm{Be}^{++} \mathrm{nH}_{2}$ has the shortest distance between ion and hydrogen, and $\mathrm{Ba}^{++} \mathrm{nH}_{2}$ has the longest distance with $\mathrm{Mg}^{++}, \mathrm{Ca}^{++}$, and $\mathrm{Sr}^{++}$in between and in the order of $\mathrm{Mg}^{++}<$ 
$\mathrm{Ca}^{++}<\mathrm{Sr}^{++}$. This is consistent with the increase of the ionic radii of the metal ions, as $\mathrm{Be}^{2+}$ $59 \mathrm{pm}, \mathrm{Mg}^{2+} 86 \mathrm{pm}, \mathrm{Ca}^{2+} 114 \mathrm{pm}, \mathrm{Sr}^{2+} 132 \mathrm{pm}$, and $\mathrm{Ba}^{2+} 149 \mathrm{pm}$. When $\mathrm{n}$ in the clusters increases (more hydrogen molecules are bonded to the metal), the distance between ion and hydrogen remains almost constant in $\mathrm{Ba}^{++}$, and $\mathrm{Sr}^{++}$, with slight increase in $\mathrm{Ca}^{++}$ when $\mathrm{n}=6$, and large increase in $\mathrm{Mg}^{++}$and $\mathrm{Be}^{++}$. This can also be understood from the radii of the ions. When the metal ion is small such as $\mathrm{Be}^{++}$and $\mathrm{Mg}^{++}$, the outer shell space for hydrogen to be occupied is limited. As more hydrogen molecules are introduced, the clusters have to expand in order to contain all the hydrogen molecules. On the other hand, large ions such as $\mathrm{Ba}^{++}$, and $\mathrm{Sr}^{++}$, the outside orbital are big enough to contain all the hydrogen so that the bond length is not affected by the number of hydrogen molecules.

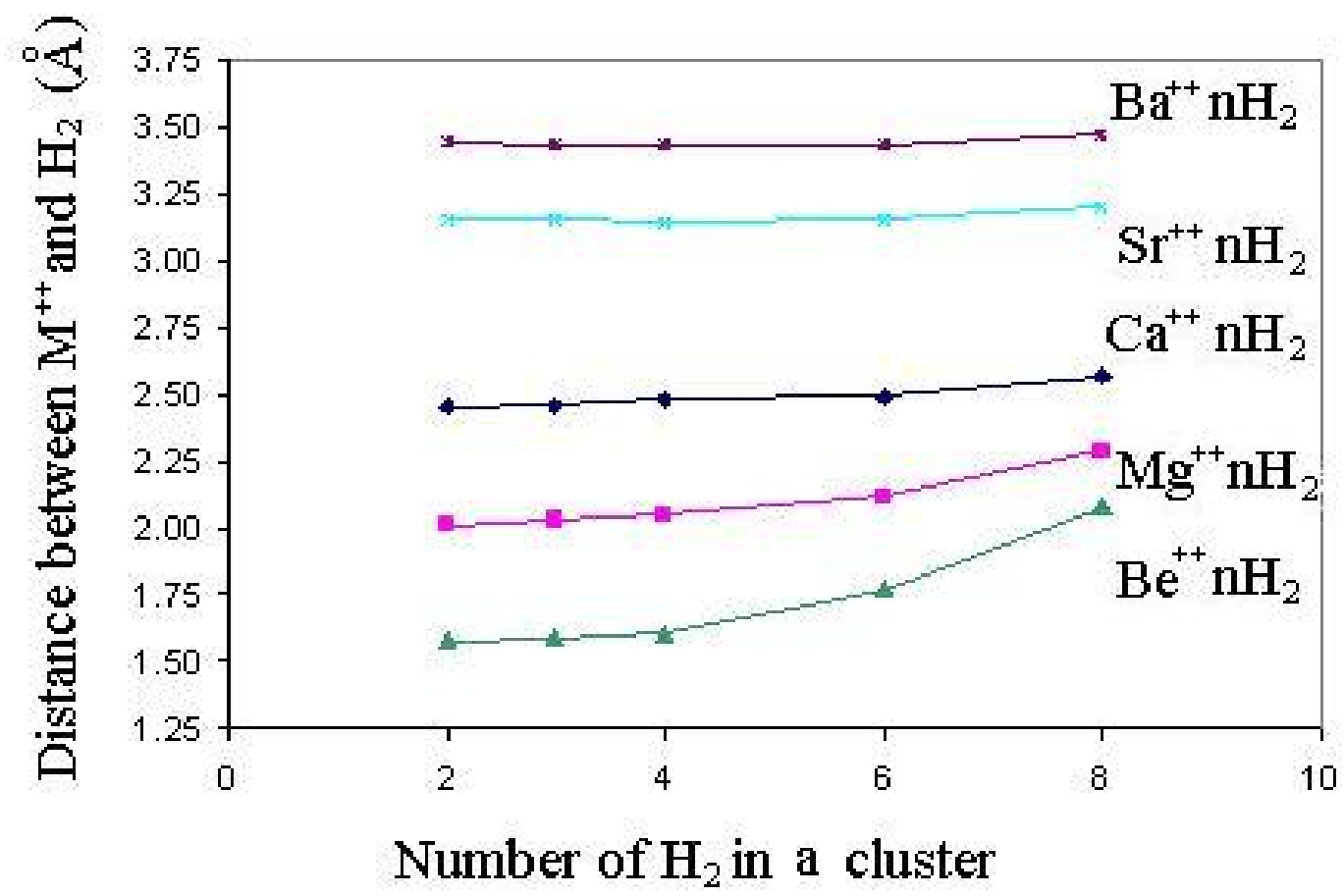

Figure 21 Calculated distance between $\mathrm{M}^{++}$and $\mathrm{H}_{2}$ as a function of number of $\mathrm{H}_{2}$ 
The $\mathrm{H}-\mathrm{H}$ distances in the $\mathrm{H}_{2}$ molecules are shown in Figure 22. The bond length $\mathrm{H}-\mathrm{H}$ of $\mathrm{Ba}^{++} \mathrm{nH}_{2}$ was found to be around $0.742 \AA$, which is almost equal to the bond length of hydrogen gas $(0.74 \AA)$. This indicates that the hydrogen $\mathrm{H}_{2}$ is not perturbed by the interaction of these molecules and the nucleus of the cluster so that the bond strength of hydrogen and ion is weak. And the number of hydrogen molecules in the cluster doesn't affect the $\mathrm{H}-\mathrm{H}$ bond distance because the distance between hydrogen and center ion doesn't show any obvious change. The $\mathrm{H}-\mathrm{H}$ bond in $\mathrm{Sr}^{++} \mathrm{nH}_{2}$ exhibits the same behavior, except that the bond length is larger corresponding to a slightly stronger bond to the nucleus. $\mathrm{Ca}^{++} \mathrm{nH}_{2}$ has the same properties with only the bond length increased to $0.76 \AA$. In $\mathrm{Mg}^{++} 2 \mathrm{H}_{2}$, the $\mathrm{H}-\mathrm{H}$ distance is about $0.778 \AA$, and it decreases slightly as more hydrogen is added to the clusters. When $\mathrm{n}$ equals 2 , the $\mathrm{H}-\mathrm{H}$ bond was more stretched indicating a stronger bond to the nucleus. However, when the cluster grows, the distance between $\mathrm{H}_{2}$ and nucleus enlarges (as in Figure 22), which results in a looser cluster bond so that less perturbation results in $\mathrm{H}-\mathrm{H}$ bond. $\mathrm{Be}^{++} \mathrm{nH}_{2}$ has the highest $\mathrm{H}-\mathrm{H}$ bond length (largest $\mathrm{H}-\mathrm{H}$ stretch) which indicates the strongest bond between hydrogen and center ion among all the five ion clusters. The decreasing trend of $\mathrm{H}-\mathrm{H}$ distance as the increasing number of $\mathrm{H}_{2}$ in the cluster is the most significant. This is also consistent with the change of distance between hydrogen and nucleus as the cluster grows. 


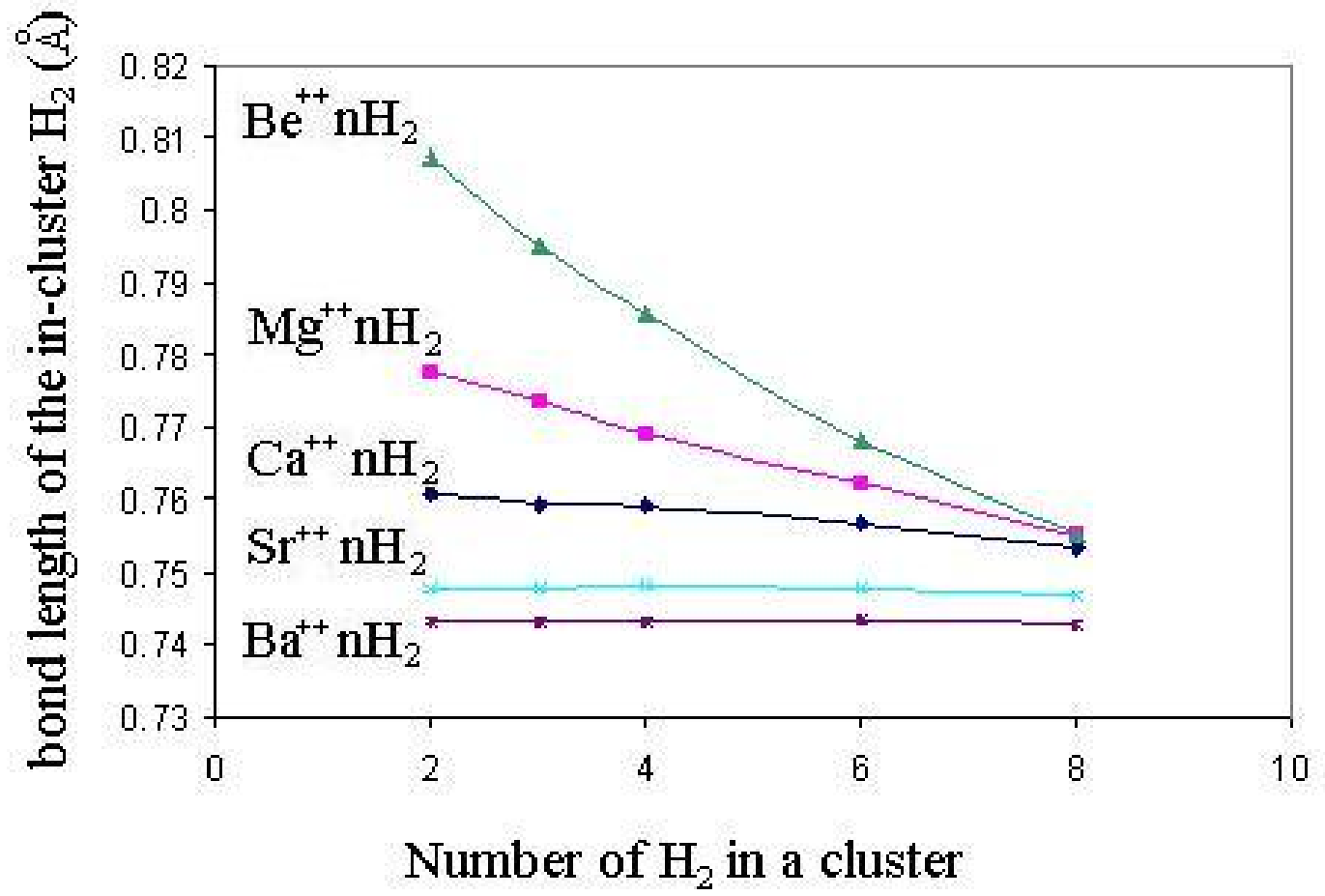

Figure 22 calculated bond length of $\mathrm{H}-\mathrm{H}$ in the clusters

The stability of the clusters can be investigated through the dissociation energies of the clusters. As in Figure 23, $\mathrm{Be}^{++} \mathrm{nH}_{2}$ is the most stable clusters with the highest total binding energy and $\mathrm{Ba}^{++} \mathrm{nH}_{2}$ is the least stable. As the number of $\mathrm{H}_{2}$ in clusters $\mathrm{Ba}^{++} \mathrm{nH}_{2}$, $\mathrm{Sr}^{++} \mathrm{nH}_{2}$, and $\mathrm{Ca}^{++} \mathrm{nH}_{2}$ increases, the total gain of energy also increases. However, each hydrogen-nucleus bonding is weakened as the cluster grows, which is consistent with the hydrogen-nucleus distance and hydrogen bond distance. $\mathrm{Mg}^{++} \mathrm{nH}_{2}$ and $\mathrm{Be}^{++} \mathrm{nH}_{2}$ clusters exhibited decreased gain of energy as the clusters grow from $n=6$ to $n=8$ although the energy trend of $\mathrm{n}<6$ is the same as other clusters. So $\mathrm{n}=6$ clusters for $\mathrm{Mg}^{++} \mathrm{nH}_{2}$, and $\mathrm{Be}^{++} \mathrm{nH}_{2}$ are more stable than $\mathrm{n}=8$. 


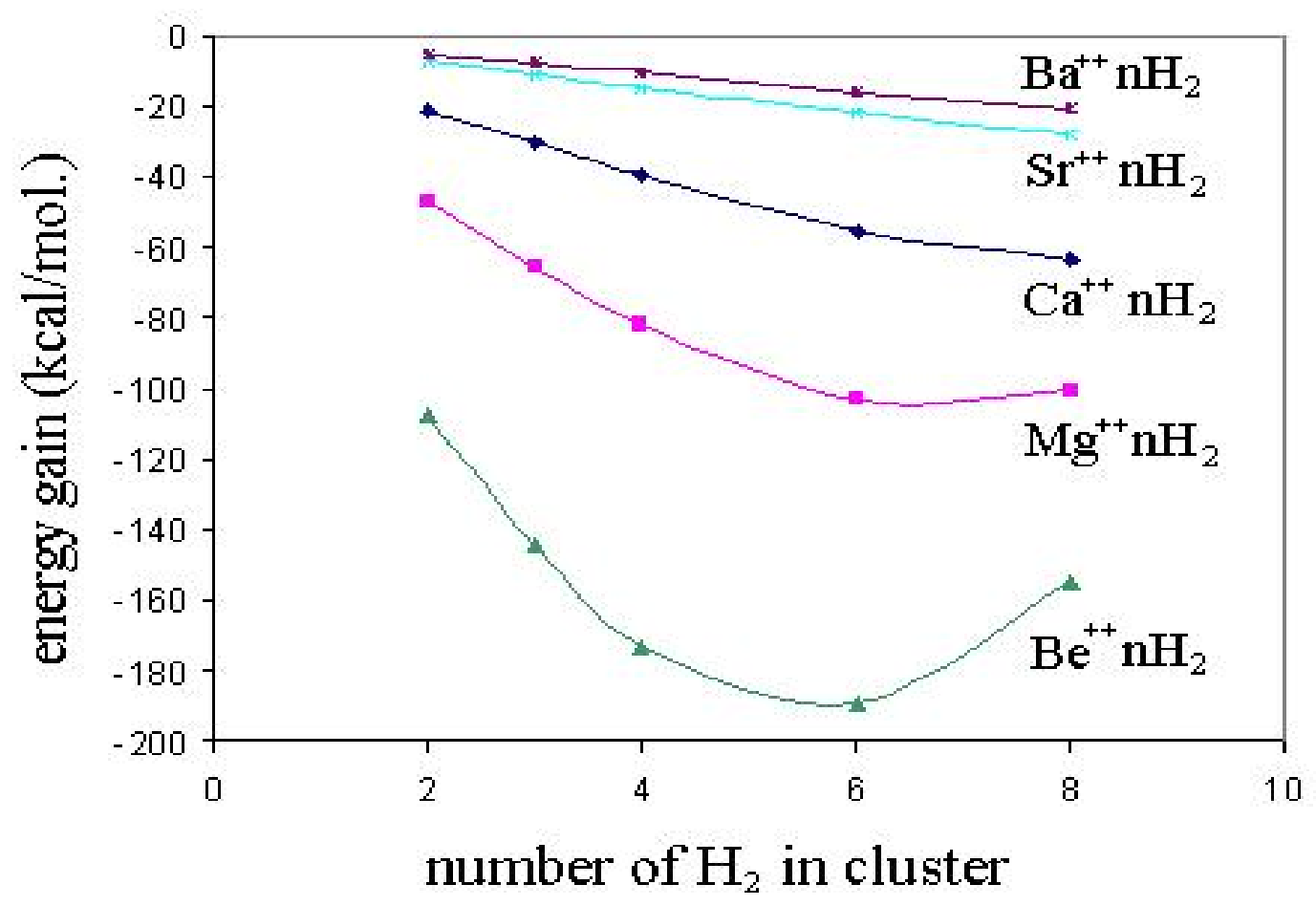

Figure 23 Stabilization energies of $\mathrm{M}^{++} \mathrm{nH}_{2}$ clusters

For alkali earth metals, smaller metals appear to have more stable hydrogen clusters with number of $\mathrm{H}_{2}$ up to 8 . The bonding energy of $\mathrm{Ba}^{++} \mathrm{nH}_{2}$ and $\mathrm{Sr}^{++} \mathrm{nH}_{2}$ are too small and these clusters are very easy to decompose when the temperature is increased. The most stable cluster is $\mathrm{Be}^{++} \mathrm{nH}_{2}$, however, $\mathrm{Be}$ is a very toxic element which could not be considered as a useful materials in application. Therefore, only $\mathrm{Ca}^{++} \mathrm{nH}_{2}$ and $\mathrm{Mg}^{++} \mathrm{nH}_{2}$ may have potential to be used as hydrogen storage clusters.

\subsubsection{Negative charged ion clusters}

Based on the principle of ion-induced electrostatic bond or the theory of ligand bond, negative charged ions also have the potential to form hydrogen clusters. Two negative ions $\mathrm{O}_{2}{ }^{-}$and $\mathrm{Cl}^{-}$have been calculated. 
Figure 24 shows the fully optimized geometry of $\left[\mathrm{O}\left(\mathrm{H}_{2}\right)_{8}\right]^{2-}$ with $D 4 h$ symmetry, predicted from the DFT calculation. The optimized structure parameters such as bond length, angles, and predicted energy are also complied in Figure 25. In this cluster, eight $\mathrm{H}_{2}$ are arranged symmetrically around the anion $\mathrm{O}^{2-}$ core. Two pairs of the eight hydrogen molecules are lying above and two pairs are below the horizontal plane. And four other hydrogen molecules are lying inside the central plane. The nearest distance between the hydrogen and the oxygen ion for all eight $\mathrm{H}_{2}$ molecules is the same $1.916 \AA$, which indicates the same bonding energy for all eight $\mathrm{H}_{2}$ molecules. The O-H-H bond angle is $180^{\circ}$ which presents that the bond direction of hydrogen molecules is extended from the $\mathrm{O}-\mathrm{H}$ bond. The $\mathrm{H}-\mathrm{H}$ bond is largely perturbed by the interaction between the oxygen ion and the hydrogen molecules and the bond energy should be significantly large. The total binding energy is $118.926 \mathrm{kcal} / \mathrm{mol}$, which lies between $\mathrm{Mg}^{++} 8 \mathrm{H}_{2}$ and $\mathrm{Be}^{++} 8 \mathrm{H}_{2}$.

The calculated $\left[\mathrm{Cl}\left(\mathrm{H}_{2}\right)_{8}\right]^{-}$cluster is show in Figure 25. The structure follows D4h symmetry and the geometry is identical to that of $\left[\mathrm{O}\left(\mathrm{H}_{2}\right)_{8}\right]^{2-}$ cluster, except that the bond angle of $\mathrm{H}_{2}-\mathrm{Cl}-\mathrm{H}_{3}$ in $\left[\mathrm{Cl}\left(\mathrm{H}_{2}\right)_{8}\right]^{-}$is 0.1 degree smaller. Here, hydrogen molecules stay far away from the central nucleus with a distance of $2.819 \AA$, which may due to the large ion size of $\mathrm{Cl}^{-}(167 \mathrm{pm})$ compared to $\mathrm{O}^{2-}(126 \mathrm{pm})$ and a weak electrostatic interaction. This is also concluded from the small perturbation of $\mathrm{H}-\mathrm{H}$ bond. The cluster binding energy is small, only $14.605 \mathrm{kcal} / \mathrm{mol}$. Such low energy may cause the cluster to easily decompose at elevated temperatures. 


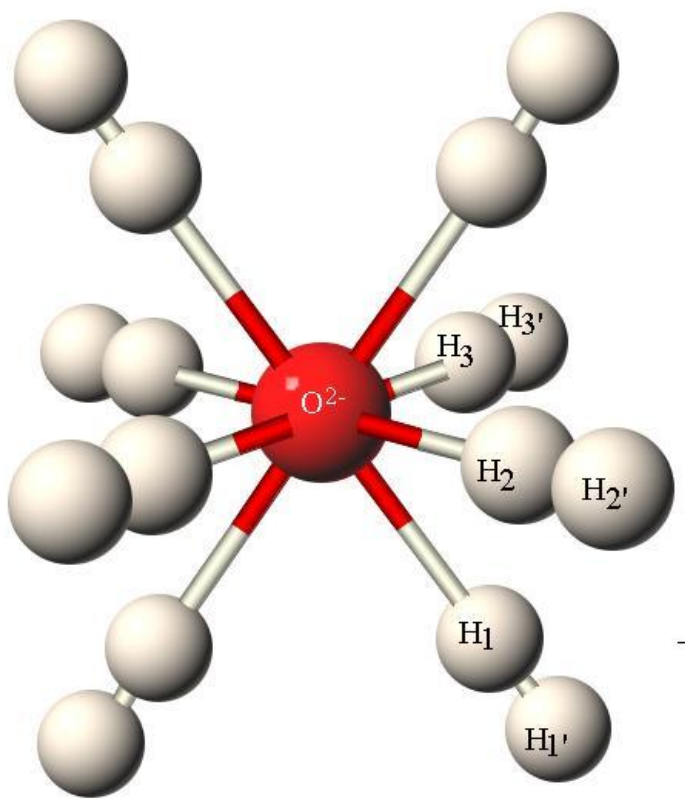

\begin{tabular}{|c|c|c|c|}
\hline \multicolumn{2}{|c|}{ Bond distance $(\AA)$} & \multicolumn{2}{|c|}{ Bond angle $\left({ }^{\circ}\right)$} \\
\hline $\mathrm{O}-\mathrm{H}_{1}$ & 1.916 & $\mathrm{H}_{1}-\mathrm{O}-\mathrm{H}_{2}$ & 70.5 \\
\hline $\mathrm{H}_{1}-\mathrm{H}_{1}$ & 0.793 & $\mathrm{H}_{2}-\mathrm{O}-\mathrm{H}_{3}$ & 109.4 \\
\hline $\mathrm{O}-\mathrm{H}_{2}$ & 1.916 & $\mathrm{O}-\mathrm{H}_{1}-\mathrm{H}_{1}$, & 180.0 \\
\hline $\mathrm{H}_{2}-\mathrm{H}_{2}$ & 0.793 & $\mathrm{O}-\mathrm{H}_{2}-\mathrm{H}_{2}$ & 180.0 \\
\hline $\mathrm{O}-\mathrm{H}_{3}$ & 1.916 & $\mathrm{O}-\mathrm{H}_{3}-\mathrm{H}_{3}$, & 180.0 \\
\hline $\mathrm{H}_{3}-\mathrm{H}_{3}$, & 0.793 & & \\
\hline \multirow{2}{*}{ Dihedral } & \multicolumn{2}{|c|}{$\mathrm{H}_{1}-\mathrm{O}-\mathrm{H}_{2}-\mathrm{H}_{2}$} & -120.0 \\
\hline & \multicolumn{2}{|c|}{$\mathrm{H}_{2}-\mathrm{O}-\mathrm{H}_{3}-\mathrm{H}_{3}$} & -180.0 \\
\hline \multicolumn{4}{|c|}{ Binding Energy } \\
\hline & \multicolumn{2}{|c|}{$\begin{array}{l}\mathrm{O}^{2-}+8 \mathrm{H} 2=\left[\mathrm{O}\left(\mathrm{H}_{2}\right)_{8}\right]^{2-} \\
\Delta \mathrm{E}=-118.926 \mathrm{kcal}\end{array}$} & \\
\hline
\end{tabular}

Figure 24 Optimized structure of $\left[\mathrm{O}\left(\mathrm{H}_{2}\right)_{8}\right]^{2-}$
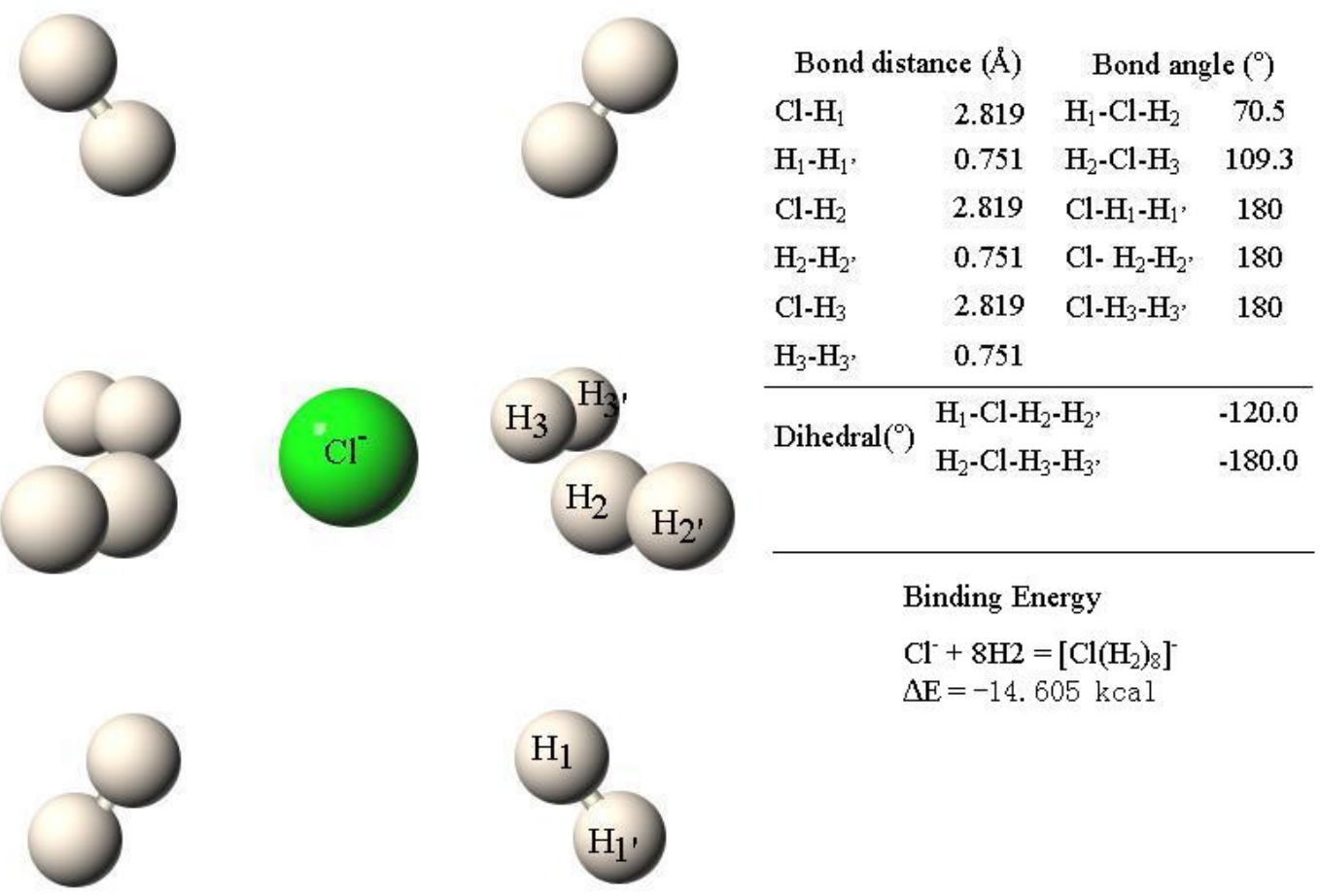

Figure 25 Optimized structure of $\left[\mathrm{Cl}\left(\mathrm{H}_{2}\right)_{8}\right]^{2-}$ 


\subsubsection{Clusters with metal oxides}

From previous calculations and published results, both the positive ion and negative ion has the potential to bind up to $8 \mathrm{H}_{2}$ molecules, which may yield the highest hydrogen capacity of $64 \mathrm{wt} \%$ for $\mathrm{Be}^{++} 8 \mathrm{H}_{2}$ cluster. However, all these cations or anions are not stable in nature. The applicable substances of these ions would be their oxides, chlorides, or any other compounds. Here, oxides of transition metals were modeled to identify their potential as applicable hydrogen storage materials.

The structure of $\mathrm{VO}\left(\mathrm{H}_{2}\right)_{8}$ cluster is shown in Figure 26. Four of the eight $\mathrm{H}_{2}$ molecules are bonded near vanadium and the other four near oxygen. The nearest hydrogen ligands (as indicated $\mathrm{H}_{2}-\mathrm{H}_{2}$ ' in the figure) are at a distance of $1.922 \AA$ to vanadium and a bond angle of $122.5^{\circ}$ to the horizontal plane. Two pairs of $\mathrm{H}_{2}$ are above the V-O plane and two are below. The $\mathrm{H}-\mathrm{H}$ bond is largely perturbed indicating a large interaction of $\mathrm{H}_{2}$ to the vanadium. The second largest bonding is between oxygen and hydrogen molecules, as $\mathrm{H}_{3}-\mathrm{H}_{3}$ ' in the figure. There are four of these types of hydrogen molecules, two of which are lying above and two pairs are below the V-O plane. Each hydrogen molecule bond is at an angle of $173.3^{\circ}$ to the $\mathrm{O}-\mathrm{H}_{3}$ bond direction. Here, $\mathrm{H}-\mathrm{H}$ is not perturbed, only 0.746 $\AA$ compared to the bond distance $0.74 \AA$ for free hydrogen gas molecules. The largest bond distance $6.004 \AA$ is observed between vanadium and $\mathrm{H}_{1}-\mathrm{H}_{1}$ ' molecules. The $\mathrm{H}_{1}-\mathrm{H}_{1}$ ' bond is even less perturbed and at an angle of $124.8^{\circ}$ to the $\mathrm{V}-\mathrm{H}_{1}$ bond. The whole cluster exhibits a $C_{2 v}$ symmetry. The total bonding energy of the cluster is $4.13 \mathrm{kcal} / \mathrm{mol}$ with probably a large contribution from the $\mathrm{V}-\mathrm{H}_{2}-\mathrm{H}_{2}$ ' bond and a small amount from the V- 
$\mathrm{H}_{3}-\mathrm{H}_{3}$ ' and the $\mathrm{V}-\mathrm{H}_{1}-\mathrm{H}_{1}$. Although from previous calculations, bonding of $\mathrm{O}^{2-}$ and eight hydrogen can have $118.9 \mathrm{kcal} / \mathrm{mol}$ energy, and the hydrogen adsorption energy in oxides was highly weakened.

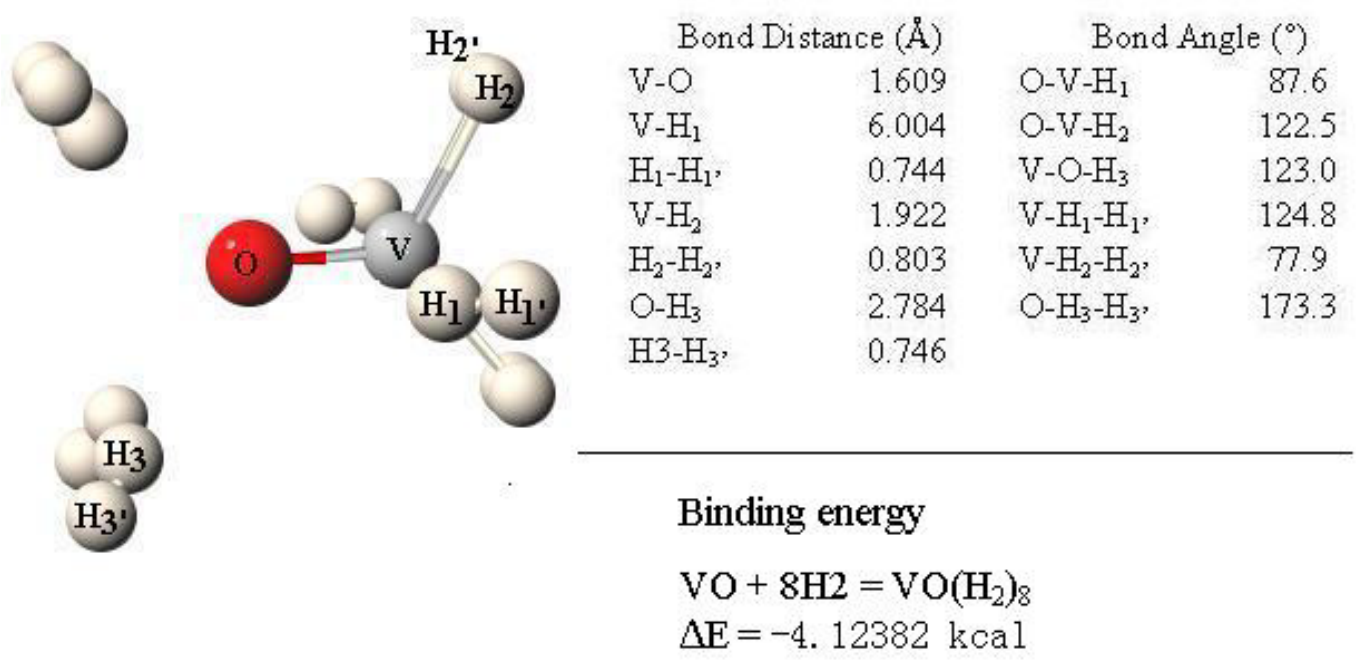

Figure 26 Geometry of $\mathrm{VO}\left(\mathrm{H}_{2}\right)_{8}$ cluster calculated from DFT

The $\mathrm{CrO}\left(\mathrm{H}_{2}\right)_{8}$ cluster shows a much larger binding energy, as from Figure 27. Here, two types of hydrogen molecules are strongly bonded to the $\mathrm{Cr}$ center with the hydrogen molecule center facing the $\mathrm{Cr}$ atom. The $\mathrm{H}_{1}-\mathrm{H}_{1}$ ' and $\mathrm{H}_{2}-\mathrm{H}_{2}$ ' bond distances are largely perturbed to $0.804 \AA$ and $0.889 \AA$, respectively. $\mathrm{H}_{2}$ type molecules are arranged in the same plane of the $\mathrm{CrO}$, and $\mathrm{H}_{1}$ type molecules are straighten along the vertical direction. Such closed accommodation yielding a significant interaction is the results of strong electrostatics. On the oxygen end, the $\mathrm{H}_{3}$ type hydrogen follows end on adsorption. The distance of $\mathrm{O}-\mathrm{H}_{3}$ is $2.738 \AA$, shorter than that of $\mathrm{VO}\left(\mathrm{H}_{2}\right)_{8}$ cluster. However, the $\mathrm{H}_{3}-\mathrm{H}_{3}$, bond length is only $0.745 \AA$, indicating a weak interaction on the oxygen end. 


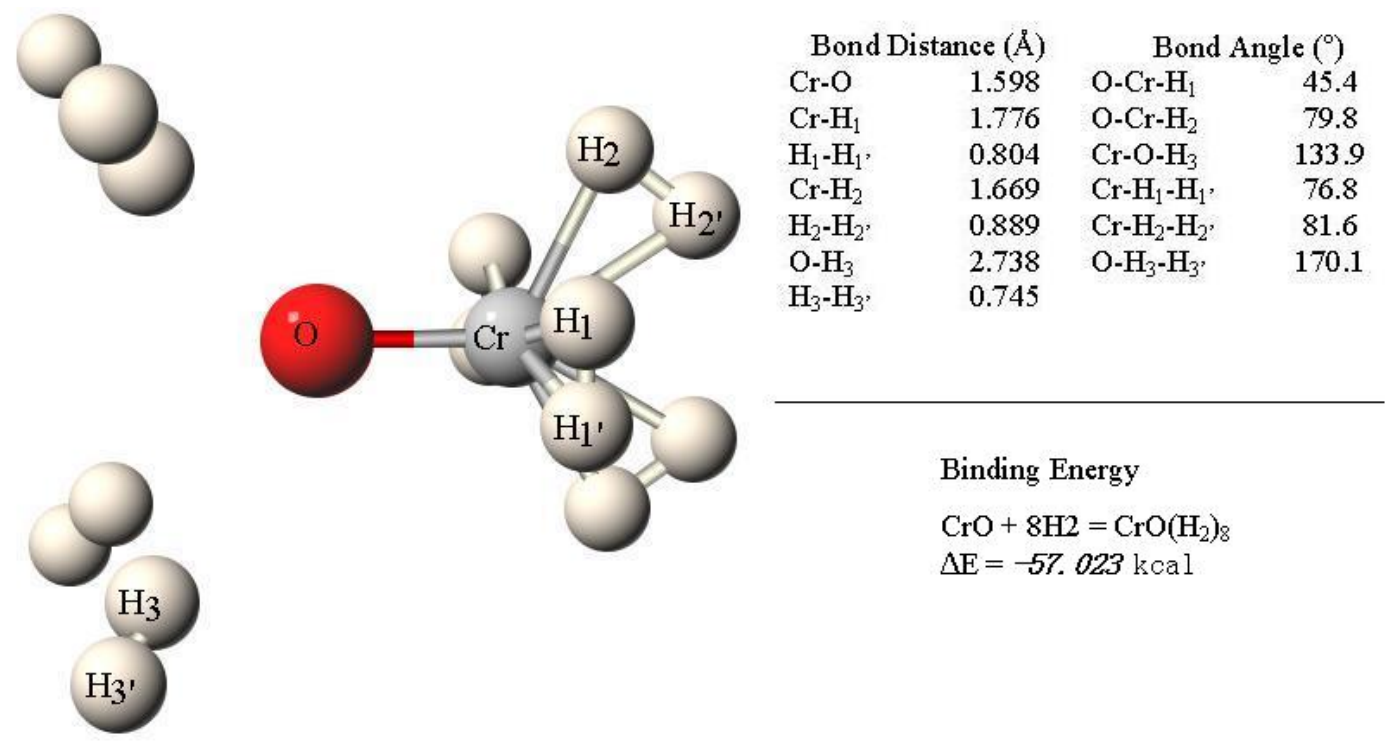

Figure 27 Geometry of $\mathrm{CrO}\left(\mathrm{H}_{2}\right)_{8}$ cluster calculated from DFT

The three types of hydrogen molecules in the $\mathrm{MnO}\left(\mathrm{H}_{2}\right)_{8}$ cluster (Figure 28) are all weakly bonded to manganese and oxygen. The arrangement of hydrogen molecules is identical to that in $\mathrm{CrO}\left(\mathrm{H}_{2}\right)_{8}$. The only difference is the larger ion-hydrogen distance in the $\mathrm{MnO}\left(\mathrm{H}_{2}\right)_{8}$ cluster. Among the three types of molecules, $\mathrm{H}_{2}-\mathrm{H}_{2}$ ' is the most affected molecule, which has a bond length $0.750 \AA$. All these indicate a weak electrostatic interaction between $\mathrm{MnO}$ and the surrounding hydrogen molecules. Therefore, the binding energy is only $3.552 \mathrm{kcal}$, even smaller than the $\mathrm{VO}\left(\mathrm{H}_{2}\right)_{8}$ cluster. 


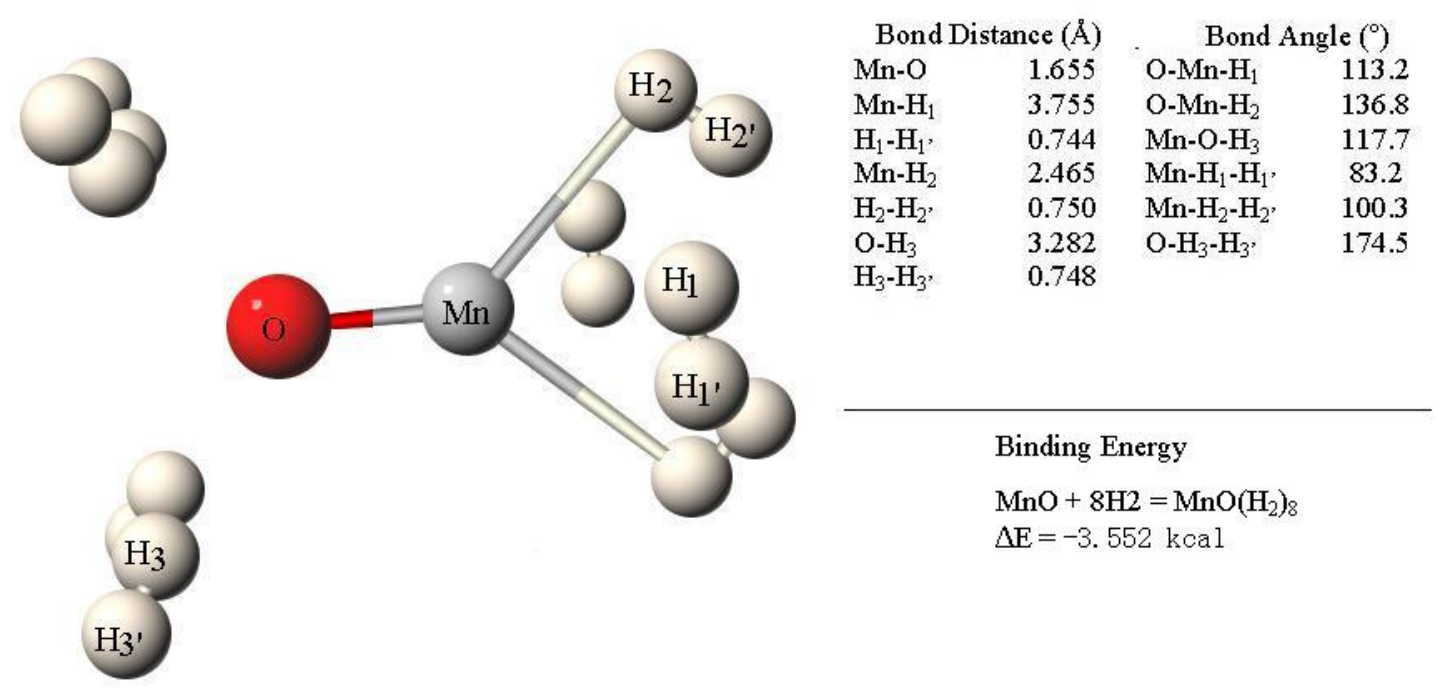

Figure 28 Geometry of $\mathrm{MnO}\left(\mathrm{H}_{2}\right)_{8}$ cluster calculated from DFT

The $\mathrm{FeO}\left(\mathrm{H}_{2}\right)_{8}$ and $\mathrm{CoO}\left(\mathrm{H}_{2}\right)_{8}$ clusters have the same symmetry and geometrical configuration as $\mathrm{CoO}\left(\mathrm{H}_{2}\right)_{8}$ and $\mathrm{MnO}\left(\mathrm{H}_{2}\right)_{8}$ clusters, as in Figure 29 and 30. However, the binding energies are much larger, $20.701 \mathrm{kcal}$ for $\mathrm{FeO}\left(\mathrm{H}_{2}\right)_{8}$ and $20.840 \mathrm{kcal}$ for $\mathrm{CoO}\left(\mathrm{H}_{2}\right)_{8}$ clusters. The hydrogen molecules at the cation end are largely perturbed and the molecules on the oxygen end follow the weak physisorption. The $\mathrm{H}_{1}$ and $\mathrm{H}_{2}$ type molecules are much closer to the cation in the $\mathrm{CoO}\left(\mathrm{H}_{2}\right)_{8}$ due to the stronger electrostatic force and the smaller ion size of cobalt cation. 


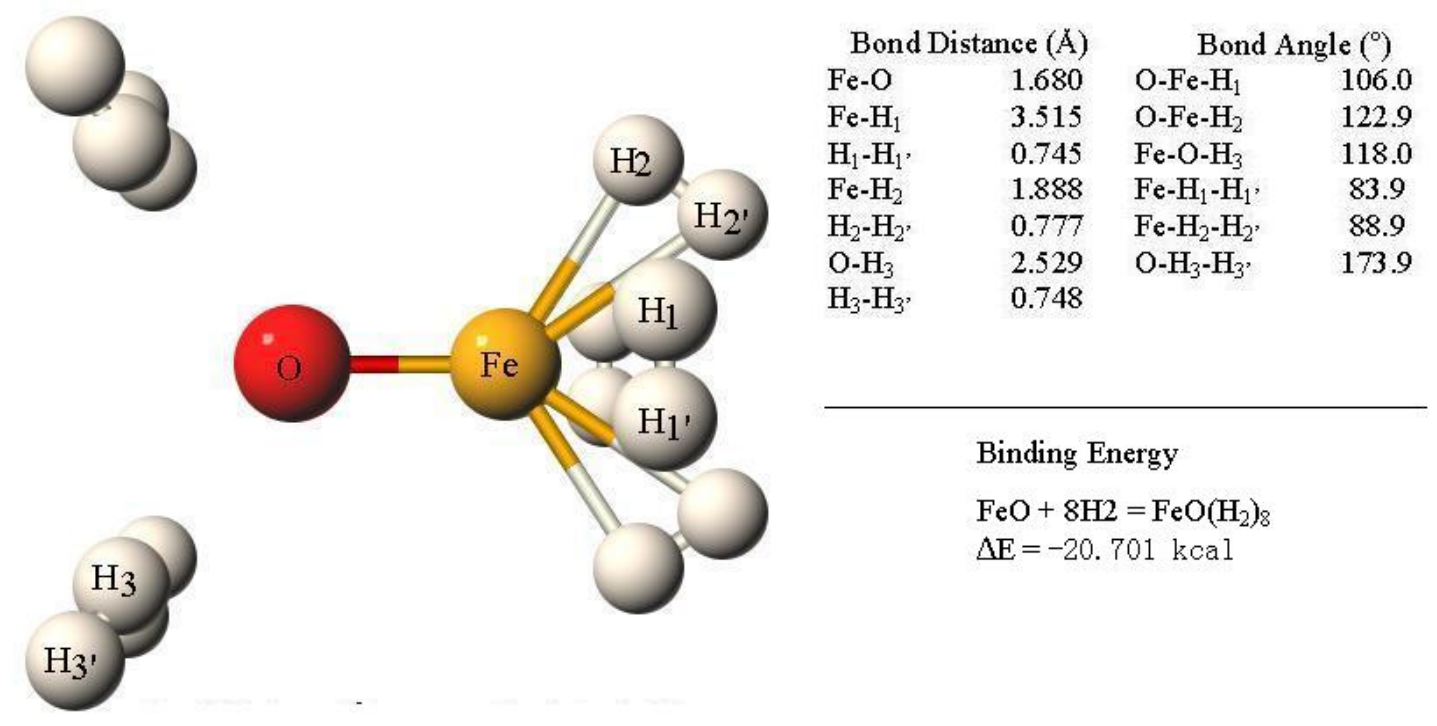

Figure 29 Geometry of $\mathrm{FeO}\left(\mathrm{H}_{2}\right)_{8}$ cluster calculated from DFT

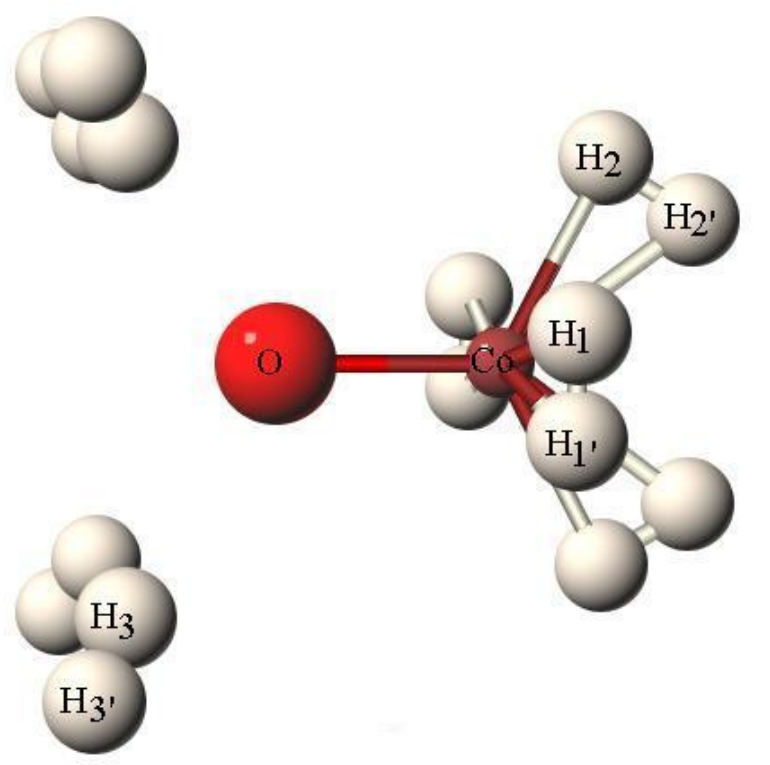

\begin{tabular}{lr}
\multicolumn{2}{c}{ Bond Distance $(\AA)$} \\
Co- $\mathrm{O}$ & 1.712 \\
$\mathrm{Co}-\mathrm{H}_{1}$ & 2.140 \\
$\mathrm{H}_{1}-\mathrm{H}_{1}$, & 0.754 \\
$\mathrm{Co}-\mathrm{H}_{2}$ & 1.727 \\
$\mathrm{H}_{2}-\mathrm{H}_{2}$, & 0.803 \\
$\mathrm{O}-\mathrm{H}_{3}$ & 2.518 \\
$\mathrm{H}_{3}-\mathrm{H}_{3}$, & 0.747
\end{tabular}

\begin{tabular}{lc}
\multicolumn{2}{c}{ Bond Angle $\left({ }^{\circ}\right)$} \\
O-Co- $\mathrm{H}_{1}$ & 93.9 \\
$\mathrm{O}-\mathrm{Co}-\mathrm{H}_{2}$ & 117.0 \\
$\mathrm{Co}-\mathrm{O}-\mathrm{H}_{3}$ & 118.4 \\
$\mathrm{Co}-\mathrm{H}_{1}-\mathrm{H}_{1}$, & 79.8 \\
$\mathrm{Co}-\mathrm{H}_{2}-\mathrm{H}_{2}$, & 82.3 \\
$\mathrm{O}-\mathrm{H}_{3}-\mathrm{H}_{3}$, & 171.1
\end{tabular}

Figure 30 Geometry of $\mathrm{CoO}\left(\mathrm{H}_{2}\right)_{8}$ cluster calculated from DFT

The same calculation was carried out for the $\mathrm{NiO}\left(\mathrm{H}_{2}\right)_{8}$ cluster and the result is shown in Figure 31 . The cluster also has a $C_{2 v}$ symmetry and presents the same apparent geometry as $\mathrm{VO}\left(\mathrm{H}_{2}\right)_{8}$ except that the bond distance and angle are quite different. Only $\mathrm{H}_{2}-\mathrm{H}_{2}{ }^{\prime}$ type molecules are largely affected by the nickel ion, and the bond distance is elongated to 
$0.804 \AA$. The $\mathrm{H}_{1}$ type and $\mathrm{H}_{3}$ type molecules are weakly adsorbed onto the nickel ion and oxygen ion. The overall binding energy of the cluster is remarkably higher at $34.623 \mathrm{kcal}$.
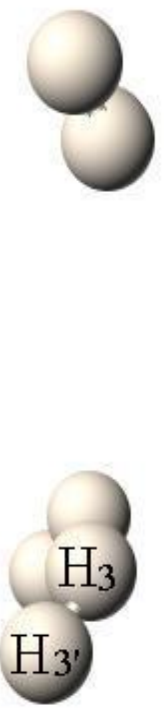

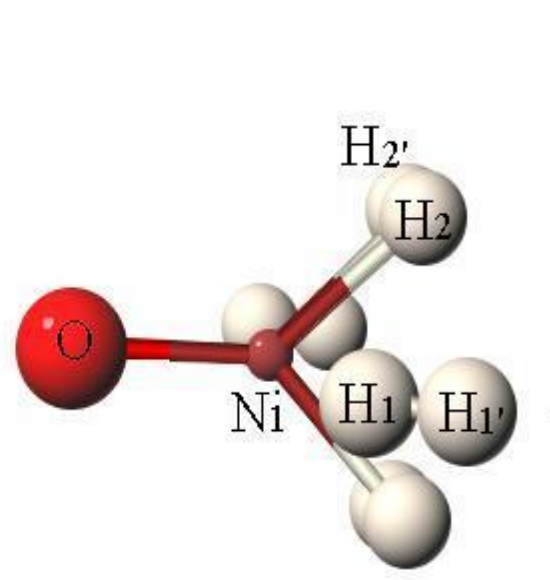

\begin{tabular}{lrlr}
\multicolumn{2}{r}{ Bond Distance $(\AA)$} & \multicolumn{2}{c}{ Bond Angle $\left(^{\circ}\right)$} \\
$\mathrm{N}_{1}-\mathrm{O}$ & 1.651 & $\mathrm{O}-\mathrm{N}_{1}-\mathrm{H}_{1}$ & 94.8 \\
$\mathrm{~N}_{1}-\mathrm{H}_{1}$ & 3.779 & $\mathrm{O}-\mathrm{N}_{1}-\mathrm{H}_{2}$ & 133.3 \\
$\mathrm{H} 1-\mathrm{H}_{1}$, & 0.745 & $\mathrm{~N} 1-\mathrm{O}-\mathrm{H}_{3}$ & 120.5 \\
$\mathrm{~N}_{1}-\mathrm{H}_{2}$ & 1.658 & $\mathrm{~N}_{1}-\mathrm{H}_{1}-\mathrm{H}_{1}$, & 123.4 \\
$\mathrm{H}_{2}-\mathrm{H}_{2}$, & 0.804 & $\mathrm{~N}_{1}-\mathrm{H}_{2}-\mathrm{H}_{2}$, & 76.0 \\
$\mathrm{O}-\mathrm{H}_{3}$ & 2.572 & $\mathrm{O}-\mathrm{H}_{3}-\mathrm{H}_{3}$, & 170.6 \\
$\mathrm{H} 3-\mathrm{H}_{3}$, & 0.746 & & \\
& & & \\
\hline
\end{tabular}

$$
\begin{aligned}
& \text { Binding Energy } \\
& \mathrm{NiO}+8 \mathrm{H} 2=\mathrm{NiO}\left(\mathrm{H}_{2}\right)_{8} \\
& \Delta \mathrm{E}=-34.623 \mathrm{kcal}
\end{aligned}
$$

Figure 31 Geometry of $\mathrm{NiO}\left(\mathrm{H}_{2}\right)_{8}$ cluster calculated from DFT

In a short summary, transition metal oxides are capable of binding eight hydrogen molecules with four on the metal cation sites and four on the oxygen sites. The $\operatorname{VO}\left(\mathrm{H}_{2}\right)_{8}$ and $\mathrm{NiO}\left(\mathrm{H}_{2}\right)_{8}$ cluster have the same molecule arrangement. And a slightly different type of configuration is observed for other clusters. The total binding energy is ordered as $\mathrm{CrO}\left(\mathrm{H}_{2}\right)_{8}>\mathrm{NiO}\left(\mathrm{H}_{2}\right)_{8}>\mathrm{CoO}\left(\mathrm{H}_{2}\right)_{8}>\mathrm{FeO}\left(\mathrm{H}_{2}\right)_{8}>\mathrm{VO}\left(\mathrm{H}_{2}\right)_{8}>\mathrm{MnO}\left(\mathrm{H}_{2}\right)_{8}$. Here, the total energy is not only the sum from the electrostatic or dipole interaction. Since transition metals have the partial filled d orbital, there are other associated mechanisms such as donation of electrons from the hydrogen sigma bond to the $\mathrm{d}$ orbital, or the backdonation of $\mathrm{d}$ electrons to the hydrogen anti-bonding orbital. Moreover, the different ion size especially on the cation site also influences the molecules arrangement and the total binding energy. 


\subsubsection{Clusters with gas molecules}

In general, the single diatomic molecules barely exist in solid materials. However, the gas molecules usually are interconnected by a weak Vander War force. Each single molecule could be considered as a free substance for hydrogen adsorption. The electrostatic interaction also exists in the common gas molecules, in which an intrinsic dipole can significantly attract hydrogen molecules. Figure 32 shows the optimized geometry of the $\mathrm{CO}\left(\mathrm{H}_{2}\right)_{8}$ cluster, where a total of eight hydrogen molecules could be bonded with four on each side. Carbon monoxide exhibits a polar structure where the carbon atom is positive charged and the oxygen is negative. However, due to the small atomic number of carbon, the electrostatic force is so weak that the smallest hydrogen-carbon bond is $\mathrm{C}-\mathrm{H}_{1}$ at 3.536 $\AA$. And the $\mathrm{H}_{1}-\mathrm{H}_{1}$ sigma bond is only slightly increased to $0.744 \AA$. The total binding energy is positive $0.336 \mathrm{kcal}$, which means that such a structure is not stable and may easily decompose.

Carbon dioxide is a nearly linear molecule with $\mathrm{O}-\mathrm{C}-\mathrm{O}$ bond angle at $179.8^{\circ}$. The molecule itself is not polarized because the oxygen atoms on each side have the same charge. However, it has two intrinsic dipoles with $\mathrm{CO}$ in the opposite direction. Compared to carbon monoxide, the carbon atom in $\mathrm{CO}_{2}$ is more positively charged and oxygen is more negatively charged. Therefore, the hydrogen interaction should be stronger than that of carbon monoxide. As from Figure 33, eight hydrogen molecules are bonded to a carbon dioxide molecule with four hydrogen molecules on each oxygen

atom. The $\mathrm{O}-\mathrm{H}$ bond distance is $3.071 \AA$ for $\mathrm{H}_{1}$ type molecules and $3.003 \AA$ for $\mathrm{H}_{2}$ type 
molecules. Such a short distance contributes to a strong interaction and good binding energy at negative $0.09844 \mathrm{kcal}$, therefore the $\mathrm{CO}_{2}\left(\mathrm{H}_{2}\right)_{8}$ structure is more stable than the $\mathrm{CO}\left(\mathrm{H}_{2}\right)_{8}$ cluster.

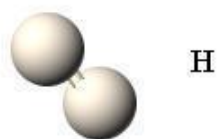

$\mathrm{H}_{3}$

( ${ }_{3}$.)

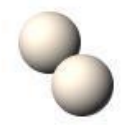

$\mathrm{H}_{2} \mathrm{H}_{2}$

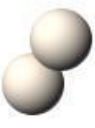

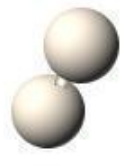

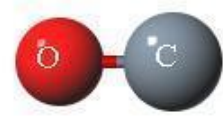

$\mathrm{H}_{2}$

$\mathrm{H}_{2}$

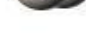

Binding Energy

$\begin{array}{lr}\text { Bond Distance }(\AA) \\ \mathrm{C}-\mathrm{O}, \quad 1.128 \\ \mathrm{Co}-\mathrm{H}_{1} & 3.536 \\ \mathrm{H}_{1}-\mathrm{H}_{1}, & 0.744 \\ \mathrm{C}-\mathrm{H}_{2}, & 3.542 \\ \mathrm{H}_{2}-\mathrm{H}_{2}, & 0.744 \\ \mathrm{O}-\mathrm{H}_{3}, & 3.695 \\ \mathrm{H}_{3}-\mathrm{H}_{3}, & 0.744 \\ \mathrm{O}-\mathrm{H}_{3}, & 3.696 \\ \mathrm{H}_{4}-\mathrm{H}_{4}, & 0.744\end{array}$

\begin{tabular}{ll}
\multicolumn{1}{c}{ Bond Angle $\left({ }^{\circ}\right)$} \\
O-C- $\mathrm{H}_{1}$ & 112.5 \\
O-C- $\mathrm{H}_{2}$ & 112.9 \\
$\mathrm{C}-\mathrm{O}-\mathrm{H}_{3}$ & 133.5 \\
$\mathrm{C}-\mathrm{O}-\mathrm{H}_{4}$, & 133.5 \\
$\mathrm{C}-\mathrm{H}_{1}-\mathrm{H}_{1}$, & 179.9 \\
$\mathrm{C}-\mathrm{H}_{2}-\mathrm{H}_{2}$, & 179.7 \\
O- $\mathrm{H}_{3}-\mathrm{H}_{3}$, & 176.9 \\
O- $\mathrm{H}_{4}-\mathrm{H}_{4}$, & 177.0
\end{tabular}

$\Delta \mathrm{E}=0.336 \mathrm{kcal}$

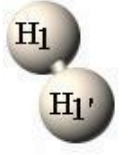

Figure 32 Geometry of $\mathrm{CO}\left(\mathrm{H}_{2}\right)_{8}$ cluster calculated from DFT

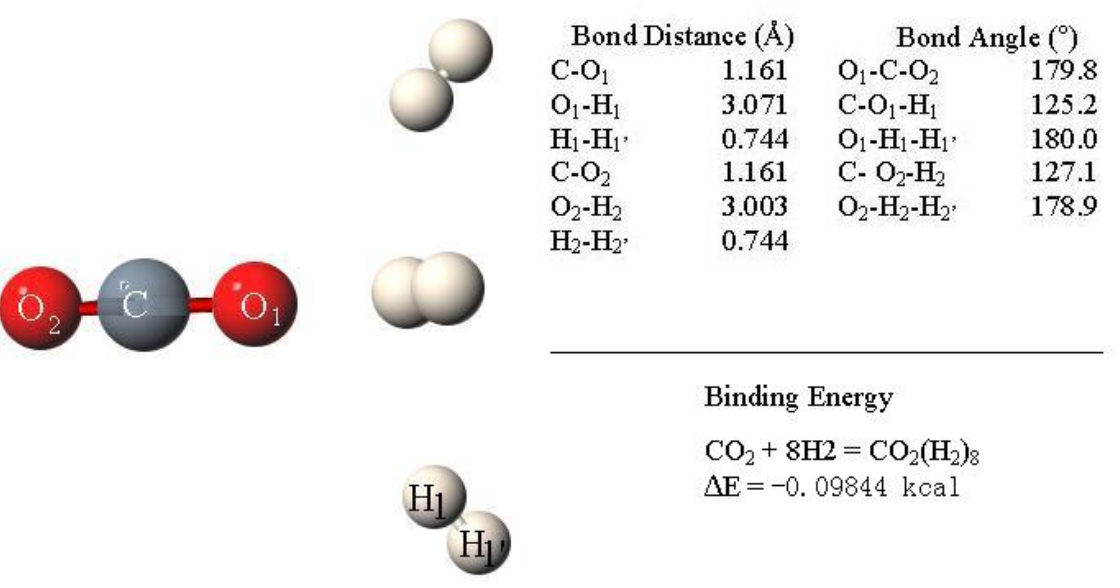

Figure 33 Geometry of $\mathrm{CO}_{2}\left(\mathrm{H}_{2}\right)_{8}$ cluster calculated from DFT 
The hydrogen chloride molecule is an ionic compound which has an intrinsic dipole moment where hydrogen donates an electron that becomes slightly positively charged and chloride accepts an electron that becomes a slightly negative charged. The dipole moment for $\mathrm{HCl}$ in the gas phase is $1.08 \mathrm{D}$ [119]. The optimized geometry of $\mathrm{HCl}\left(\mathrm{H}_{2}\right)_{8}$ cluster is shown in Figure 34. At the chloride end, four hydrogen molecules have the characteristic of end on adsorption and the $\mathrm{Cl}-\mathrm{H}$ distance is quite large at $5.324 \AA$. The negative charge effect of chloride is negligible. On the other end, two $\mathrm{H}_{3}$ type hydrogen molecules bonded side on to the positive charged hydrogen atom at a distance of $3.860 \AA$. The other two $\mathrm{H}_{2}-\mathrm{H}_{2}$ ' molecules stand above and below the $\mathrm{HCl}$ horizontal plane at a distance of $4.093 \AA$ to the hydrogen atom. The shorter distance on the hydrogen end is because the hydrogen atom has a smaller size than the chloride atom and it also could be because the positive charge is more effective in bonding hydrogen molecules. The overall binding energy is negative $0.285 \mathrm{kcal}$, which is stronger than carbon monoxide and carbon dioxide. 


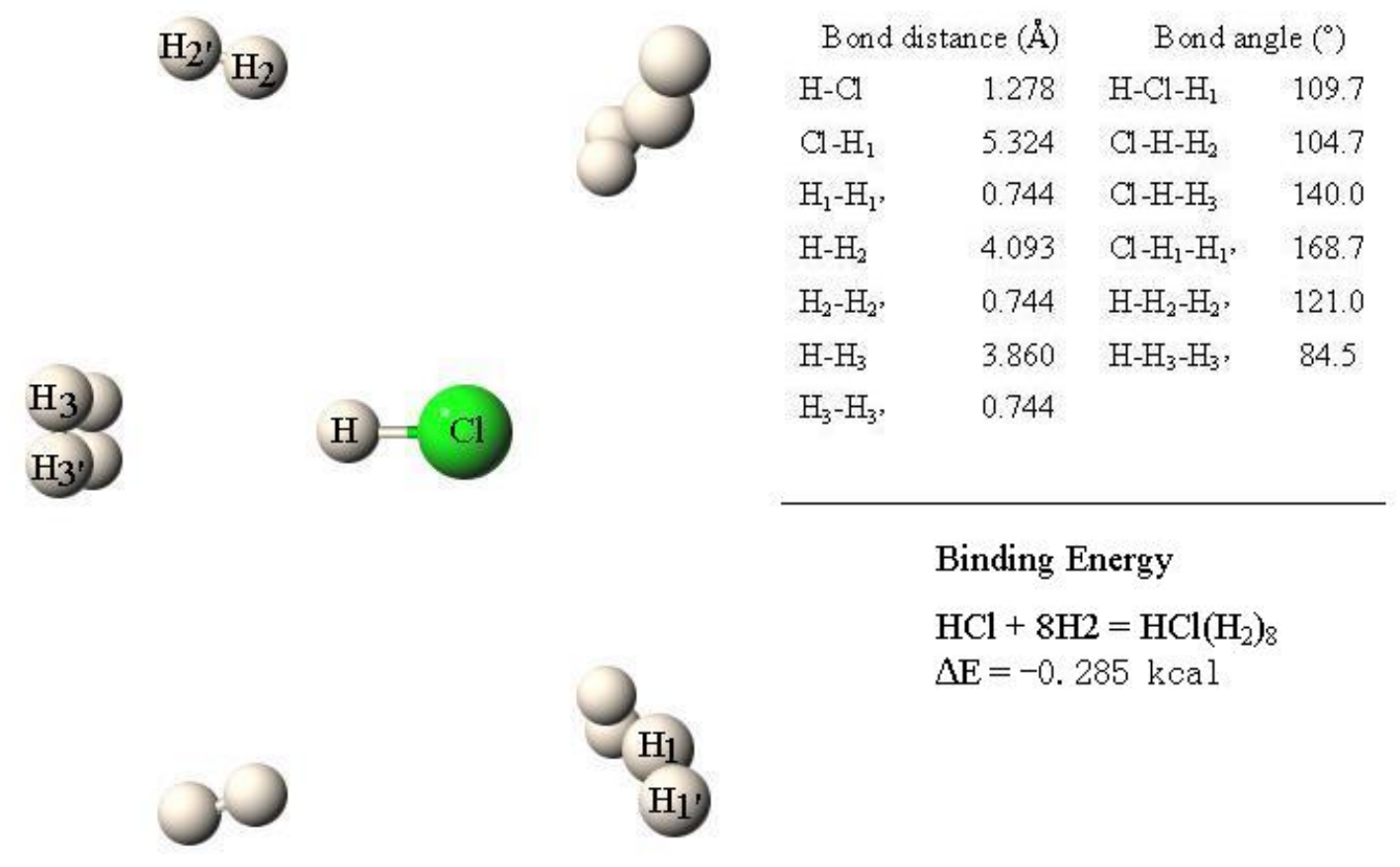

Figure 34 Geometry of $\mathrm{HCl}\left(\mathrm{H}_{2}\right)_{8}$ cluster calculated from DFT

\subsection{Conclusion}

Hydrogen clusters with alkaline metal ions, first row transition metal oxides, and also inorganic gas compounds have been calculated to study the geometry, stability, binding energy and examine the effects of electrostatic interaction on the hydrogen-molecule substances. The alkaline cations can form clusters with up to eight hydrogen molecules. The total binding energy increases with the decreasing of cation size. When the metal cations form oxides with oxygen, the electrostatic force is weakened so that the total binding energy is lowered to some extent. However, the metal oxides can bind up to eight hydrogen molecules and the stability does not follow the pure electrostatic force since some molecules with higher dipole moment result in lower binding energy. Accordingly, there might be other mechanisms such as sigma bond donation and d orbital back- 
donations due to the partially filled d orbital. Although inorganic gas molecules have free space to accommodate hydrogen, weak dipole moments have made the clusters to have small binding energy and unstable structures. From all these results, hydrogen clusters could be formed based on the electrostatic interaction. 


\section{CHAPTER 6 SALT IMPREGNATED ACTIVATED CARBON FOR HYDROGEN STORAGE}

\subsection{Introduction}

The previous calculations have been performed under the assumption of a single molecule, however, such an assumption cannot stand in a real case unless it is in a super rarefied gas phase. In order to better understand and prove the idea that the electrostatic force could assist the adsorption interaction, real experimental work and combined computational work are needed.

Alkaline salts such as chlorides or bromides are ionic compounds where the ability of attracting hydrogen by electrostatic forces can exist on the surface of such substances. However, these salts usually have small surface area which means that the adsorption sites are limited. The overall adsorption capacity is negligible and the difference between each compound is not easily identified. Activated carbon has been widely used in adsorption of pollution in gaseous or liquid phases, storage of gas, catalyst support, and also doubles layer supercapacitors [120-123]. The use of activated carbon for hydrogen storage is mainly depending on its total porosity [124]. The weak interaction force (usually physisorption) prevents the activated carbon to be used as good hydrogen storage materials since significant adsorption can only occur at cryogenic temperature $(77 \mathrm{~K})$. The extremely large surface area of activated carbon makes it an excellent adsorbent of 
chemicals. Here, activated carbon was used as a substrate where the ionic compounds were adsorbed onto the surface. The enhancement of hydrogen storage from the adsorbed ionic compounds on carbon could be differentiated from that of the plain carbon. Moreover, detailed information about the electrostatic force enhanced adsorption could be obtained by impregnating various ionic compounds composed of different cations and anions.

The theoretical calculations on the interaction of small molecules with bulk crystal surface often fail to correctly describe the crystal structure, bonding energy, and optimized geometry [125]. There is large discrepancy between experimental and theoretical data. Periodic ab initio is often employed in crystal calculations and is believed to match well with experimental results. However, such method is time consuming and sometimes works poorly in adsorption studies, as described by Damin [126] in their periodic study of $\mathrm{CO}$ adsorption on $\mathrm{MgO}$ surface. The calculated result is underestimated in comparison to the experimental data. The use of the cluster model to describe the adsorption with crystal surfaces is proved by the fact that there are only limited atoms which are involved in the adsorption. Early on, the cluster calculations were carried on bulk clusters where there are no surrounding charges. The accuracy depends on the size of the chosen cluster and there are reported examples that such "bare" cluster calculations yield problems in overestimating band gap [127] and inaccurate lattice parameter [128]. The Madelung potential could be compensated by embedding the cluster into an array of point charges and the calculation accuracy could 
be enhanced. The magnitude of point charge is not necessary to be the nominal charge, because by using nominal charge, the Madelung potential of the crystal is often overestimated [129]. In general, the point charge is to reproduce the chemical environment and background for the cluster in simulating the bulk lattice, whereas it is not involved in direct chemical bonding. The criteria for determining the value of point charge requires the cluster to be self-consistent whether in charge consistency or bond length consistency. The value of point charge depends strongly on the cluster size. The charge value decreases as the cluster size becomes larger in order to satisfy the consistency criteria $[125,129]$. Charge consistency requires that the input array of point charge results in the cluster having the same magnitude of charges as the input value, while bond length consistency requires that the value of the surrounding charges can reproduce the bulk crystal lattice parameter. Kadossov and coworkers [125] studied the correlation between the electronic properties of the $\mathrm{NiO}$ clusters with the magnitude of the surrounding point charges, and obtained reasonable value compared with experimental and calculated data by choosing charge value empirically to reproduce the Ni-O bond length. Here, a similar method is used for obtaining the right surrounding point charge, which can best describe the correct lattice parameter of the cluster. Then the system composed of hydrogen molecule and embedded cluster is optimized to obtain the final geometry and corresponding bonding energy. 
The theoretical results combined with experimental approach reveal well the charge induced enhancement of the deposited ionic salts on the adsorption of hydrogen molecules.

\subsection{Experimental}

\subsubsection{Preparation of samples}

The salt impregnated carbon samples were prepared via impregnating 1.2 grams of activated carbon Norit A (acquired from Norit Americas Inc.) with $60 \mathrm{ml}$ salt solutions under magnetic stirring for 24 hours at room temperature. The products were filtered and then dried at $120^{\circ} \mathrm{C}$ overnight.

\subsubsection{Characterization}

The surface area and the pore size distribution were measured by using a Micromeritics ASAP2000 instrument. The samples were evacuated by heating at $300{ }^{\circ} \mathrm{C}$ under vacuum for 12 hours before testing. The tubing containing degassed samples were then sealed and carefully transferred to a balance to obtain the sample weight.

A Hitachi S-4700 field emission-scanning electron microscopy (FE-SEM) was used to examine the microstructure of the samples.

The accurate weight percentage of salt impregnated on activated carbon was determined by Inductively Coupled Plasma Emission Spectrophotometer (ICP). Before analysis, the 
solutions were prepared by flushing the samples several times using $10 \%$ hydrochloride acid and distill water. The cation concentration analyzed by ICP was used to calculate the total salt weight by assuming that the positive and negative ions adsorbed on carbon follow the charge stoichiometry.

\subsubsection{Hydrogen adsorption measurements}

Hydrogen adsorption at pressure between 0.1 bar and 80 bar was measured by using static volumetric techniques with an automatic Sieverts' apparatus (PCT-Pro 2000 from Hy-Energy LLC) at both room temperature and $77 \mathrm{k}$. The simple schematic diagram of Sieverts' apparatus and principle of volumetric measurement could be found elsewhere [130]. Figure 35 and 36 show the outlook of the instrument and the operating screen of the control software. The samples were extensively evacuated for 12 hours at $300^{\circ} \mathrm{C}$ and transferred with care to the PCT sample holder. Further degas of samples was performed in PCT apparatus at $150{ }^{\circ} \mathrm{C}$ for 3 hours to remove any contaminations during the transfers. Around $600 \mathrm{mg}$ of samples were used in each test, and ultra pure $(99.999 \%)$ hydrogen and helium gases were used for all calibrations and measurements. 


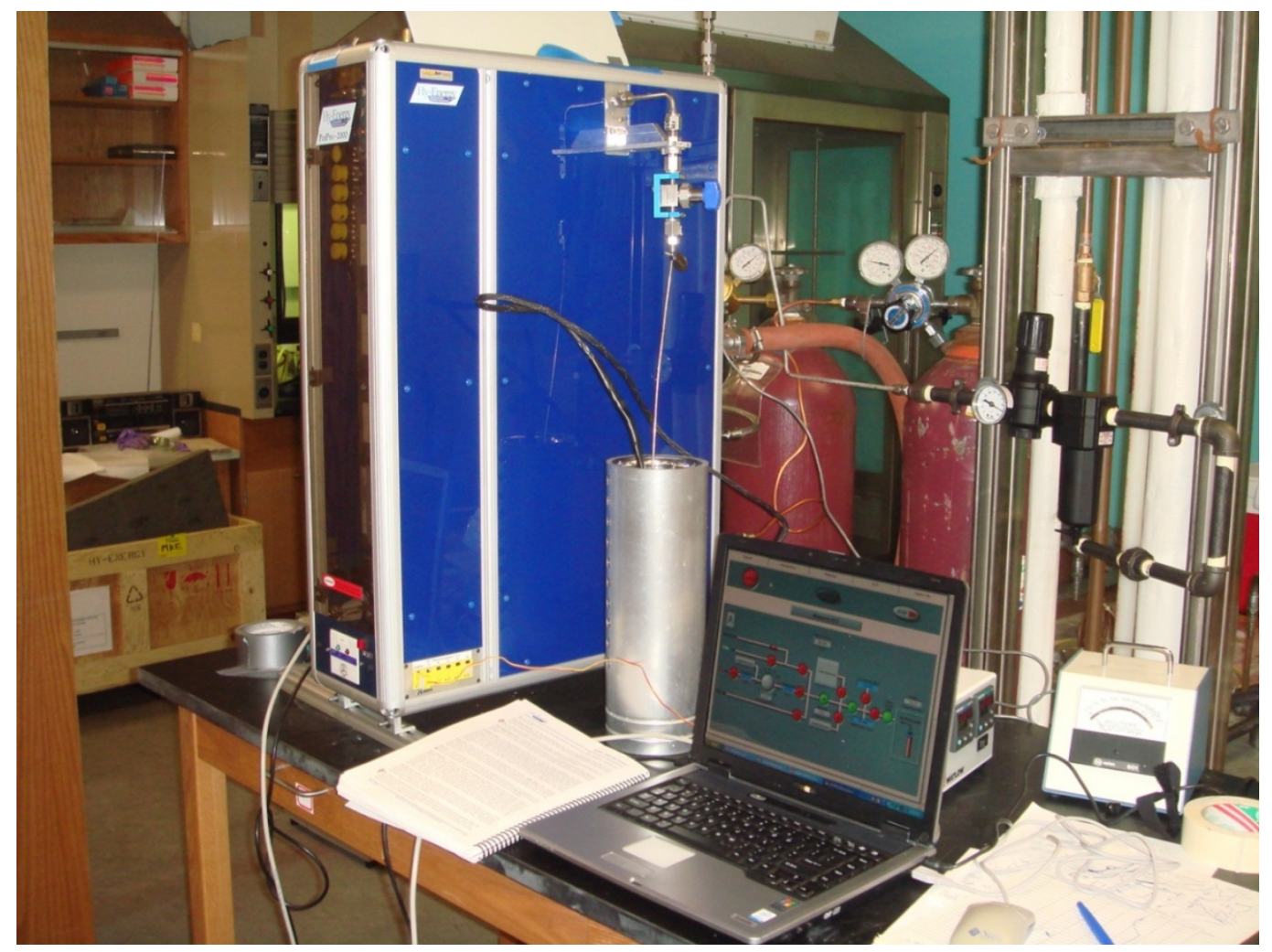

Figure 35 Outlook of the PCT-Pro 2000 instrument

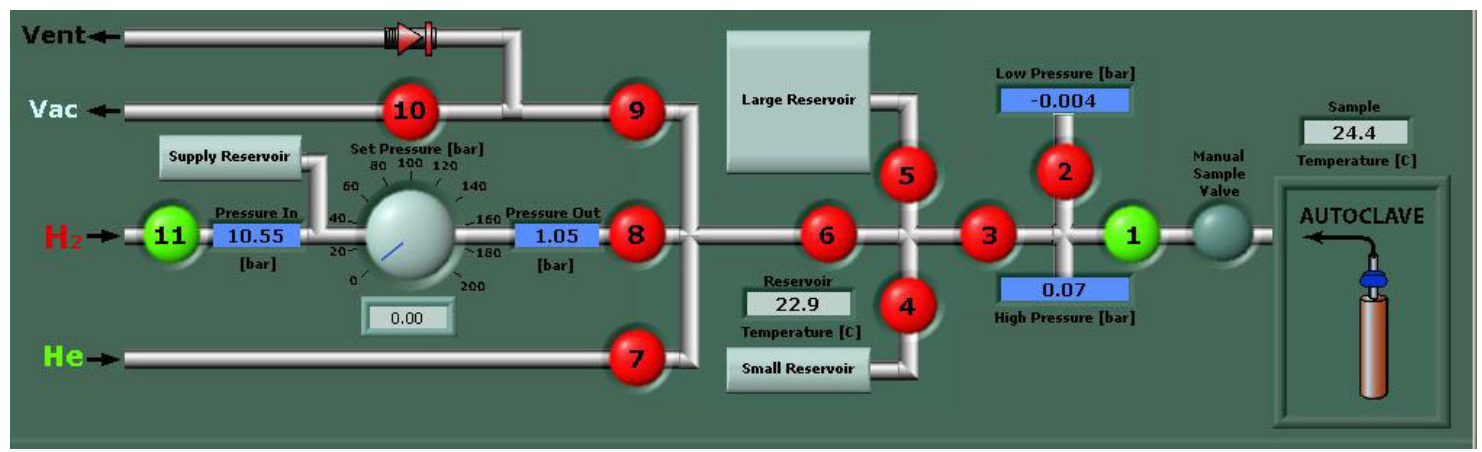

Figure 36 Operating screen of the PCT-Pro 2000 software

\subsubsection{Computational method}

The salts with only cubic structures were calculated. The clusters used here have been chosen to satisfy the criteria of being neutral, and stoichiometric. The salt solids were 
represented by various $\mathrm{M}_{5} \mathrm{~N}_{5}$ clusters, where $\mathrm{M}$ indicates the cation and $\mathrm{N}$ indicates the anion. The clusters were embedded in an alternating positive and negative point charge of equal value. The point charge arrays were arranged at a construction of $13 \times 13 \times 13$ system. All the bonds, angels, and crystal data (CIF files) of salt crystals were obtained from an online crystallography database [131]. Geometry optimization of clusters was first performed at different values of surrounding point charges by varying the bond length of the lattice parameter while fixing all the bond angles so as to obtain the correct magnitude of point charge. The criteria used here is that the magnitude of point charges were varied until the optimized lattice parameter could well reproduce the number from the standard database.

After obtaining the correct point charge value, the point charge array was moved down along the z-axis to expose the surface atoms with the charge magnitude and structure unchanged, as shown in the schematic diagram of Figure 37. For modeling of hydrogen adsorption, the salt clusters were fixed at the initial structure while the hydrogen molecules were free to move. The total binding energy was calculated by the difference between the total energy of the whole adsorption system and the total energy of the separate reactants before combination, as presented in following equation:

$$
M_{5} N_{5}+H_{2} \rightarrow M_{5} N_{5} H_{2}
$$



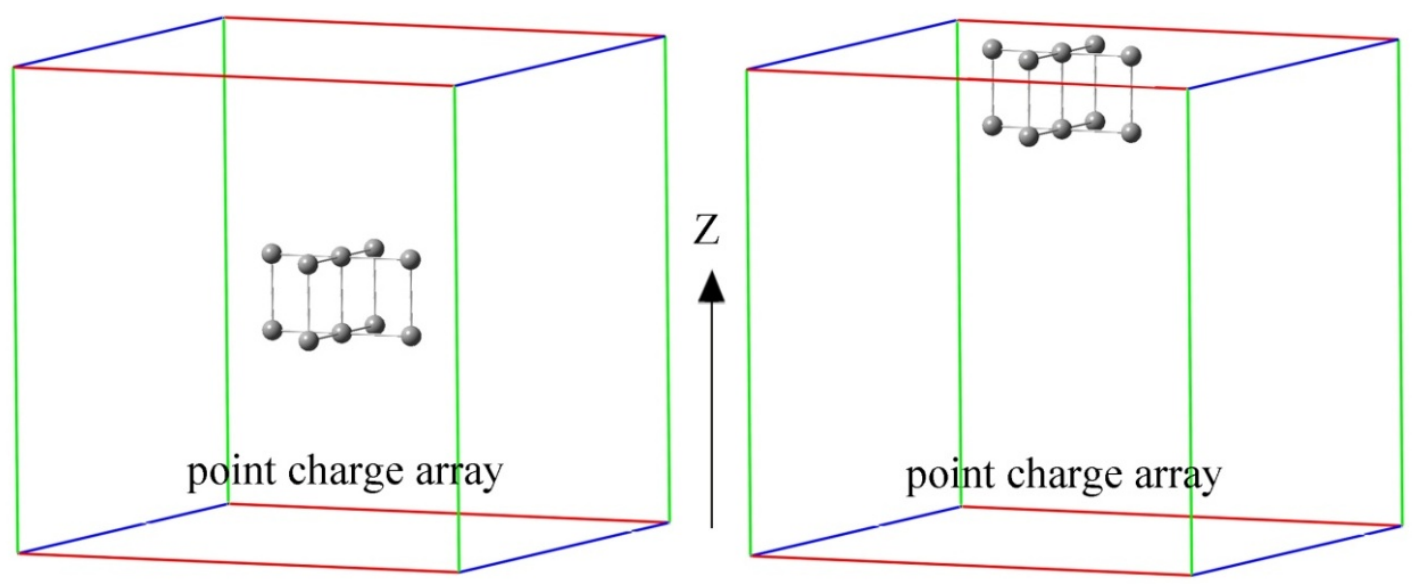

Figure 37 Point charge array for cluster simulation

All the calculations were performed by using DFT/B3LYP method and a basis set of 6-31 G(d) in GAUSSIAN 03 program [118].

\subsection{Results and discussion}

\subsubsection{Raw activated carbon}

Table 5 contains the BET characterization of all the samples studied. AC indicates the Norit A activated carbon. Second part identifies the solution concentration and salt type used for impregnation. The raw carbon has a BET surface area of $1836 \mathrm{~m}^{2} / \mathrm{g}$ and micropore volume of $0.25 \mathrm{cc} / \mathrm{g}$.

As summarized in a recent study [124], hydrogen adsorption capacity of carbon materials only depends on the total porosity of the materials, not on the pore structure. The small micropore volume of this carbon barely affects the total hydrogen storage capacity. 
Table 5 BET analysis of raw carbon and salt impregnated carbon

\begin{tabular}{llll}
\hline Sample & $\begin{array}{l}\text { BET surface } \\
\text { area }\left(\mathbf{m}^{\mathbf{2}} / \mathbf{g}\right)\end{array}$ & $\begin{array}{l}\text { Micropore } \\
\text { volume }(\mathbf{c c} / \mathbf{g})\end{array}$ & $\begin{array}{l}\text { Average pore } \\
\text { diameter }(\mathbf{\AA})\end{array}$ \\
\hline $\mathbf{A C}$ & 1836.15 & 0.25 & 21.78 \\
$\mathbf{A C}+\mathbf{1 M L i C l}$ & 1702.37 & 0.23 & 21.75 \\
$\mathbf{A C + 1 M N a C l}$ & 1652.44 & 0.23 & 21.94 \\
$\mathbf{A C}+\mathbf{1} \mathbf{M K C l}$ & 1559.38 & 0.21 & 21.93 \\
$\mathbf{A C}+\mathbf{1} \mathbf{M K B r}$ & 1398.90 & 0.20 & 21.95 \\
$\mathbf{A C}+\mathbf{1} \mathbf{M N i C l}_{\mathbf{2}}$ & 1377.26 & 0.16 & 21.99 \\
\hline
\end{tabular}

As shown in Figure 38, the total hydrogen storage capacity of NoritA carbon reaches 0.45 $\mathrm{wt} \%$ at the pressure of 80 bars at room temperature and the trend is almost a linear line. This indicates that the weak interaction requires higher pressure to obtain the significant storage [125]. At $77 \mathrm{~K}$, the capacity reaches the saturation point of $3.38 \mathrm{wt} \%$ at around 60 bars. All the adsorption data of this type of carbon are in good agreement with the published results [124], although NoritA carbon has smaller micropore volume. This again proves that the hydrogen adsorption ability of activated carbon depends only on the total surface area with no relevance to the pore structures. 


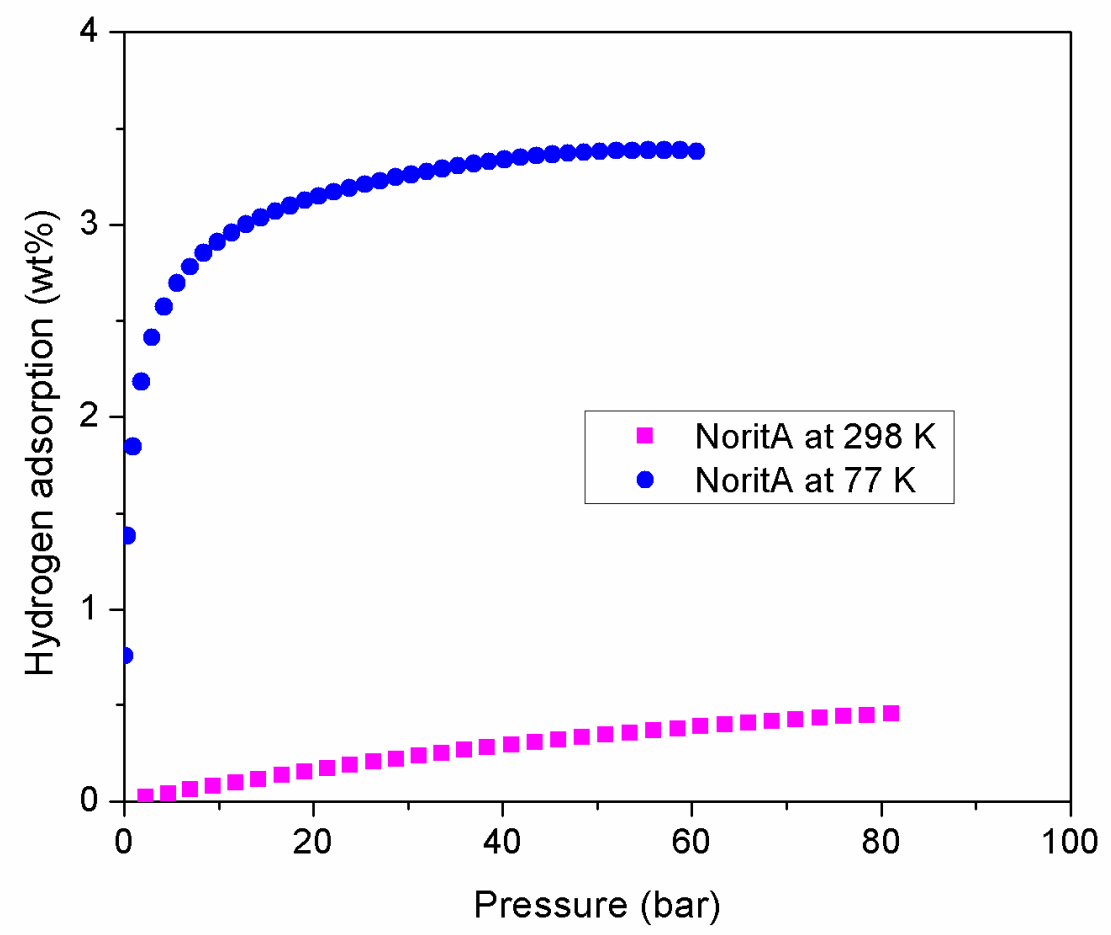

Figure 38 Hydrogen adsorption of activated carbon at $298 \mathrm{~K}$ and $77 \mathrm{~K}$

\subsubsection{Salt impregnated carbon}

$1 \mathrm{M}$ of salt solutions including $\mathrm{LiCl}, \mathrm{NaCl}, \mathrm{KCl}, \mathrm{KBr}$, and $\mathrm{NiCl}_{2}$ were used as impregnation agents. The surface areas of treated samples are shown in Table 5. Obviously, the BET surface areas dropped significantly in comparison with the untreated sample. Among those, the $\mathrm{NiCl}_{2}$ treated sample was most affected and the total surface area reduced about $30 \%$. The micropore volume was also affected to some extent, however, the average pore diameter increased. The surface properties obtained by BET method were calculated as surface area per gram of sample. The salts adsorbed on carbon account for significant weight, which can cause underestimation of the calculation. 
Table 6 Concentration of the impregnated salts

\begin{tabular}{llllll}
\hline Sample & AC- & AC- & AC-1MKCl & AC-1MKBr & AC-1MNiCl \\
& 1 MLiCl & $\mathbf{1 M N a C l}$ & & & \\
\hline Cation (wt \%) & 0.40 & 2.00 & 3.76 & 3.05 & 5.14 \\
Cation (mole\%) & 0.058 & 0.087 & 0.096 & 0.078 & 0.088 \\
Salt (wt \%) & 2.45 & 5.10 & 7.19 & 9.30 & 11.36 \\
\hline
\end{tabular}

Table 6 shows the mole percentage and weight percentage of the cation and accordingly the salt of the treated samples. Except for $\mathrm{LiCl}$, all other salts showed similar mole ratio, which refers to the similar dispersion on the carbon surface. Due to the differences in molecule weight, the weight percentage varied accordingly. The surface area should be adjusted based on the salt weight in order to obtain the true total surface. As shown in Table 7 , the adjusted surface area of samples are still significantly smaller than the plain carbon, which indicates the blocking of the pores on the original carbon due to the crystallization of the impregnated salts.

Table 7 Adjusted surface area based on the salt concentration

\begin{tabular}{lllllll}
\hline Sample & AC & AC-1MLiCl & AC-1MNaCl AC-1MKCl & AC-1MKBr & AC-1MNiCl \\
\hline $\begin{array}{l}\text { Adjusted } \\
\text { surface area } \\
\left(\mathbf{m}^{2} / \mathbf{g}\right)\end{array}$ & 1836.15 & 1745.17 & 1741.17 & 1680.12 & 1542.39 & 1553.79 \\
\hline
\end{tabular}

It is noted that the electrostatic force is supposed to increase the interaction so that the hydrogen adsorption in room temperature could be increased. However, every salt tested is heavier than carbon materials so that the magnitude of the total hydrogen capacity of 
salt impregnated carbon in weight percentage is not supposed to suppress the plain carbon. Therefore, the adsorption capacity in weight percent should be adjusted to the adsorbed hydrogen weight divided by the total carbon weight which equals to the total sample weight minus the weight of salt. Such calculation could minimize the effects from differences in molecule weight of salts. Figure 39 shows the hydrogen adsorption of salt impregnated samples as a function of pressure. The inserted figure pointed out that $\mathrm{KBr}$ and $\mathrm{NiCl}_{2}$ impregnated carbon have better adsorption than plain carbon at pressure lower than 10 bars. $\mathrm{NaCl}$ and $\mathrm{KCl}$ samples are in close value with original carbon and $\mathrm{LiCl}$ samples being lower. As the pressure increased, the surface area plays a more important role in adsorption so that only the $\mathrm{NiCl}_{2}$ sample showed better improvement while others were significantly lower.

It should be noted from Table 7 that the surface areas of samples are significantly affected by the impregnated salts, therefore a profile of weight of adsorbed hydrogen (g) divided by the total surface $\left(\mathrm{m}^{2}\right)$ could give a more obvious picture of the effects from salt impregnations. 


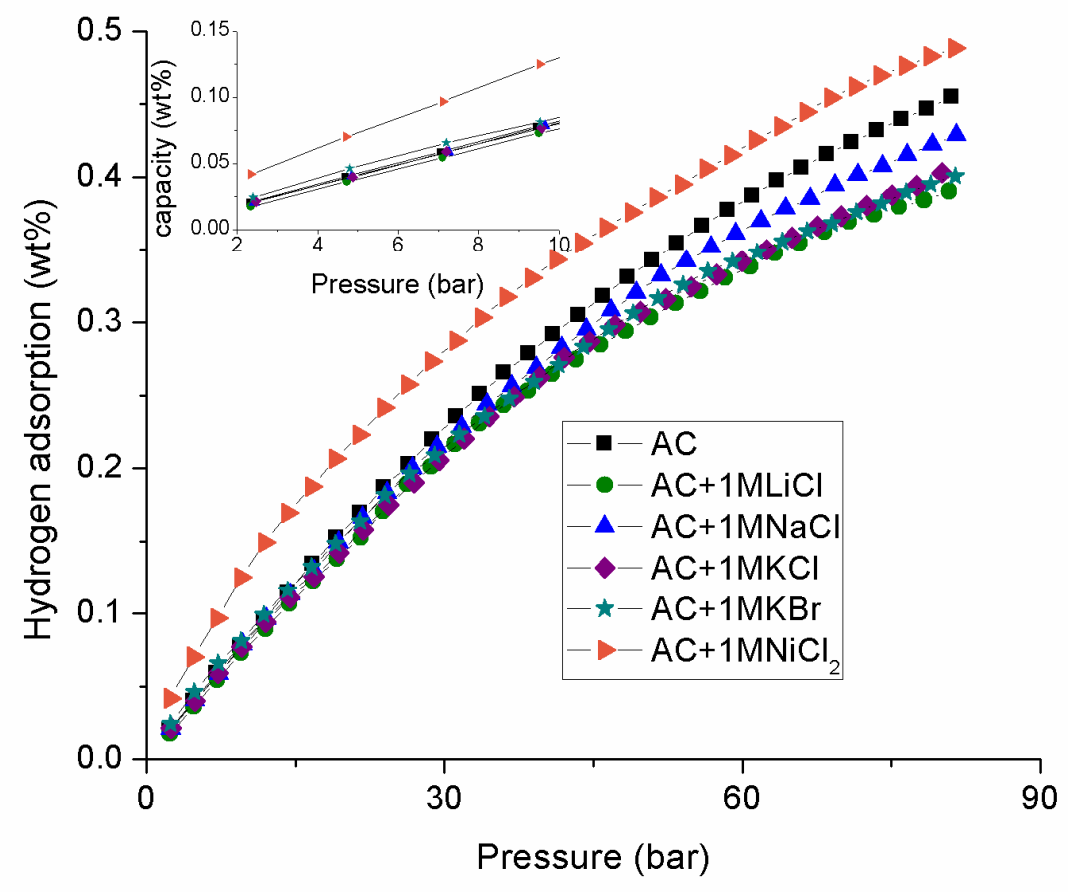

Figure 39 Hydrogen adsorption of salt impregnated carbon at $298 \mathrm{~K}$

Figure 40 shows the hydrogen adsorption on impregnated carbons in weight per square meter, which describes how each surface compound contributes to the total adsorption. With respect to the original carbon, $\mathrm{LiCl}$ impregnated samples show smaller capacity although the difference is quite insignificant. $\mathrm{NaCl}$ and $\mathrm{KCl}$ are nearly overlapped with plain carbon indicating that coating these salts on carbon made no difference on adsorption, which also demonstrated that the adsorption energy was in close value to that of carbon. Samples with $\mathrm{KBr}$ showed significant enhancement indicating a stronger interaction. The increase of the $\mathrm{NiCl}_{2}$ sample was so remarkable that nearly $30 \%$ enhancement could be achieved. As discussed in the previous chapter, the transition metal ions have unfilled $d$ orbital whereas the donation from $d$ electrons to hydrogen anti- 
bonding orbital and back-donation from hydrogen electrons to metal ion are significant. Thereby unlike alkaline salts, transition metal compounds exhibited stronger interaction in addition to the electrostatic force.

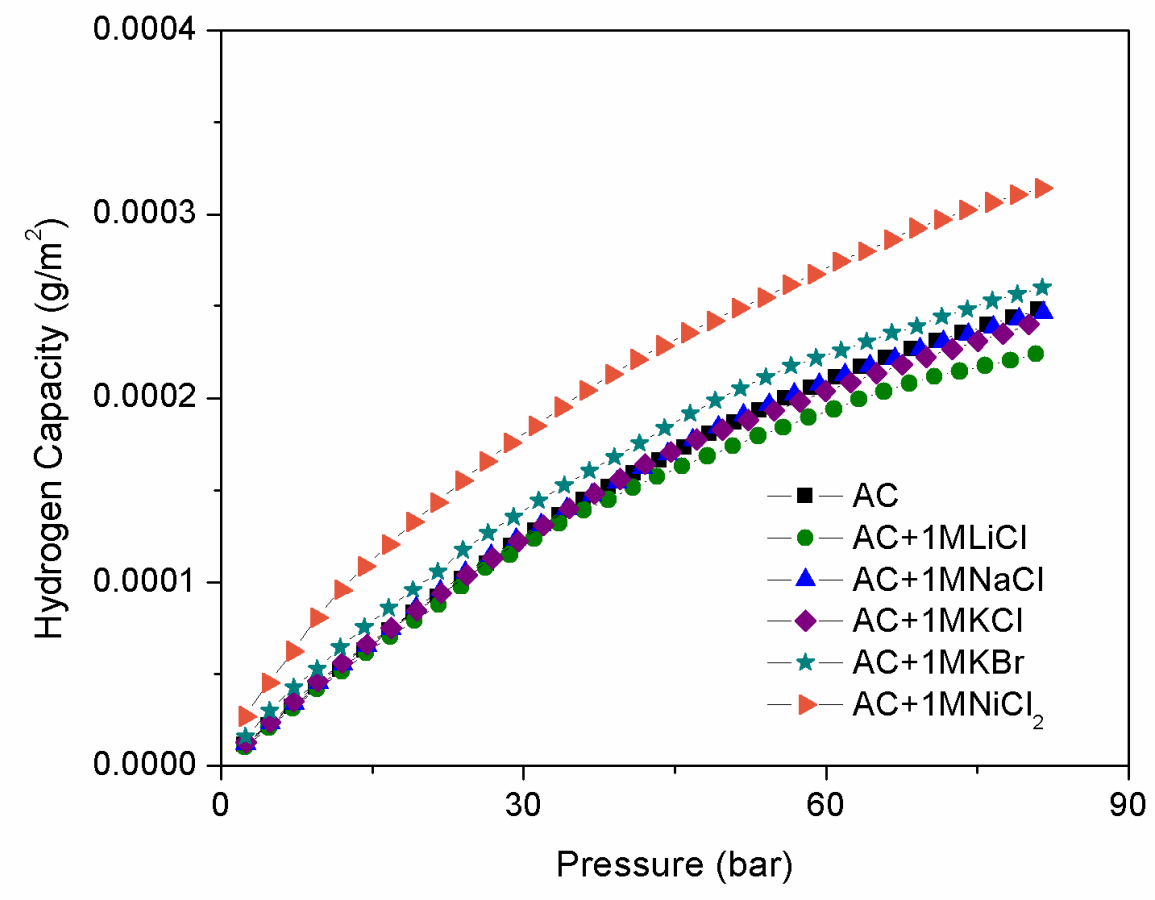

Figure 40 Hydrogen capacity per surface area of salt impregnated carbon

\subsubsection{Computational results}

\subsubsection{Cluster optimization}

The salt clusters of $\mathrm{LiCl}, \mathrm{NaCl}, \mathrm{KCl}$, and $\mathrm{KBr}$ in point charges were first optimized to obtain the correct value of point charge which can well represent the crystal lattice parameters. Figure 41 shows the optimized structure and Table 8 summarizes the obtained parameters. The lattice parameter a $(\AA)$ is the cation and anion bond length 
which is also equal to half of length of the unit cell. The magnitude of the surrounding point charge $\mathrm{Q}_{\mathrm{p}}$ is much smaller than the natural charge of the salts. And with $\mathrm{Q}_{\mathrm{p}}$ equals 0 or 1 , the lattice parameter was in poor agreement with the experimental value.

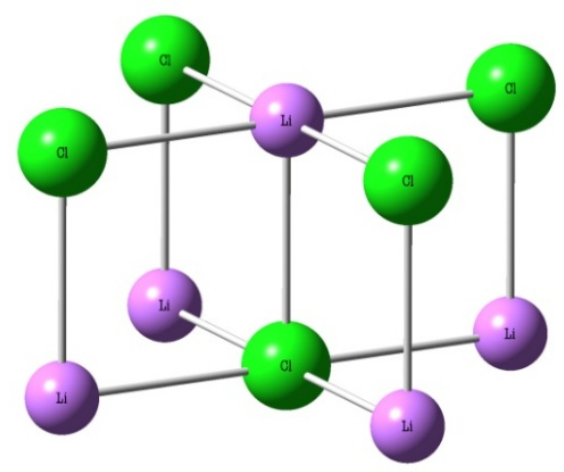

(a)

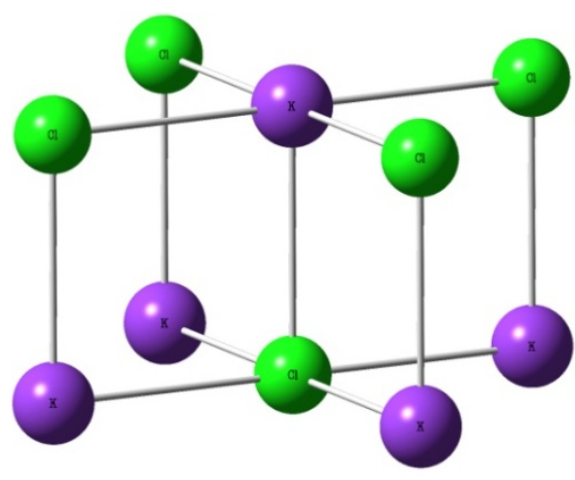

(c)

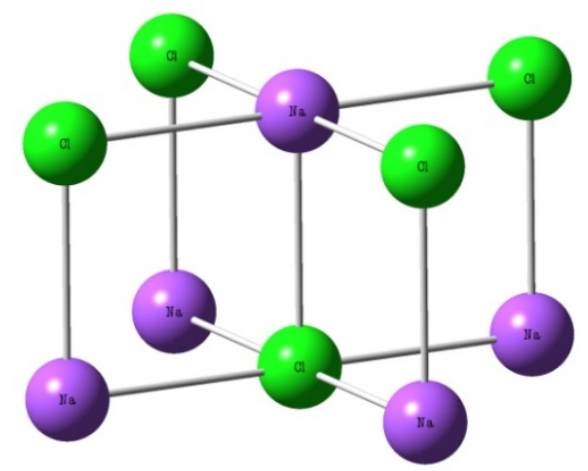

(b)

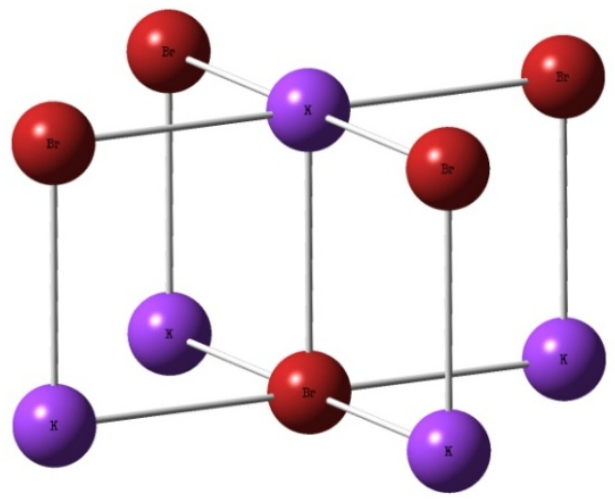

(d)

Figure 41 Optimized clusters in point charge

As the cation changed from lithium to potassium, the value of point charge decreased from 0.461 to 0.302 , while the average Mulliken charge increased. Contradictory results were observed as the anion changes from chloride to bromide in which the point charge value increased and the Mulliken charge increased. These obtained point charges were used as the background for all the sequential hydrogen adsorption calculations. 
Table 8 Optimized cluster parameters, where a is the lattice parameter, $Q_{p}$ is the value of the surrounding point charge and $Q_{M}$ is the average Mulliken charges

\begin{tabular}{llll}
\hline Cluster & $\mathbf{a}(\AA)$ & $\mathbf{Q}_{\mathbf{p}}$ & $\mathbf{Q}_{\mathbf{M}}$ \\
\hline $\mathbf{L i}_{\mathbf{5}} \mathbf{C l}_{\mathbf{5}}$ & 2.565 & 0.461 & 0.61 \\
$\mathbf{N a}_{\mathbf{5}} \mathbf{C l}_{\mathbf{5}}$ & 2.820 & 0.421 & 0.68 \\
$\mathbf{K}_{\mathbf{5}} \mathbf{C l}_{\mathbf{5}}$ & 3.144 & 0.302 & 0.75 \\
$\mathbf{K}_{\mathbf{5}} \mathbf{B} \mathbf{r}_{\mathbf{5}}$ & 3.292 & 0.478 & 0.68 \\
\hline
\end{tabular}

\subsubsection{Hydrogen adsorption on first group halides}

The surface atoms of the crystals have unbalanced dangling bonds which are responsible for strong surface adsorption ability. Moreover, in ionic crystals, the unsaturated bond means unbalanced charges; therefore the interaction with hydrogen molecules is stronger due to the electrostatic forces. As shown in Figure 42 that the surfaces of all the first group halides have the ability to absorb hydrogen molecules either on the cation site or the anion site. It follows side on adsorption (Yeager model) at the cation site and end on adsorption (Pauling model) on the anion site [132]. The free hydrogen molecules optimized by the same DFT method and basis set 6-31 G(d) had a bond distance of H-H at $0.74279 \AA$. For $\mathrm{LiCl}$, the hydrogen molecule on the $\mathrm{Li}$ site was slightly elongated $0.00048 \AA$. The charge on $\mathrm{Li}$ accounted for the small electrostatic attraction and the electron cloud of the hydrogen sigma bond was weakly perturbed, which was demonstrated by the resulting positive charges on adsorbed hydrogen. On the $\mathrm{Cl}$ site, the end on adsorption attracted by the negative charged chloride ion caused an intrinsic dipole in the hydrogen molecule, as in Figure 42(b) that hydrogen 1 had a charge of 0.002 while hydrogen 2 had charge of 0.007 . The interaction on the $\mathrm{Cl}$ site was a little stronger 
since the distance of the H-H bond was elongated $0.00126 \AA$. Figure 42(c) and 42(d) show the similar optimized arrangement for $\mathrm{NaCl}$. However, the $\mathrm{H}-\mathrm{H}$ perturbation was larger due to the more positively charged sodium 0.450 and more negative charged chloride -0.594 . Better adsorption was achieved in $\mathrm{KCl}$, where higher charged potassium (0.599) and chloride (-0.749) contributed to the stronger electrostatic force. The hydrogen intrinsic dipole on chloride site was promising strong, whereas the hydrogen 1 atom showed a negative charge -0.001 which indicated a vigorous force impacting on the electrons of the hydrogen molecule. By changing the anion from chloride to bromide, the potassium was less positively charged showing a number of 0.300 , so did the bromide ion showing a number of -0.637 . However, the $\mathrm{H}-\mathrm{H}$ distance was larger, with 0.74381 on the potassium site and 0.74558 on the bromide site.

A more detailed comparison is summarized in Table 9. Clearly, the trend is obvious that by keeping the chloride ion unchanged, increasing of cation radii from $\mathrm{Li}$ to $\mathrm{K}$ increased the adsorption energy and about $1.36 \mathrm{~kJ} /$ mole could be achieved on potassium of potassium chloride. The adsorption energy was consistent of the perturbation of $\mathrm{H}-\mathrm{H}$ bond length which enlarged as the cation became larger. From the Mulliken charge analysis and the dipole moment of the cluster, it is obvious that the adsorption energy was enhanced as the charge and dipole moment increased. Therefore, the interaction was verified to be caused by electrostatic force. However, these results are contradictory with those obtained by calculating hydrogen interaction with isolated cation. 
(a)

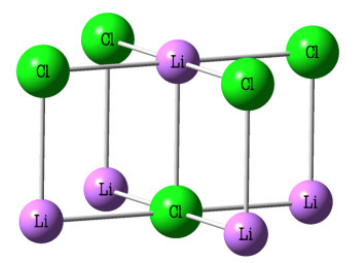

$\begin{array}{ll}\left.\text { H. }-\mathrm{H}_{2}\right) & \text { bond length }(\AA) \\ \text { H1- } 220.74327\end{array}$

H1- Li 3.236

bond angle $\left({ }^{\circ}\right)$

H1-Li-H2 13.168

Mulliken charge

$\begin{array}{ll}\text { H1 } & 0.011 \\ \text { H2 } & 0.012\end{array}$

$\begin{array}{ll}\text { H2 } & 0.012 \\ \text { Li } & 0.359\end{array}$

Dipole moment (Debye)

30.7251 (c)
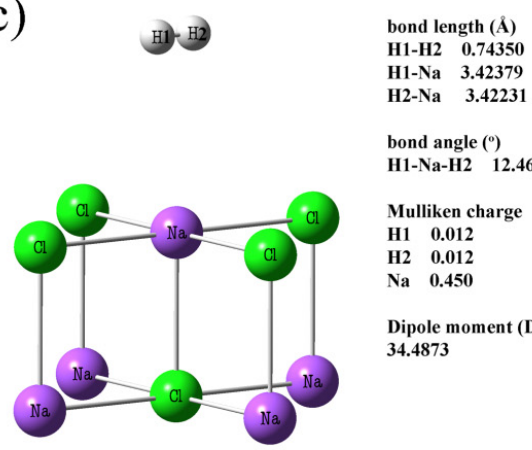

(e)

바)파)

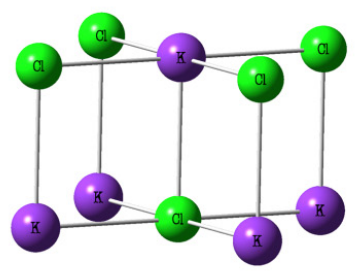

Mulliken charge

H1 0.011

$\begin{array}{lc}\text { H2 } & \mathbf{0 . 0 1 1} \\ \text { K } & 0.599\end{array}$

Dipole moment (Debye)

38.7279

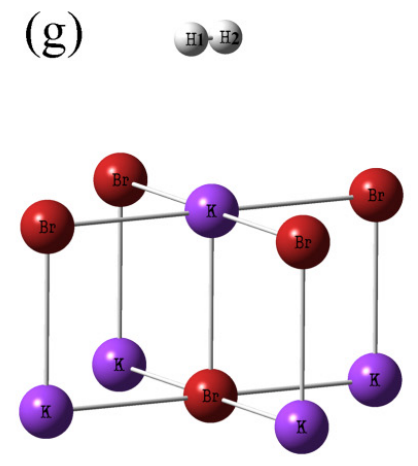

(b)

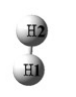

bond length $(\AA)$

H1-H2 0.74405

H1-Cl 3.262

bond angle $\left({ }^{\circ}\right)$

H2-H1-Cl 175.953

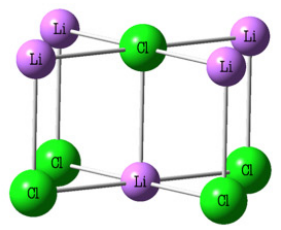

Mulliken charge

H1 0.002

$\begin{array}{ll}\text { H2 } & 0.007\end{array}$

Cl $\mathbf{- 0 . 4 7 1}$

Dipole moment (Debye)

31.6493 (d)
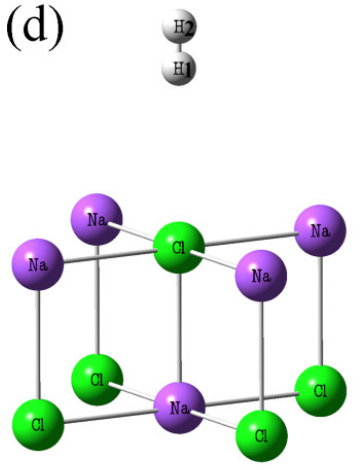

(f)
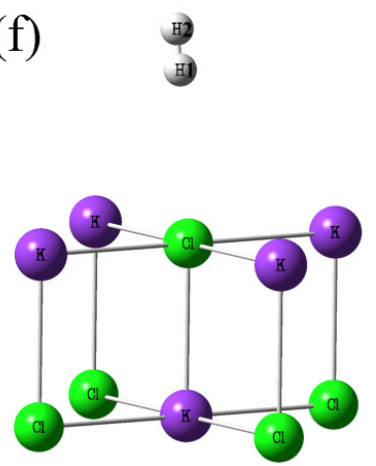

bond length $(\AA)$ $\begin{array}{ll}\mathrm{H} 1-\mathrm{H} 2 & 0.7438 \\ \mathrm{H} 1-\mathrm{K} & 3.0855\end{array}$ $\begin{array}{ll}\text { H1-K } & 3.08551 \\ \text { H2-K } & 3.09187\end{array}$

bond angle $\left({ }^{\circ}\right)$ H1-K-H2 13.83089

Mulliken charge H1 0.013 $\begin{array}{ll}\mathrm{H} 2 & 0.014 \\ \mathrm{~K} & 0.300\end{array}$

K $\quad 0.300$

Dipole moment (Debye) 40.8884 (h) ilis

(h) 반)

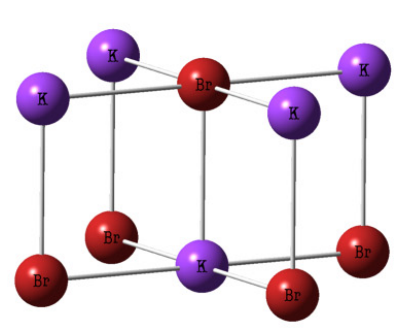

bond length $(\AA \AA)$ H1-H2 0.74431 H1-Cl 3.159

bond angle $\left({ }^{\circ}\right)$ H2-H1-Cl 178.017

Mulliken charge H1 0.001 H2 0.010 $\begin{array}{ll}\text { Cl } & -\mathbf{0 . 5 9 4}\end{array}$

Dipole moment (Debye) 35.1889 bond length $(\AA)$ H1-H2 0.74493

H1-Cl 3.13665

bond angle $\left({ }^{\circ}\right)$ H2-H1-Cl 175.398

Mulliken charge

H1 -0.001

H2 0.013

$\begin{array}{lr}\text { Cl } & \mathbf{- 0 . 7 4 9}\end{array}$

Dipole moment (Debye) 38.9008
Figure 42 Optimized geometry of $\mathrm{H} 2$ adsorbed on $\mathrm{LiCl} \mathrm{Li}$ site (a) and $\mathrm{Cl}$ site (b), $\mathrm{NaCl} \mathrm{Na}$ site (c) and $\mathrm{Cl}$ site (d), $\mathrm{KCl} \mathrm{K}$ site (e) and $\mathrm{Cl}$ (f) site, $\mathrm{KBr} \mathrm{K}$ site (g) and $\mathrm{Br}$ site (h) 
Bushnell and coworkers [96] reported that the hydrogen adsorption energy on $\mathrm{Na}^{+}$is stronger than that on $\mathrm{K}^{+}$. It is pointed out that in their system, the cation is isolated, whereas the hydrogen molecule could be arranged in the 3-D space around the center ion. However, after introducing the anion, the positive charge was partially compensated and now the only space available for attaching hydrogen was the surface, whereby the dominating factor in compounds was that the dipole moment which was determined by both the cation and anion. It is also noted that the anion in the chloride compounds yielded better interaction with hydrogen by end on adsorption mechanism. The adsorption energy was nearly doubled by comparison with the cation in the same compound. This was attributing to the larger ionic charge magnitude and the stronger dipole moment, as summarized in the Figure 42 . The same story was observed in $\mathrm{KBr}$, where the adsorption energy was much stronger $5.307 \mathrm{~kJ} /$ mole for $\mathrm{K}$ and $3.98 \mathrm{~kJ} / \mathrm{mole}$ for Br. The large dipole moment was accounted for the strong interaction energy.

Table 9 The optimized hydrogen bond length $\mathbf{r}_{\mathrm{H}-\mathrm{H}}(\AA)$, Mulliken charge $\mathbf{Q}_{\mathrm{M}}$, adsorption energy Ead (kJ/mole), and dipole moment $\mathrm{D}$ (debye) of hydrogen adsorption on cluster surface

\begin{tabular}{|c|c|c|c|c|}
\hline $\begin{array}{l}\text { Adsorption } \\
\text { site }\end{array}$ & $\mathbf{r}_{\mathrm{H}-\mathrm{H}}(\AA)$ & $\mathbf{Q}_{\mathbf{M}}$ & $E_{a d}(k J / m o l e)$ & $\overline{D(d e b y e)}$ \\
\hline $\mathrm{Li}$ of $\mathrm{LiCl}$ & 0.74327 & 0.359 & 0.57948 & 30.7251 \\
\hline Cl of $\mathrm{LiCl}$ & 0.74405 & -0.471 & 1.16394 & 31.6493 \\
\hline $\mathrm{Na}$ of $\mathrm{NaCl}$ & 0.74350 & 0.450 & 0.94737 & 34.4873 \\
\hline $\mathrm{Cl}$ of $\mathrm{NaCl}$ & 0.74431 & -0.594 & 1.73851 & 35.1889 \\
\hline $\mathrm{K}$ of $\mathrm{KCl}$ & 0.74377 & 0.599 & 1.36453 & 38.7279 \\
\hline $\mathrm{Cl}$ of $\mathrm{KCl}$ & 0.74493 & -0.749 & 2.02167 & 38.9008 \\
\hline $\mathrm{K}$ of $\mathrm{KBr}$ & 0.74381 & 0.300 & 5.30696 & 40.8884 \\
\hline $\mathrm{Br}$ of $\mathrm{KBr}$ & 0.74558 & -0.637 & 3.98134 & 41.3921 \\
\hline
\end{tabular}




\subsubsection{Comparison of experimental and computational results}

The experimental data showed that the trend of salt impregnated samples followed the order of $\mathrm{NiCl}_{2}>\mathrm{KBr}>\mathrm{KCl}>\mathrm{NaCl}>\mathrm{LiCl}$, whereas the computational work of hydrogen adsorption on pure alkaline salts in terms of adsorption energy followed the same trend. Clearly, the computational results were in good agreement with the experimental data. It has been reported that the enthalpies for hydrogen adsorption on activated carbon are in the range of 3-6 kJ/mole [133-135]. From the above calculations, $\mathrm{LiCl}$ had the lowest adsorption energy which was smaller than $3 \mathrm{~kJ} /$ mole so that the adsorption capacity from experiment was below that of plain carbon. By comparing $\mathrm{NaCl}$ and $\mathrm{KCl}$ impregnated samples with original carbon, the adsorption energy was in close value around $3 \mathrm{~kJ} / \mathrm{mole}$ whereas experimentally, the three adsorption curves almost overlapped. KBr impregnated sample exhibited the highest adsorption energy among all the alkaline impregnated samples so that the experimental adsorption curve was above the plain carbon. It is summarized that experimental results were in good agreement with computational works and both demonstrated that electrostatic forces could enhance the hydrogen adsorption and the adsorption energy could be highly increased. 


\section{CHAPTER 7 QUALITATIVE EXAMINATION OF ELECTRIC FIELD ASSISTED HYDROGEN ADSORPTION}

\subsection{Introduction}

Since interaction between hydrogen and polarized substances is still weak at room temperature or at applicable cryogenic conditions $(77 \mathrm{~K})$, by applying extremely high electric fields, the polarity of the materials could be further enhanced so that the interaction of hydrogen could be increased. Moreover, if metallic electrodes are used (e.g. Ni), such high electric fields would make the electrodes of the anode side lose their electrons, temporary becoming ionic electrodes (e.g. $\mathrm{Ni}^{2+}$ ). From previous discussion, such metallic ions may form stronger bonding to hydrogen, so that the hydrogen uptake could be enhanced. Overall, significant adsorption at room temperature may be realized.

\subsection{Experimental}

\subsubsection{High electric field testing device}

A schematic diagram of the whole system is described in Figure 43. A stainless steel gas line was connected to a safety high pressure case constructed with 0.25 inch thick steel. A high pressure stainless steel reactor having a 3000 psi pressure relief valve was put at the center of the steel case. The sample was put in the reactor with the two end electrodes connected to the external electrical system. A high voltage DC power supply device which is capable of providing voltage from 200 volts to 20000 volts from Del High 
Voltage Corp. (model RLPS 100-100 P) was used. A high voltage switch and an electric circuit were connected between the power supply and the sample. The electrical signals coming from the circuit was transformed to the computer by an InstruNet PCI Network Controller (OMEGA Engineering, INC).

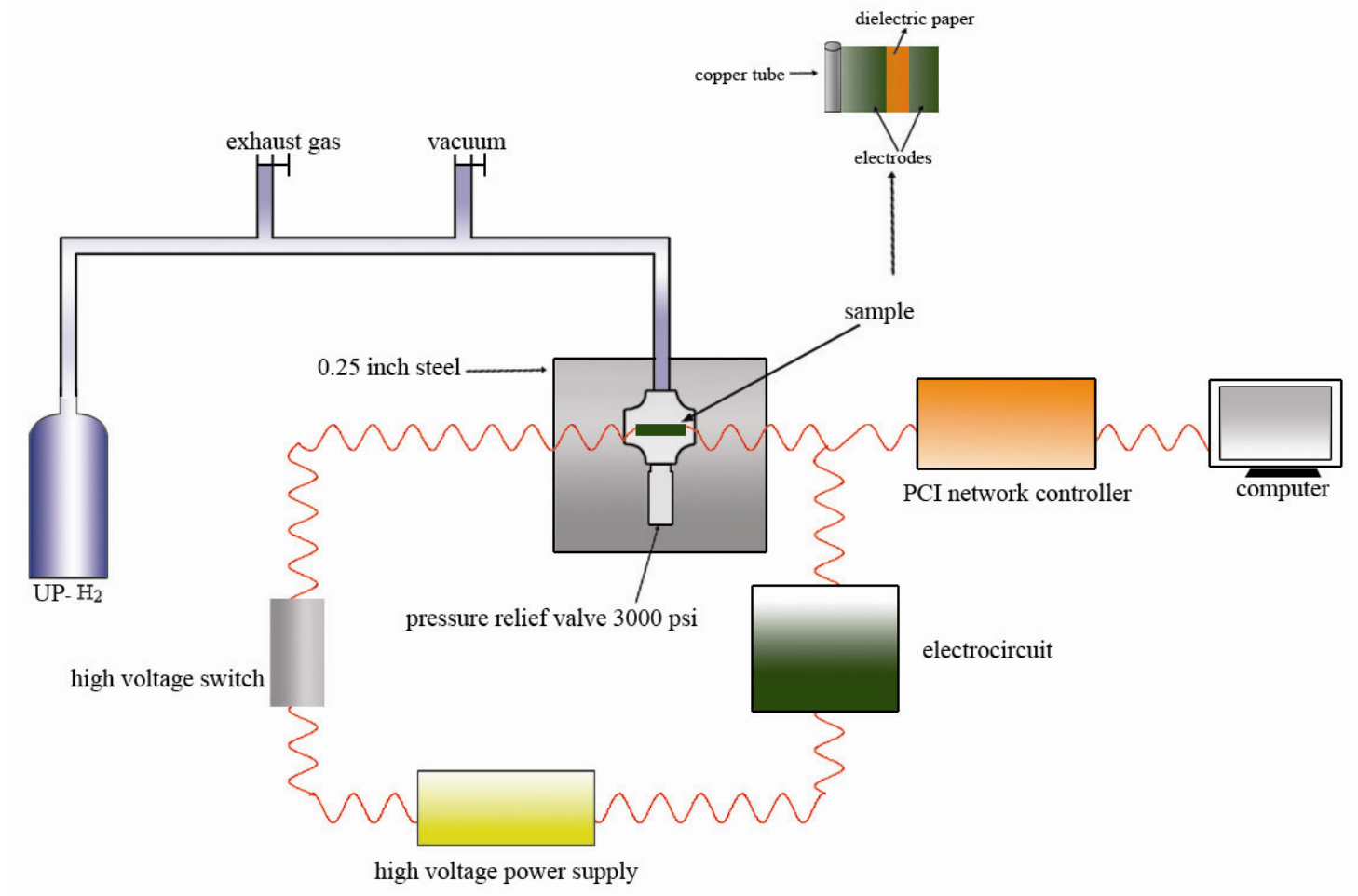

Figure 43 High electrical field testing system

A more detailed diagram of the electrical circuit is shown in Figure 44. There are two parallel voltage lines connected to the power supply. The resistor 2 connected with the reactor was used to record the leakage signals at the charging process. If there are any leaks from the reactor or if the reactor is shorted, the resistor 2 would have significant voltage on it. Resistor 1 in another parallel line was used to record the charge and discharge signals. When the reactor was being charged, there was also a voltage applied 
on resistor 1 and the voltage variation of resistor 1 would indicate how the reactor was being charged. After the charging process, when the high voltage switch was opened, the charges stored in the reactor would be released via the parallel line so that the responding voltage on resistor 1 can give the discharge signals. Both resistor 1 and resistor 2 were connected to a PCI network controller to transform the electrical signals to data signals. And the computer would record these signals and store them in the hard disk. The samples were rolled as the form of an aluminum electrolytic capacitor with two metal layers and two dielectric paper layers. Figure 43 insert shows how the electrodes were constructed.

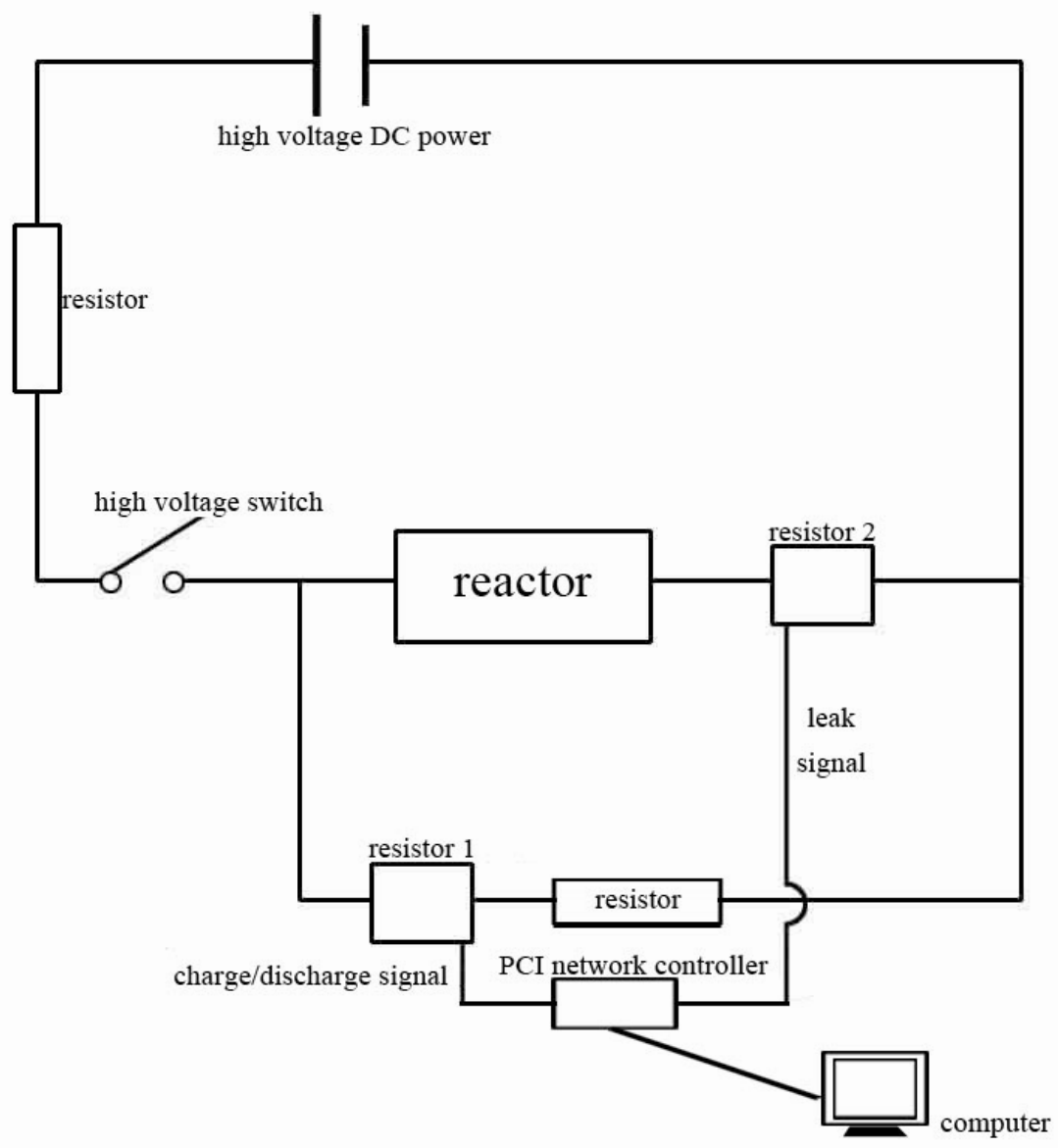

Figure 44 Electric circuit of the high electric field system 
It is proposed that under the high electric field, the electrode itself would be ionized (e.g. $\mathrm{Ni} \rightarrow \mathrm{Ni}^{2+}$ ). And also the hydrogen molecule would be polarized under such high electric fields and then attached to the electrode surface. The surrounding hydrogen molecules may also be polarized by the previous hydrogen molecule and form hydrogen clusters. Moreover, hydrogen molecules may dissociate on the electrode surface becoming hydrogen atoms, which can in turn bond to the ionized electrode. Under extreme condition, hydrogen plasma may form and the hydrogen ions can also form bonding with the electrode surface. A detailed schematic of such a mechanism is shown in Figure 45.

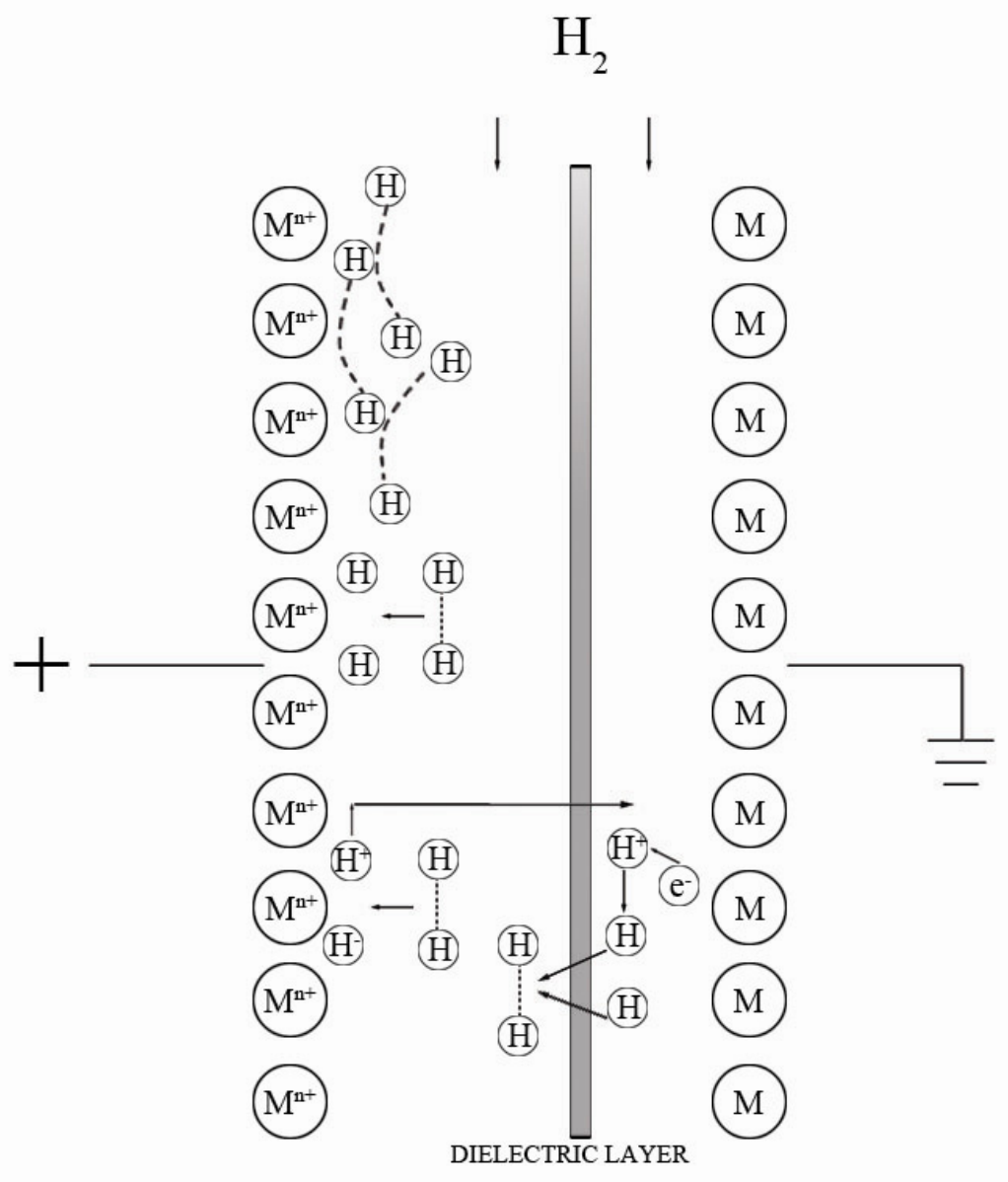

Figure 45 Adsorption mechanism of the electrodes 
When the electric field was released, the hydrogen substances would go back to their normal condition and became hydrogen gas. The electric circuit would give corresponding signals when this phenomenon occurred. In such cases, electrodes with high surface areas would be utilized to have substantial adsorption ability.

\subsubsection{Electrode formation}

Two layers of nickel screen and two layer of dielectric paper were rolled up and tested. The nickel screen was at the dimension of 32.75 inch (length) $\times 1.375$ inch (width) $\times$ 0.003 inch (thickness) and sieve size of 400 mesh $(37 \mu \mathrm{m})$. The dielectric paper was at the same dimension.

\subsection{Results and discussion}

\subsubsection{Nitrogen gas adsorption}

Because nitrogen gas is more easily to be adsorbed than hydrogen, it was first tested in the high electrical device. The experiments were conducted at room temperature. The charging signals from resistor 1 for nitrogen gas at pressure of 50 psi and different voltage are shown in Figure 46. Here the notation of the lines is that $\mathrm{n}$ stands for nitrogen gas, 0050 stands for gas pressure in psi, and 0200 stands for the applied voltage in volts. At the same gas pressure, applying higher voltage may increase the interaction between gas molecules and electrodes. It took less than 0.1 second for the capacitor to reach the saturated voltage indicating that the charging process was very fast. The voltage added on the electrodes increased consistently with the increasing of the applied external voltage. 
However, at $50 \mathrm{psi}$, when the voltage increased to $2000 \mathrm{~V}$, the voltage signals began to fluctuate. This is an indication of the generation of plasma. When the voltage was higher than the breakdown voltage of nitrogen gas, the nitrogen molecules would become high energy state atoms and molecules or be split into positive and negative ions. With these substances especially the ions in the chamber, the electric circuit may temporarily be shorted so that the voltage could not be added on.

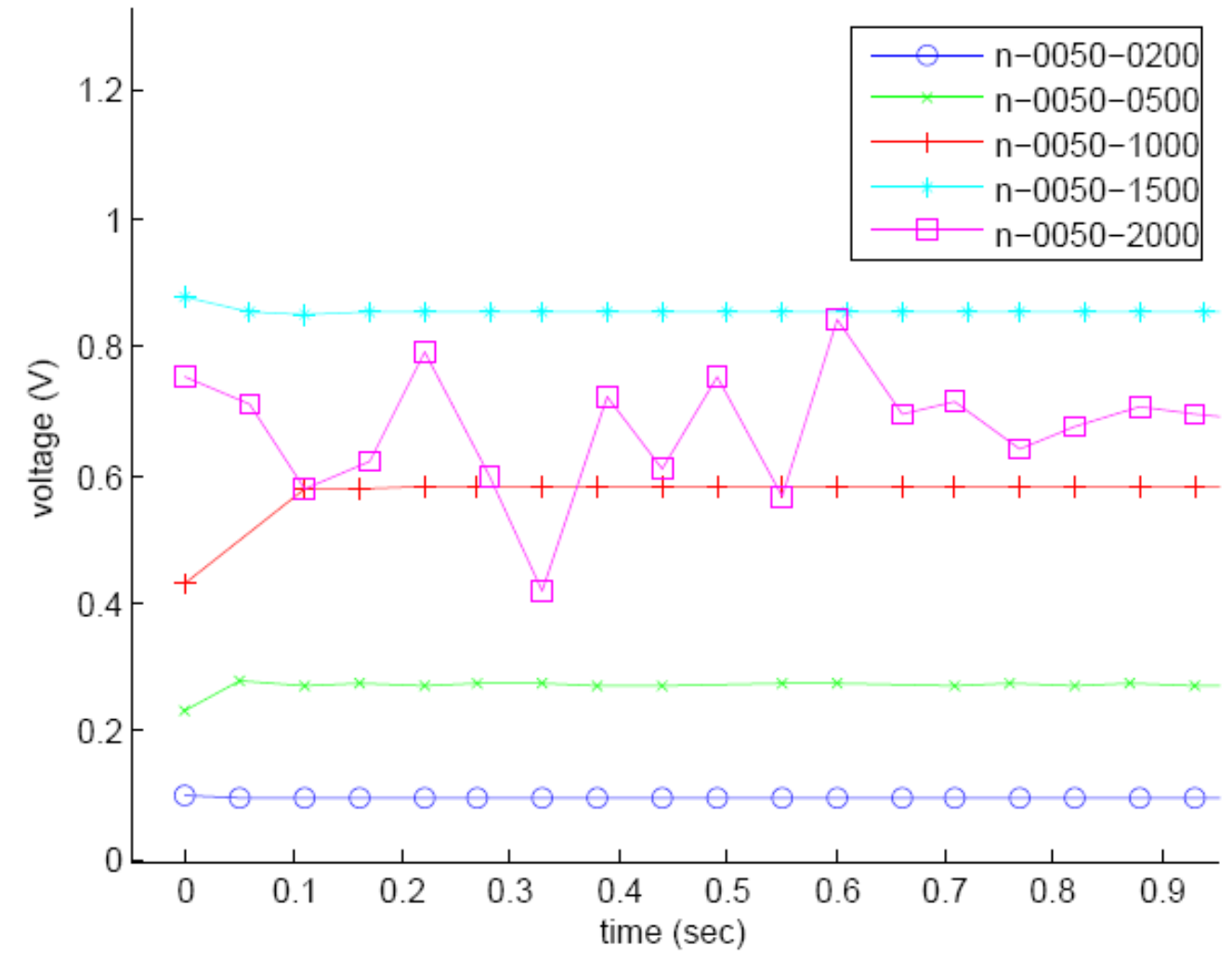

Figure 46 Charging signals at resistor 1 at 50 psi nitrogen pressure, applied voltage $200 \mathrm{~V}$ to $2000 \mathrm{~V}$

The voltage signals from resistor 2 , which gives the leakage signals, also confirmed this opinion. As in Figure 47, the leakage for voltage below 2000 volts was negligible. Big differences occurred when the voltage reached 2000 volts. Here, the voltage leaked was 
very high in comparison with the charging voltage. Plasma is the reason that the charging process at such voltage looked like adding voltage onto a temporary shorted circuit.

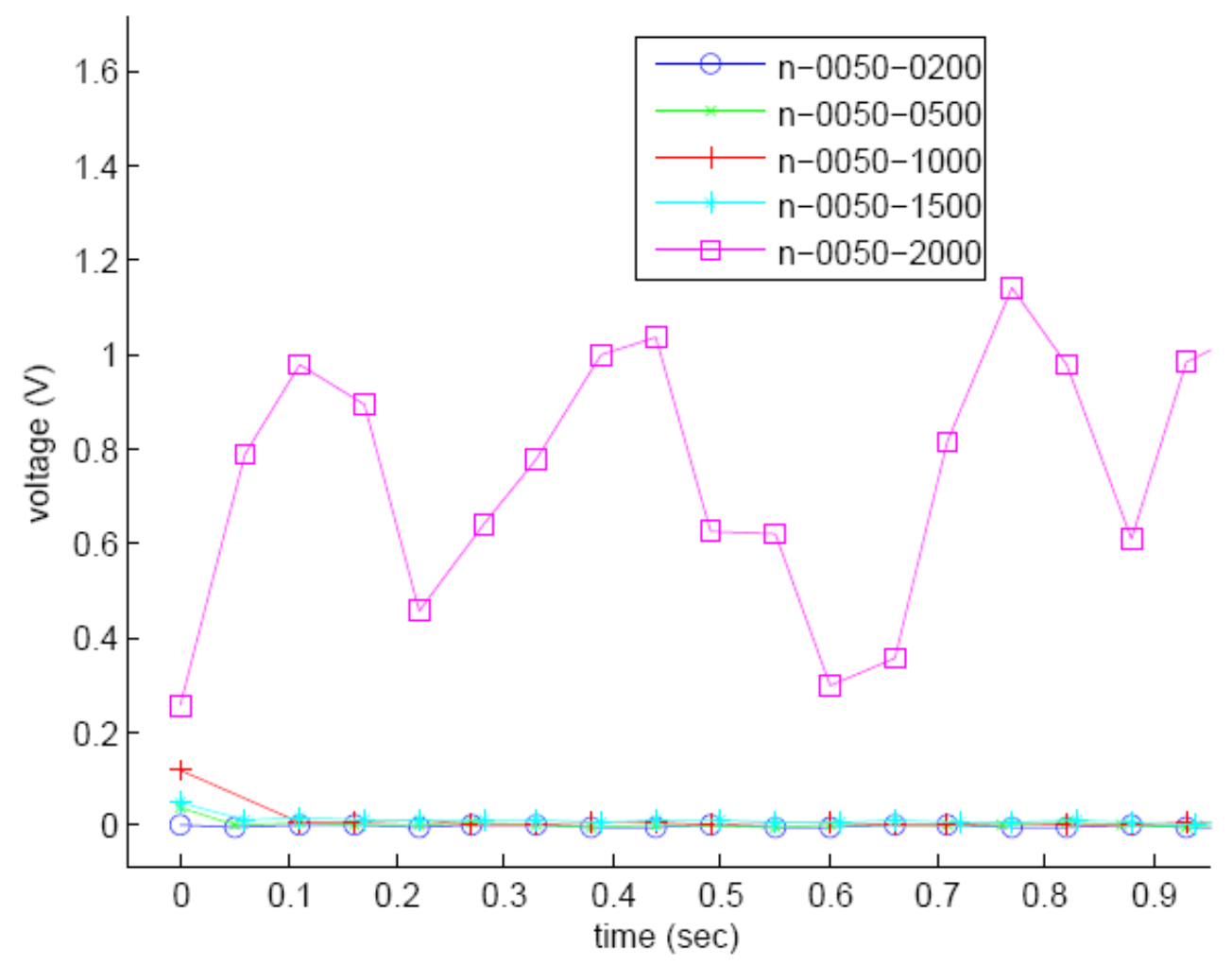

Figure 47 Leakage signals at charging at 50 psi nitrogen pressure, applied voltage $200 \mathrm{~V}$ to $2000 \mathrm{~V}$

When the voltage was released, the discharge began and the signals from resistor 1 presented the discharge magnitude, which was also an indication of how much nitrogen was stored during the charging process. As shown in Figure 48, the discharging lines have the same characteristic shape as the normal discharge line in the capacitor. This was an obvious indication that some charges were stored on the electrodes. The trend lines also showed that at the same gas pressure, the discharging voltage increased with the increasing of charging voltage. This is easy to understand. Based on the equation (9), 
total charges (Q) stored in the capacitor are equal to the product of capacity (C) and applied voltage (V).

$$
Q=C V
$$

Higher voltage would result more charges stored and more nitrogen adsorbed on the electrodes. At 2000 volts, because the plasma was initiated, the actual voltage applied on the capacitor was lower than 2000 volts, so that the final discharging voltage or nitrogen capacity was lower than 1500 volts. Therefore, for gas pressure of $50 \mathrm{psi}, 1500$ volts yielded the best adsorption.

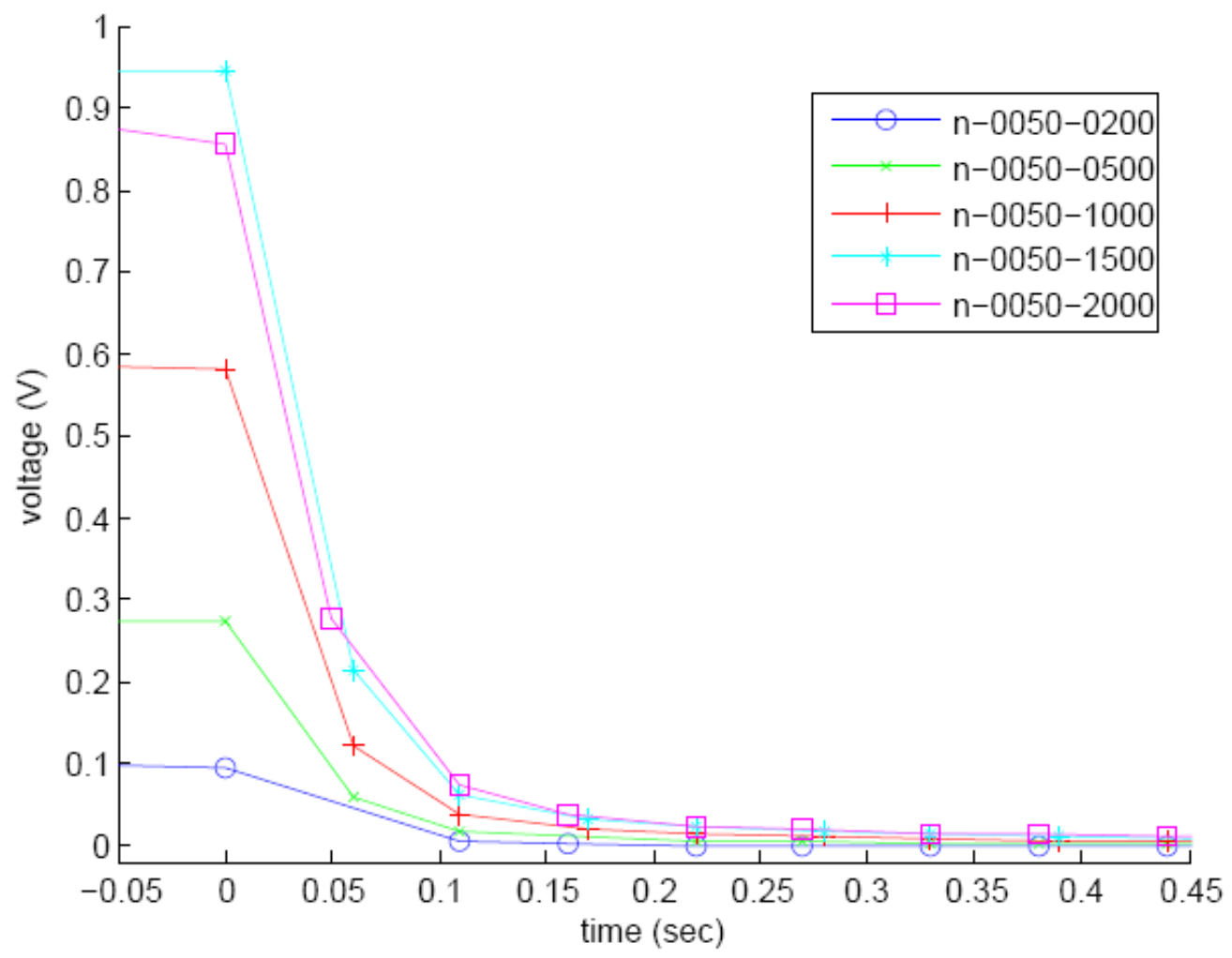

Figure 48 Discharge signals at 50 psi nitrogen pressure, applied voltage $200 \mathrm{~V}$ to $2000 \mathrm{~V}$ 
The nitrogen gas pressure was raised to 150 Psi to study the pressure effects. The charging signals from resistor 1 are shown in Figure 49. The voltage charged on the electrodes increased with the increasing of applied external voltage, the same as the 50 Psi pressure. However, here the signals at 2000 volts didn't show any fluctuations, indicating no plasma was produced. It took about 0.2 seconds for the voltage to become stable. This is because that at higher gas pressure, the gas molecules are harder to be split since much more energy should be applied in order to break down so many molecules. In plasma science, usually plasma is generated under gas pressure of several millitorr. At high gas pressure, usually a field concentrator or higher energy should be used to generate plasma. The magnitude of the voltage applied on the electrode is higher than the magnitude in $50 \mathrm{Psi}$, for example, $1 \mathrm{~V}$ in $150 \mathrm{psi}$ and $0.85 \mathrm{~V}$ in $50 \mathrm{psi}$, both at 1500 volts external voltage. This indicated that more nitrogen species were adsorbed on the electrodes.

From the leakage signals of resistor 2 during charging (Figure 50), the leaking for every external voltage was nearly zero except the beginning of 2000 volts. This also confirms that there was no plasma generated during the charging process. 


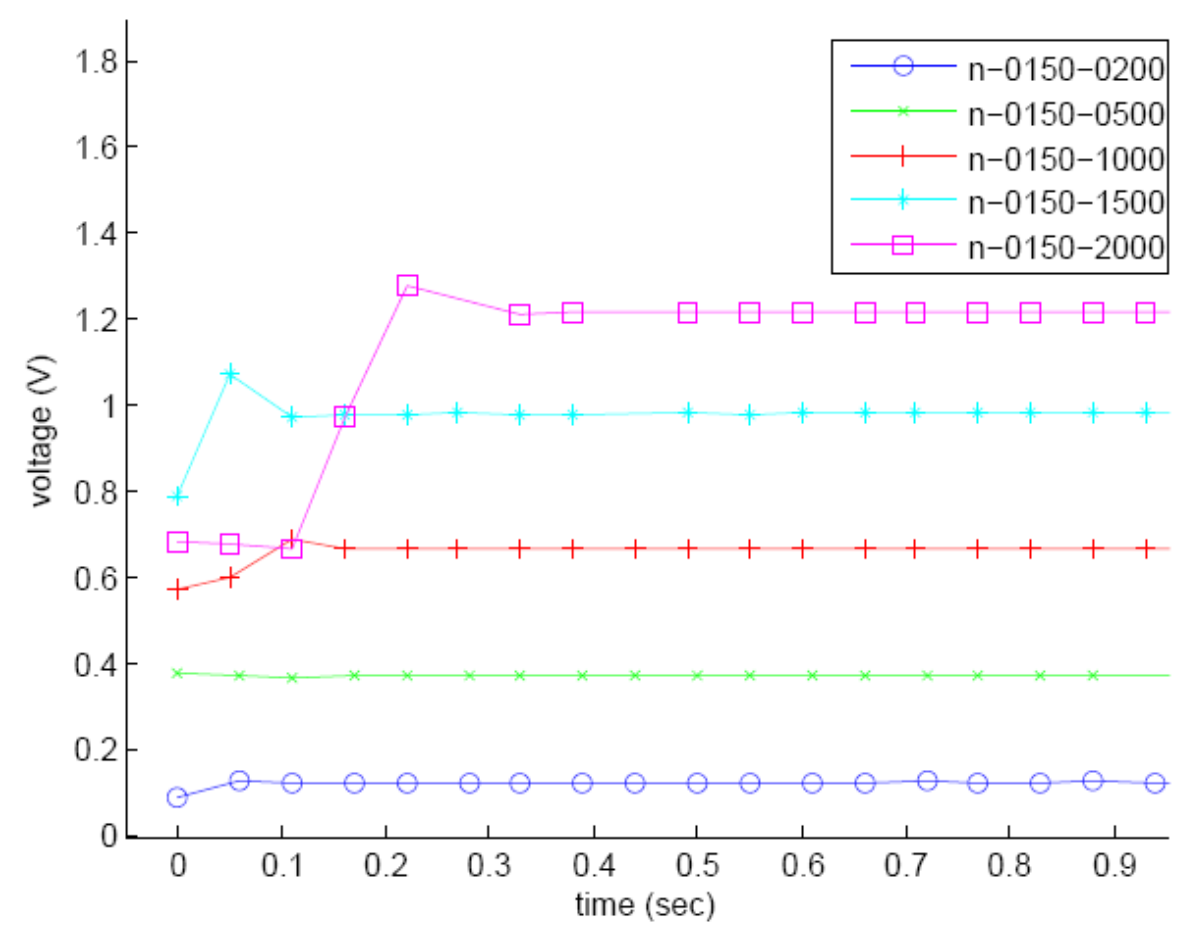

Figure 49 Charging signals at 150 psi nitrogen pressure, applied voltage $200 \mathrm{~V}$ to $2000 \mathrm{~V}$

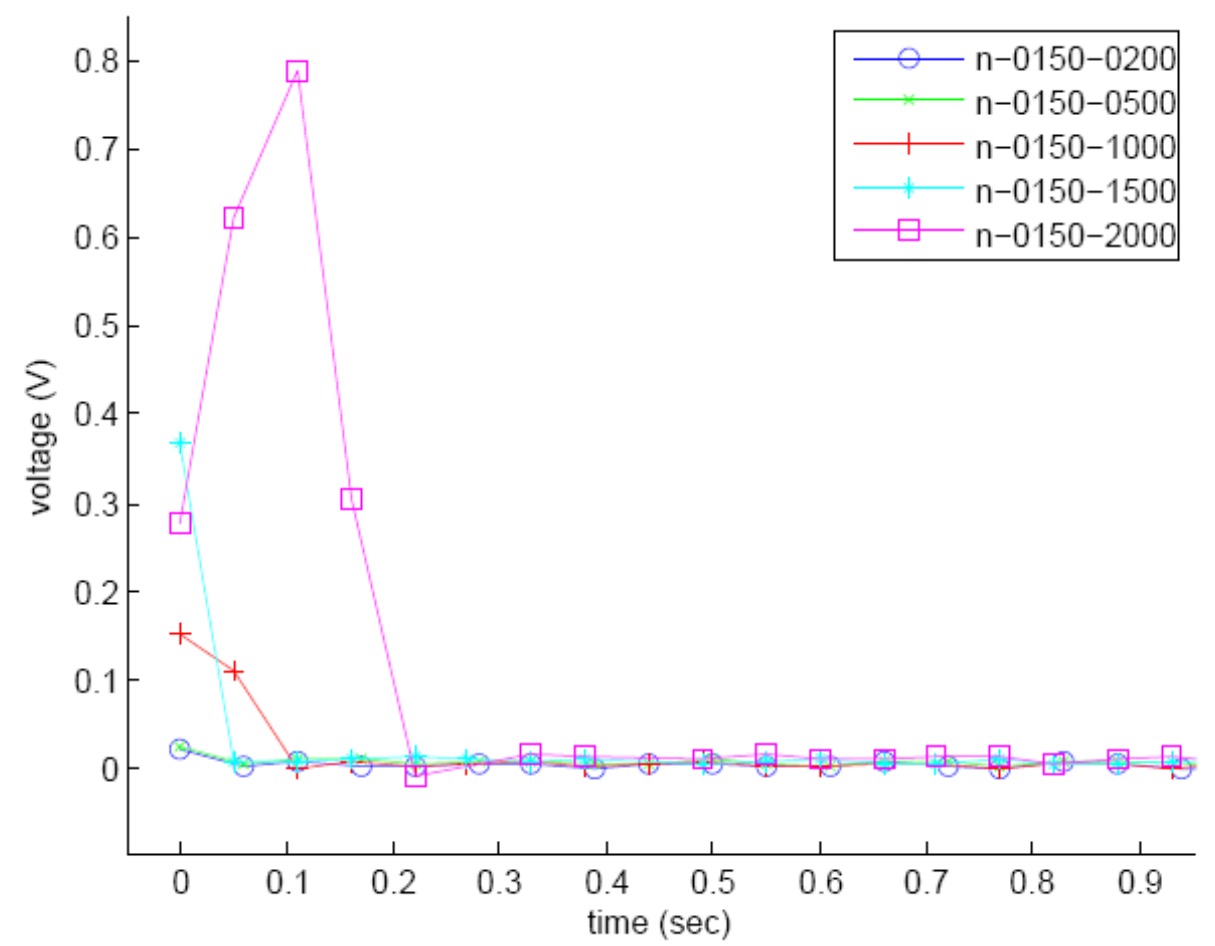

Figure 50 Leakage signals at 150 psi nitrogen pressure, applied voltage $200 \mathrm{~V}$ to $2000 \mathrm{~V}$ 
The discharge signals which are also the characteristics of nitrogen capacity are presented in Figure 51. Here the trend is very clear. Higher external voltage would result in better adsorption. By comparing with the results of $50 \mathrm{psi}$, the discharging magnitude was higher, which also indicated that the adsorption was better at higher pressure. Overall, higher pressure and higher applied voltage would favor nitrogen adsorption.

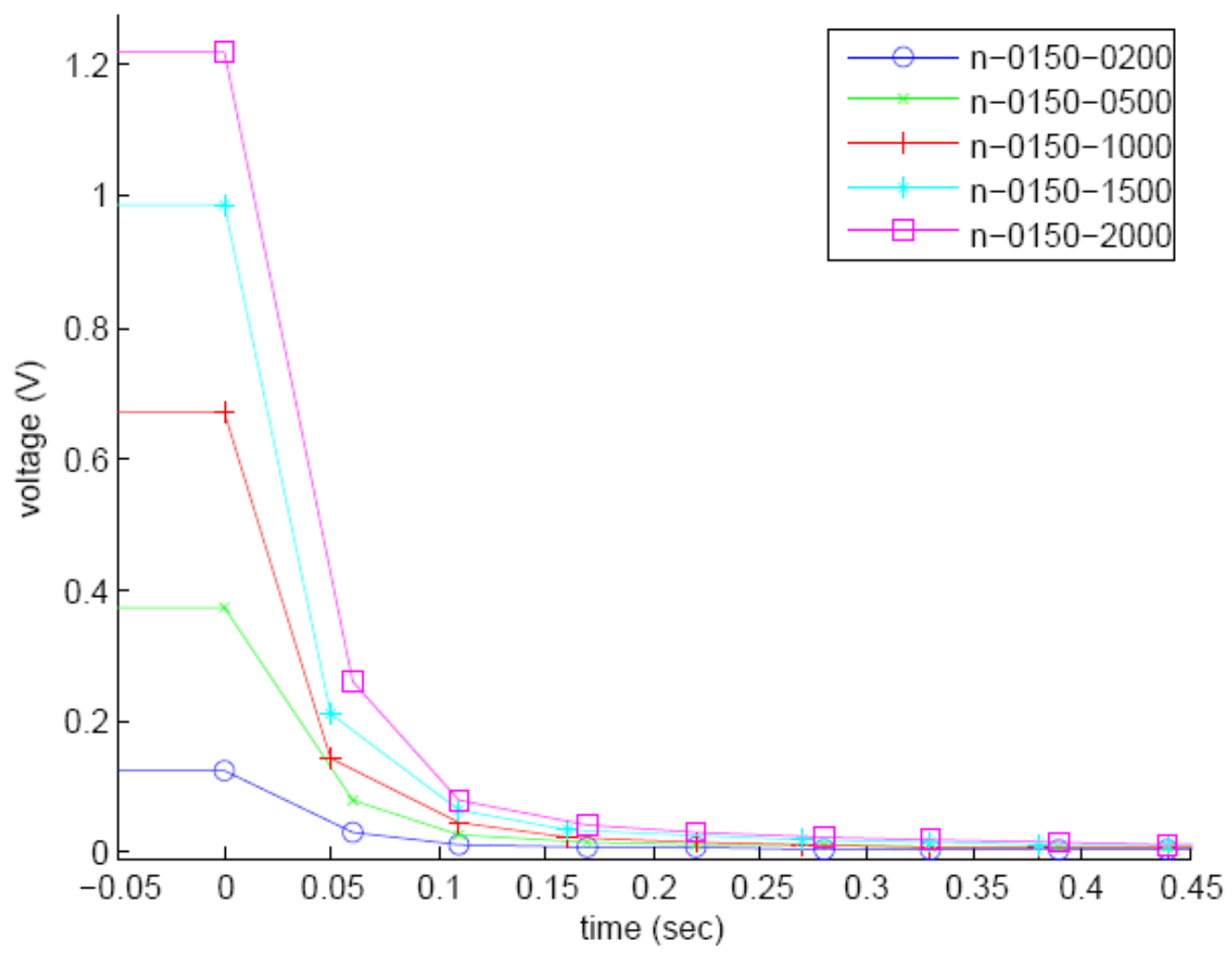

Figure 51 Discharge signals at 150 psi nitrogen pressure, applied voltage $200 \mathrm{~V}$ to $2000 \mathrm{~V}$

\subsubsection{Hydrogen gas adsorption}

Hydrogen gas was tested the same way as nitrogen gas. The charging signals of resistor 1 for hydrogen pressure of 40 Psi are shown in Figure 52. The trend was the same as nitrogen gas; higher external voltage would result in higher voltage on the electrodes. 
However, at 1500 volts and 2000 volts, plasma was generated as presented by the fluctuated voltage signals. The voltage could not be added on under such circumstance.

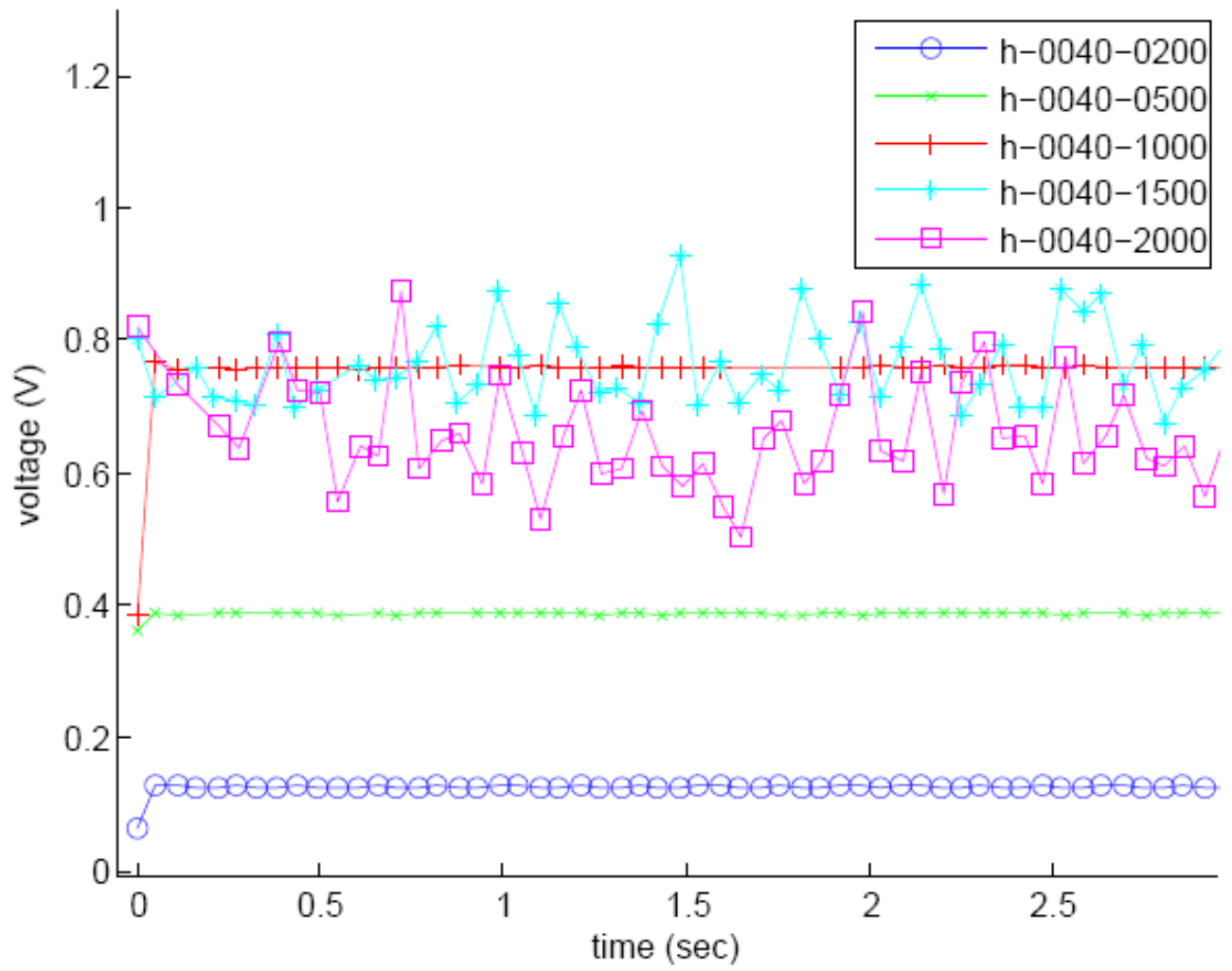

Figure 52 Charging signals at 40 psi hydrogen pressure, applied voltage $200 \mathrm{~V}$ to $2000 \mathrm{~V}$

A more presented look about the plasma is shown in Figure 53 as the leakage signals during charging. The voltage leak for 1500 volts and 2000 volts were very large comparing nearly zero leaks at other voltages. Plasma was produced and the condition at 2000 volts was more severe.

The hydrogen adsorption capacity was presented by the discharging curve on resistor 1 . As shown in Figure 54, higher voltage yielded better hydrogen adsorption ability. However, with the occurrence of plasma, part of the external applied high voltage was 
wasted in the short circuit, so that the overall adsorption was equal or less than 1000 volts.

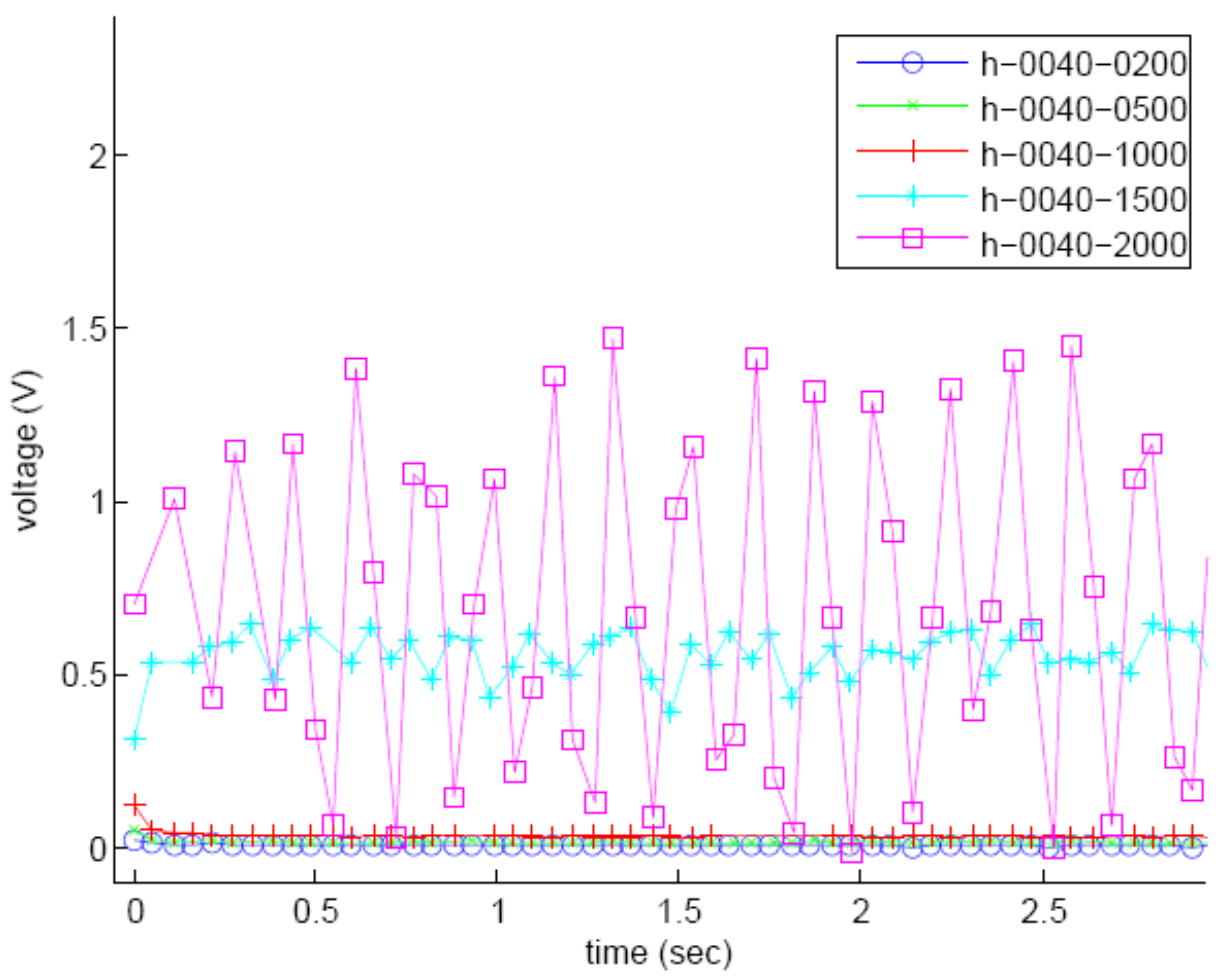

Figure 53 Leakage signals at 40 psi hydrogen pressure, applied voltage $200 \mathrm{~V}$ to $2000 \mathrm{~V}$

More experiments at higher hydrogen gas pressure were also conducted. Selected results at charging process are shown in Figure 55. At 200 psi, there was still plasma generated as presented at the swing charging signals at high voltage. With higher pressure, the signals became stable at every voltage level because more hydrogen molecules needed higher energy to generate plasma. 


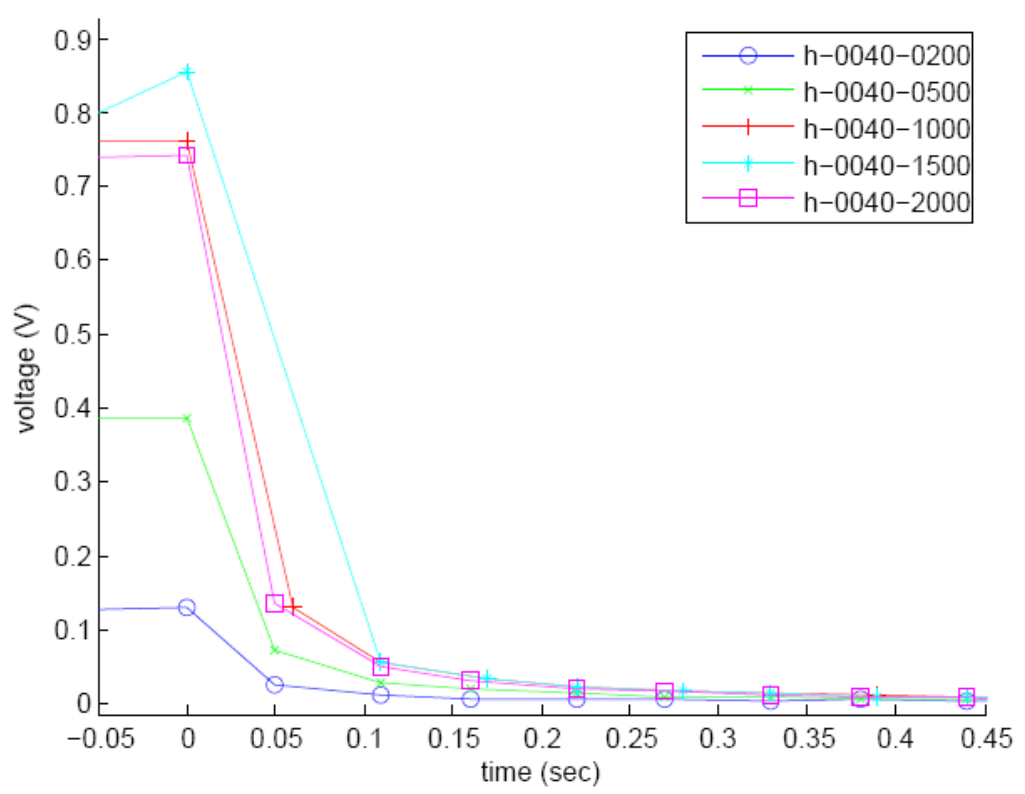

Figure 54 Discharge signals at 40 psi hydrogen pressure, applied voltage $200 \mathrm{~V}$ to $2000 \mathrm{~V}$
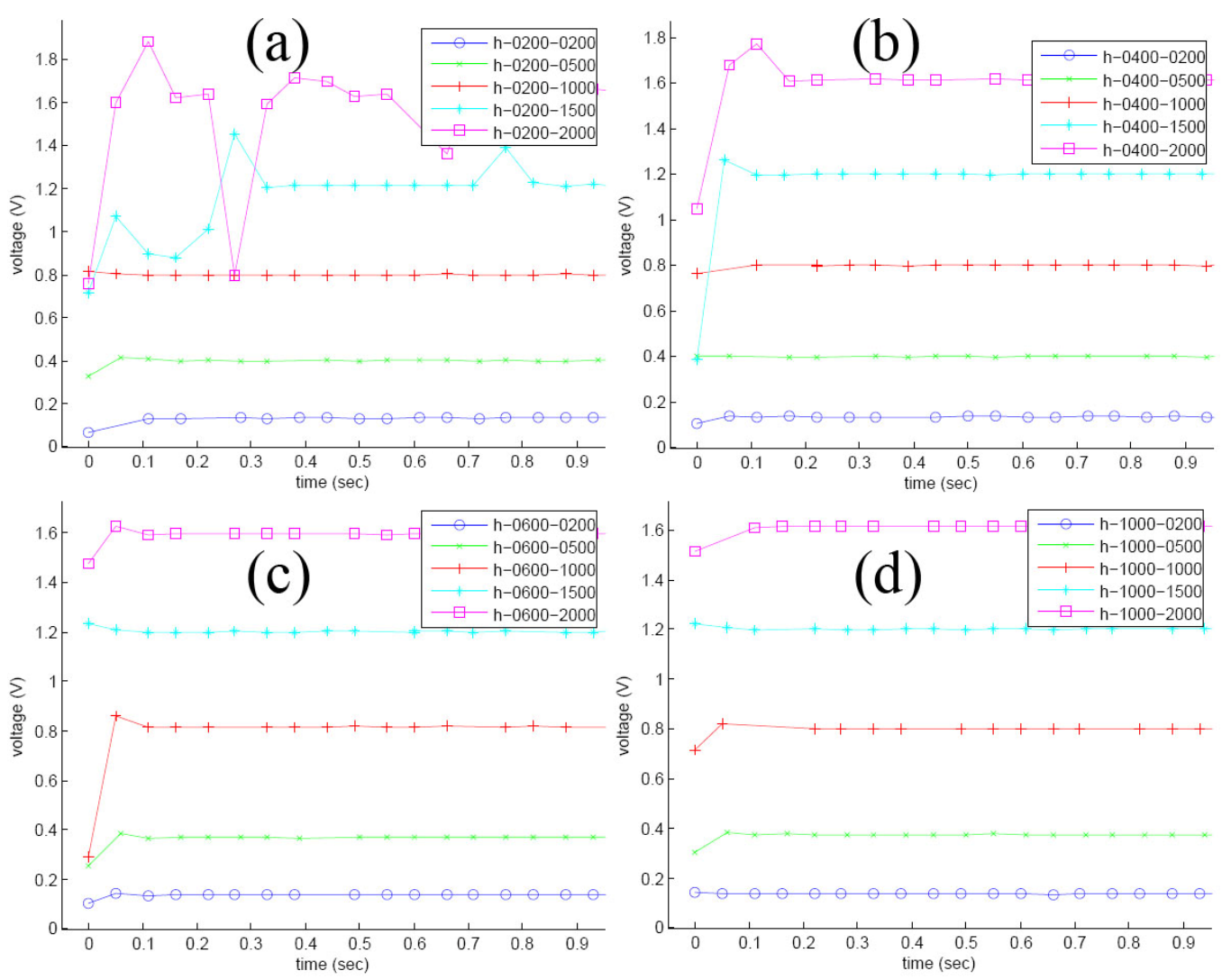

Figure 55 Charging signals at hydrogen pressure (a) 200 psi, (b) 400 psi, (c) 600 psi, (d) 1000 psi, applied voltage $200 \mathrm{~V}$ to $2000 \mathrm{~V}$ 
Their corresponding discharge signals are shown in Figure 56. Higher external voltage would result in better hydrogen adsorption at any gas pressure. However, with the increasing of the gas pressure from 200 psi to 1000 psi, the magnitude of discharge or in other words, the hydrogen adsorption capacity didn't increase. For example, at 2000 volts, the highest discharge point for every pressure was about the same, which was about 1.6 volts. On the other hand, by comparing with 40 psi, the highest point at 2000 volts was 0.73 . Obviously, the difference was caused by the generated plasma at 40 psi that the total voltage was not added on. If we compare all gas pressure at 1000 volts, where no plasma was produced, the discharging point was 0.77 for 40 psi and around 0.8 for other pressure. Therefore, increasing pressure from 40 psi to 200 psi was beneficial for hydrogen adsorption. However, further higher pressure was not useful.

A closer look of the discharging signals of different gas pressure and the same applied external voltage is shown in Figure 57. At any applied voltage, changing pressure from 200 psi to 1000 psi didn't show any significant effects on the hydrogen adsorption. On the other hand, increasing applied voltage was beneficial. This is because that higher voltage would increase the interaction between hydrogen species and the electrodes so that the total hydrogen adsorbed would be increased. 

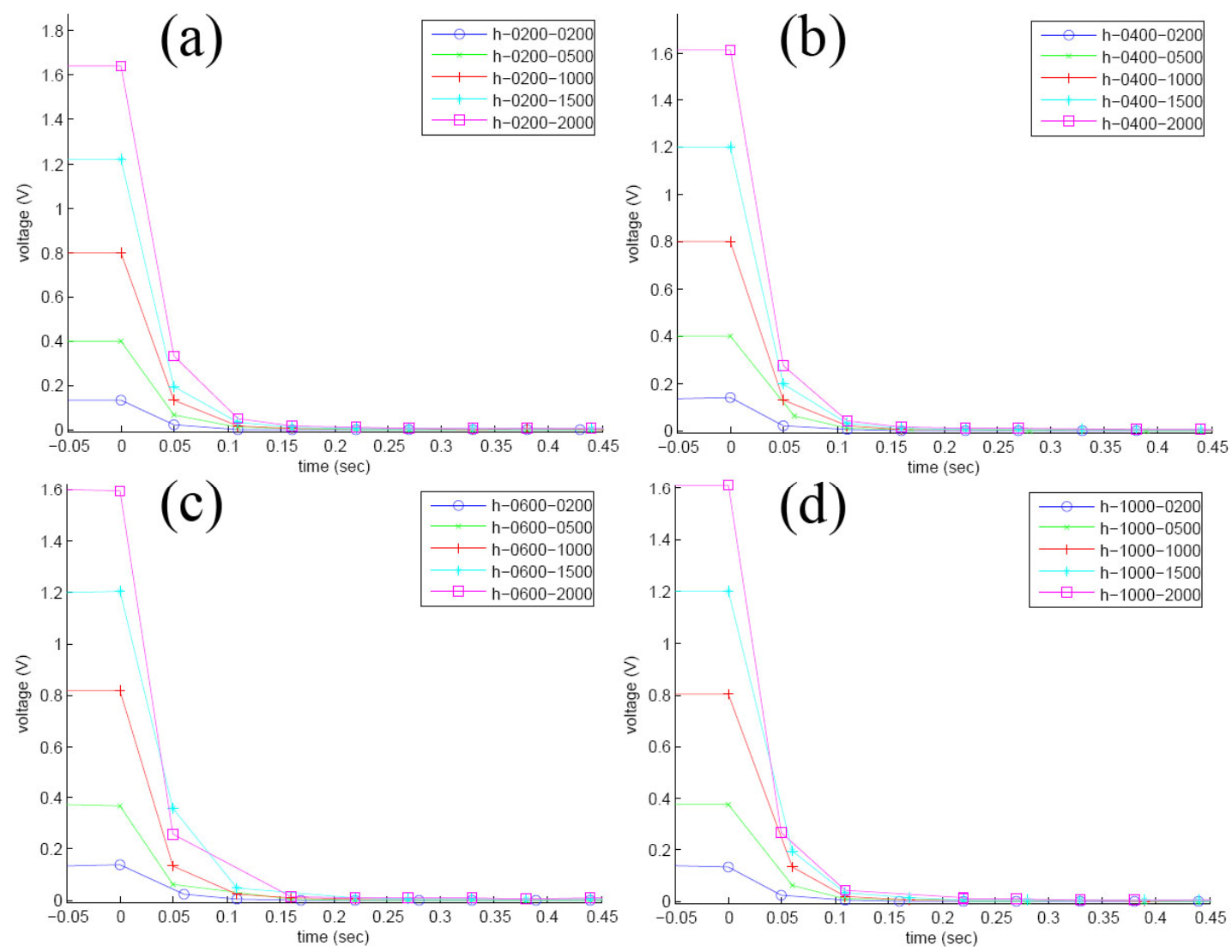

Figure 56 Discharge signals at hydrogen pressure (a) 200 psi, (b) 400 psi, (c) 600 psi, (d) 1000 psi, applied voltage $200 \mathrm{~V}$ to $2000 \mathrm{~V}$

For the pressure, a possible explanation is that when the pressure was increased from 40 psi to $200 \mathrm{psi}$, the electrode surface was not saturated with the adsorbed hydrogen, so that more hydrogen would be attached to the electrode at higher gas pressure. However, when the pressure was above $200 \mathrm{psi}$, the electrode surface was total covered with hydrogen species so that there were no space for other hydrogen to be attached on even the total number of hydrogen molecules was in large amount. 

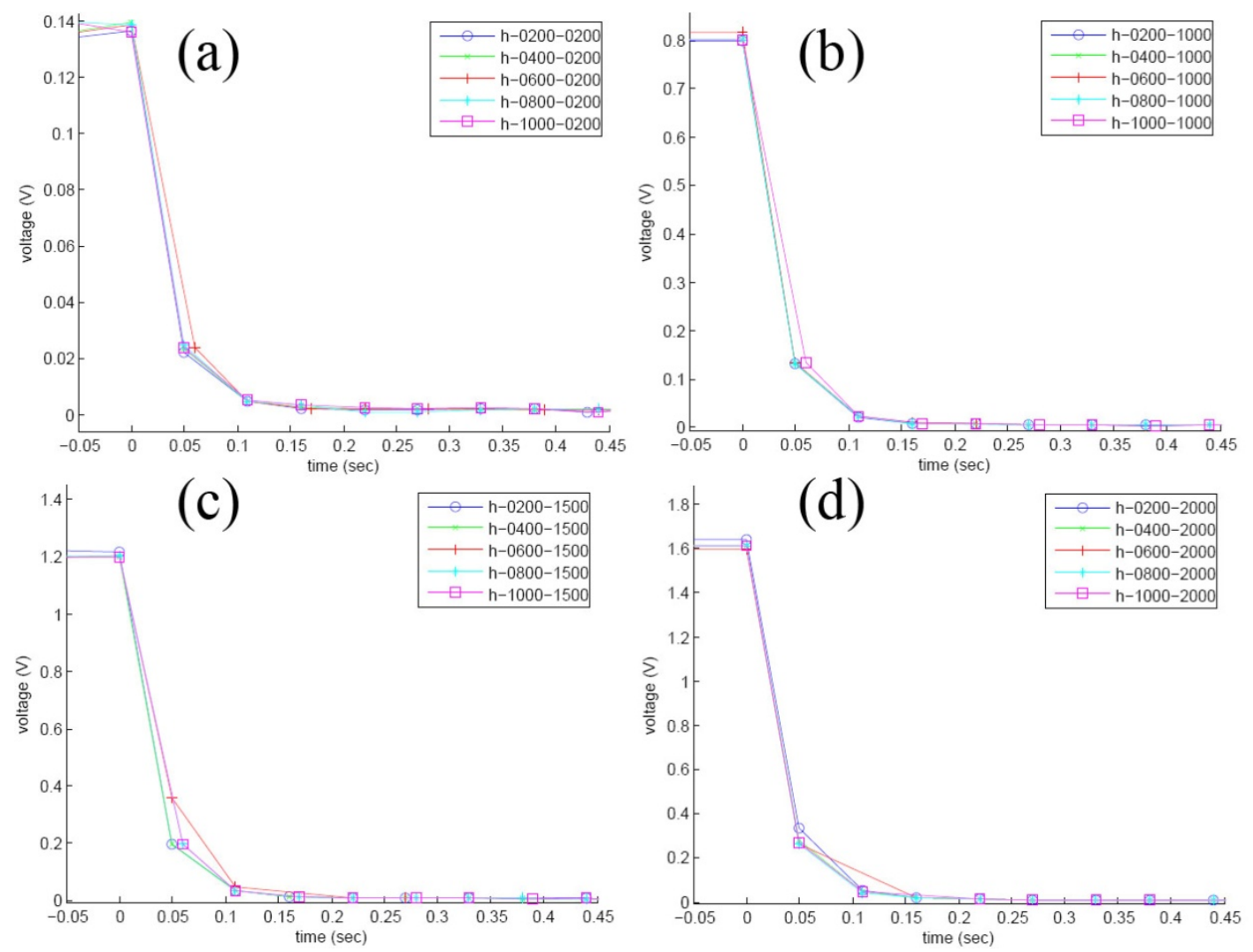

Figure 57 Discharge signals at applied voltage (a) $200 \mathrm{~V}$, (b) $1000 \mathrm{~V}$, (c) $1500 \mathrm{~V}$, (d) $2000 \mathrm{~V}$, Hydrogen pressure from 200 psi to $1000 \mathrm{psi}$ 


\section{CHAPTER 8 QUANTITATIVE EXAMINATION OF ELECTRIC FIELD ASSISTED HYDROGEN ADSORPTION ON POROUS METAL OXIDES}

\subsection{Introduction}

After successfully observing that external electric fields showed potential enhancement on hydrogen adsorption both in experimental and by computational means, a quantitative examination was carried out to determine how much enhancement could be generated by applying the electric fields on storage materials.

Porous metal oxides have been researched and used extensively for catalyst support [136], gas storage [137-138], and sensors [139]. Among these, nickel oxides and magnesium oxides have received extensive focus due to their inexpensive costs and better properties. Moreover, due to increasing current interest in energy storage, supercapacitors have been researched extensively in recent years. Besides carbon materials, porous metal oxides including nickel oxides have been researched as alternative materials to increase capacity [140-141]. Both nickel oxides and magnesium oxides are ionic solids and have rocksalt structure, making them ideal materials for studying electrostatic attraction of hydrogen molecules. The major task of developing metal oxides for hydrogen storage is to generate oxides with high surface area and coordinative unsaturation of the metal cation sites [138]. Surfactant templating growth of nano sized metal oxides has been 
recently developed to achieve mesorporous oxides with high surface area, and high thermal and hydrothermal stability [142-143].

Besides the intrinsic electrostatic induced dipole, externally applied electrical potential could further enhance the electrostatic effects. Piezoelectric materials are substances that can generate electrical potential in response to the external stress [144]. Under high hydrostatic hydrogen gas pressure, substantial voltage potential could be generated across the positive and negative sides of the piezoelectric materials [145]. By embedding the piezoelectric material into the ionic adsorbent, the electrostatic interaction could be further enhanced so that the total hydrogen storage could be remarkably increased.

Here highly porous nickel oxide and magnesium oxide have been synthesized by surfactant directed growth and studied for hydrogen storage. A commercially available piezoelectric material PMN-PT was applied to generate external electric field across the oxides and corresponding effects on hydrogen adsorption have been investigated. Moreover, DFT computational work has been carried out on hydrogen adsorption on oxide surfaces and the effects of external electric field on adsorption have also been studied to reveal underlying principles. 


\subsection{Experimental}

\subsubsection{Synthesis of porous oxides}

The porous oxides were synthesized following previously developed techniques $[143,146]$. Typically, for porous nickel oxides, $13.19 \mathrm{~g} \mathrm{NiCl}_{2} \cdot 6 \mathrm{H}_{2} \mathrm{O}, 32.01 \mathrm{~g}$ sodium dodecyl sulfate (SDS), $100 \mathrm{~g}$ urea, and $60 \mathrm{ml}$ DI water were magnetic stirred at $40{ }^{\circ} \mathrm{C}$ for 1 hour to obtain a transparent solution. For porous magnesium oxides, $10.17 \mathrm{~g}$ $\mathrm{MgCl}_{2} \cdot 6 \mathrm{H}_{2} \mathrm{O}, 28.84 \mathrm{~g}$ SDS, $90 \mathrm{~g}$ urea, and $54 \mathrm{ml}$ DI water were mixed. And then the mixture was transferred to an $80^{\circ} \mathrm{C}$ oil bath and further reacted for 6 hours. The obtained slurry was cooled and filtrated, and then dried at $120{ }^{\circ} \mathrm{C}$ overnight. The solids were then ground and washed several times with ethanol to remove the surfactant. The final products were dried in oven and then heated at different temperature for various times to obtain porous oxides.

\subsubsection{Platinum deposition}

The platinum deposition on porous nickel oxide was prepared by the wet impregnationreduction method [147-149]. Typically, $0.6 \mathrm{~g}$ porous $\mathrm{NiO}$ was mixed with $80 \mathrm{ml} \mathrm{DI}$ water in a $90^{\circ} \mathrm{C}$ oil bath with a continuous Argon gas purge. A $6.4 \mathrm{ml} 50 \mathrm{mM} \mathrm{H}_{2} \mathrm{PtCl}_{6}$ solution was added to the slurry. A $2 \mathrm{M} \mathrm{NaOH}$ solution was used to adjust the slurry $\mathrm{PH}$ to 11-13. Subsequently, a $3.75 \mathrm{ml} \mathrm{HCHO} \mathrm{(37 \% )} \mathrm{was} \mathrm{added} \mathrm{dropwise} \mathrm{and} \mathrm{stirred} \mathrm{continuously} \mathrm{for}$ $2 \mathrm{~h}$. The final products were washed, filtrated and dried in air. 


\subsubsection{Characterization of the synthesized oxides}

The surface area and pore size distribution were analyzed by using a Micromeritics ASAP2000 instrument. The samples were evacuated by heating at $200{ }^{\circ} \mathrm{C}$ under vacuum for 12 hours before testing. The tubing containing the degassed samples were then sealed and carefully transferred to a balance to obtain the sample weight.

Differential thermo analysis was performed on NET DSC404 at a heating rate of 10 $\mathrm{K} / \mathrm{min}$. X-ray diffraction (XRD) analysis was carried out on a Scintag XDS2000 Powder Diffractometer at a scan rate of $0.08 \mathrm{o} / \mathrm{s}$ with $\mathrm{Cu}$ radiation at $45 \mathrm{kV}, 35 \mathrm{~mA}$.

A Hitachi S-4700 field emission-scanning electron microscopy (FE-SEM) was used to examine the microstructure of the samples. The incorporated Energy Dispersive Analysis (EDS) was employed to analyze the element concentrations.

\subsubsection{Hydrogen storage measurements}

Hydrogen adsorption at pressure between 0.1 bar and 80 bar was measured by using static volumetric techniques with an automatic Sieverts' apparatus (PCT-Pro 2000 from Hy-Energy LLC) at both room temperature and 77k. Previous to the test, samples were degassed extensively at $200{ }^{\circ} \mathrm{C}$ for 12 hours and then carefully moved into the sample holder and evacuated again at $100{ }^{\circ} \mathrm{C}$ for 2 hours to ensure the remove of any contaminations on the sample surface. Around 100-300 mg of the sample was used in each test, and ultra pure (99.999\%) hydrogen and helium gases were used for all calibrations and measurements. 
A single crystal PMN-PT disk was acquired from Morgan Electro Ceramics, $5 \mathrm{~mm}$ in length and width, and $1 \mathrm{~mm}$ in thickness. As shown in Figure 58, the positive side of the PMN-PT was covered by a non-conductive thin $\mathrm{BaTiO}_{3}$ film to prevent electron transfer. The film was made by $\mathrm{BaTiO}_{3}$ powders and glue. The PMN-PT was immersed in the tested adsorbents and both were positioned in a glass tube which was placed in a stainless steel sample holder. In such arrangement, the electrons from the PMN-PT were not able to transfer to the outside so that the electric field could be preserved inside the adsorbents. The $\mathrm{g}_{33}$ parameter of the PMN-PT is $15.8 \times 10^{-3} \mathrm{Vm} / \mathrm{N}$, which means that the PMN-PT can generate significant voltage under pressure.

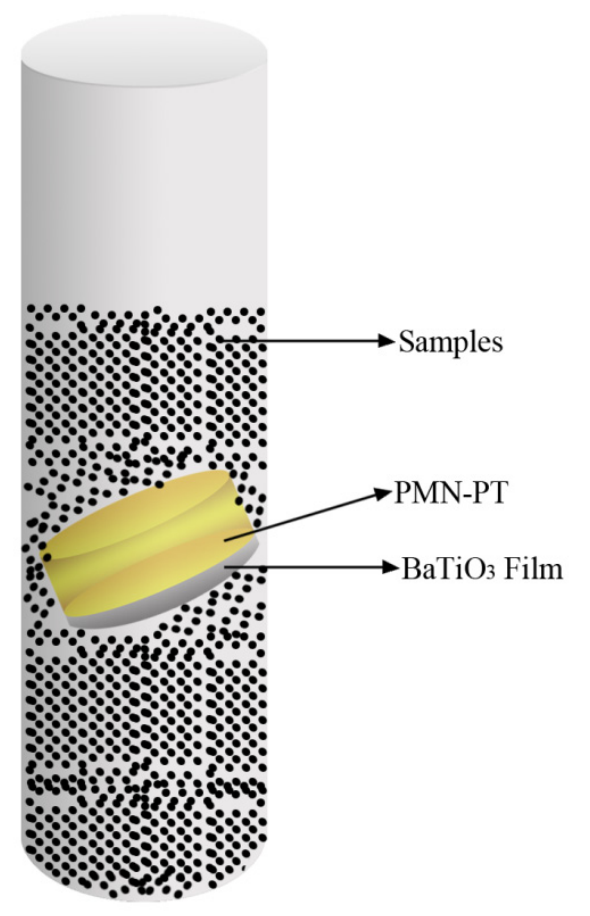

Figure 58 Schematic of sample holder arrangement 


\subsubsection{Computational method}

Similar computational methods as described in Chapter six were used. The $\mathrm{M}_{5} \mathrm{O}_{5}$ oxide clusters were first embedded in $13 \times 13 \times 13$ point charges to find the value of the point charges that can well reproduce the cluster bond length. Then the clusters were moved to the surface and hydrogen adsorption was calculated. For the calculation of the effects of the external electric field, the applied field was applied along the vertical direction at a field strength of $0.001 \mathrm{au}, 0.005 \mathrm{au}$, and $0.015 \mathrm{au}$, which equals to $5.14 \times 10^{8} \mathrm{~V} / \mathrm{m}$, $2.57 \times 10^{9} \mathrm{~V} / \mathrm{m}$, and $7.71 \times 10^{9} \mathrm{~V} / \mathrm{m}$, respectively. The total binding energy was calculated by the difference between the total energy of the whole adsorption system and the total energy of the separate reactants before combination, as presented in equation (10):

$$
M_{5} O_{5}+H_{x} \rightarrow M_{5} O_{5} H_{x}
$$

All the calculations were performed by using DFT/B3LYP method and a basis set of 6-31 G(d) in GAUSSIAN 03 program [118]. DOS analysis was visualized in GAUSSSUM software [150].

\subsection{Results and discussion}

\subsubsection{Porous nickel oxides}

\subsubsection{Characterization of as synthesized oxides}

The XRD graph of as synthesized porous nickel hydroxide is shown in Figure 59. The pattern is a good match of nickel hydroxide hydrate $3 \mathrm{Ni}(\mathrm{OH})_{2} \cdot 2 \mathrm{H}_{2} \mathrm{O}$. The wide peak interspace indicated the small particle size and low degree of crystallization. 
This is consistent with the SEM analysis of the synthesized particles. As in Figure 60, the particles are interconnected with each other and the particles size is around 100-300 nm.

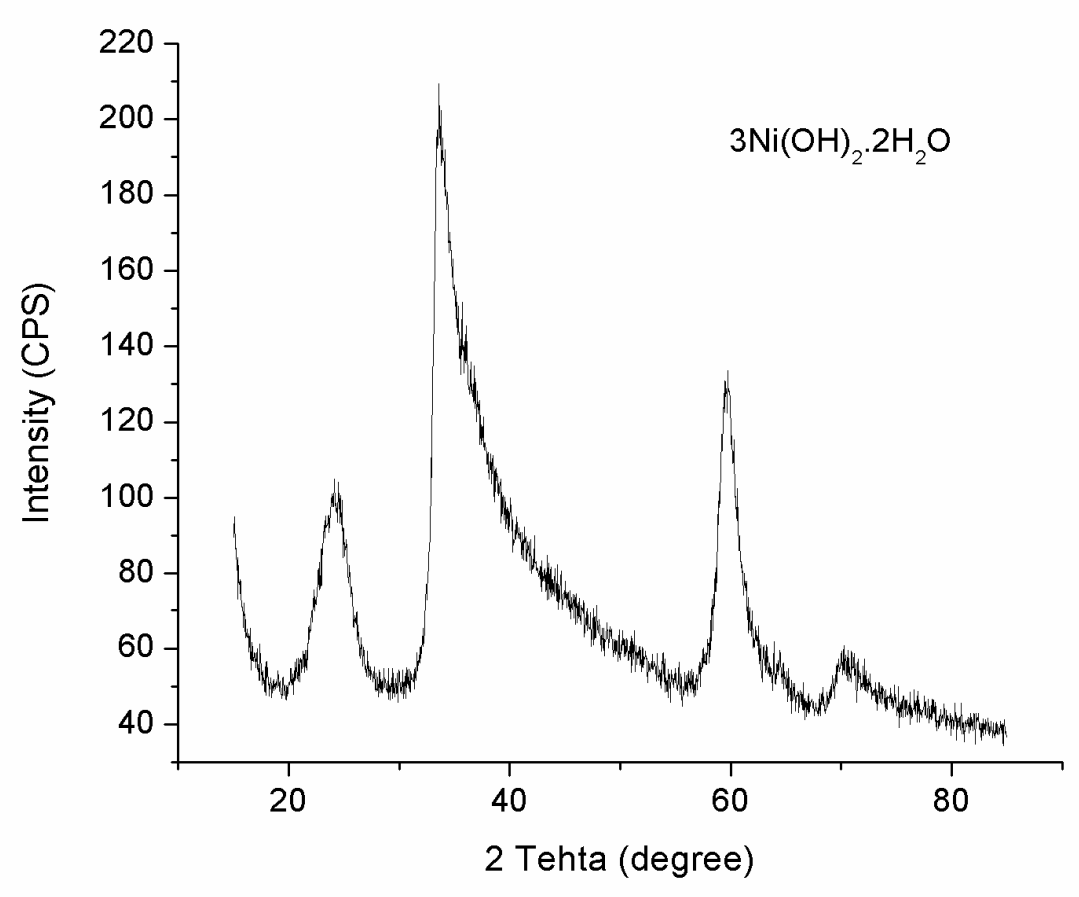

Figure 59 XRD pattern of as-synthesized nickel oxide
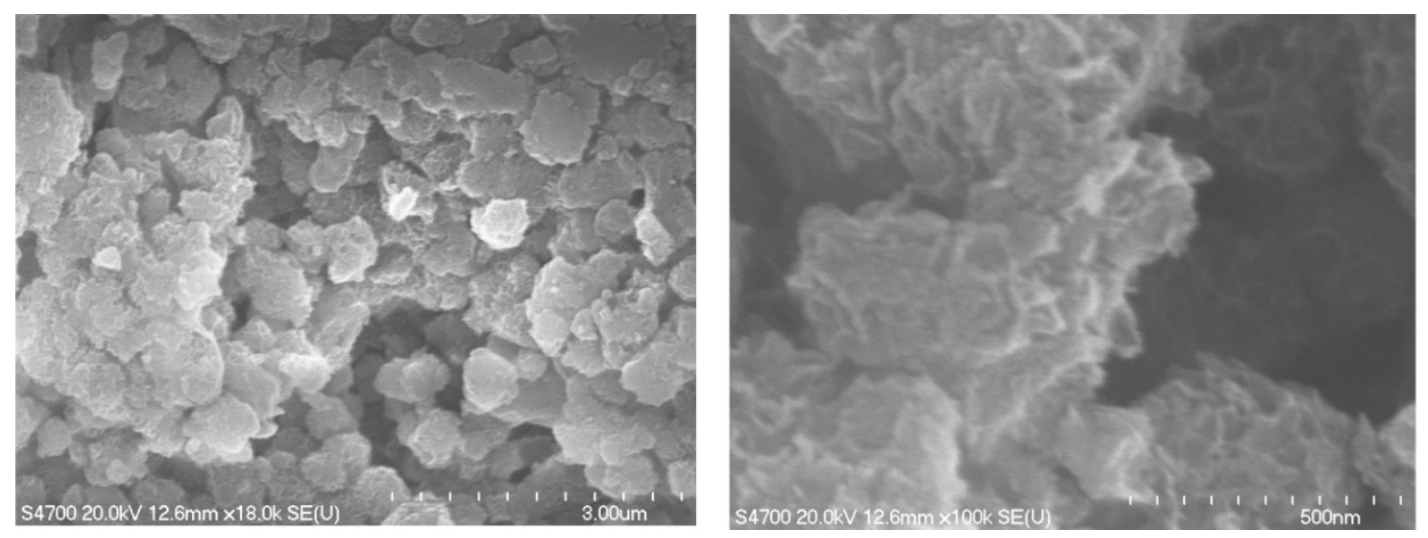

Figure 60 FE-SEM images of as-synthesized nickel oxides 
The urea was used as the hydroxide provider for precipitation where the urea undergoes hydrolysis at temperature above $60{ }^{\circ} \mathrm{C}$, as described by following reaction:

$$
\left(\mathrm{NH}_{2}\right)_{2} \mathrm{CO}+3 \mathrm{H}_{2} \mathrm{O} \leftrightarrow 2 \mathrm{NH}_{4}^{+}+2 \mathrm{OH}^{-}+\mathrm{CO}_{2}
$$

Then the precipitation grew along the direction of the surfactant so that the synthesized particle surface preserved the surfactant texture, as seen from the accidented edges of the particles.

DTA analysis was carried out for as-synthesized nickel hydroxide in air to study the reaction process under calcinations conditions. The obtained DTA curve is shown in Figure 61 . Two endothermic peaks were observed. The wide peak presented between 50 to $250{ }^{\circ} \mathrm{C}$ corresponds to the removal of water from the $\mathrm{Ni}(\mathrm{OH})_{2}$. The sharp peak between 300 to $400{ }^{\circ} \mathrm{C}$ corresponded to the removal of hydroxyl groups to form $\mathrm{NiO}$. The calcinations temperature and time are two critical factors for obtaining oxides with highly porous structures. With the increase of temperature, the pore structure of the samples may undergo major changes so that less calcinations time should be used to prevent the collapse of the pore structure [146]. From the DTA curve, the reaction started from 300 ${ }^{\circ} \mathrm{C}$ and the center position of the peak was at around $360{ }^{\circ} \mathrm{C}$. Therefore, calcinations of $\mathrm{Ni}(\mathrm{OH})_{2}$ were conducted at $300{ }^{\circ} \mathrm{C}$ and $360{ }^{\circ} \mathrm{C}$ for different time to obtain the optimum condition for achieving the porous $\mathrm{NiO}$ with the highest surface area. 


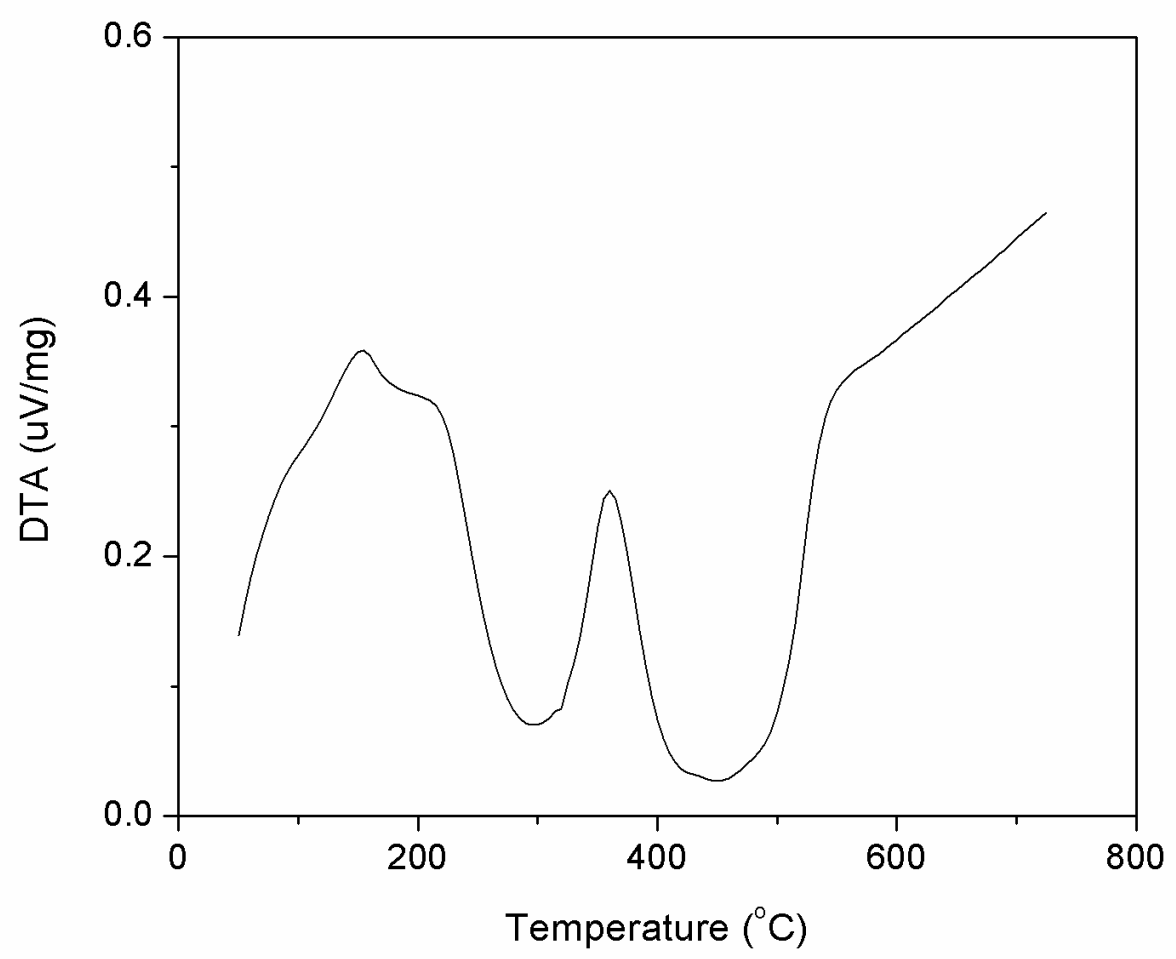

Figure 61 DTA curve of as-synthesized nickel oxides

The adsorption isothermals of mesoporous nickel oxides calcined at $300^{\circ} \mathrm{C}$ and $360{ }^{\circ} \mathrm{C}$ for various time are shown in Figure 62. Regardless of the calcination temperature and time, the obtained porous nickel oxides preserved mesoporous characteristic. However, by comparing curves at $300^{\circ} \mathrm{C}$ and $360{ }^{\circ} \mathrm{C}$, higher temperature yielded smaller mesopore volume, and longer calcination time at high temperature caused widening of the pore structure, as revealed by the shrinkage of the hysteresis of the adsorption isotherms. 


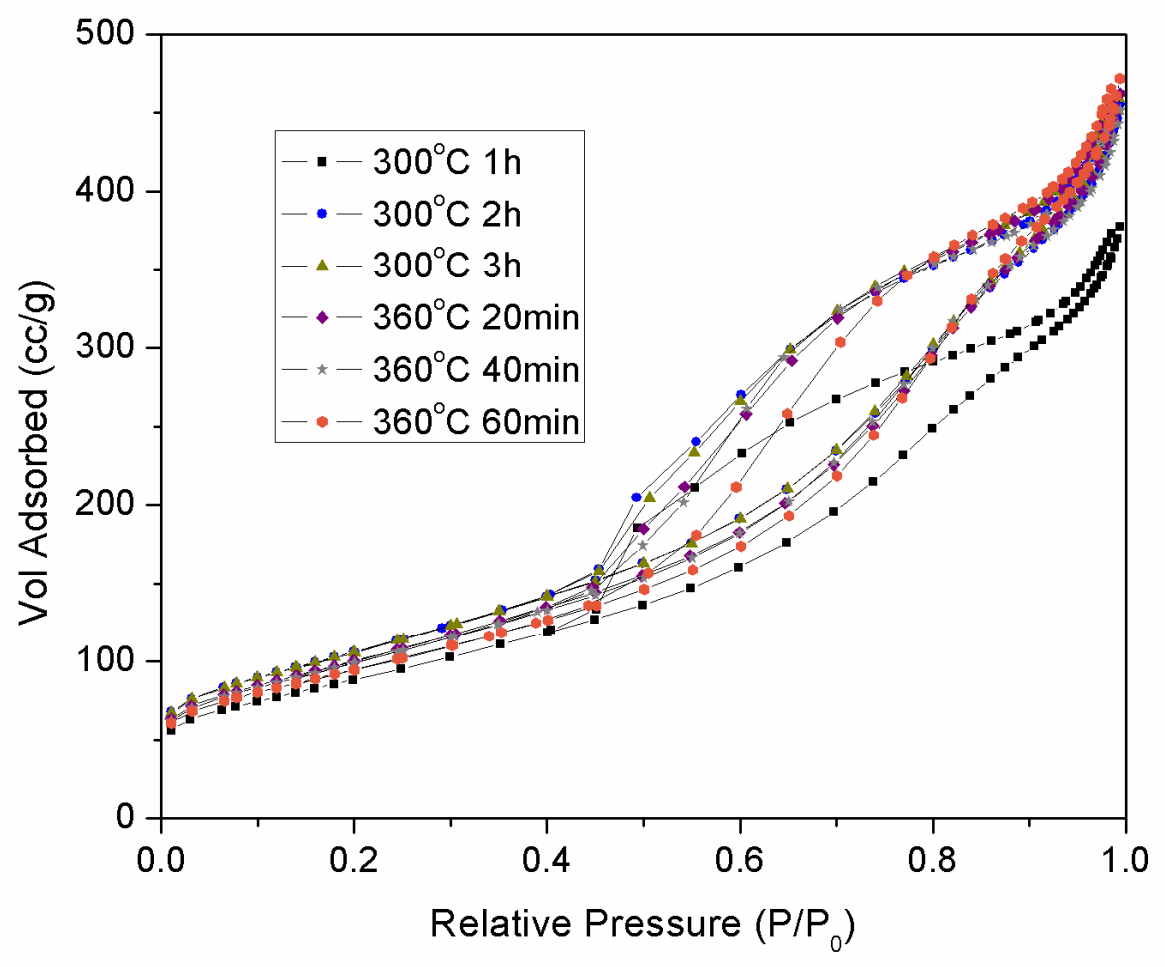

Figure 62 Adsorption isotherms of the mesoporous nickel oxides calcined at $300{ }^{\circ} \mathrm{C}$ and $360{ }^{\circ} \mathrm{C}$ for different time

Surface area and pore size properties of calcined products were summarized in Table 10. The BET surface area increased with the increasing of calcinations time from 1 hour to 2 hours at $300{ }^{\circ} \mathrm{C}$ and further increasing calcinations time causeed minor enhancement on the total surface area. The average pore diameter was around $7 \mathrm{~nm}$. At such temperature, the decomposition of $\mathrm{Ni}(\mathrm{OH})_{2}$ slowly developed and the pore skeleton generated was very stable. With the calcinations temperature increased from $300{ }^{\circ} \mathrm{C}$ to $360{ }^{\circ} \mathrm{C}$, the total surface area dropped and longer heating time resulted lower surface area. Obviously, the decomposition of $\mathrm{Ni}(\mathrm{OH})_{2}$ took place too fast at such temperature and the pore structure collapsed upon heated. And as the calcinations proceeded longer, the pore size was 
enlarged and the small pores began to be sintered, as observed that the pore diameter increased to $8 \mathrm{~nm}$ for 1 hour heating. Therefore, slowly decomposition at lower temperature was critical for obtaining highly porous nickel oxide, where the best result was achieved at calcinations at $300{ }^{\circ} \mathrm{C}$ for 3 hour and the highest surface area obtained was $382.56 \mathrm{~m}^{2} / \mathrm{g}$ with an average pore diameter of $7.08 \mathrm{~nm}$.

Table 10 Surface properties of calcined nickel oxides

\begin{tabular}{|c|c|c|}
\hline Samples & BET surface area $\left(\mathrm{m}^{2} / \mathrm{g}\right)$ & Average pore diameter (nm) \\
\hline $\mathrm{NiO}\left(300{ }^{\circ} \mathrm{C} 1 \mathrm{~h}\right)$ & 318.29 & 6.95 \\
\hline $\mathrm{NiO}\left(300{ }^{\circ} \mathrm{C} 2 \mathrm{~h}\right)$ & 382.23 & 7.08 \\
\hline $\mathrm{NiO}\left(300{ }^{\circ} \mathrm{C} 3 \mathrm{~h}\right)$ & 382.56 & 7.08 \\
\hline $\mathrm{NiO}\left(360^{\circ} \mathrm{C} 20 \mathrm{~min}\right)$ & 361.82 & 7.47 \\
\hline $\mathrm{NiO}\left(360^{\circ} \mathrm{C} 40 \mathrm{~min}\right)$ & 357.57 & 7.48 \\
\hline $\mathrm{NiO}\left(360^{\circ} \mathrm{C} 60 \mathrm{~min}\right)$ & 341.25 & 8.09 \\
\hline
\end{tabular}

Figure 63 shows the SEM images of mesoporous $\mathrm{NiO}$ calcined at $300{ }^{\circ} \mathrm{C}$ for 3 hours. The particles preserved the texture and size of the as-synthesized nickel hydroxide. The macropores and mesopores could be observed clearly on the right figure. Obviously, such porous structures are ideal adsorption sties for hydrogen storage. 

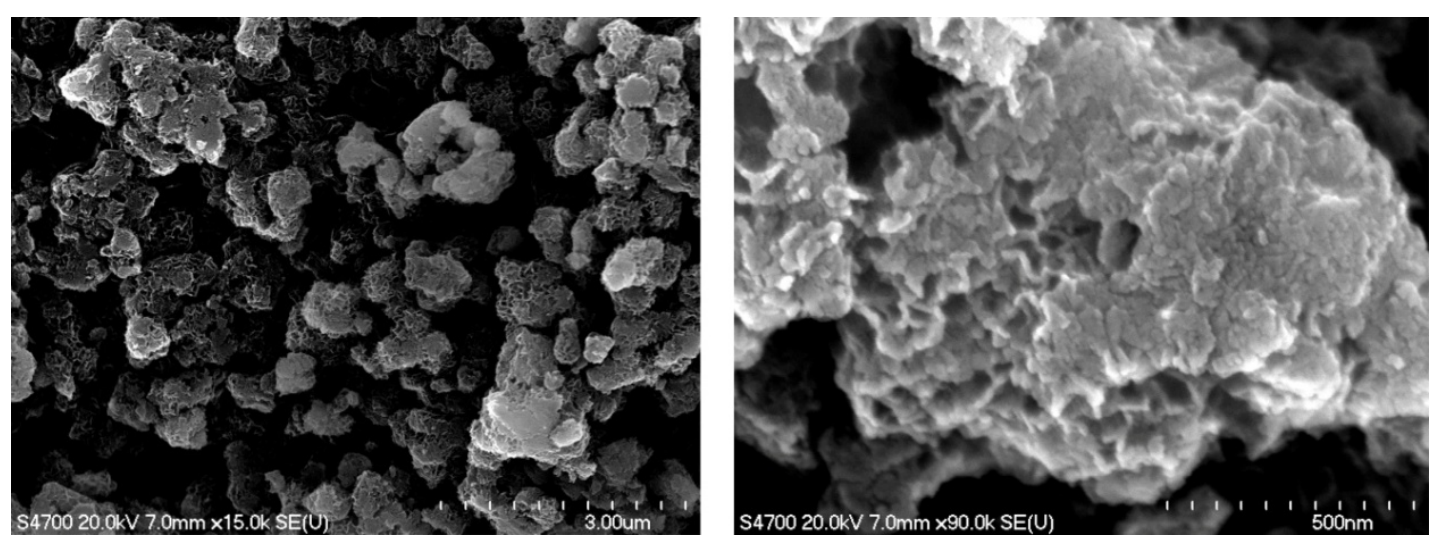

Figure 63 FE-SEM images of NiO calcined at $300{ }^{\circ} \mathrm{C}$ for 3 hours

\subsubsection{Hydrogen storage of nickel oxide}

\subsection{Hydrogen storage of electric field assisted porous nickel oxide}

Hydrogen adsorption isotherms at $298 \mathrm{~K}$ for porous $\mathrm{NiO}$ (calcined at $300{ }^{\circ} \mathrm{C}$ for 3 hours) and $\mathrm{NiO}+\mathrm{PMN}-\mathrm{PT}$ are shown in Figure 64. The porous nickel oxide had a total hydrogen capacity of about $0.08 \mathrm{wt} \%$ at 135 bars. The shape of the adsorption curve was almost a linear line, which indicated the absences of a saturation point and suggested that further increase in capacity could be realized at pressure greater than 135 bars. The curve also presented a typical physisorption type caused by the low interaction force of the hydrogen molecule and nickel oxide surface. By simply embedding an electric field generating material PMN-PT into the porous nickel oxide, the hydrogen uptake had been remarkably enhanced to $0.11 \mathrm{wt} \%$ at 135 bars, which was about $37.5 \%$ increase. It should be noted that the PMN-PT alone had almost zero adsorption at the same condition. Such significantly enhancement was clearly the evidence of the assisted increase from the PMN-PT generated electric field. Moreover, it is noted that the magnitude difference between the two lines continuously increased from 0 bar to $60 \mathrm{bar}$, and became almost 
constant at pressure higher than 60 bars. This implied that there was a saturation point from where further enhancement of the electrical strength had no effect on the hydrogen interaction.

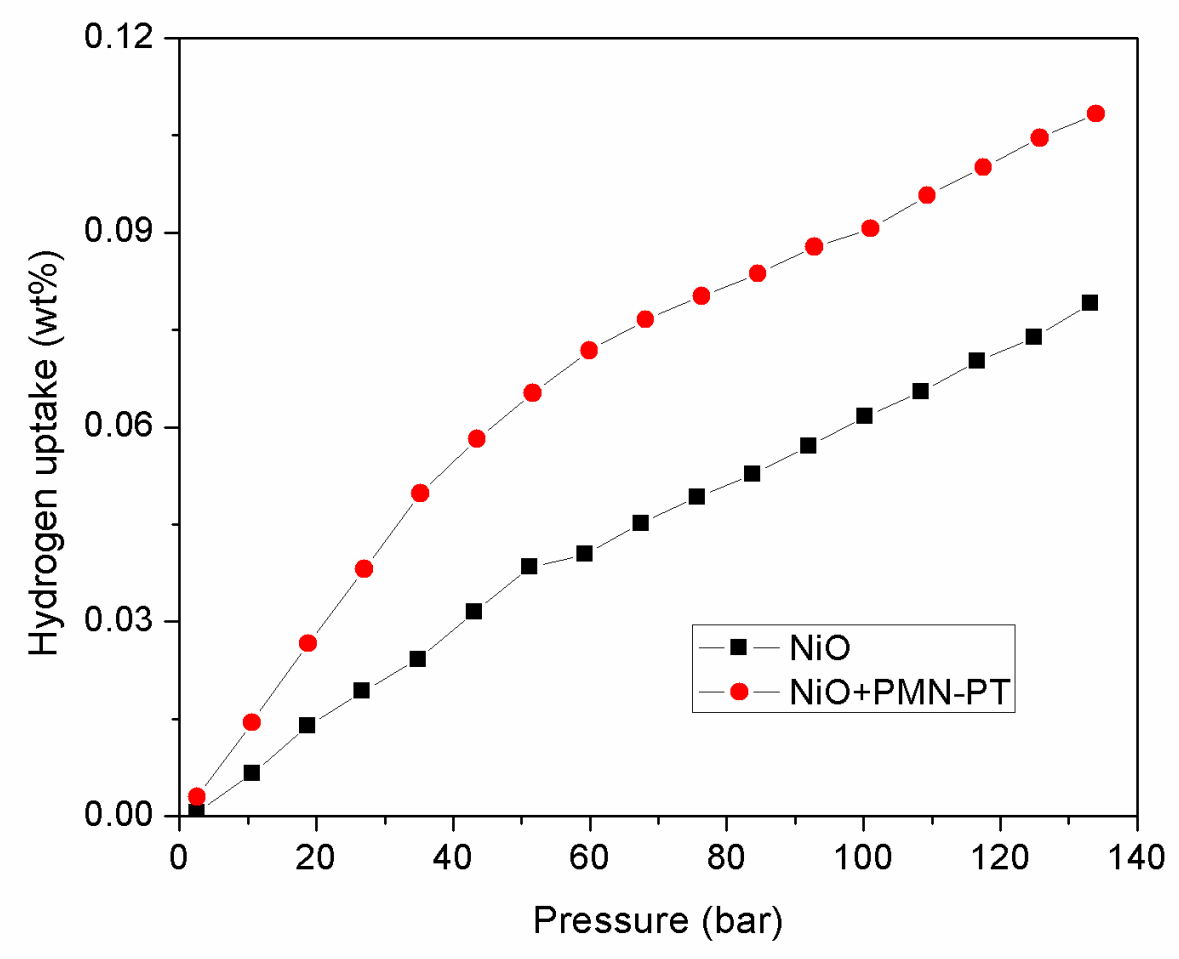

Figure 64 Hydrogen adsorption isotherms at $298 \mathrm{~K}$ for $\mathrm{NiO}$ samples

\subsection{Hydrogen storage of electric field assisted spillover on nickel oxide}

Hydrogen spillover has become a hot topic in hydrogen storage research in recent years. It is believed that the hydrogen molecules would dissociate into atomic hydrogen when they are in contact or closed range with the catalytic surface. The atomic hydrogen then spills over to the adsorbent surface via surface diffusion [151]. Spillover has been successfully used for hydrogen storage in carbon materials [151], metal-organic frameworks [152-154], and porous inorganic materials [155]. The bonding between 
atomic hydrogen and the materials surface is much stronger than that of molecule hydrogen so that significant adsorption could be realized especially at room temperature. The possible drawbacks are the blocking of the pores by the deposited catalysts and also the decreased surface area for adsorption.

The nitrogen adsorption/desorption of the platinum deposited porous nickel oxide (calcined at $300{ }^{\circ} \mathrm{C}$ for 3 hours) is shown in Figure 65. After deposition of platinum by wet chemical method, the nickel oxide still maintained its mesorporous characteristics which were determined from the hysteresis loop of the adsorption/desorption isotherms and the pore size distribution (insert). However, the total surface area dropped to 243.29 $\mathrm{m}^{2} / \mathrm{g}$, a nearly $35 \%$ decrease from the calcined product.

Figure 66 shows the FE-SEM images and the EDS analyzed elemental compositions of the platinum deposited nickel oxides. The tiny spheroids on the surface were mainly deposited platinum particles at the size of about 50-100 nm. Such small particle size made the platinum very reactive where the hydrogen dissociation would easily occur on the platinum surface. The EDS spectrum shows that the deposited platinum is about 20 $\mathrm{wt} \%$. 


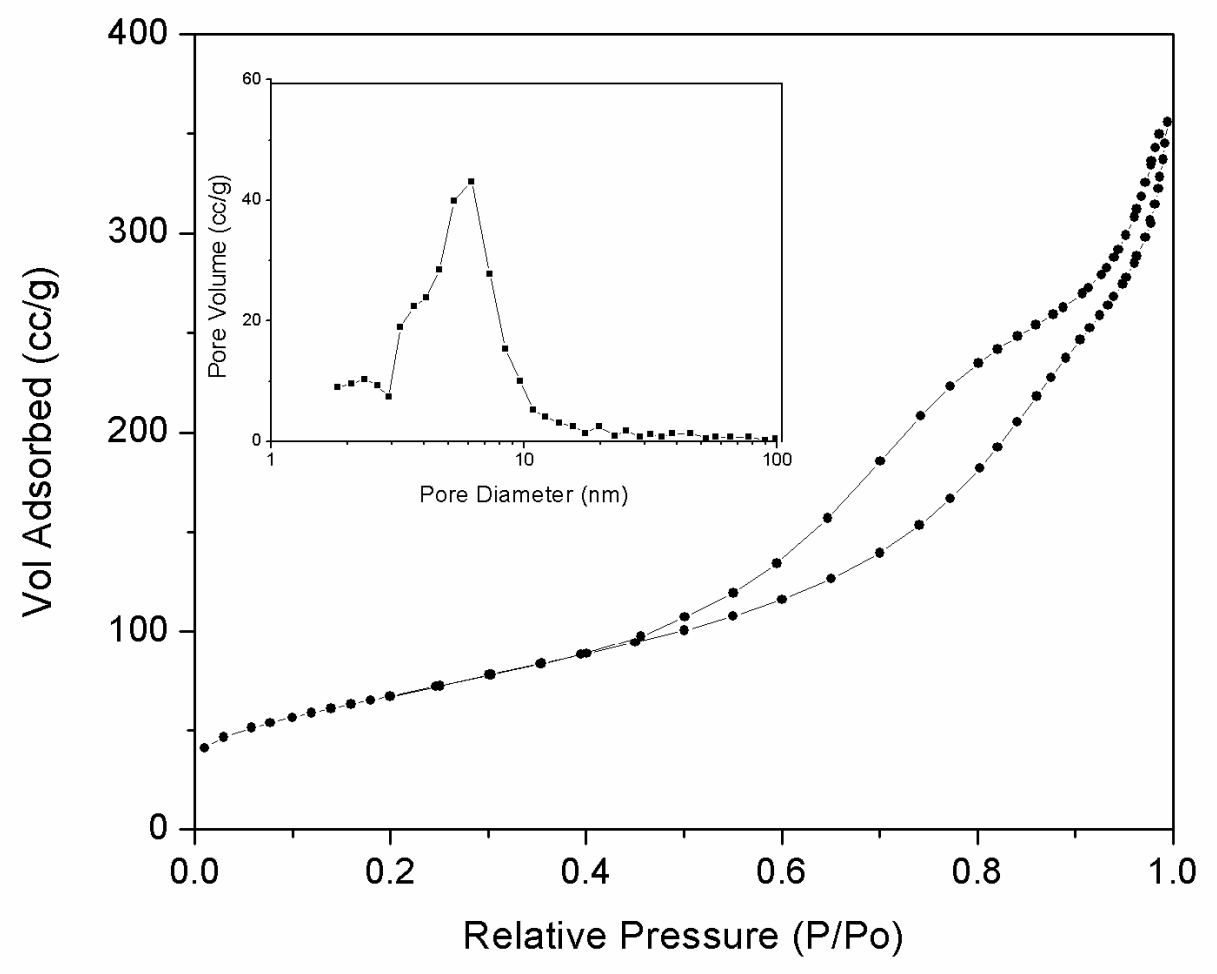

Figure 65 Nitrogen adsorption/desorption isotherms of Pt deposited porous NiO, insert: BJH pore size distribution obtained by desorption isotherms

The hydrogen adsorption curves of the Pt deposited $\mathrm{NiO}$ at $298 \mathrm{~K}$ are shown in Figure 67. Hydrogen spillover on nickel oxide improved the uptake to $0.22 \mathrm{wt} \%$ at 120 bars, which was about 3 times the capacity of the nickel oxide without platinum. No apparent saturation point was approached for the Pt deposited sample and the adsorption trend followed a linear line where further increase in total capacity could be expected at higher pressure. 

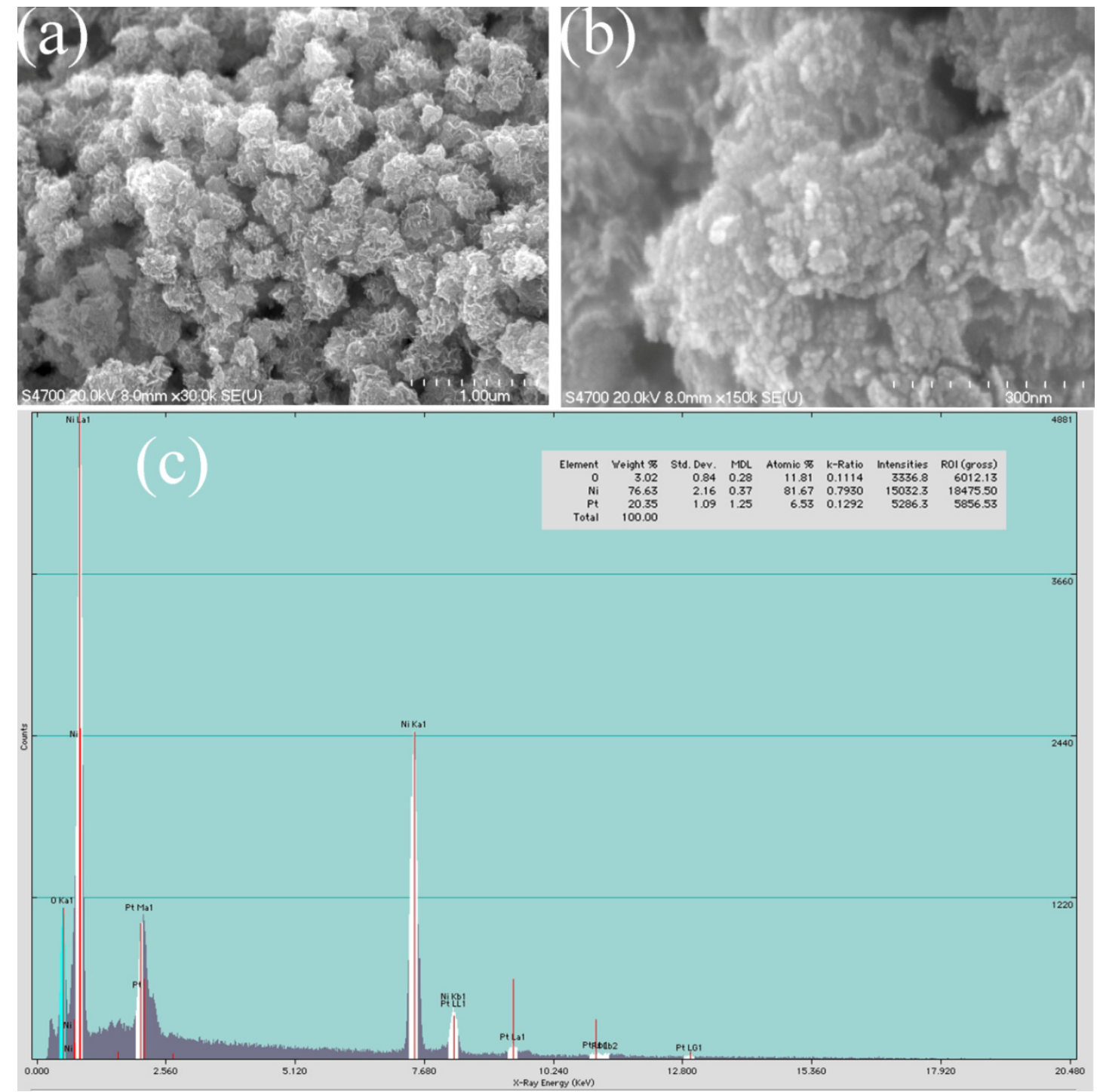

Figure 66 FE-SEM images of platinum deposited porous nickel oxide (a)(b), and EDS spectrum (c)

Under the PMN-PT generated electric field, the total hydrogen uptake has been tremendously improved. It reached about $0.31 \mathrm{wt} \%$ at 120 bars, which was another $50 \%$ increase over the spillover nickel oxides. There was also no apparent saturation value for adsorption. The results also proved that the external electric field imposed on the nickel oxide could also attract atomic hydrogen and enhance the bonding interaction. The enhancement from PMN-PT was small at low pressure whereas it increased as the 
pressure increased. At about 20 bars, the magnitude of the enhancement became constant indicating that the significant effect of the electric field on atomic hydrogen adsorption only occured at low pressure. By combining the enhancement from hydrogen spillover and PMN-PT generated electric field, the total capacity has been increased remarkably by a factor of 4 .

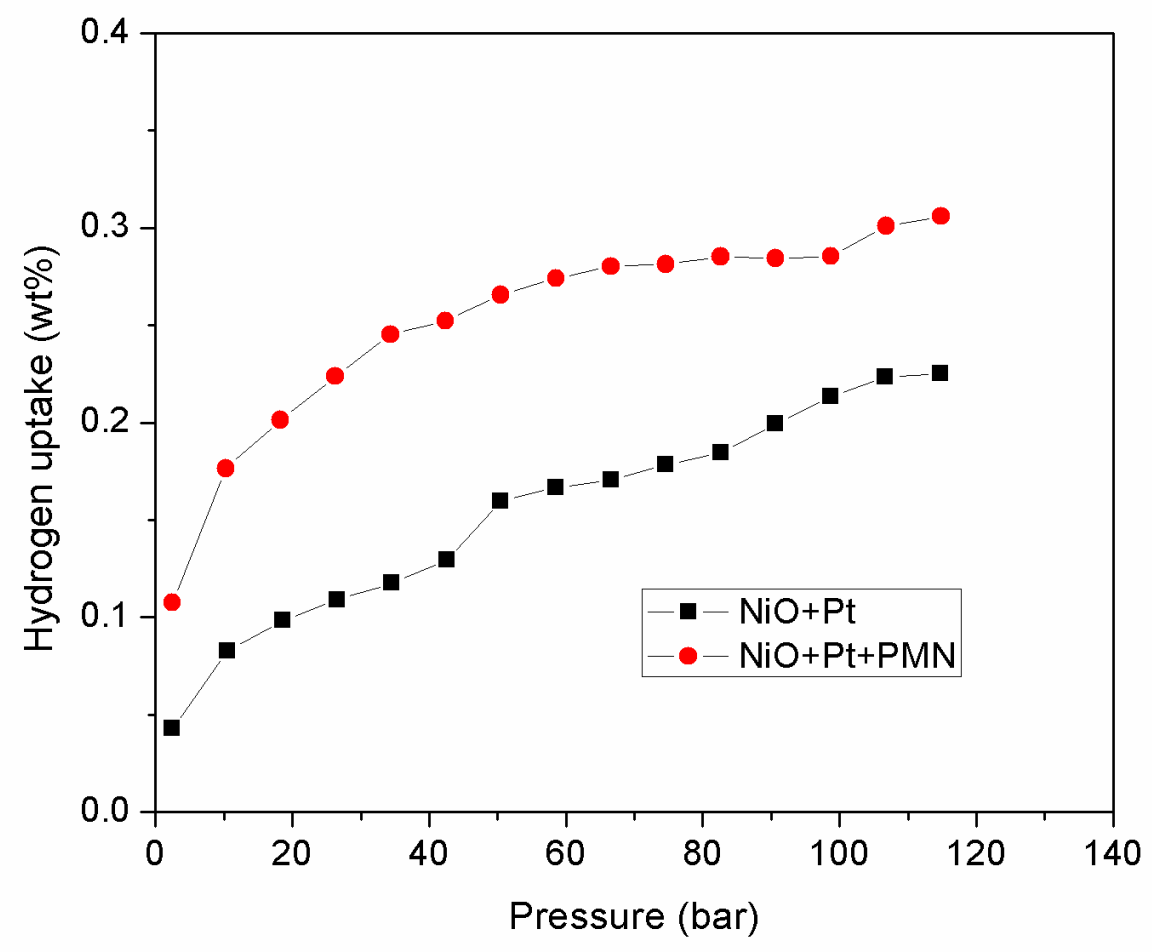

Figure 67 Hydrogen storage of Pt deposited porous NiO and enhancement from the PMN-PT

The computer simulation of optimized nickel oxide clusters is shown in Figure 68. The nominal charge for nickel oxide is 2 ; however, the point charge used to reproduce the lattice parameter is 1.2648 . Carefully selecting the point charge value is critical to have reliable modeling results. 


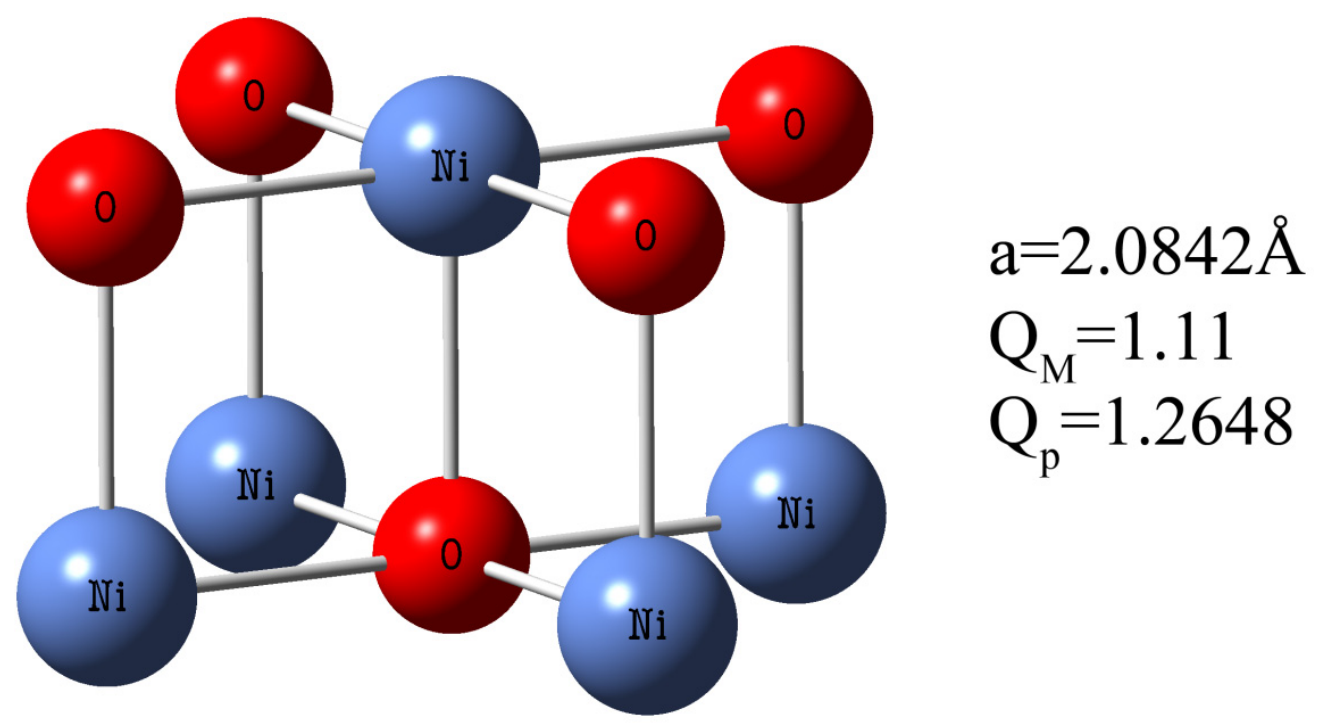

Figure 68 Optimized $\mathrm{Ni}_{5} \mathrm{O}_{5}$ clusters in $13 \times 13 \times 13$ point charges, where a is the lattice parameter, $Q_{M}$ is the average Mulliken charge, and $Q_{p}$ is the magnitude of the point charge

The modeling work of hydrogen adsorption on nickel cation site of nickel oxides under different electrical field strength is shown in Figure 69. Hydrogen molecules could be adsorbed onto the nickel site of nickel oxide with a small binding energy. When the electrical field is applied, the hydrogen molecules are more perturbed and attracted closer to the nickel atom, indicating a stronger interaction. The effects increase consistently with the increasing of electrical field strength, where the highest binding energy at 0.015 au increased three times. These remarkable phenomena are in good agreement with the experimental observations. 

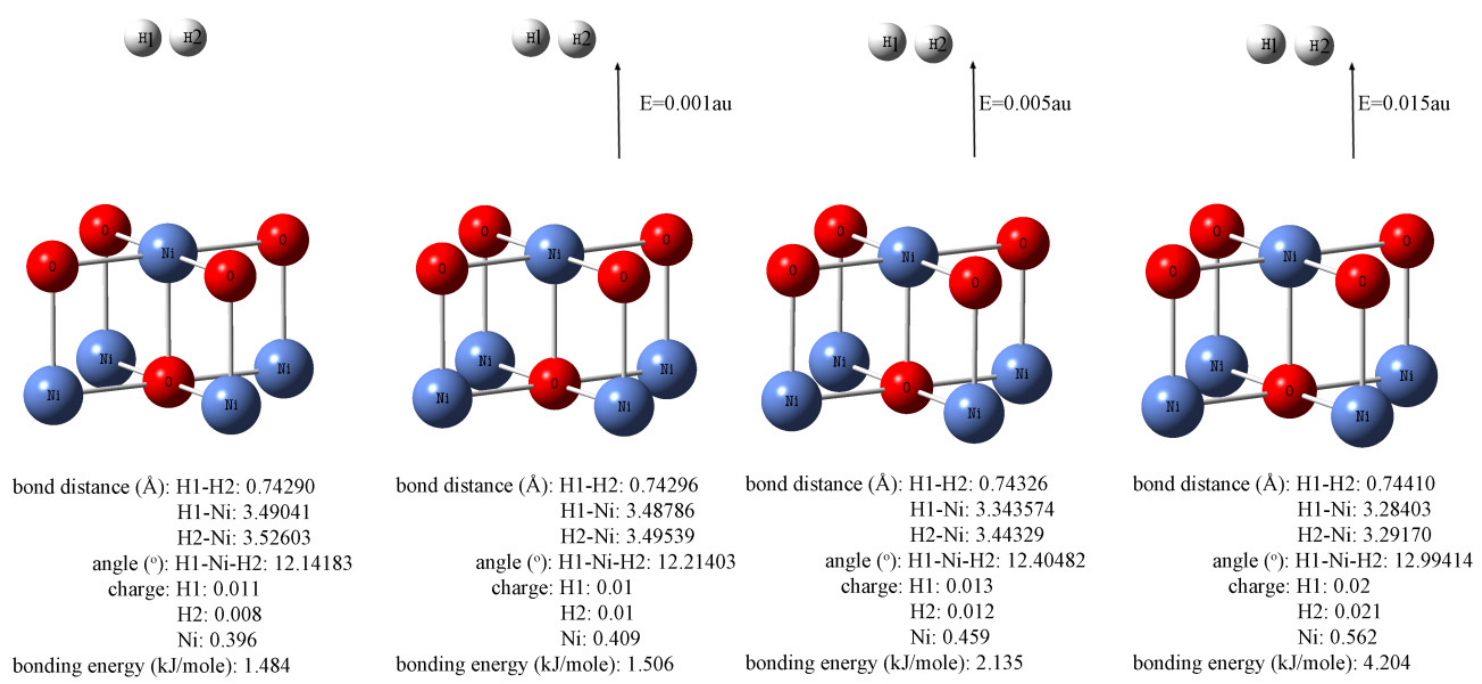

Figure 69 Optimized geometry of hydrogen adsorbed on nickel site under the influence of electric field

An explanation could be well obtained from the DOS analysis of atom orbital. Figure 70 shows the DOS spectrum of hydrogen orbital. Free hydrogen molecules only have one peak at around $-12 \mathrm{eV}$, indicating the localization of the electrons. When they are adsorbed onto nickel site, there are two more peaks occurring at energy between -10 to -2 $\mathrm{eV}$, indicating part of the electrons moving to higher energy state. Such electrons overlap with the electrons from nickel outer shell so that the adsorption bonding is formed. When an electrical field was applied, there were more peaks presented due to more electron overlapping and better interaction between hydrogen and nickel. The overall effects increased with the increasing of electrical strength, which explained why the bonding energy increased consistently with the field strength. 


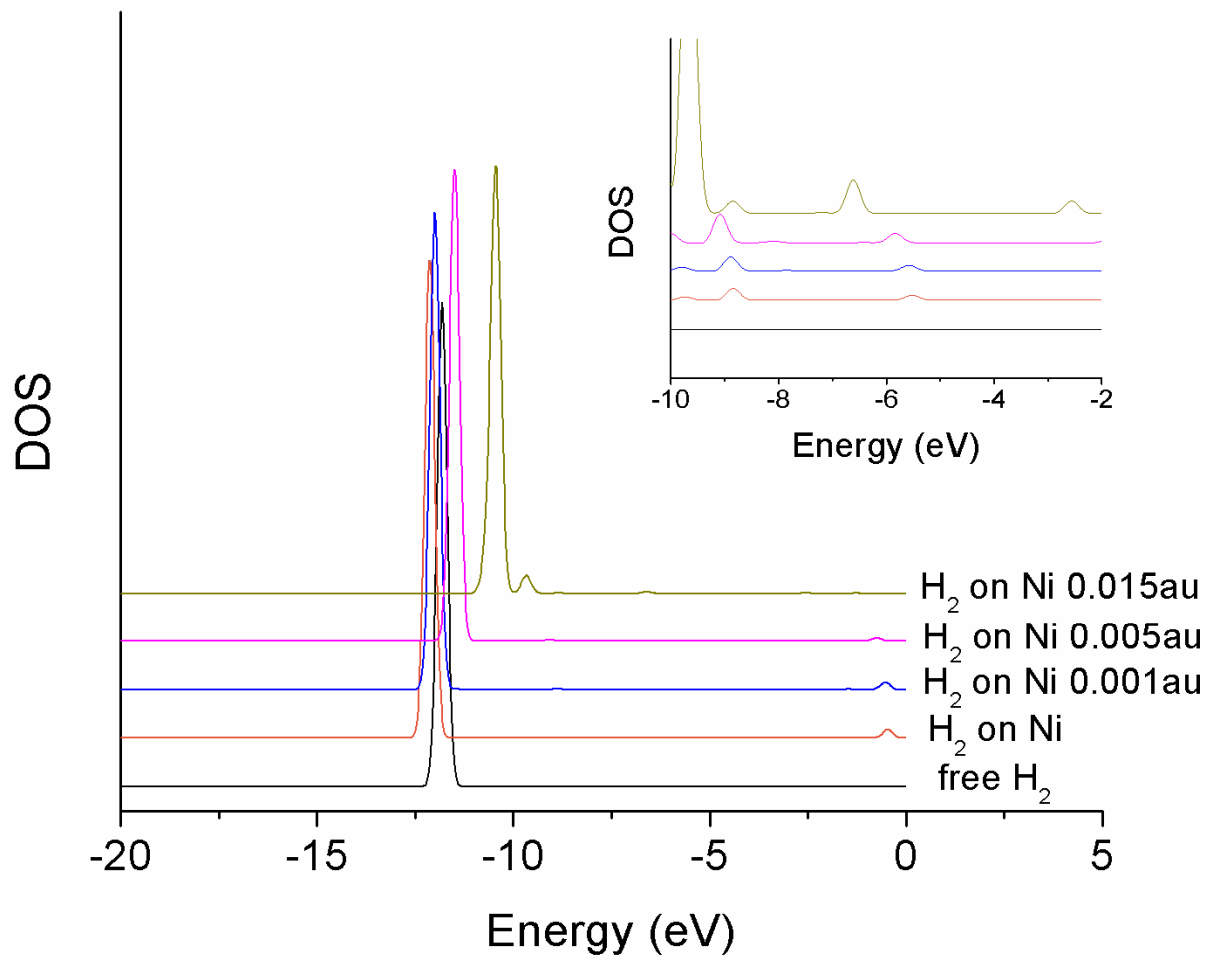

Figure 70 DOSs of orbital of hydrogen molecules which adsorbed on nickel site of the nickel oxide under the applied electric field, insert: higher magnification of the DOSs between -10 to $-2 \mathrm{eV}$

The same modeling work was performed on oxygen site of the nickel oxide. Figure 71 shows that the same trend occurs on oxygen site. The bonding energy increased with the increasing strength of the electric field. The DOS analysis (Figure 72) also showed that the electron clouds were pulled over to the oxygen site, and the bonding was formed due to the overlapped electrons. 

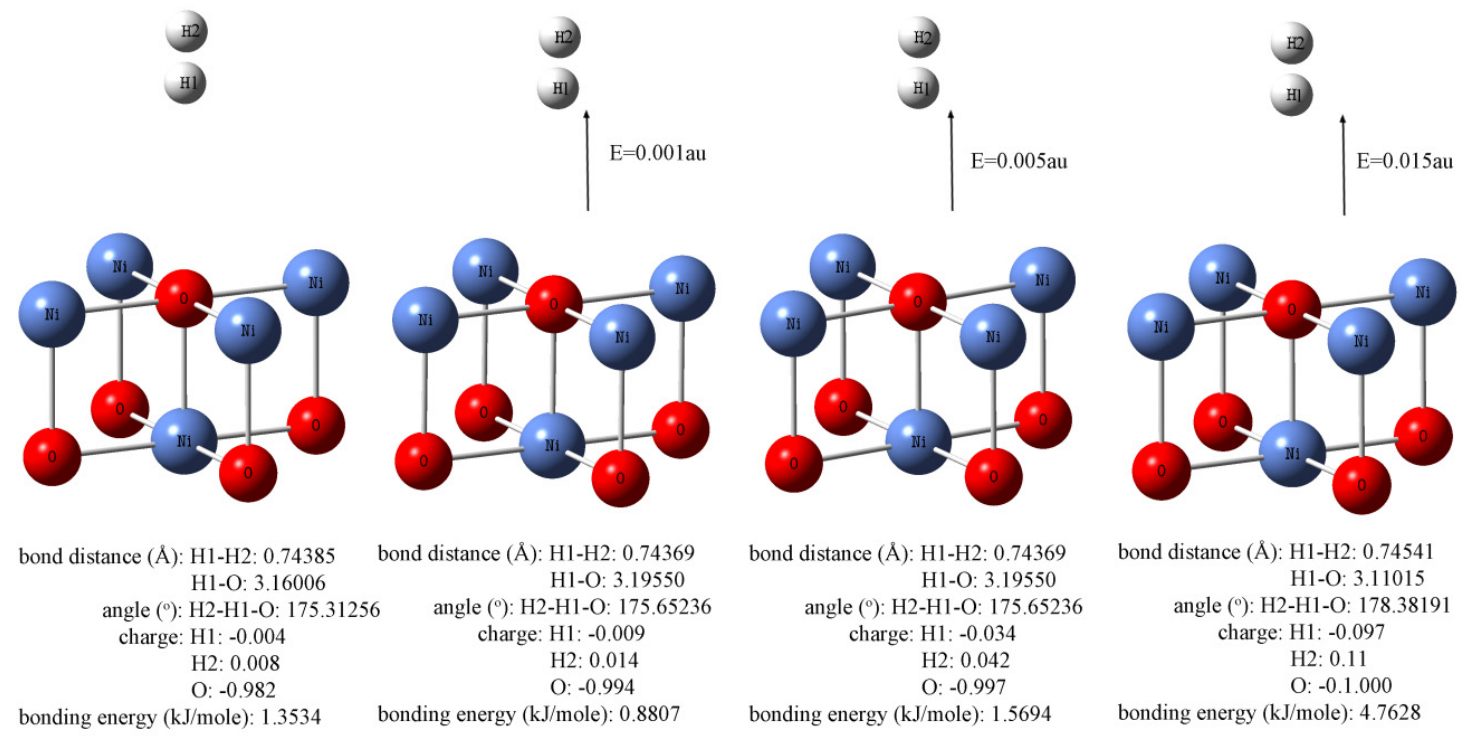

Figure 71 Optimized geometry of hydrogen adsorbed on oxygen site under the influence of electric field

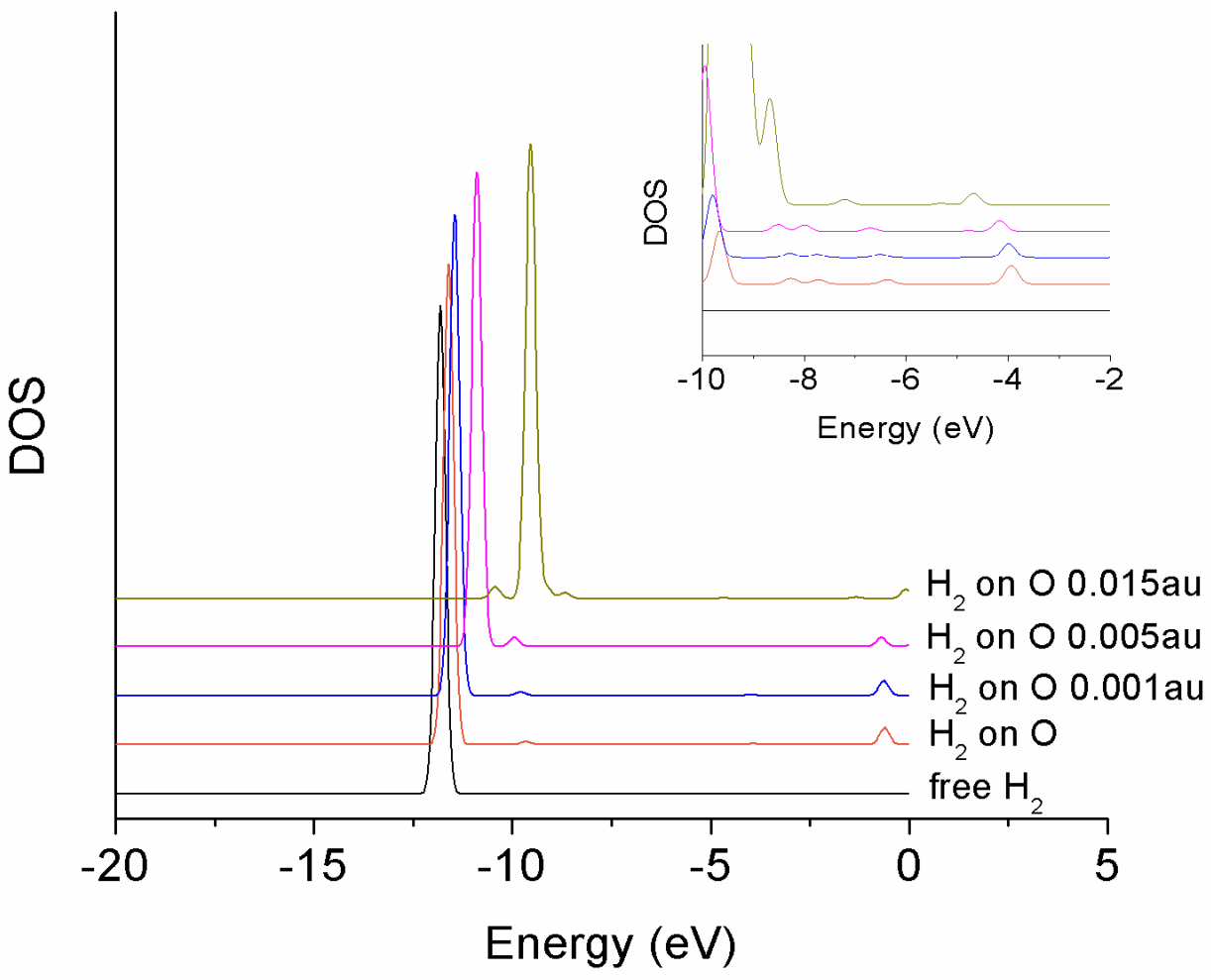

Figure 72 DOSs of orbital of hydrogen molecules which adsorbed on oxygen site of the nickel oxide under the applied electric field, insert: higher magnification of the DOSs between -10 to $-2 \mathrm{eV}$ 


\subsubsection{Porous magnesium oxides}

\subsubsection{Characterization of as synthesized oxides}

Figure 73 shows the XRD pattern of the as-synthesized magnesium oxide. The pattern is a good match of the magnesium carbonate hydroxide hydrate which is also called hydromagnesite. The compound was formed by the reaction of magnesium cations and the carbon dioxides and hydroxide ions from the hydrolysis of urea. Upon heating, the decomposition of the compound caused carbon dioxide and water vapor to be developed and the porous structures to be generated.

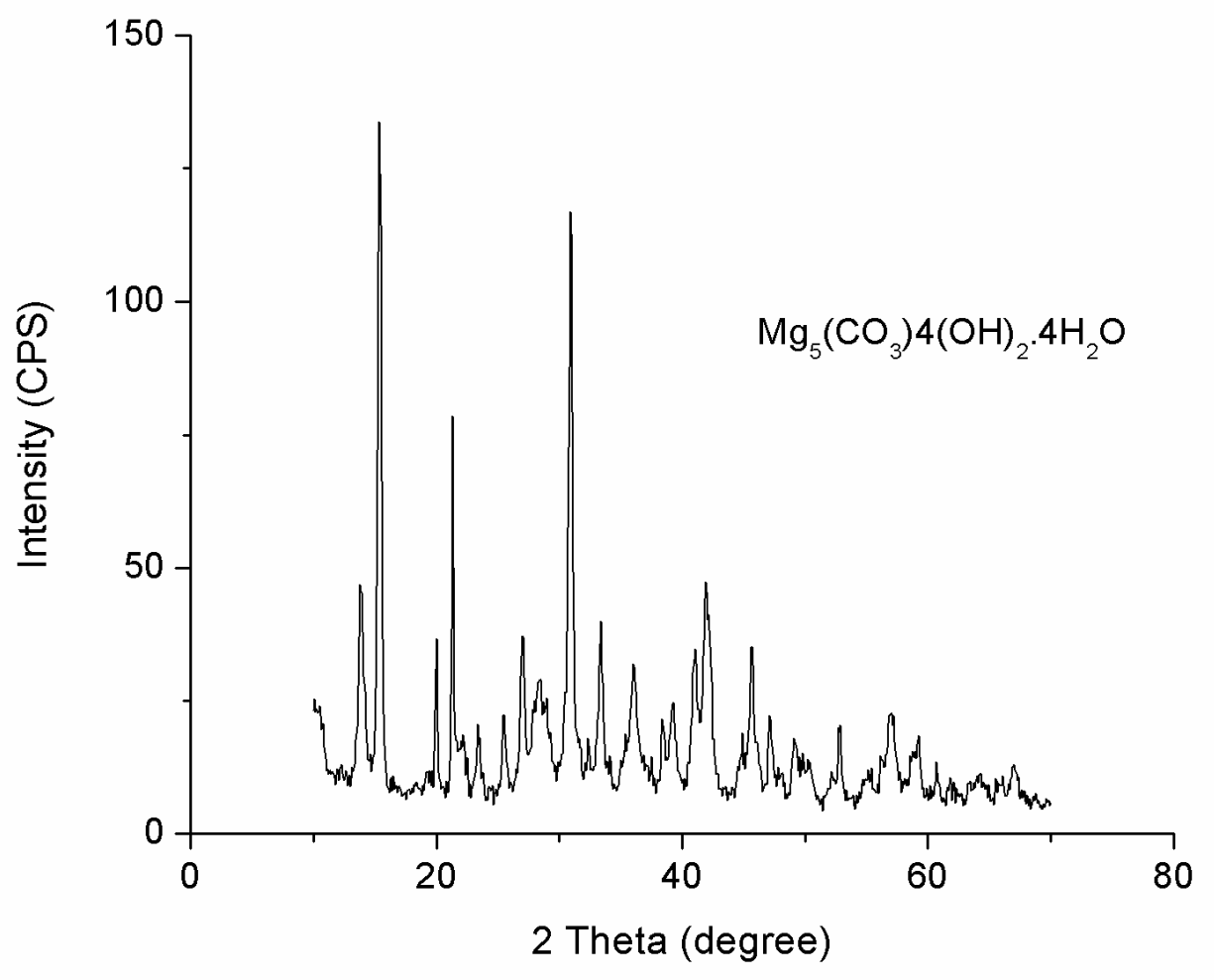

Figure 73 XRD pattern of as-synthesized hydromagnesite 
Figure 74 shows the DTA curve in air of the as-synthesized hydromagnesite. A wide peak was presented between $200{ }^{\circ} \mathrm{C}$ and $350{ }^{\circ} \mathrm{C}$ and a sharp peak was observed between $400{ }^{\circ} \mathrm{C}$ and $500{ }^{\circ} \mathrm{C}$, which corresponded to the dehydration reaction and decarbonization reaction of the hydromagnesite, respectively. As with the nickel hydroxide, low calcinations temperature of $400{ }^{\circ} \mathrm{C}$ and long time period of 3 hours were selected to obtain the porous product with the highest surface area.

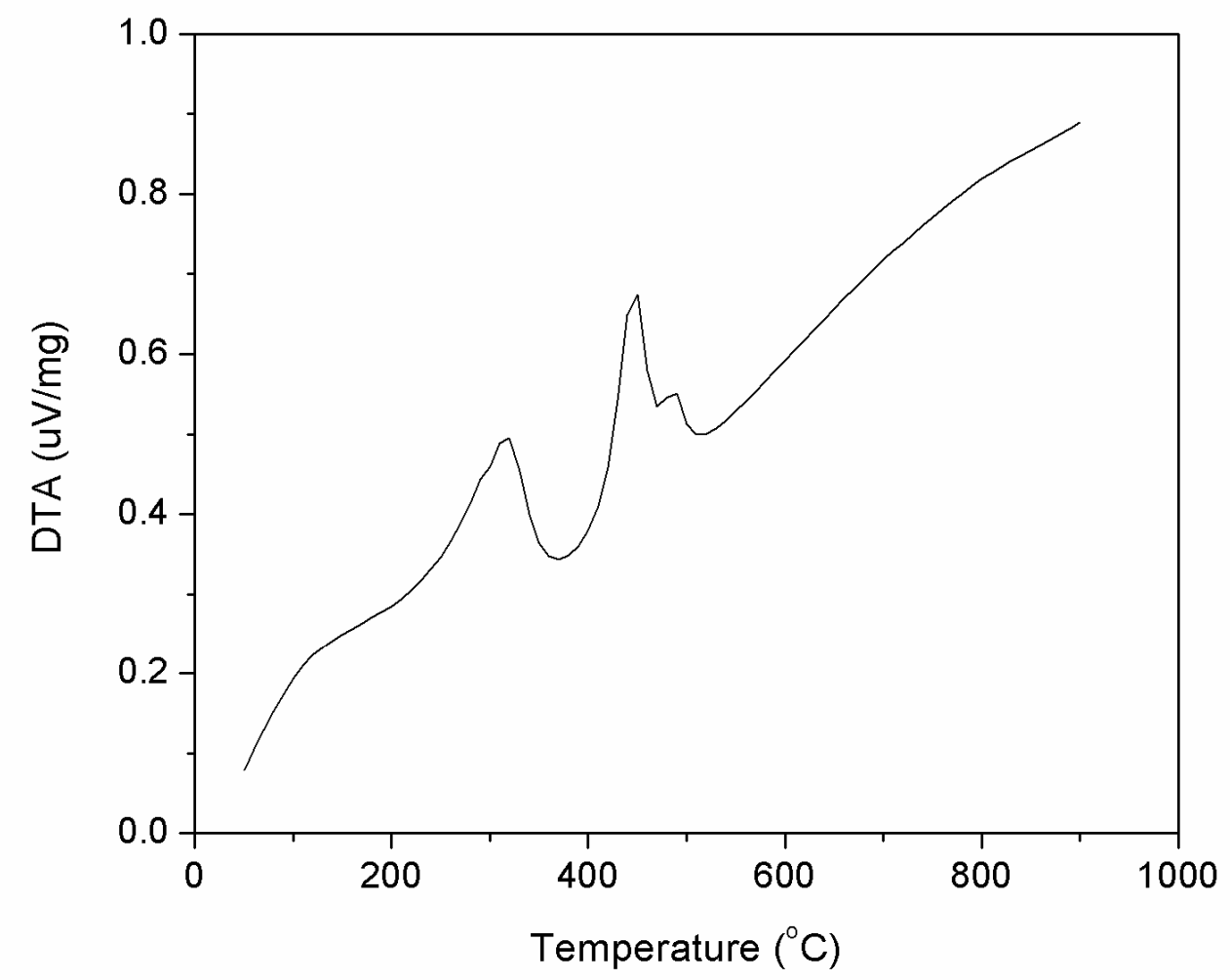

Figure 74 DTA curve of as-synthesized hydromagnesite

Representative x-ray diffraction pattern of the calcined product is shown in Figure 75. It clearly represented the single phase of only magnesium oxide with no other impurities, 
indicating that the decomposition reaction was complete. The significant peak broadening revealed that the calcined particles have small grain size.

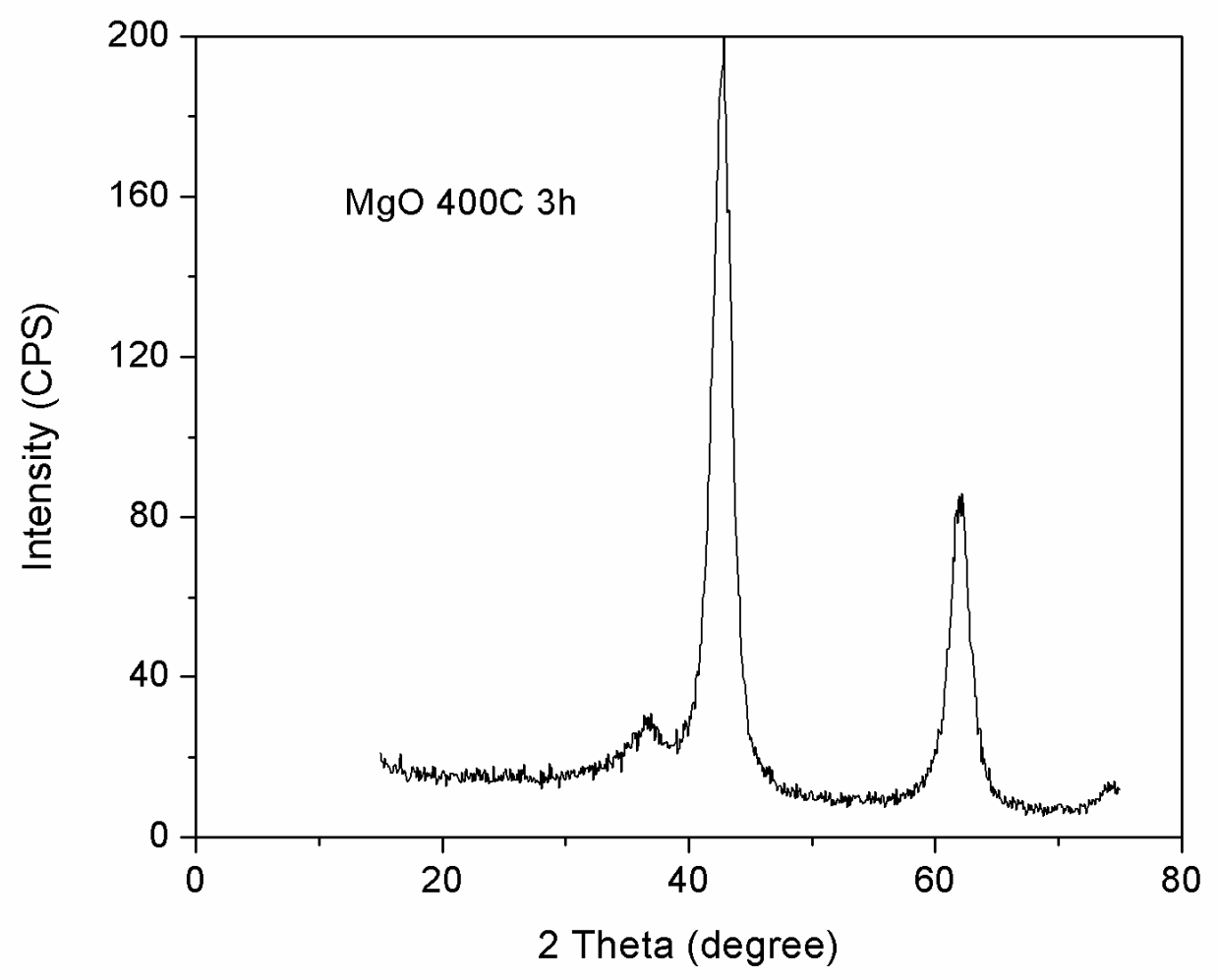

Figure 75 XRD pattern of calcined magnesium oxide

The corresponding morphology was examined by FE-SEM. As shown in Figure 76, the particles had nano-plate structures, which were stacked together irregularly. The higher magnification image, as in Figure 76(b), revealed that each particle looked like well defined nano-platelet with a thickness of 30-50 $\mathrm{nm}$ and a lateral dimension of around several microns. More details about developed pore structures are presented in Figure 76(c) and 76(d), where obvious pores and cracks generated by calcinations were well 
observed. Various macropores and mesorpores revealed that the product was highly porous.

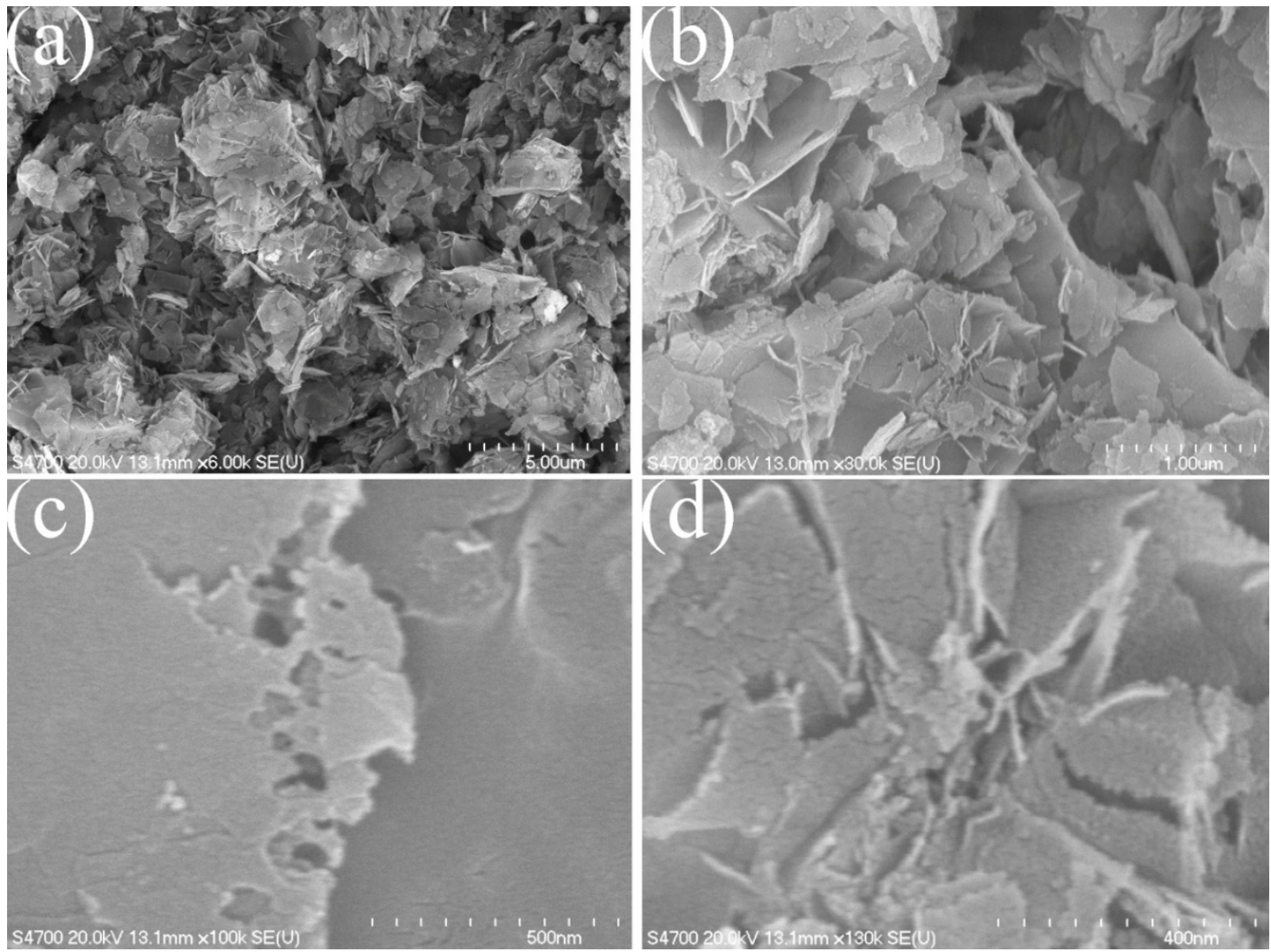

Figure $76 \mathrm{FE}-\mathrm{SEM}$ image of the $\mathrm{MgO}$ calcined at $400{ }^{\circ} \mathrm{C}$ for 3 hours

Nitrogen adsorption/desorption isotherms and BJH pore size distributions are shown in

Figure 77. The significant hysteresis loop of the isotherms indicated that the product had mesopore structure. The pore size distribution as calculated by BJH desorption isotherms confirmed that the calcined $\mathrm{MgO}$ was mainly composed of small mesopores with average pores diameter of $3.87 \mathrm{~nm}$. The total surface area and pore volume are $363.59 \mathrm{~m}^{2} / \mathrm{g}$ and $0.35 \mathrm{cc} / \mathrm{g}$, respectively. Such surfactant directed grown porous magnesium oxide had much higher surface area than other porous $\mathrm{MgO}$ obtained by hydrothermal treatment [156], direct dehydration [157], and wet precipitation methods [158]. 


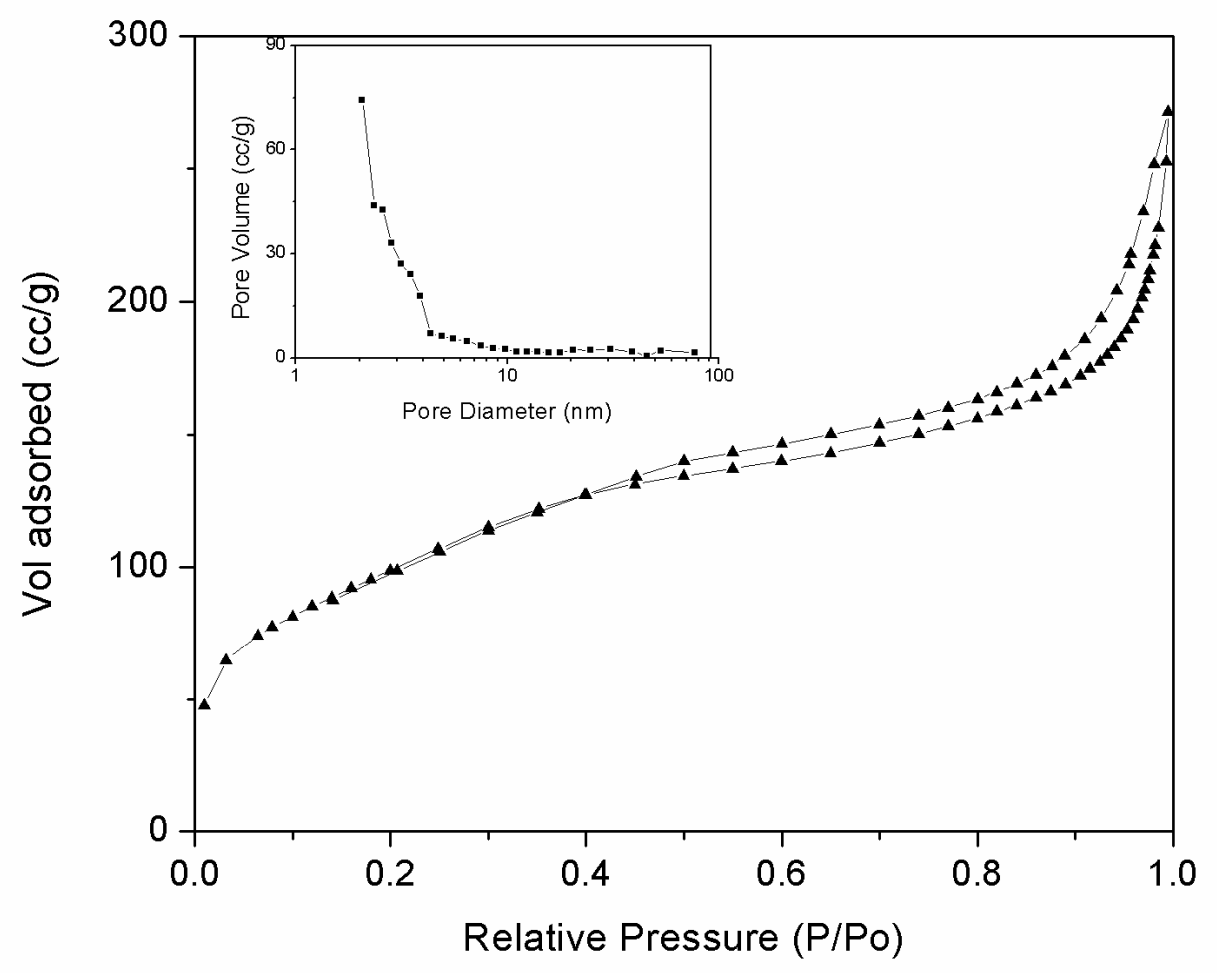

Figure 77 Nitrogen adsorption/desorption isotherms of the $\mathrm{MgO}$ product calcined at $400{ }^{\circ} \mathrm{C}$ for 3 hour, insert: BJH pore size distribution obtained from desorption isotherms

\subsubsection{Hydrogen storage of electric field assisted porous magnesium oxide}

The hydrogen uptake curves of porous magnesium oxide at $298 \mathrm{~K}$ are shown in Figure 78. The curve followed a linear trend indicating that no apparent saturation point was observed. It had very low hydrogen uptake at pressure below 30 bars whereas the uptake increased vigorously when the pressure reached over 30 bars. The optimum adsorption at 90 bars reached about $0.2 \mathrm{wt} \%$. With the assistance from the PMN-PT, the hydrogen uptake had improved remarkably to $0.25 \mathrm{wt} \%$ at 90 bars, about $25 \%$ increase. The curve still preserved the linear trend and no saturation was expected. The enhancement increased with the increasing of hydrogen pressure and at over 60 bars, the magnitude of 
the enhancement became almost constant indicating the optimum effects of the PMN-PT generated electric field. In order to better understand the effects from the external electric field, DFT computer simulation was carried out on the $\mathrm{Mg}_{5} \mathrm{O}_{5}$ clusters embedded in point charge.

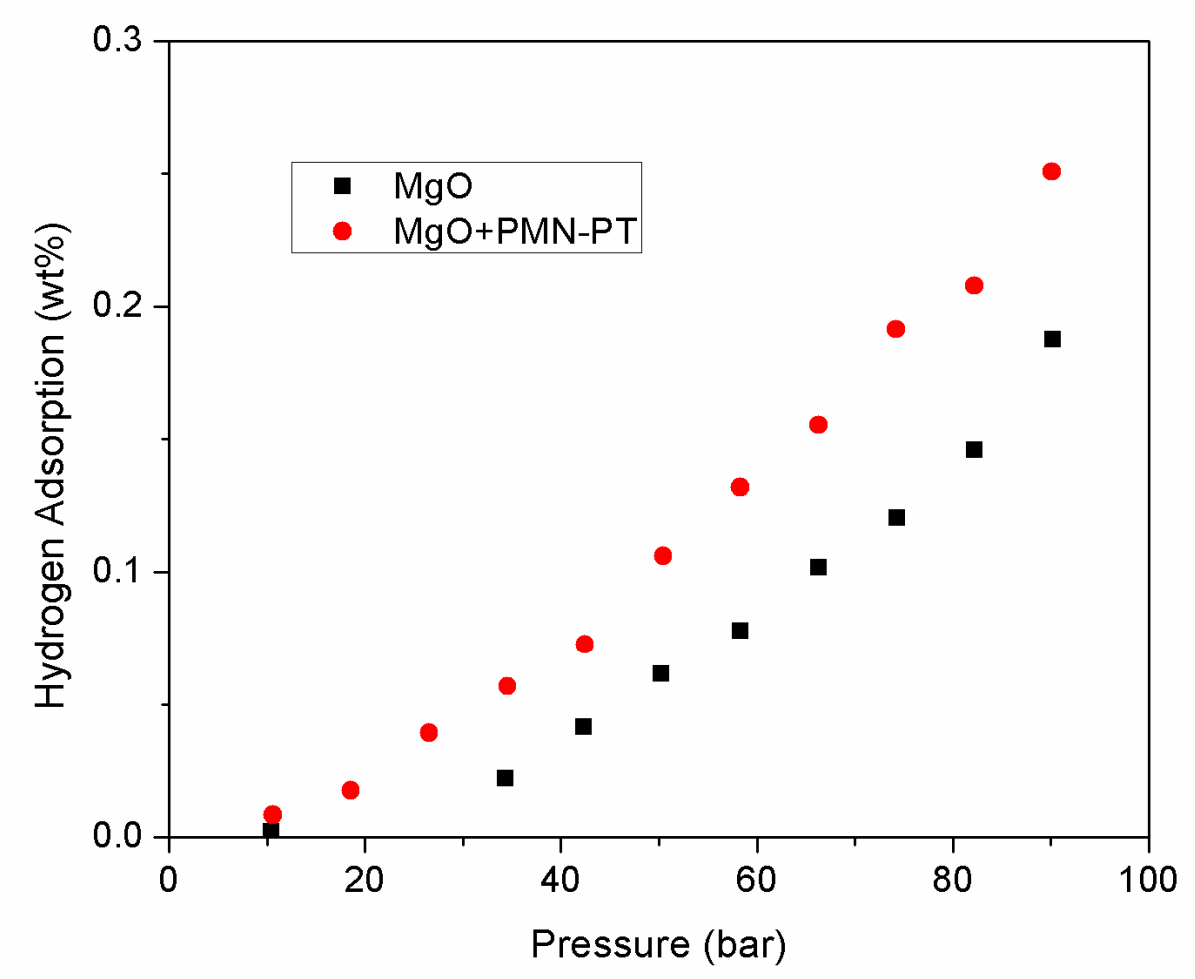

Figure 78 Hydrogen adsorption at $298 \mathrm{~K}$ for the porous MgO sample and MgO+PMN-PT sample

Figure 79 shows the optimized geometry of $\mathrm{Mg}_{5} \mathrm{O}_{5}$ clusters embedded in $13 \times 13 \times 13$ point charges. The surrounding point charges were found to be 0.706 to reproduce the lattice parameter of the $\mathrm{MgO}$ crystal. The cluster was then moved to the point charge surface to calculate the hydrogen adsorption interactions. 


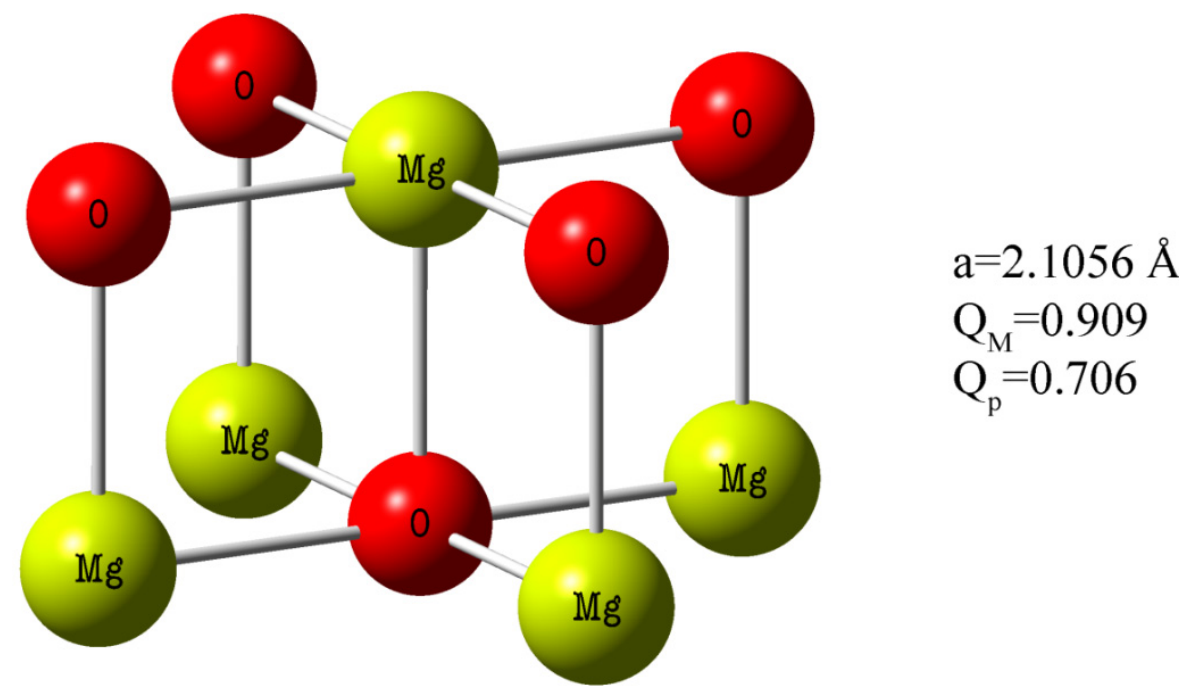

Figure 79 Optimized Mg5O5 clusters in $13 \times 13 \times 13$ point charges, where a is the lattice parameter, $\mathrm{QM}$ is the average Mulliken charge, and $\mathrm{Qp}$ is the magnitude of the point charge

Figure 80 shows the optimized geometry of hydrogen adsorption on magnesium site in magnesium oxide without and under the external electric field.
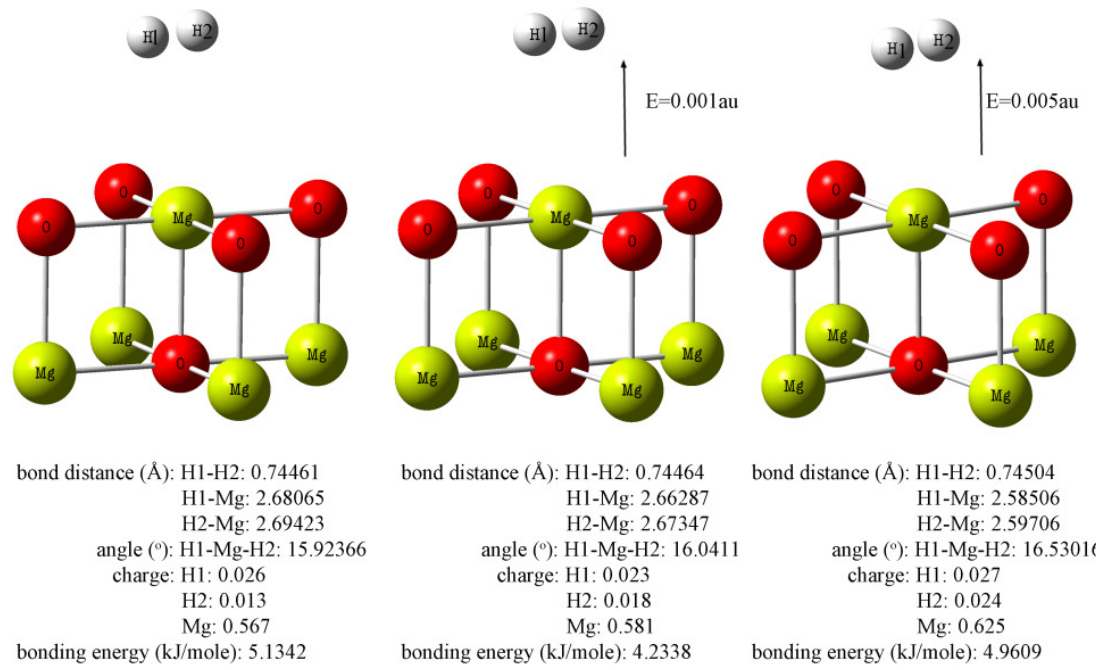
bond distance $(\AA): \mathrm{H} 1-\mathrm{H} 2: 0.74504$ Hl-Mg: 2.58506 angle $\left(^{\circ}\right)$ : H1-Mg-H2: 16.53016 charge: $\mathrm{H} 1: 0.027$ $\mathrm{H} 2: 0.024$ bonding energy ( $\mathrm{kJ} / \mathrm{mole}): 4.2338$

bonding energy ( $\mathrm{kJ} /$ mole) 4.9609

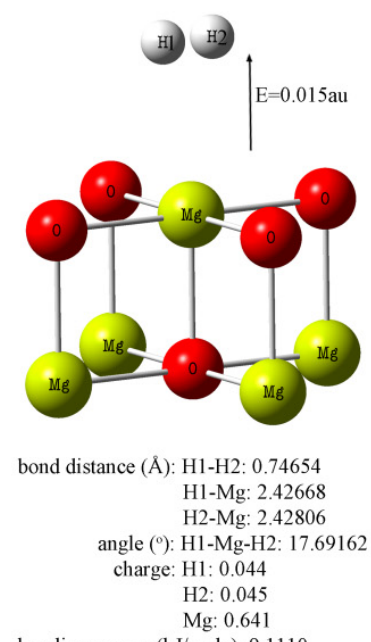

bonding energy $(\mathrm{kJ} / \mathrm{mole}): 9.1110$

Figure 80 Optimized geometry of hydrogen adsorbed on magnesium site under the influence of electric field

Without the external electric field, the $\mathrm{H}-\mathrm{H}$ distance was perturbed about $0.00182 \AA$ (recall from chapter six that the free hydrogen molecule distance is $0.74279 \AA$ ). The 
charges on hydrogen atoms were positive indicating that the electron cloud was pulled to the magnesium site. The electric field was applied along vertical direction, as described in the figure. By supplying a small electric field $0.001 \mathrm{au}$, the $\mathrm{H}-\mathrm{H}$ distance was further affected that the bonding energy increased. With each increase of the electric field strength, hydrogen molecules became more perturbed along with the total binding energy. At electric field of $0.015 \mathrm{au}$, the charges on hydrogen became positive 0.044 , which was about two times of the adsorbed hydrogen without electric field.

From calculations of the partial density of states (DOS), the nature of the chemical bonding in the studied system could be visualized. Figure 81 shows the calculated DOSs of s orbital of hydrogen molecules that adsorbed on the magnesium site of $\mathrm{MgO}$ under the different electric field. For the free hydrogen molecules, there was only one peak which indicated the localization of the s orbital. As the hydrogen molecule adsorbed onto the magnesium site, a small peak around $-6 \mathrm{eV}$ appeared. When the applied electric field strength increased, more peaks emerged and the intensity of the peaks increased. The appearance of the new peaks indicated the overlap of electrons between hydrogen and magnesium. The trend demonstrated that more electrons overlapping occurred as the field strength increased. 


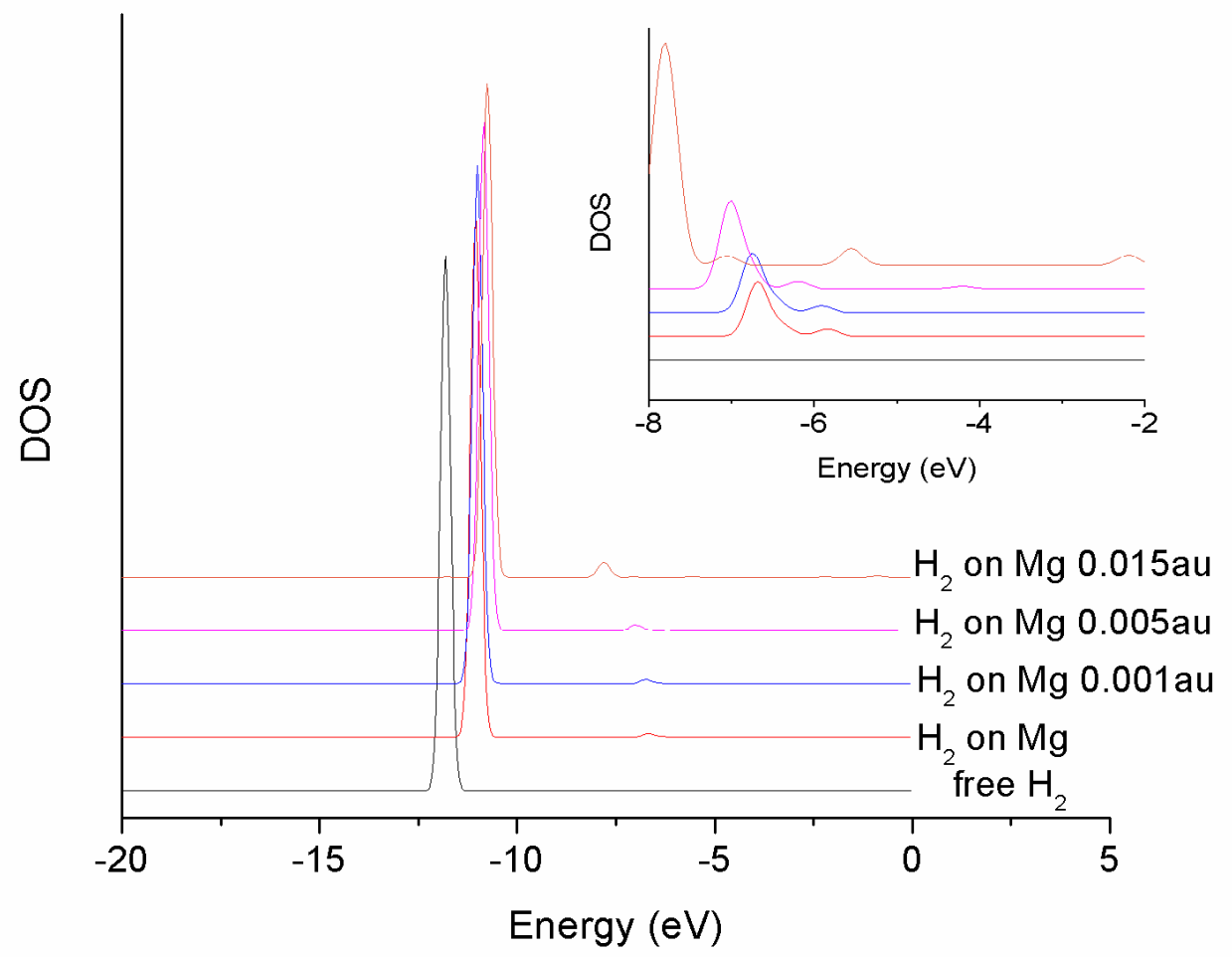

Figure 81 DOSs of s orbital of hydrogen molecules which adsorbed on magnesium site of the magnesium oxide under the applied electric field, insert: higher magnification of the DOSs between 8 to $-2 \mathrm{eV}$

Figure 82 shows a schematic figure of the electron movement under the electric field. With the applied field, the electron clouds of hydrogen molecules were more strongly pulled over the magnesium site, as was evident from the resulting high positive charges of the hydrogen atoms. Therefore, the hydrogen electrons overlapped with the magnesium electrons so that total bonding strength increased. 

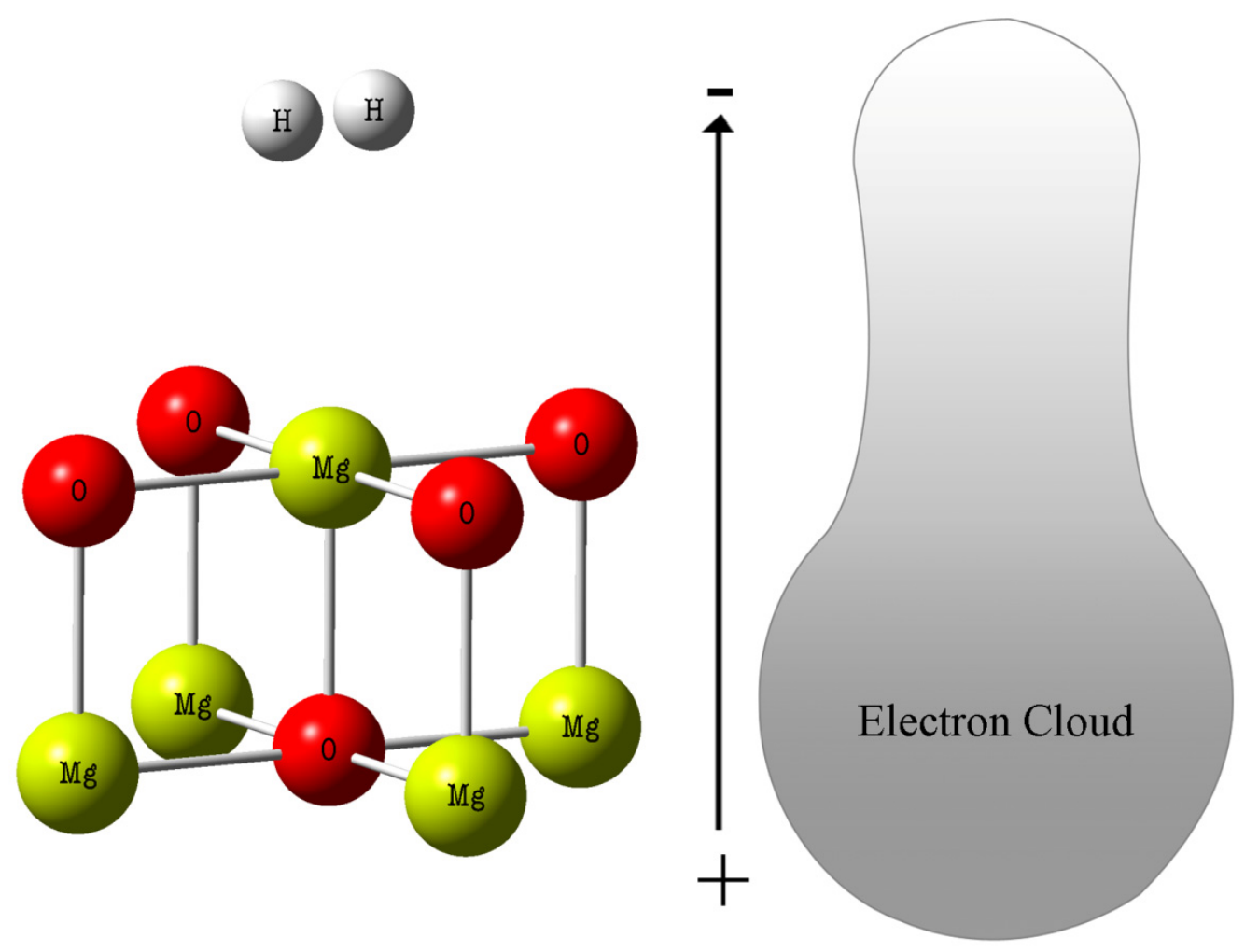

Figure 82 Schematic of the shape of the electron cloud under external electric field

The same calculation was carried out on the hydrogen adsorption on oxygen site of the $\mathrm{MgO}$ under various applied fields, as shown in Figure 83. The adsorption on oxygen site still followed end-on model. Without an electric field, the bonding energy was very small, only $0.5219 \mathrm{~kJ} / \mathrm{mole}$. However, as the field was applied, the bonding energy increased consistent with the increasing of the electric field strength. The $\mathrm{H}-\mathrm{H}$ bond length, H-O distance, and charges also supported this observation. Furthermore, the alignment of hydrogen molecule became more vertical toward the oxygen atom when the field strength became larger. Also large intrinsic dipole moment of the hydrogen molecule was generated by the electric field, as demonstrated by the different signs of charges on two hydrogen atoms. 


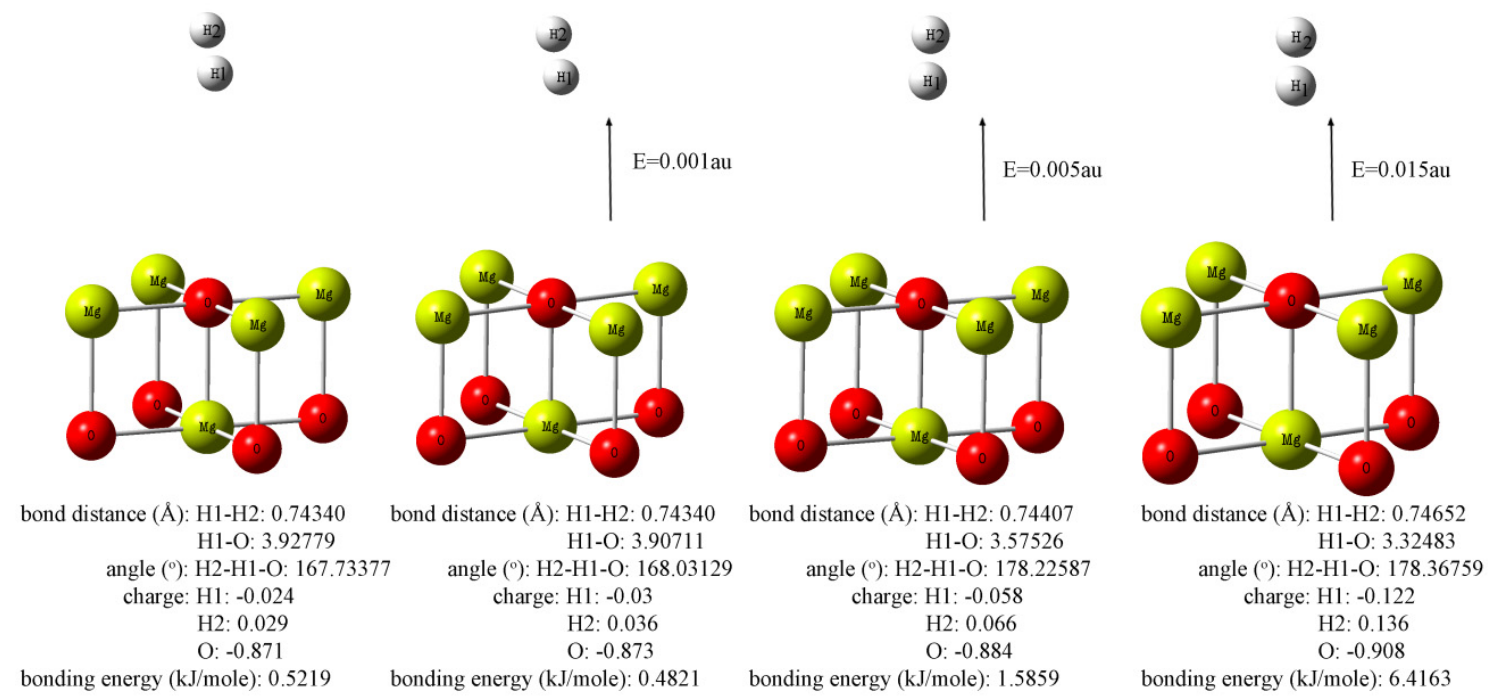

Figure 83 optimized geometry of hydrogen adsorbed on oxygen site under the influence of electric field

Similar to what happened on magnesium site, the electric field had the potential to cause the electrons from hydrogen molecules and oxygen ion to be overlapped. As from Figure 84, more peaks were observed under higher electric field strength, whereas the intensity of the peaks followed the same trend. 


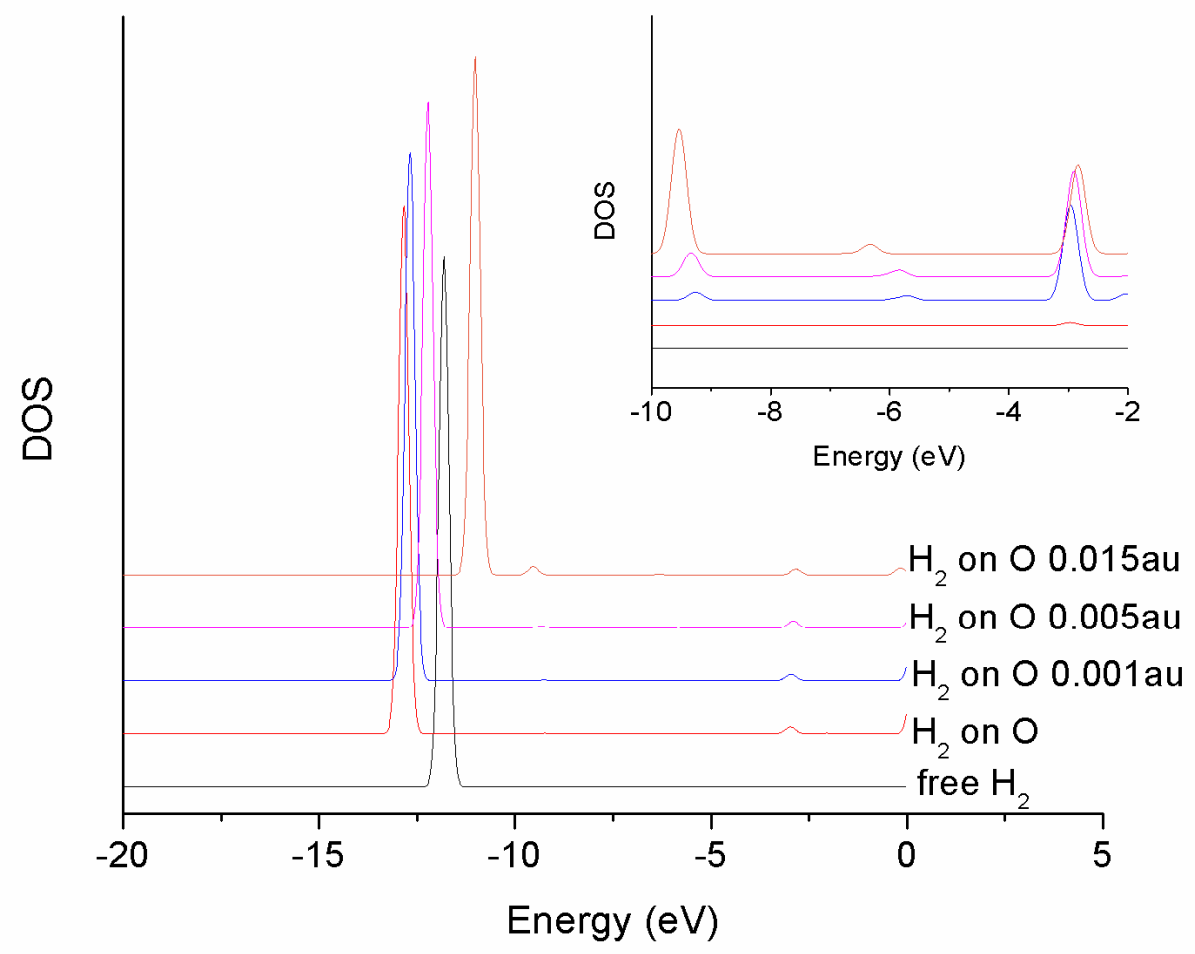

Figure 84 DOSs of s orbital of hydrogen molecules which adsorbed on oxygen site of the magnesium oxide under the applied electric field, insert: higher magnification of the DOSs between $-10 \mathrm{to}-2 \mathrm{eV}$

\subsection{Summary}

The adsorption of hydrogen on porous nickel oxides and magnesium oxides under an external electric field has been quantitatively studied both experimentally and theoretically. The results demonstrated that the storage enhancement from an electric field was remarkable. About $35 \%$ and $25 \%$ increase could be achieved in nickel oxides and magnesium oxides, respectively. Moreover, by combining hydrogen spillover and electric field effects, the storage capacity could be enormously enhanced about $400 \%$. Computer simulation had consistent results with the experimental observations and 
revealed that the electric field pulled hydrogen electrons to the adsorbent sites causing electron overlapping, which tremendously increased the bonding energy. 


\section{CHAPTER 9 SUMMARY}

A novel way to increase the interaction energy between hydrogen and adsorbents has been developed based on the charge enhanced adsorption interaction. Starting from a single molecule computational work, substances with ionic charges could potentially form clusters with hydrogen. These promising effects have been realized experimentally by adsorption enhancement of salt impregnated activated carbon, and computational cluster simulation also verified that the dipole moment of the ionic salts contribute to the enhanced adsorption. Moreover, the application of the externally applied electrical fields has been proposed as another way to induce charges on the adsorbents. The quantitative examination on porous nickel oxides and magnesium oxides clearly demonstrate the concepts that the external field has remarkable enhancement on the total adsorption. And the effects increase with the increasing of field strength. Furthermore, corresponding computer simulations on oxide clusters reveal that the electric field causes the electron clouds of the hydrogen molecules to be attracted to the adsorbent site where overlapping of electrons causes the enhanced interaction.

The DOE target is expected to be realized by future work using highly porous ionic compounds such as magnesium oxides combined with external electric field. 


\section{REFERENCES}

[1] DOE Hydrogen Posture Plan,

www1.eere.energy.gov/hydrogenandfuelcells/pdfs/hydrogen_posture_plan.pdf

[2] Carole Read, John Petrovic, Grace Ordaz, Sunita Satyapal, Advanced Materials for Energy Conversion III: A Symposium in Honor of Drs. Gary Sandrock, Louis Schlapbach, and Seijirau Suda, (2006) 25-35, “The U.S. Department of Energy's Hydrogen Storage Program: The Grand Challenge of Vehicular Hydrogen Storage”.

[3] Transportation Energy Data Book: Edition 22, September 2002, and EIA Annual Energy Outlook 2003, January 2003.

[4] Inventory of U.S. Greenhouse Gas Emissions and Sinks: 1990-2000, EPA-430-R-02003, April 2002.

[5] Hydrogen economy, Wikipedia, http://en.wikipedia.org/wiki/Hydrogen_economy

[6] President speech, http://www.hydrogen.gov/president.html

[7] A. Haryanto, S. Fernando, N. Murali, and S. Adhikari, Energy \& Fuels, 19 (2005) 2098-2106, "Current status of hydrogen production techniques by steam reforming of ethanol: a review".

[8] Z. Chen, Y. Yan, and S. S. E. H. Elnashaie, Chem. Eng. Sci., 59 (2004) 1965-1978, "Catalyst deactivation and engineering control for steam reforming of higher hydrocarbons in a novel membrane reformer".

[9] A National Vision of America's Transition to A Hydrogen Economy-To 2030 and beyond; U.S. Department of Energy (DOE): Washington, DC, 2002. 
[10] J. Ohi, J. Mater. Res., 20 (2005) 3180-3187, “Hydrogen energy cycle: an overview”.

[11] F. Kreith, Journal of Energy Resources Technology, 126 (2004) 249-257, "Fallacies of a hydrogen economy: a critical analysis of hydrogen production and utilization".

[12] J. A. Turner, Science, 305 (2004) 972-974, “Sustainable hydrogen production”.

[13] O. Khaselev, J. A. Turner, Science, 280 (1998) 425-427, “A MonolithicPhotovoltaic-Photoelectrochemical Device for hydrogen production via water splitting”.

[14] R. Agrawal, M. Offutt, M. P. Ramage, AIChE Journal, 51 (2005) 1582-1589, "Hydrogen economy - an opportunity for chemical engineers?"

[15] D. B. Levin, L. Pitt, M. Love, Int. J. Hydrogen Energy, 29 (2004) 173-185, "Biohydrogen production: prospects and limitations to practical application".

[16] S. Kasahara, G. J. Hwang, H. Nakajima, H. S. Choi, K. Onuki and M. Nomura, Journal of Chemical Engineering of Japan, 36 (2003) 887-899, "Effects of process parameters of the IS process on total thermal efficiency to produce hydrogen from water".

[17] DOE hydrogen delivery

sheet http://www1.eere.energy.gov/hydrogenandfuelcells/pdfs/doe h2 delivery.pdf

[18] FY2005 Annual Progress Report for Hydrogen, Fuel Cells and Infrastructure Technologies Program, DOE Office of Hydrogen, Fuel Cells and Infrastructure Technologies, October 2005.

[19] L. Schlapbach and A. Züttel, Nature, 414 (2001) 353-358, "Hydrogen-storage materials for mobile applications". 
[20] DOE hydrogen fuel cell fact

sheet, http://www1.eere.energy.gov/hydrogenandfuelcells/pdfs/doe_h2_fuelcell_factsheet . pdf

[21] DOE hydrogen fuel cell comparison

sheet, http://www.eere.energy.gov/hydrogenandfuelcells/fuelcells/pdfs/fccomparison_cha rt.pdf

[22] JoAnn Milliken, Workshop on Manufacturing R\&D for the Hydrogen Economy, Washington, DC, July 13, 2005, "The President's Hydrogen Fuel Initiative".

[23] W. B. Leung, N. H. March and H. Motz, Physics Letters A, 56 (1976) 425-426, "Primitive phase diagram for hydrogen".

[24] L. Zhou, Renewable \& Sustainable Energy Reviews, 9 (2005) 395-408, "Progress and problems in hydrogen storage methods".

[25] Giselle Sandí, The Electrochemical Society Interface, Fall 2004, 40-44, "Hydrogen storage and its limitations".

[26] A. Züttel, IEA Renewable Energy Working Party Seminar, 2003, "Storage and Distribution", http://www.iea.org/Textbase/work/2003/hydrogen/sessioniii/zuttel.pdf [27] Hydrogen Materials Group, http://www.aacg.bham.ac.uk/hydrogen/storage.htm [28] A. Züttel, Naturwissenschaften, 91 (2004) 157-172, "Hydrogen storage methods".

[29] S. Brunauer, P. H. Emmett, and E. Teller, Journal of the American Chemical Society, 60 (1938) 309-319, "Adsorption of gases in multimolecules layers".

[30] R. A. Beebe, J. Biscoe, W. R. Smith, and C. B. Wendell, Journal of the American Chemical Society, 69 (1947) 95-101, "Heats of Adsorption on Carbon Black". 
[31] H. Jin, Y. S. Lee, and I. Hong, Catalysis Today, 120 (2007) 399-406, "Hydrogen adsorption characteristics of activated carbon".

[32] M. G. Nijkamp, J. E. M. J. Raaymakers, A. J. van Dillen, and K. P. de Jong, Applied Physics A, 72 (2001) 619-623, "Hydrogen storage using physisorption - materials demands".

[33] S. J. Gregg and K. S. W. Sing, "Adsorption, Surface Area and Porosity", London and New York, 1967.

[34] X. B. Zhao, B. Xiao, A. J. Fletcher, K. M. Thomas, Journal of Physical Chemistry B, 109 (2005) 8880-8888, “Hydrogen Adsorption on Functionalized Nanoporous Activated Carbons".

[35] K. M. Thomas, Catalysis Today, 120 (2007) 389-398, "Hydrogen adsorption and storage on porous materials".

[36] G. Sandi, The Electrochemical Society Interface, 13 (2004) 40-44, "Hydrogen storage and its limitations".

[37] A. C. Dillon, K. M. Jones, T. A. Bekkedahl, C. H. Kiang, D. S. Bethune, and M. J. Heben, Nature, 386 (1997) 377-379, "Storage of hydrogen in single walled carbon nanotubes".

[38] G. G. Tibbetts, C. P. Meisner, and C. H. OLK, Carbon, 39 (2001) 2291-2301, "Hydrogen storage capacity of carbon nanotubes, filaments, and vapor grown fibers".

[39] H. Takagi, H. Hatori, Y. Soneda, N. Yoshizawa, and Y. Yamada, Materials Science and Engineering B, 108 (2004) 143-147, “Adsorptive hydrogen storage in carbon and porous materials". 
[40] B. Panella, M. Hirscher, and S. Roth, Carbon, 43 (2005) 2209-2214, "Hydrogen adsorption in different carbon nanostructures".

[41] R. Zacharia, K. Y. Kim, S. W. Hwang, and K. S. Nahm, Catalysis Today, 120 (2007) 426-431, "Intrinsic linear scaling of hydrogen storage capacity of carbon nanotubes with the specific surface area".

[42] G. Stan and M. W. Cole, Journal of Low Temperature Physics, 110 (1998) 539-544, "Hydrogen adsorption in nanotubes".

[43] K. A. Williams and P. C. Eklund, Chemical Physics Letters, 320 (2000) 352-358, "Monte Carlo simulations of $\mathrm{H} 2$ physisorption in finite-diameter carbon nanotube ropes". [44] S. Li, W. Pan, and Z. Mao, International Journal of Hydrogen Energy, 30 (2005) 643-648, "A comparative study of the electrochemical hydrogen storage properties of activated carbon and well-aligned carbon nanotubes mixed with copper".

[45] H. Feng, Y. Wei, C. Shao, Y. Lai, S. Feng, and Z. Dong, International Journal of Hydrogen Energy, 32 (2007) 1294-1298, "Study on overpotential of the electrochemical hydrogen storage of multiwall carbon nanotubes".

[46] X. Chen, Y. Zhang, X. P. Gao, G. L. Pan, X. Y. Jiang, J. Q. Qu, F. Wu, J. Yan, and D. Y. Song, International Journal of Hydrogen Energy, 29 (2004) 743-748, "Electrochemical hydrogen storage of carbon nanotubes and carbon nanofibers".

[47] M. Miranda-Hernández and M. E. Rincón, Journal of Solid State Electrochemistry, 9 (2005) 646-652, "Carbon paste electrodes: correlation between the electrochemical hydrogen storage capacity and the physicochemical properties of carbon blacks". 
[48] X. B. Yu, G. S. Walker, N. Bowering, D. M. Grant, J. Chen, Z. Wu, and B. J. Xia, Electrochemical and Solid-State Letter, 8 (2005) A596-A598, "Electrochemical hydrogen storage in hydride-carbon composite".

[49] A. Züttel, P. Sudan, Ph. Mauron, T. Kiyobayashi, Ch. Emmenegger, and L. Schlapbach, International Journal of Hydrogen Energy, 27 (2002) 203-212, "Hydrogen storage in carbon nanostructures".

[50] X. Yan, X. Gao, Y. Li, Z. Liu, F. Wu, Y. Shen, and D. Song, Chemical Physics Letters, 372 (2003) 336-341, “The surface decoration and electrochemical hydrogen storage of carbon nanofibers".

[51] Z. Y. Zhong, Z. T. Xiong, L. F. Sun, J. Z. Luo, P. Chen, X. Wu, J. Lin, and K. L. Tan, The Journal of Physical Chemistry B, 106 (2002) 9507-9513, "Nanosized Nickel(or Cobalt)/Graphite Composites for Hydrogen Storage".

[52] G. G. Libowitz, H. F. Hayes, and T. R. P. Gibb, Journal of Physical Chemistry, 62 (1958) 76-79, “The System Zirconium-Nickel and Hydrogen”.

[53] J. J. Reilly and R. H. Wiswall, Inorganic Chemistry, 7 (1968) 2254-2256, "Reaction of hydrogen with alloys of magnesium and nickel and the formation of $\mathrm{Mg} 2 \mathrm{NiH} 4$ ".

[54] J. J. Reilly and R. H. Wiswall, Inorganic Chemistry, 13 (1974) 218-222, "Formation and properties of iron titanium hydride".

[55] M. V. C. Sastri, B. Viswanathan, and S. Srinivasa Murthy, "Metal Hydrides: Fundamentals and Applications”, Narosa Publishing House, 1998.

[56] A. Züttel, "Hydrogen storage methods and materials". http://www.ifres.ch/Homepage/DB/Hydrogen.pdf 
[57] B. Bogdanović, R. A. Brand, A. Marjanović, M. Schwickardi, and J. Tolle, Journal of Alloys and Compounds, 302 (2000) 36-58, "Metal-doped sodium aluminium hydrides as potential new hydrogen storage materials".

[58] H. I. Schlesinger and Herbert C. Brown, Journal of the American Chemical Society, 62 (1940) 3429-3435, "Metallo Borohydrides. III. Lithium Borohydride”.

[59] A. Züttel, P. Wenger, S. Rentsch, P. Sudan, Ph. Mauron and Ch. Emmenegger, Journal of Power Sources, 118 (2003) 1-7, “LiBH 4 a new hydrogen storage material”.

[60] H. I. Schlesinger, Herbert C. Brown, Henry R. Hoekstra, and Louis R. Rapp, Journal of the American Chemical Society, 75 (1953) 199-204, "Reactions of Diborane with Alkali Metal Hydrides and Their Addition Compounds. New Syntheses of Borohydrides. Sodium and Potassium Borohydrides".

[61] W. Grochala and P. P. Edwards, Chemical Reviews, 104 (2004) 1283-1315, "Thermal Decomposition of the Non-Interstitial Hydrides for the Storage and Production of Hydrogen".

[62] G. J. Thomas, K. J. Gross, N. Y. C. Yang and C. Jensen, Journal of Alloys and Compounds, 330-332 (2002) 702-707, "Microstructural characterization of catalyzed NaAlH4"

[63] F. W. Dafert and R. Miklauz, Monatshefte für Chemie, 31 (1910) 981-996, Über einige neue Verbindungen von Stickstoff und Wasserstoff mit Lithium".

[64] Y. H. Hu and E. Ruckenstein, Industrial \& Engineering Chemistry Research, 42 (2003) 5135 - 5139, "H2 Storage in Li3N. Temperature-Programmed Hydrogenation and Dehydrogenation". [65] P. Chen, Z. Xiong, J. Luo, J. Lin and K. L. Tan, Nature, 420 (2002) 302-304, "Interaction of hydrogen with metal nitrides and imides".

[66] Y. H. Hu and E. Ruckenstein, Journal of Physical Chemistry A, 107 (2003) 9737-9739, 
"Ultrafast Reaction between LiH and NH3 during H2 Storage in Li3N".

[67] F. Schüth, B. Bogdanović, and M. Felderhoff, Chemical Communications, (2004) 22492258, "Light metal hydrides and complex hydrides for hydrogen storage".

[68] Renzhi Ma, Yoshio Bando, Hongwei Zhu, Tadao Sato, Caliu Xu, and Dehai Wu, Journal of the American Chemical Society, 124 (2002) 7672-7673, "Hydrogen Uptake in Boron Nitride Nanotubes at Room Temperature".

[69] R. E. Barajas-Barraza and R. A. Guirado-López, Physical Review B, 66 (2002) 1554261-15542612, “Clustering of H2 molecules encapsulated in fullerene structures”.

[70] Seung-Hoon Jhi and Young-Kyun Kwon, Physical Review B, 69 (2004) 2454071-4, "Hydrogen adsorption on boron nitride nanotubes: A path to room-temperature hydrogen storage".

[71] Xiaojun Wu, Jinlong Yang, J. G. Hou, and Qingshi Zhu, Physical Review B, 69 (2004) 153411-4, “ Deformation-induced site selectivity for hydrogen adsorption on boron nitride nanotubes".

[72] Chengchun Tang, Yoshio Bando, Xiaoxiao Ding, Shouren Qi, and Dmitri Golberg, Journal of the American Chemical Society, 124 (2002) 14550-14551, “Catalyzed collapse and enhanced hydrogen storage of BN nanotubes".

[73] N.1 L. Rosi, J. Eckert, M. Eddaoudi, D. T. Vodak, J. Kim, M. O'Keeffe and O. M. Yaghi, Science, 300 (2003) 1127-1129, "Hydrogen storage in microporous metal-organic frameworks. (Reports)".

[74] T. Yildirim and M. R. Hartman, Physical Review Letters, 95 (2005) 2155041-4, "Direct Observation of Hydrogen Adsorption Sites and Nanocage Formation in MetalOrganic Frameworks". 
[75] H. Li, M. Eddaoudi, M. O'Keeffe and O. M. Yaghi, Nature, 402 (1999) 276-279, "Design and synthesis of an exceptionally stable and highly porous metal-organic framework".

[76] R. N. Barnett1 and K. B. Whaley, Zeitschrift für Physik D Atoms, Molecules and Clusters, 31 (1994) 75-84, "Molecules impurities in helium clusters".

[77] G. Tejeda, J.M. Fernández, S. Montero, D. Blume, and J. P. Toennies, Physical Review Letters, 92 (2004) 223401-223404, "Raman Spectroscopy of Small Para-H2 Clusters Formed in Cryogenic Free Jets".

[78] Jesús Navarro and Rafael Guardiola, Journal of Low Temperature Physics, 148 (2007) 857-861, “Energetics and Structure of Small Para-Hydrogen Clusters”.

[79] K. Hiraoka and P. Kebarle, Journal of Chemical Physics, 62 (1975) 2267-2270, “A Determination of the Stabilities of $\mathrm{H}_{5}^{+}, \mathrm{H}_{7}{ }^{+}, \mathrm{H}_{9}{ }^{+}$and $\mathrm{H}_{11}{ }^{+}$from Measurement of the Gas Phase Ion Equilibria $\mathrm{H}_{\mathrm{n}}^{+}+\mathrm{H}_{2}=\mathrm{H}_{\mathrm{n}+2}^{+}(\mathrm{n}=3,5,7,9)$ '.

[80] R. J. Beuhler, S. Ehrenson, and L. Friedman, Journal of Chemical Physics, 79 (1983) 5982-5990, "Hydrogen cluster ion equilibria".

[81] M. Okumura, L. I. Yeh, and Y. T. Lee, Journal of Chemical Physics, 88 (1988) 7991, "Infrared Spectroscopy of the Cluster Ions $\mathrm{H}_{3}{ }^{+}\left(\mathrm{H}_{2}\right)_{\mathrm{n}}$ ".

[82] R. Mills, Fusion Technology, 37 (2000) 157-182, "Novel hydrogen compounds from a potassium carbonate electrolytic cell”.

[83] M. Farizon, H. Chermette, and B. Farizon-Mazuy, Journal of Chemical Physics, 96 (1992) 1325-1332, "Structure and energetic of hydrogen clusters. Structures of $\mathrm{H}_{11}{ }^{+}$and $\mathrm{H}_{13}{ }^{+}$. Vibrational frequencies and infrared intensities of the $\mathrm{H}_{2 \mathrm{n}+1}{ }^{+}$clusters $(\mathrm{n}=2-6)$ ”. 
[84] M. Barbatti, G. Jalbert, M. A. C. Nascimento, Journal of Chemical Physics, 113 (2000) 4230-4237, "Isomeric structures and energies of $\mathrm{H}_{\mathrm{n}}{ }^{+}$clusters $(\mathrm{n}=13,15$, and 17)".

[85] Y. Ohta, K. Ohta, and K. Kinugawa, Journal of Chemical Physics, 121 (2004) 10991-109999, “Quantum effect on the internal proton transfer and structural fluctuation in the $\mathrm{H}_{5}^{+}$cluster".

[86] I. Štich, D. Marx, M. Parrinello, and K. Terakura, Journal of Chemical Physics, 107 (1997) 9482-9492, "Protonated hydrogen clusters".

[87] B. Farizon, M. Farizon, H. Razafinjanahary, and H. Chermette, Physical Review B, 60 (1999) 3821-3828, "Structure and energetic of $\mathrm{H}_{15}{ }^{+}$hydrogen clusters".

[88] H. Chermette, and I. V. Ymmud, Physical Review B, 63 (2001) 1654271-16542710, "Structure and stability of hydrogen clusters up to $\mathrm{H}_{21}{ }^{+}$".

[89] H. Chermette, H. Razafinjanahary, and L. Carrion, Journal of Chemical Physics, 107 (1997) 10643-10651, “A density functional especially designed for hydrogen-only systems".

[90] L. Gagliardi, and Pekka Pyykkő, Journal of American Chemical Society, 126 (2004) 15014-15015, "How many hydrogen atoms can be bound to a metal? Predicted $\mathrm{MH}_{12}$ species".

[91] C. W. Bauschlicher, Jr., and P. Maitre, Journal of Physical Chemistry, 99 (1995) 3444-3447, "Structure of $\mathrm{Co}(\mathrm{H} 2) \mathrm{n}+$ clusters, for $\mathrm{n}=1-6$ ".

[92] P. R. Kemper, J. Bushnell, G. V. Helden, and M. T. Bowers, Journal of Physical Chemistry, 97 (1993) 52-58, “Cobalt-hydrogen (Co+.cntdot.(H2)n) clusters: binding energies and molecules parameters". 
[93] J. E. Bushnell, P. R. Kemper, P. Maitre, and M. T. Bowers, Journal of American Chemical Society, 116 (1994) 9710-9718, "Insertion of $\mathrm{Sc}^{+}$into $\mathrm{H}_{2}$ : The first example of cluster-mediated $\sigma$-bond activation by a transition metal center".

[94] J. E. Bushnell, P. Maitre, P. R. Kemper and M. T. Bowers, Journal of Chemical Physics, 106 (1997) 10153-10167, "Binding energies of $\operatorname{Ti}^{+}\left(\mathrm{H}_{2}\right)_{1-6}$ clusters: theory and experiment".

[95] M. J. Manard, J. E. Bushnell, S. L. Bernstein, and M. T. Bowers, Journal of Physical Chemistry, 106 (2002) 10027-10032, "Origin of bonding interactions in $\mathrm{Cu}_{2}^{+}\left(\mathrm{H}_{2}\right)_{\mathrm{n}}$ clusters: an experimental and theoretical investigation”.

[96] J. E. Bushnell, P. R. Kemper, and M. T. Bowers, Journal of Physical Chemistry, 98 (1994) 2044-2049, " $\mathrm{Na}^{+} / \mathrm{K}^{+} \cdot\left(\mathrm{H}_{2}\right)_{1,2}$ clusters: binding energies from theory and experiment".

[97] C. Emmeluth, B. L. J. Poad, C. D. Thompson, G. H. Weddle, and E. J. Bieske, Journal of Chemical Physics, 126 (2007) 204309, "Infrared spectra of the $\mathrm{Li}^{+}-\left(\mathrm{H}_{2}\right)_{\mathrm{n}}(\mathrm{n}=1-$ 3) cation complexes".

[98] Y. K. Bae, P. C. Cosby and D. C. Lorents, Chemical Physics Letters, 159 (1989) 214-220, "Observation of shell structures in the growth of microcluster ions".

[99] S. Moroni, M. Botti, S. De Palo, and A. R. W. McKellar, Journal of Chemical Physics, 122 (2005) 094314, "Small para-hydrogen clusters doped with carbon monoxide: Quantum Monte Carlo simulations and observed infrared spectra”.

[100] M. A. Lieberman and A. J. Lichtenberg, Principles of Plasma Discharges and Materials Processing, 1994, New York, NY, John Wiley and Sons, Inc. 
[101] Plasma etching fundamentals, http://www.clarycon.com/plasmacoupling2.html

[102] F. F. Chen, Plasma Physics and Controlled Fusion, 33 (1991) 339-364, "Plasma ionization by helicon waves".

[103] R. W. Boswell, Plasma Physics and Controlled Fusion, 26 (1984) 1147-1162,

"Very efficient plasma generation by whistler waves near the lower hybrid frequency".

[104] R. W. Boswell and F. F. Chen, IEEE Transactions on Plasma Science, 25 (1997) 1229-1244, "Helicons-the early years".

[105] F. F. Chen, J. D. Evans and G. R Tynan, Plasma Sources Science and Technology, 10 (2001) 236-249, "Design and performance of distributed helicon sources".

[106] E. Thomas, Jr., W. E. Amatucci, C. Compton, B. Christy, and J. D. Jackson, Physics of Plasmas, 10 (2003) 1159-1163, "Periodic long-range transport in a large volume de glow discharge dusty plasma".

[107] M. Mozjetchkov, T. Takanashi, Y. Oka, K. Tsumori, M. Osakabe, O. Kaneko, Y. Takeiri, and T. Kuroda, Review of Scientific Instruments, 69 (1998) 971-973, "Microwave plasma source for the negative hydrogen ion production".

[108] J. Park, I. Henins, H. W. Herrmann, G. S. Selwyn, J. Y. Jeong, R. F. Hicks, D. Shim and C. S. Chang, Applied Physics Letters, 76 (2000) 288-290, “An atmoshperic pressure plasma source".

[109] L. Lianos, D. Parrat, H. Q. Tran, and D. M. Tran, Journal of Vacuum Science \& Technology, A: Vacuum, Surfaces, and Films, 12 (1994) 2491-2498, "Secondary ion mass spectrometry time of flight and in situ x-ray photoelectron spectroscopy studies of polymer surface modifications by a remote oxygen plasma treatment". 
[110] S. R. Wylie, A. I. Al-Shamma'a, J. Lucas, and R. A. Stuart, Journal of Materials Processing Technology, 153-154 (2004) 288-293, “An atmoshperci microwave palsma jet for ceramic material processing”.

[111] Y. B. Golubovskii, R. V. Kozakov, V. A. Maiorov, A. V. Meshchanov, I. A. Porokhova, and A. Rousseau, Journal of Physics D: Applied Physics, 37 (2004) 868-874, "Dynamics of gas heating in a pulsed microwave nitrogen discharge at intermediate pressures".

[112] A. I. Al-Shamma'a, S. R. Wylie, J. Lucas and C. F. Pau, Journal of Physics D: Applied Physics, 34 (2001) 2734-2741, "Design and construction of a $2.45 \mathrm{GHz}$ waveguide-based microwave plasma jet at atmoshperic pressure for material processing”. [113] M. J. Shenton and G. C. Stevens, IEEE Transactions on Plasma Science, 30 (2002) 184-185, “Optical emission from atmospheric pressure nonequilibrium plasma”.

[114] P. J. Stephens, F. J. Devlin, C. F. Chabalowski, and M. J. Frisch, Journal of Physical Chemistry, 98 (1994) 11623-11627, “Ab Initio Calculation of Vibrational Absorption and Circular Dichroism Spectra Using Density Functional Force Fields”.

[115] C. Lee, W. Yang, and R. G. Parr, Physical Review B, 37 (1988) 785-789, "Development of the Colle-Salvetti correlation-energy formula into a functional of the electron density".

[116] A. D. Becke, Physical Review A, 38 (1988) 3098-3100, "Density-functional exchange-energy approximation with correct asymptotic behavior".

[117] A. D. Becke, Journal of Chemical Physics, 98 (1993) 5648-5652, "Densityfunctional thermochemistry. III. The role of exact exchange". 
[118] M. J. Frisch, et al., GAUSSIAN 03, Revision C.02, Gaussian Inc., Wallingford, CT, 2004.

[119] R. C. Weast, et al., CRC Handbook of Chemistry and Physics, $66^{\text {th }}$ edition, 1985, Chemical Rubber Company.

[120] J. Hayashi, T. Horikawa, I. Takeda, K. Muroyama, F. N. Ani, Carbon, 40 (2002) 2381-2386, "Preparing activated carbon from various nutshells by chemical activation with $\mathrm{K}_{2} \mathrm{CO}_{3} "$.

[121] J. Yang, Z. Shen, Z. Hao, Carbon, 42 (2004) 1872-1875, "Preparation of highly microporous and mesoporous carbon from the mesophase pitch and its carbon foams with KOH”.

[122] Y. Ji, T. Li, L. Zhu, X. Wang, Q. Lin, Applied Surface Science, 254 (2007) 506512, "Preparation of activated carbons by microwave heating KOH activation".

[123] Y. Guo, S. Yang, K. Yu, J. Zhao, Z. Wang, H. Xu, Materials Chemistry and Physics, 74 (2002) 320-323, "The preparation and mechanism studies of rice husk based porous carbon".

[124] M. Jordá-Beneyto, F. Suárez-García, D. Lozano-Castelló, D. Cazorla-Amorós, A. Linares-Solano, Carbon, 45 (2007) 293-303, "Hydrogen storage on chemically activated carbons and carbon nanomaterials at high pressures".

[125] Y. Xu, J. Li, Y. Zhang, W. Chen, Surface Science, 525 (2003) 13-23, "CO adsorption on $\mathrm{MgO}(001)$ surface with oxygen vacancy and its low-coordinated surface sites: embedded cluster model density functional study employing charge self-consistent technique". 
[126] A. Damin, R. Dovesi, A. Zecchina, P. Ugliengo, Surface Science, 479 (2001) 255272, " $\mathrm{CO} / \mathrm{MgO}\left(\begin{array}{ll}0 & 0\end{array}\right)$ at different $\mathrm{CO}$ coverages: a periodic ab initio Hartree-Fock and B3-LYP study".

[127] T. Bredow, G. Geudtner, K. Jug, Journal of Computational Chemistry, 22 (2001) 89-101, "Development of the cyclic cluster approach for ionic systems".

[128] A. B. Anderson, Chemical Physics Letters, 72 (1980) 514-517, "NiO Bulk properties: Initial-state molecules-orbital $\mathrm{Ni}_{4} \mathrm{O}_{4}$ and $\mathrm{Ni}_{13} \mathrm{O}_{14}$ cluster studies".

[129] X. Xu, H. Nakatsuji, M. Ehara, X. Lü, N. Q. Wang, Q. E. Zhang, Chemical Physics Letters, 292 (1998) 282-288, "Cluster modeling of metal oxides: the influence of the surrounding point charges on the embedded cluster".

[130] T.P. Blacha and E.MacA. Gray, Journal of Alloys and Compounds, 446-447 (2007) 692697, "Sieverts apparatus and methodology for accurate determination of hydrogen uptake by light-atom hosts".

[131] Crystallography Open Database, http://www.crystallography.net/

[132] Zheng Shi, Jiujun Zhang, Zhong-Sheng Liu, Haijiang Wang, David P. Wilkinson, Electrochimica Acta, 51 (2006) 1905-1916, "Current status of ab initio quantum chemistry study for oxygen electroreduction on fuel cell catalysts".

[133] P. Bénard and R. Chahine, Langmuir, 17 (2001) 1950-1955, "Determination of the adsorption isotherms of hydrogen on activated carbons above the critical temperature of the adsorbate over wide temperature and pressure ranges".

[134] X. B. Zhao, B. Xiao, A. J. Fletcher, and K. M. Thomas, Journal of Physical Chemistry B, 109 (2005) 8880-8888, "Hydrogen adsorption on functionalized nanoporous activated carbons". 
[135] Y. Kojima, Y. Kawai, A. Koiwai, N. Suzuki, T. Haga, T. Hioki and K. Tange, Journal of Alloys and Compounds, 421 (2006) 204-208, "Hydrogen adsorption and desorption by carbon materials".

[136] Y. H. Hu and E. Ruckenstein, Advances in Catalysis, 48 (2004) 297-345, "Catalytic conversion of methane to synthesis gas by partial oxidation and $\mathrm{CO}_{2}$ reforming".

[137] Z. P. Guo, L. Yuan, K. Konstantinov, Z. G. Huang, H. K. Liu, Materials Letters, 60 (2006) 3891-3894, "Preparation of spherical clusters of metal oxide nanorods and their hydrogen storage behavior".

[138] X. Hu, B. O. Skadtchenko, M. Trudeau, and D. M. Antonelli, Journal of the American Chemical Society, 128 (2006) 11740-11741, "Hydrogen storage in chemically reducible mesoporous and microporous Ti oxides".

[139] Y. Wang, J. Cao, S. Wang, X. Guo, J. Zhang, H. Xia, S. Zhang, and S. Wu, Journal of Physical Chemistry C, 112 (2008) 17840-17808, "Facile synthesis of porous \#-FeO nanorods and their application in ethanol sensors".

[140] K-W. Nam, K-B. Kim, Journal of the Electrochemical Society, 149 (2002) A346A354, "A study of the preparation of $\mathrm{NiO}_{\mathrm{x}}$ electrode via electrochemical route for supercapacitor applications and their charge storage mechanism”.

[141] Venkat Srinivasan and John W. Weidner, Journal of the Electrochemical Society, 147 (2000) 880-885, “Studies on the capacitance of nickel oxide films: effect of heating temperature and electrolyte concentration”. 
[142] Q. Huo, D. I. Margolese, G. D. Stucky, Chemistry of Materials, 8 (1996) 11471160, "Surfactant control of phases in the synthesis of mesoporous silica-based materials".

[143] S. Banerjee, A. Santhanam, A. Dhathathreyan, and P. M. Rao, Langmuir, 19 (2003) 5522-5525, "Synthesis of ordered hexagonal mesostructured nickel oxide".

[144] Piezoelectric, Wikipedia, http://en.wikipedia.org/wiki/Piezoelectric

[145] Piezoelectric materials, http://www.piezomaterials.com/

[146] W. Xing, F. Li, Z-F. Yan, G. Q. Lu, Journal of Power Sources, 134 (2004) 324330, "Synthesis and electrochemical properties of mesoporous nickel oxide".

[147] J. Zhang, X. Wang, C. Wu, H. Wang, B. Yi, and H. Zhang, React. Kinet. Catal. Lett., 83 (2004) 229-236, "Preparation and characterization of Pt/C catalysts for PEMFC cathode: effect of different reduction methods".

[148] M. Kim, J-N. Park, H. Kim, S. Song, W-H. Lee, Journal of Power Sources, 163 (2006) 93-97, “The preparation of $\mathrm{Pt} / \mathrm{C}$ catalysts using various carbon materials for the cathode of PEMFC".

[149] H. Kim, J-N. Park, W-H. Lee, Catalysis Today, 87 (2003) 237-245, "Preparation of platinum-based electrode catalysts for low temperature fuel cell”.

[150] N. M. O'Boyle, A. L. Tenderholt and K. M. Langner. J. Comp. Chem., 29 (2008) 839-845, "cclib: A library for package-independent computational chemistry algorithms".

[151] A. J. Lachawiec, G. Qi, and R. T. Yang, Langmuire, 21 (2005) 11418-11424, "Hydrogen storage in nanostructured carbons by spillover: bridge-building enhancement". 
[152] Y. Li, and R. T. Yang, Journal of the American Chemical Society, 128 (2006) 8136-8137, "Hydrogen storage in metal-organic frameworks by bridged hydrogen spillover".

[153] Y-Y. Liu, J-L. Zeng, J. Zhang, F. Xu, and L-X. Sun, International Journal of Hydrogen Energy, 32 (2007) 4005-4010, "Improved hydrogen storage in the modified metal-organic frameworks by hydrogen spillover effect”.

[154] Y. Li, and R. T. Yang, AlChE Journal, 54 (2008) 269-279, "Hydrogen storage in metal-organic and covalent-organic frameworks by spillover".

[155] Y. Li and R. T. Yang, Journal of Physical Chemistry B, 110 (2006) 17175-17181, "Hydrogen storage in low silica type X zeolites".

[156] J. C. Yu, A. Xu, L. Zhang, R. Song, and L. Wu, Journal of Physical chemistry B, 108 (2004) 64-70, "Synthesis and characterization of porous magnesium hydroxide and oxide nanoplates".

[157] M. H. Lee and D. G. Park, Bull. Korean Chem. Soc., 24 (2003) 1437-1443, "Preparation of $\mathrm{MgO}$ with High Surface Area and Modification of Its Pore Characteristics".

[158] J. Lv, L. Qiu, B. Qu, Journal of Crystal Growth, 267 (2004) 676-684, “Controlled growth of three morphological structures of magnesium hydroxide nanoparticles by wet precipitation method". 


\section{$\underline{\text { APPENDIX }}$}

\section{Figure 1, reference [3]}

\section{Copyright Status}

Documents provided from the web server were sponsored by a contractor of the U.S. Government under contract DE-AC05-00OR22725. Accordingly, the U.S. Government retains a nonexclusive, royalty-free license to publish or reproduce these documents, or to allow others to do so, for U.S. Government purposes. These documents may be freely distributed and used for non-commercial, scientific and educational purposes.

http://www.ornl.gov/ornlhome/disclaimers.shtml

Figure 2, reference [4], Figure 3, 4, 5, 6, reference [1], Table 1, reference [18], Figure 7, reference [20], Figure 8, reference [22], Table 2, reference [21]

Copyright

Materials on the EERE Web site are in the public domain. EERE requests that it be acknowledged as the source in any subsequent use of its information.

Photographs

Most photographs on EERE are in the public domain and may be used. Please include any credits that appear alongside the photograph; where no credits are listed, please credit DOE's Office of Energy Efficiency and Renewable Energy.

http://www1.eere.energy.gov/webpolicies/\#photographs 
Figure 9, reference [23]

ELSEVIER LICENSE

TERMS AND CONDITIONS

Apr 24, 2009

This is a License Agreement between Xiang Sun ("You") and Elsevier ("Elsevier") provided by Copyright Clearance Center ("CCC"). The license consists of your order details, the terms and conditions provided by Elsevier, and the payment terms and conditions.

All payments must be made in full to CCC. For payment instructions, please see information listed at the bottom of this form.

Supplier

Elsevier Limited

The Boulevard,Langford Lane

Kidlington,Oxford,OX5 1GB,UK

Registered Company Number

1982084

Customer name

Xiang Sun

Customer address

1812 A Woodmar Drive

Houghton, MI 49931

License Number

2175520406627 
License date

Apr 24, 2009

Licensed content publisher

Elsevier

Licensed content publication

Physics Letters A

Licensed content title

Primitive phase diagram for hydrogen

Licensed content author

W. B. Leung, N. H. March and H. Motz

Licensed content date

3 May 1976

Volume number

Issue number

Pages

0

Type of Use

Thesis / Dissertation

Portion

Figures/table/illustration/abstracts

Portion Quantity

1 
Format

Electronic

You are an author of the Elsevier article

No

Are you translating?

No

Order Reference Number

Expected publication date

Jun 2009

Elsevier VAT number

GB 494627212

Permissions price

0.00 USD

Value added tax $0.0 \%$

0.00 USD

Total

0.00 USD

Terms and Conditions

\section{INTRODUCTION}

1. The publisher for this copyrighted material is Elsevier. By clicking "accept" in connection with completing this licensing transaction, you agree that the following terms and conditions apply to this transaction (along with the Billing and Payment terms and conditions established by Copyright Clearance 
Center, Inc. ("CCC"), at the time that you opened your Rightslink account and that are available at any time at http://myaccount.copyright.com).

\section{GENERAL TERMS}

2. Elsevier hereby grants you permission to reproduce the aforementioned material subject to the terms and conditions indicated.

3. Acknowledgement: If any part of the material to be used (for example, figures) has appeared in our publication with credit or acknowledgement to another source, permission must also be sought from that source. If such permission is not obtained then that material may not be included in your publication/copies. Suitable acknowledgement to the source must be made, either as a footnote or in a reference list at the end of your publication, as follows:

"Reprinted from Publication title, Vol /edition number, Author(s), Title of article / title of chapter, Pages No., Copyright (Year), with permission from Elsevier [OR APPLICABLE SOCIETY COPYRIGHT OWNER]." Also Lancet special credit - "Reprinted from The Lancet, Vol. number, Author(s), Title of article, Pages No., Copyright (Year), with permission from Elsevier."

4. Reproduction of this material is confined to the purpose and/or media for which permission is hereby given.

5. Altering/Modifying Material: Not Permitted. However figures and illustrations may be altered/adapted minimally to serve your work. Any other abbreviations, additions, deletions and/or any other alterations shall be made only with prior written authorization of Elsevier Ltd. (Please contact Elsevier at permissions@elsevier.com)

6. If the permission fee for the requested use of our material is waived in this instance, please be advised that your future requests for Elsevier materials may attract a fee.

7. Reservation of Rights: Publisher reserves all rights not specifically granted in the combination of (i) the license details provided by you and accepted in the course of this licensing transaction, (ii) these terms and conditions and (iii) CCC's Billing and Payment terms and conditions.

8. License Contingent Upon Payment: While you may exercise the rights licensed immediately upon issuance of the license at the end of the licensing process for the transaction, provided that you have disclosed complete and 
accurate details of your proposed use, no license is finally effective unless and until full payment is received from you (either by publisher or by CCC) as provided in CCC's Billing and Payment terms and conditions. If full payment is not received on a timely basis, then any license preliminarily granted shall be deemed automatically revoked and shall be void as if never granted. Further, in the event that you breach any of these terms and conditions or any of CCC's Billing and Payment terms and conditions, the license is automatically revoked and shall be void as if never granted. Use of materials as described in a revoked license, as well as any use of the materials beyond the scope of an unrevoked license, may constitute copyright infringement and publisher reserves the right to take any and all action to protect its copyright in the materials.

9. Warranties: Publisher makes no representations or warranties with respect to the licensed material.

10. Indemnity: You hereby indemnify and agree to hold harmless publisher and CCC, and their respective officers, directors, employees and agents, from and against any and all claims arising out of your use of the licensed material other than as specifically authorized pursuant to this license.

11. No Transfer of License: This license is personal to you and may not be sublicensed, assigned, or transferred by you to any other person without publisher's written permission.

12. No Amendment Except in Writing: This license may not be amended except in a writing signed by both parties (or, in the case of publisher, by CCC on publisher's behalf).

13. Objection to Contrary Terms: Publisher hereby objects to any terms contained in any purchase order, acknowledgment, check endorsement or other writing prepared by you, which terms are inconsistent with these terms and conditions or CCC's Billing and Payment terms and conditions. These terms and conditions, together with CCC's Billing and Payment terms and conditions (which are incorporated herein), comprise the entire agreement between you and publisher (and CCC) concerning this licensing transaction. In the event of any conflict between your obligations established by these terms and conditions and those established by CCC's Billing and Payment terms and conditions, these terms and conditions shall control.

14. Revocation: Elsevier or Copyright Clearance Center may deny the permissions described in this License at their sole discretion, for any reason or no reason, with a full refund payable to you. Notice of such denial will be made using the contact information provided by you. Failure to receive such notice will not alter or invalidate the denial. In no event will Elsevier or 
Copyright Clearance Center be responsible or liable for any costs, expenses or damage incurred by you as a result of a denial of your permission request, other than a refund of the amount(s) paid by you to Elsevier and/or Copyright Clearance Center for denied permissions.

\section{LIMITED LICENSE}

The following terms and conditions apply to specific license types:

15. Translation: This permission is granted for non-exclusive world English rights only unless your license was granted for translation rights. If you licensed translation rights you may only translate this content into the languages you requested. A professional translator must perform all translations and reproduce the content word for word preserving the integrity of the article. If this license is to re-use 1 or 2 figures then permission is granted for non-exclusive world rights in all languages.

16. Website: The following terms and conditions apply to electronic reserve and author websites:

Electronic reserve: If licensed material is to be posted to website, the web site is to be password-protected and made available only to bona fide students registered on a relevant course if:

This license was made in connection with a course, This permission is granted for 1 year only. You may obtain a license for future website posting, All content posted to the web site must maintain the copyright information line on the bottom of each image, A hyper-text must be included to the Homepage of the journal from which you are licensing at http://www.sciencedirect.com/science/journal/xxxxx or, for books, to the Elsevier homepage at http://www.elsevier.com, Central Storage: This license does not include permission for a scanned version of the material to be stored in a central repository such as that provided by Heron/XanEdu.

17. Author website for journals with the following additional clauses:

All content posted to the web site must maintain the copyright information line on the bottom of each image, and The permission granted is limited to the personal version of your paper. You are not allowed to download and post the published electronic version of your article (whether PDF or HTML, proof or final version), nor may you scan the printed edition to create an electronic version, A hyper-text must be included to the Homepage of the journal from which you are licensing at http://www.sciencedirect.com/science/journal/xxxxx, 
Central Storage: This license does not include permission for a scanned version of the material to be stored in a central repository such as that provided by Heron/XanEdu.

18. Author website for books with the following additional clauses:

Authors are permitted to place a brief summary of their work online only. A hyper-text must be included to the Elsevier homepage at http://www.elsevier.com.

All content posted to the web site must maintain the copyright information line on the bottom of each image

You are not allowed to download and post the published electronic version of your chapter, nor may you scan the printed edition to create an electronic version.

Central Storage: This license does not include permission for a scanned version of the material to be stored in a central repository such as that provided by Heron/XanEdu.

19. Website (regular and for author): A hyper-text must be included to the Homepage of the journal from which you are licensing

at http://www.sciencedirect.com/science/journal/xxxxx or, for books, to the Elsevier homepage at http://www.elsevier.com.

20. Thesis/Dissertation: If your license is for use in a thesis/dissertation your thesis may be submitted to your institution in either print or electronic form. Should your thesis be published commercially, please reapply for permission. These requirements include permission for the Library and Archives of Canada to supply single copies, on demand, of the complete thesis and include permission for UMI to supply single copies, on demand, of the complete thesis. Should your thesis be published commercially, please reapply for permission.

\section{Other conditions: None}

$\vee 1.5$

Gratis licenses (referencing \$0 in the Total field) are free. Please retain this printable license for your reference. No payment is required.

If you would like to pay for this license now, please remit this license along with your payment made payable to "COPYRIGHT CLEARANCE CENTER" otherwise you will be invoiced within 30 days of the license date. Payment should be in the form of a check or money order referencing your account number and this license number 2175520406627.

If you would prefer to pay for this license by credit card, please go to http://www.copyright.com/creditcard to download our credit card payment 
authorization form.

Make Payment To:

Copyright Clearance Center

Dept 001

P.O. Box 843006

Boston, MA 02284-3006

If you find copyrighted material related to this license will not be used and wish to cancel, please contact us referencing this license number 2175520406627 and noting the reason for cancellation.Questions? customercare@copyright.com or +1-877-6225543 (toll free in the US) or +1-978-646-2777. 
Figure 10, reference [28], Figure 12, reference [28]

SPRINGER LICENSE

TERMS AND CONDITIONS

Apr 26, 2009

This is a License Agreement between Xiang Sun ("You") and Springer ("Springer") provided by Copyright Clearance Center ("CCC"). The license consists of your order details, the terms and conditions provided by Springer, and the payment terms and conditions.

All payments must be made in full to CCC. For payment instructions, please see information listed at the bottom of this form.

License Number

2176720190060

License date

Apr 26, 2009

Licensed content publisher

Springer

Licensed content publication

Naturwissenschaften

Licensed content title

Hydrogen storage methods

Licensed content author

Andreas Züttel

Licensed content date 
Apr 1, 2004

Volume number

91

Issue number

4

Type of Use

Thesis/Dissertation

Portion

Figures

Order reference number

Title of your thesis / dissertation

Charge Induced Enhancement for Hydrogen Storage Materials

Estimated size(pages)

170

Total

0.00 USD

Terms and Conditions

Introduction

The publisher for this copyrighted material is Springer Science + Business Media. By clicking "accept" in connection with completing this licensing transaction, you agree that the following terms and conditions apply to this transaction (along with the Billing and Payment terms and conditions established by Copyright Clearance Center, Inc. ("CCC"), at the time that you opened your Rightslink account and that are available at any time at http://myaccount.copyright.com).

Limited License

With reference to your request to reprint in your thesis material on which Springer 
Science and Business Media control the copyright, permission is granted, free of charge, for the use indicated in your enquiry. Licenses are for one-time use only with a maximum distribution equal to the number that you identified in the licensing process.

This License includes use in an electronic form, provided it is password protected or on the university's intranet, destined to microfilming by UMI and University repository. For any other electronic use, please contact Springer at (permissions.dordrecht@springer.com or permissions.heidelberg@springer.com)

The material can only be used for the purpose of defending your thesis, and with a maximum of 100 extra copies in paper.

Although Springer holds copyright to the material and is entitled to negotiate on rights, this license is only valid, provided permission is also obtained from the (co) author (address is given with the article/chapter) and provided it concerns original material which does not carry references to other sources (if material in question appears with credit to another source, authorization from that source is required as well). Permission free of charge on this occasion does not prejudice any rights we might have to charge for reproduction of our copyrighted material in the future.

Altering/Modifying Material: Not Permitted However figures and illustrations may be altered minimally to serve your work. Any other abbreviations, additions, deletions and/or any other alterations shall be made only with prior written authorization of the author(s) and/or Springer Science + Business Media. (Please contact Springer at permissions.dordrecht@springer.com or permissions.heidelberg@springer.com)

Reservation of Rights Springer Science + Business Media reserves all rights not specifically granted in the combination of (i) the license details provided by you and accepted in the course of this licensing transaction, (ii) these terms and conditions and (iii) CCC's Billing and Payment terms and conditions.

Copyright Notice:

Please include the following copyright citation referencing the publication in which the material was originally published. Where wording is within brackets, please include verbatim.

"With kind permission from Springer Science+Business Media: <book/journal title, chapter/article title, volume, year of publication, page, name(s) of author(s), figure number(s), and any original (first) copyright notice displayed with material>."

Warranties: Springer Science + Business Media makes no representations or warranties with respect to the licensed material. 
Indemnity

You hereby indemnify and agree to hold harmless Springer Science + Business Media and $\mathrm{CCC}$, and their respective officers, directors, employees and agents, from and against any and all claims arising out of your use of the licensed material other than as specifically authorized pursuant to this license.

No Transfer of License

This license is personal to you and may not be sublicensed, assigned, or transferred by you to any other person without Springer Science + Business Media's written permission.

No Amendment Except in Writing

This license may not be amended except in a writing signed by both parties (or, in the case of Springer Science + Business Media, by CCC on Springer Science + Business Media's behalf).

Objection to Contrary Terms

Springer Science + Business Media hereby objects to any terms contained in any purchase order, acknowledgment, check endorsement or other writing prepared by you, which terms are inconsistent with these terms and conditions or CCC's Billing and Payment terms and conditions. These terms and conditions, together with CCC's Billing and Payment terms and conditions (which are incorporated herein), comprise the entire agreement between you and Springer Science + Business Media (and CCC) concerning this licensing transaction. In the event of any conflict between your obligations established by these terms and conditions and those established by CCC's Billing and Payment terms and conditions, these terms and conditions shall control.

\section{Jurisdiction}

All disputes that may arise in connection with this present License, or the breach thereof, shall be settled exclusively by the country's law in which the work was originally published.

v1.2

Gratis licenses (referencing $\$ 0$ in the Total field) are free. Please retain this printable license for your reference. No payment is required.

If you would like to pay for this license now, please remit this license along with your payment made payable to "COPYRIGHT CLEARANCE CENTER" otherwise you will be invoiced within 30 days of the license date. Payment should be in the form of a check or money order referencing your account number and this license number 2176720190060.

If you would prefer to pay for this license by credit card, please go to http://www.copyright.com/creditcard to download our credit card payment authorization form. 
Make Payment To:

Copyright Clearance Center

Dept 001

P.O. Box 843006

Boston, MA 02284-3006

If you find copyrighted material related to this license will not be used and wish to cancel, please contact us referencing this license number $\mathbf{2 1 7 6 7 2 0 1 9 0 0 6 0}$ and noting the reason for cancellation.

Questions? customercare@copyright.com or +1-877-622-5543 (toll free in the US) or +1-978-646-2777.

Figure 11, reference [27]

Copyright

All aspects of the University of Birmingham website design, text, graphics and all software compilations, underlying source code, software (including applets) and all other material on this website are copyright the University of Birmingham and its affiliates, or their content and technology providers.

The University of Birmingham grants permission for the browsing of material it has published on its website pages. It also grants permission to electronically copy and to print in hard copy portions one copy only of any page of this material for personal reference only.

Copyright in all material on this website (unless otherwise indicated) is held by the University of Birmingham. The express permission of the Copyright holder must be obtained for any use of this material other than for purposes permitted by law.

Permission is granted to electronically copy and to print in hard copy portions of the University of Birmingham online payment or online donation facility for the sole purpose of placing an order with the University of Birmingham. 